\title{
AGC-3 Specimen Post-Irradiation Examination Data Package Report
}

William E. Windes

David T. Rohrbaugh

W. David Swank

David L. Cottle

December 2017
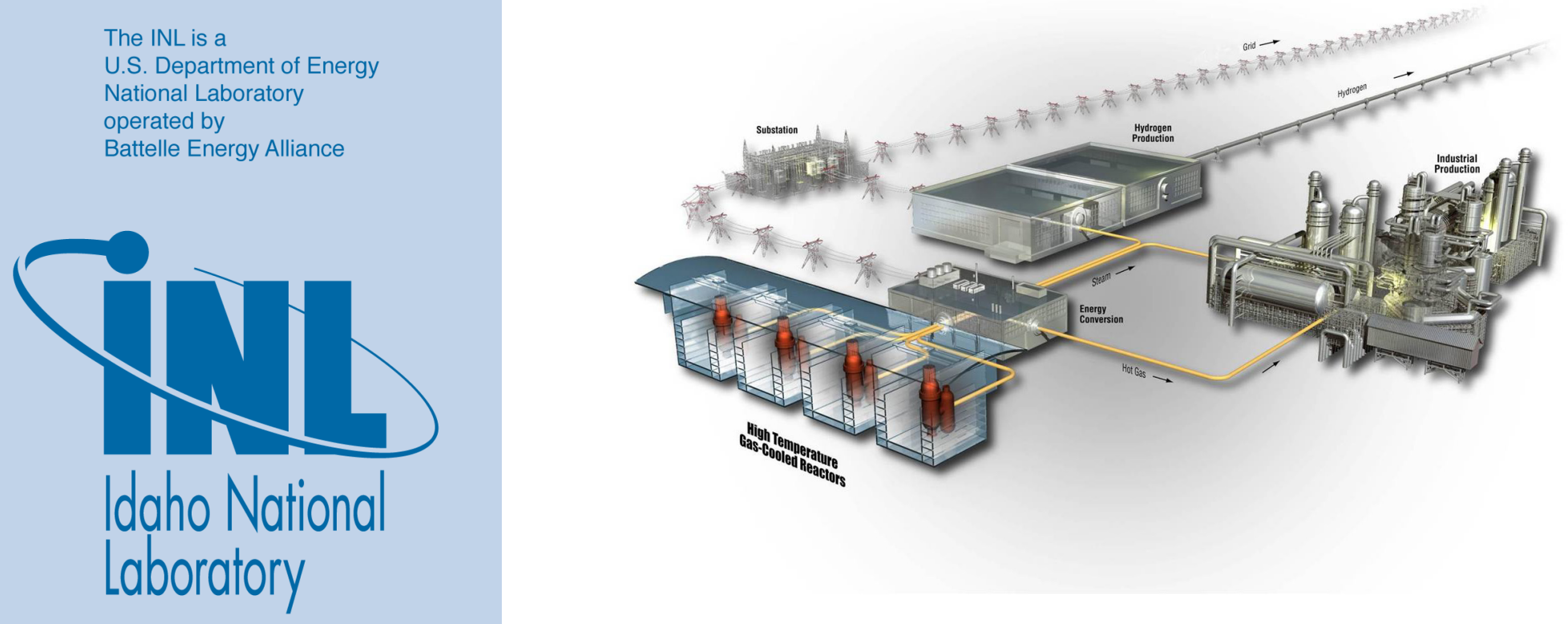


\section{DISCLAIMER}

This information was prepared as an account of work sponsored by an agency of the U.S. Government. Neither the U.S. Government nor any agency thereof, nor any of their employees, makes any warranty, expressed or implied, or assumes any legal liability or responsibility for the accuracy, completeness, or usefulness, of any information, apparatus, product, or process disclosed, or represents that its use would not infringe privately owned rights. References herein to any specific commercial product, process, or service by trade name, trade mark, manufacturer, or otherwise, does not necessarily constitute or imply its endorsement, recommendation, or favoring by the U.S. Government or any agency thereof. The views and opinions of authors expressed herein do not necessarily state or reflect those of the U.S. Government or any agency thereof. 
INL/EXT-17-43823

Revision 0

\title{
AGC-3 Specimen Post-Irradiation Examination Data Package Report
}

\author{
William E. Windes \\ David T. Rohrbaugh \\ W. David Swank \\ David L. Cottle
}

December 2017

\begin{abstract}
Idaho National Laboratory
INL ART TDO Program

Idaho Falls, Idaho 83415
\end{abstract}

http://www.inl.gov

Prepared for the

U.S. Department of Energy

Office of Nuclear Energy

Under DOE Idaho Operations Office

Contract DE-AC07-05ID14517 



\title{
INL ART TDO Program
}

\section{AGC-3 Specimen Post-Irradiation Examination Data Package Report}

\author{
INL/EXT-17-43823
}

Revision 0

December 2017

Approved by:

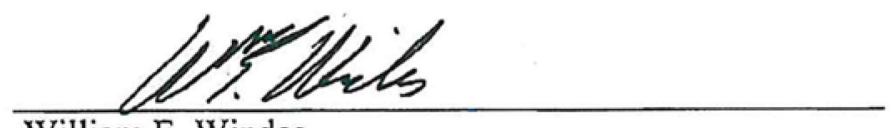

William E. Windes

Author/INL ART TDO Graphite R\&D Technical Lead

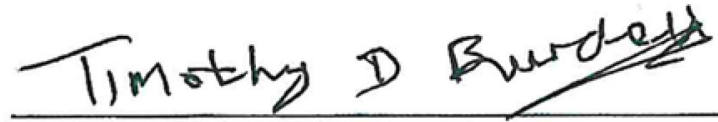

Timothy D. Burchell

ORNL Graphite Technical Peer Reviewer

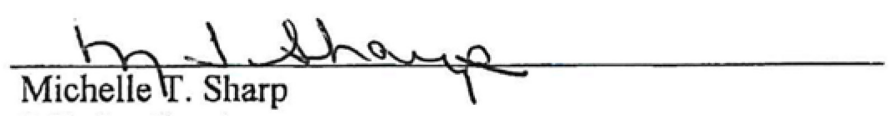

INL Quality Assurance

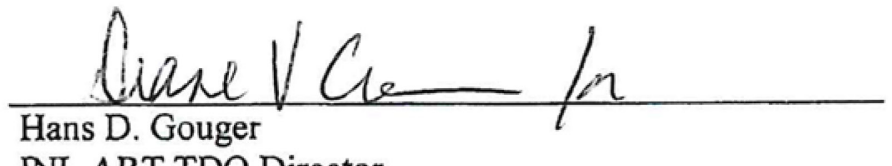

$\operatorname{Dec} 1,2017$ Date

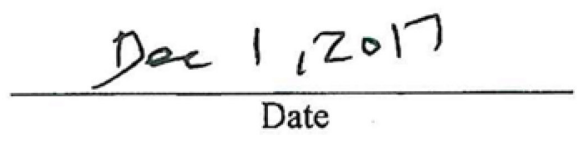

INL ART TDO Director 



\section{SUMMARY}

This report documents results of the post-irradiation examination material property testing from the third advanced graphite creep (AGC), AGC-3, capsule specimens. This is the third of a series of six irradiation test trains planned as part of the AGC experiment to fully characterize the neutron irradiation effects and radiation creep behavior of current nuclear graphite grades to moderate dose levels ( $\leq 7 \mathrm{dpa}$ ). The AGC-3 capsule was irradiated in the Idaho National Laboratory Advanced Test Reactor at a nominal temperature of $820^{\circ} \mathrm{C}$ and to a peak dose of 3.7 dpa. Half of the AGC-3 specimens were subjected to compressive stresses to induce irradiation creep. All post-irradiation testing and measurement results are reported with the exception of the irradiation mechanical strength testing, which is the last destructive testing stage of the irradiation testing program. The data reported includes specimen dimensions for both stressed and unstressed specimens to establish the irradiation creep rates, mass and dimensional data necessary to derive density, elastic constants (Young's modulus, shear modulus, and Poisson's ratio) from ultrasonic time of flight velocity measurements, Young's modulus from the fundamental frequency of vibration, electrical resistivity, and thermal diffusivity and thermal expansion data from 100 to $650^{\circ} \mathrm{C}$.

An abridged statistical analysis was performed on the irradiated data and a limited comparison between pre- and post-irradiation properties is presented to ensure that any property measurements exhibiting values significantly higher or lower than the average were not a measurement error. A more complete evaluation of trends in the material property changes, as well as irradiationinduced creep due to the irradiation environment and applied load on the specimens, will be discussed later in AGC-3 post-irradiation examination analysis reports. 


\section{CONTENTS}

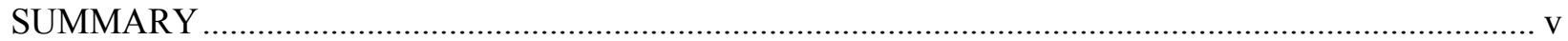

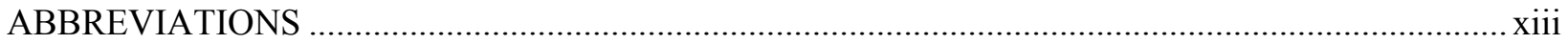

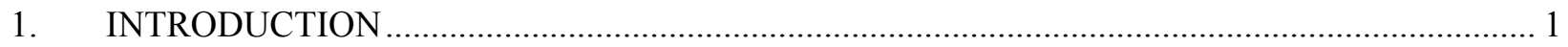

2. ADVANCED GRAPHITE CREEP EXPERIMENT …......................................................... 2

2.1 Design Parameters of AGC Experiment ......................................................................... 2

2.2 AGC Graphite Grades and Specimen Dimensions .......................................................... 4

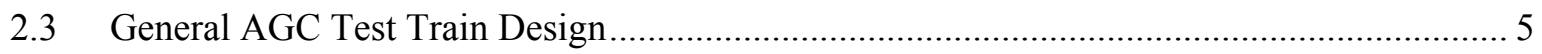

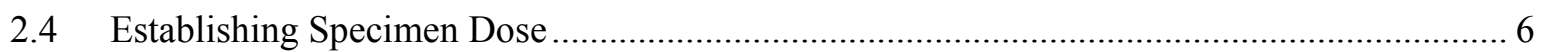

2.5 Physical Positions of Creep Specimens in the Stacks ..................................................... 8

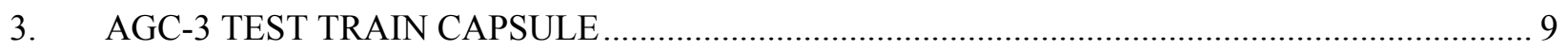

3.1 AGC-3 Graphite Grades and Changes to Dimensions …................................................... 9

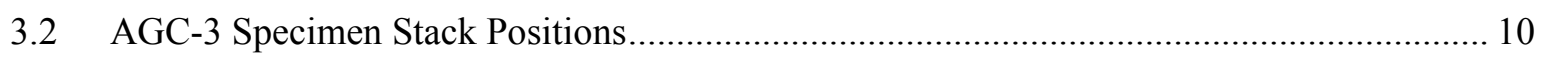

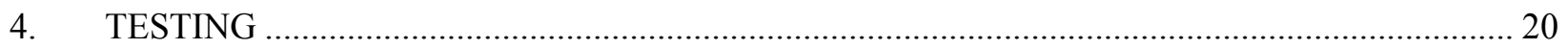

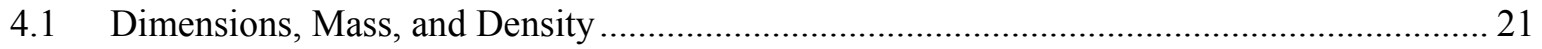

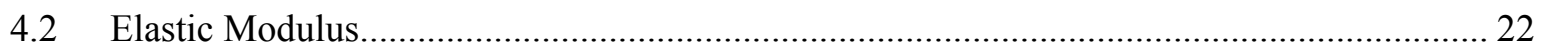

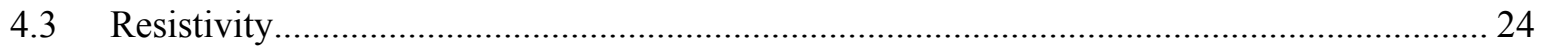

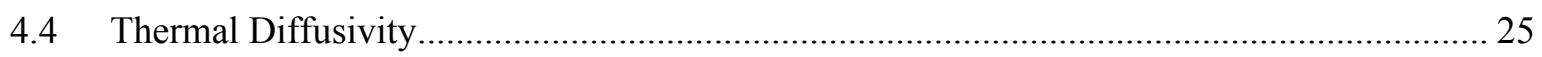

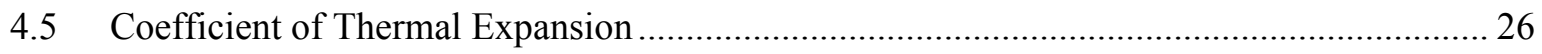

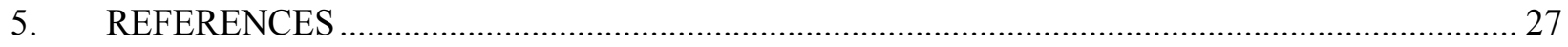

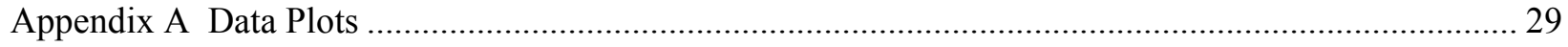

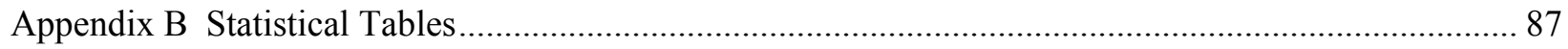

Appendix C Shipping Documentation for Experimental Grades.................................................... 106

\section{FIGURES}

Figure 1. Irradiation dose and temperature parameters for the AGC experiment (MSR is molten salt reactor, HTV is high temperature vessel, and $\mathrm{PB}$ is pebble bed) ....................................... 3

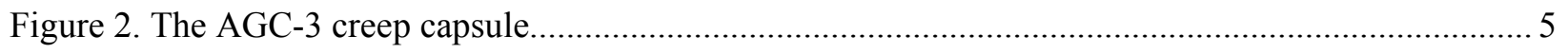

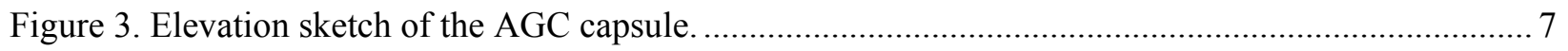

Figure 4. A typical dose profile for creep graphite specimens using similar applied stress levels in

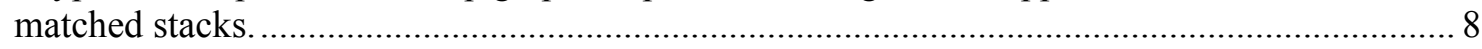

Figure 5. Volume decrease due to irradiation creep for five major grades of graphite..............................2 21

Figure 6. Density increase due to irradiation volume shrinkage for five major grades of graphite and three stress conditions. Error bars represent one standard deviation in the percent density increase. 
Figure 7. Young's modulus derived from the measurement of fundamental frequency for five grades of graphite and three different stress conditions.

Figure 8. Young's modulus derived from the measurement of ultrasonic velocity for five grades of graphite and three different stress conditions.

Figure 9. Electrical resistivity for five grades of graphite and three different stress conditions.

Figure 10. Percent change in diffusivity as a function of measurement temperature for six grades of graphite.

Figure 11. Percent change in CTE for six different grades of graphite as a function of temperature for stressed and unstressed conditions.

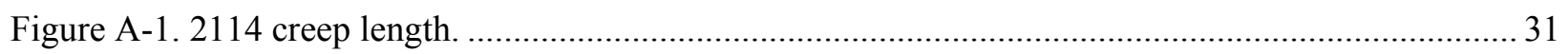

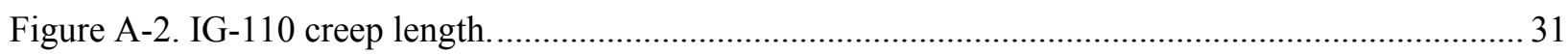

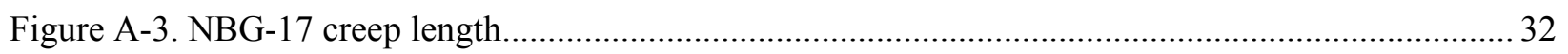

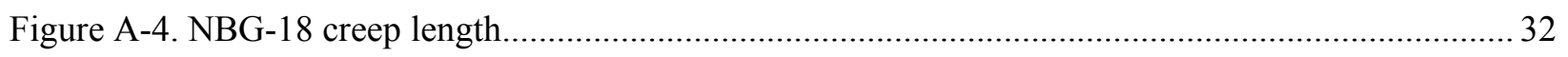

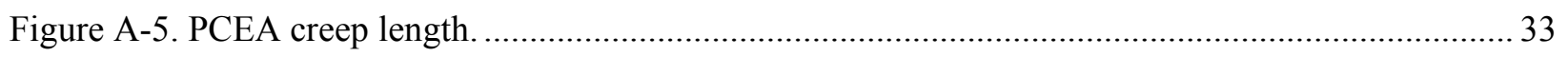

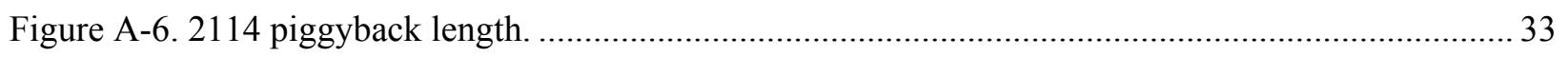

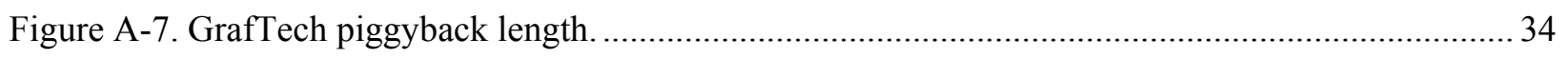

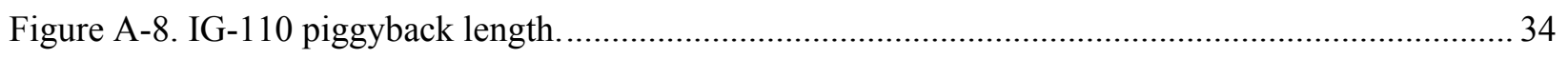

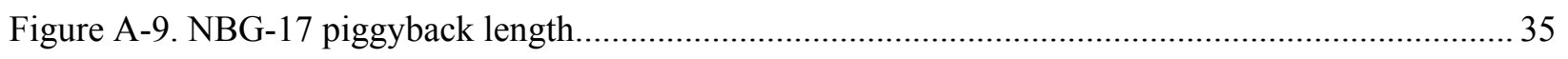

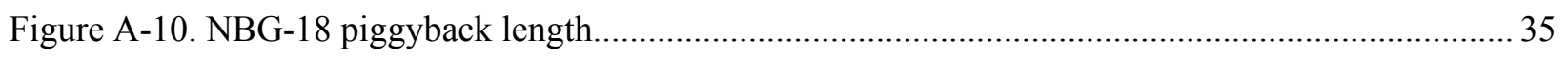

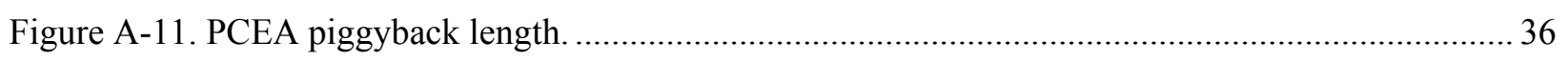

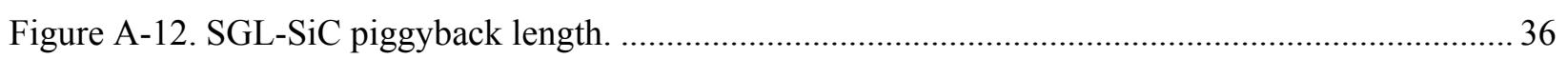

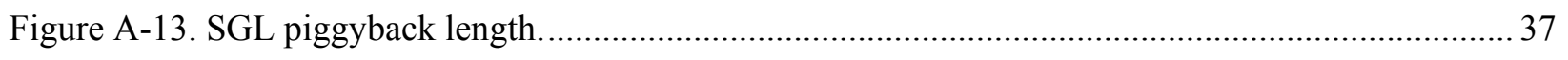

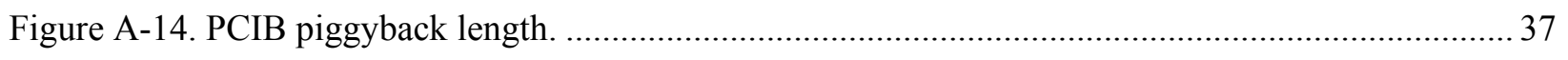

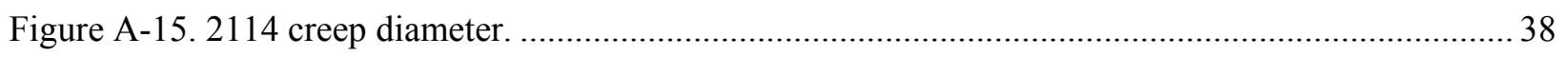

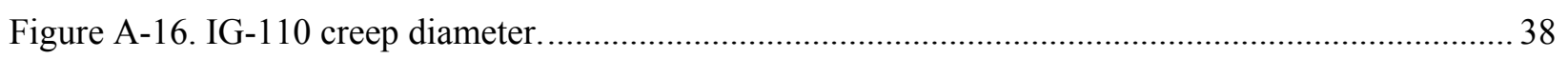

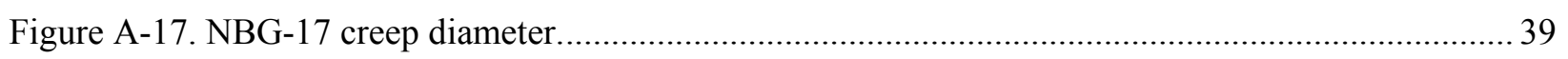

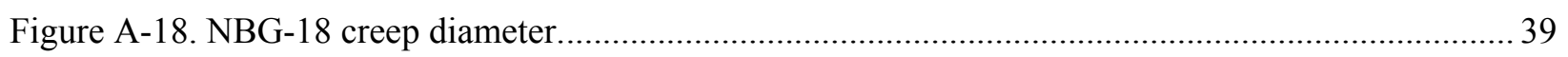

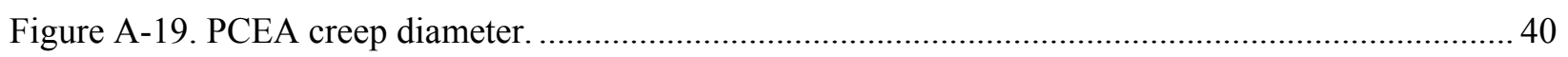

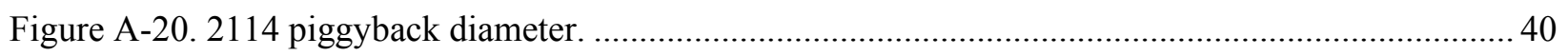

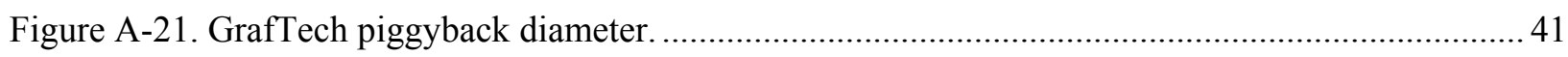

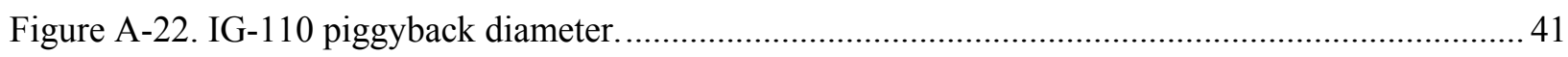

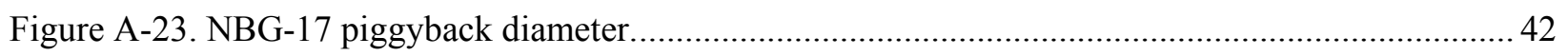

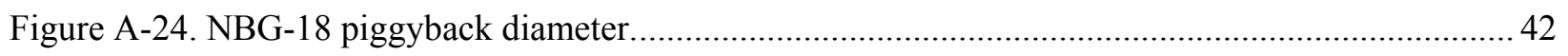

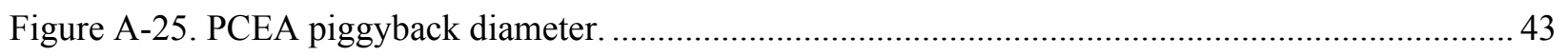

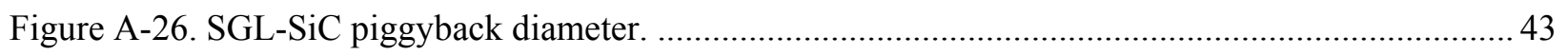

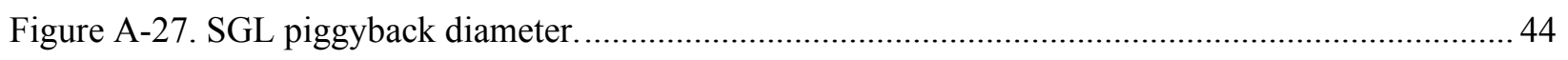




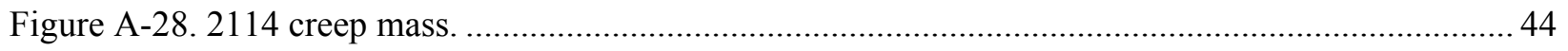

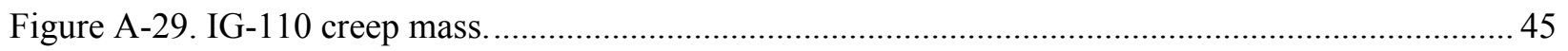

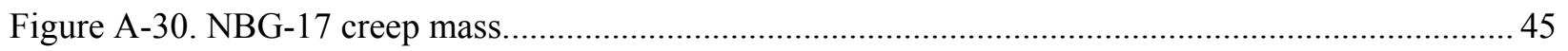

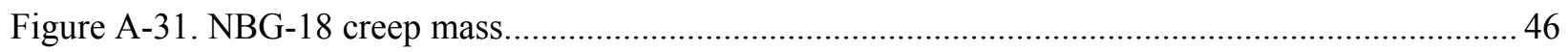

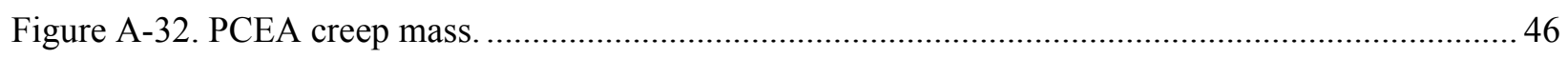

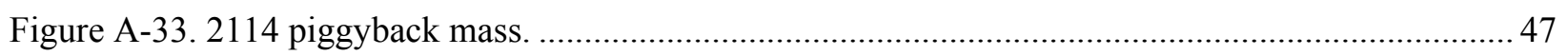

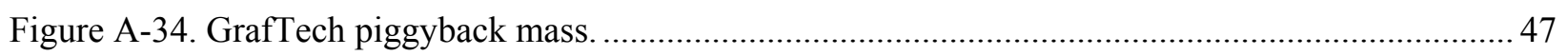

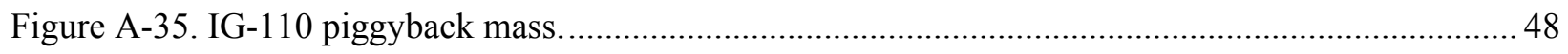

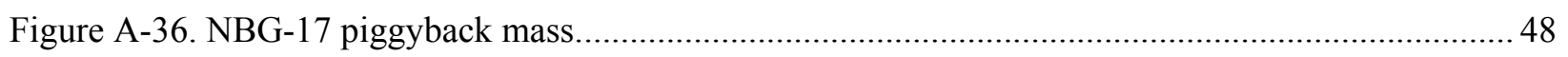

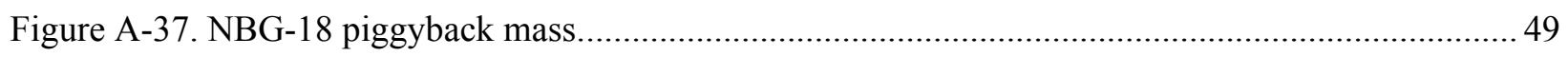

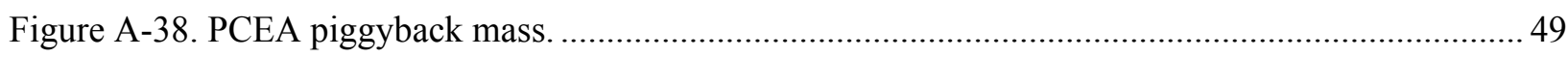

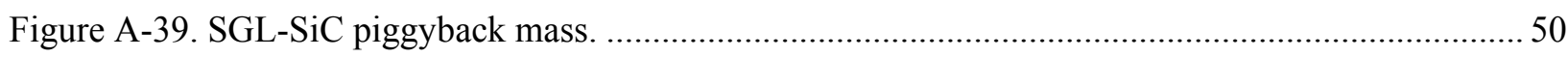

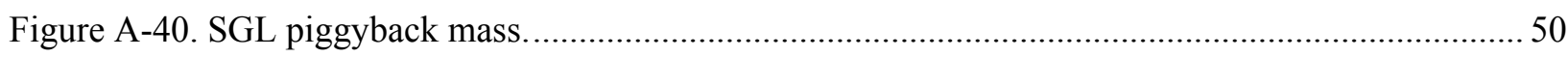

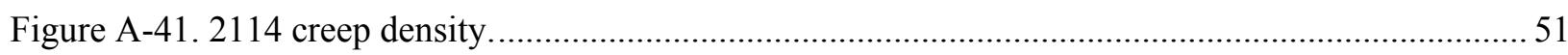

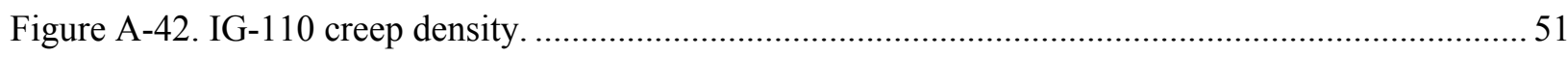

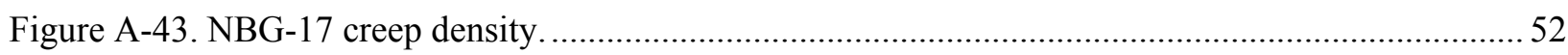

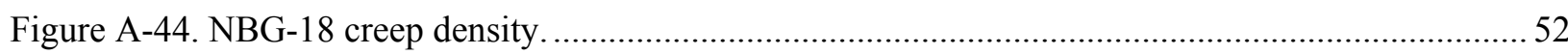

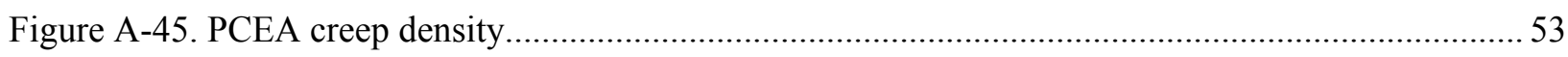

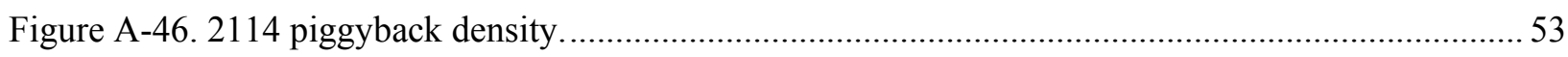

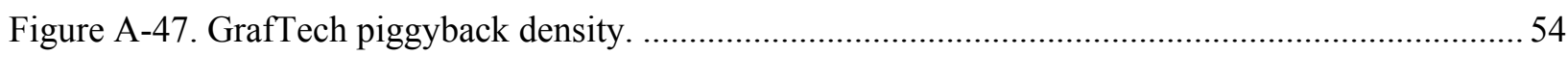

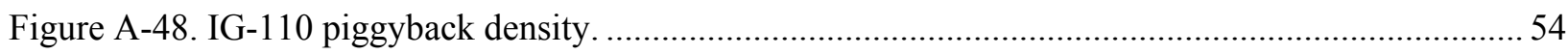

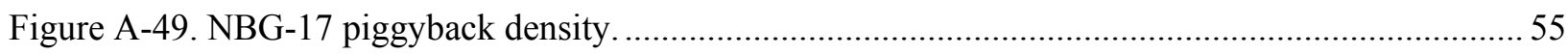

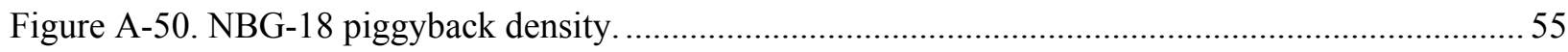

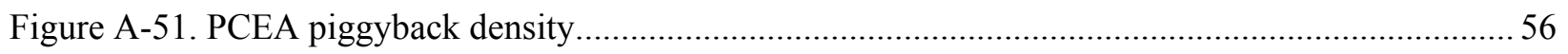

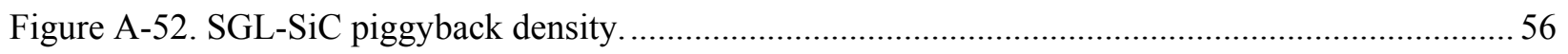

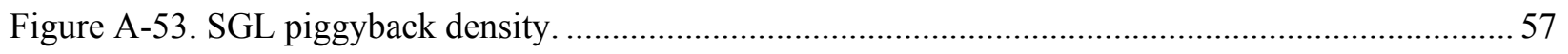

Figure A-54. 2114 creep modulus by resonant frequency.................................................................. 57

Figure A-55. IG-110 creep modulus by resonant frequency................................................................ 58

Figure A-56. NBG-17 creep modulus by resonant frequency. ...............................................................5

Figure A-57. NBG-18 creep modulus by resonant frequency. ...............................................................5 59

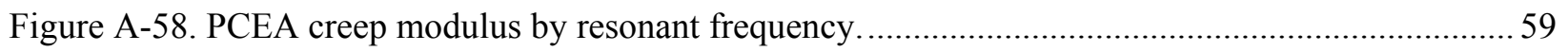

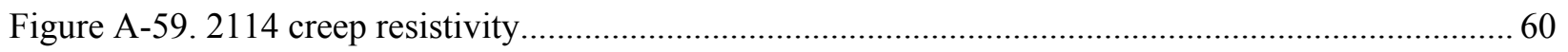

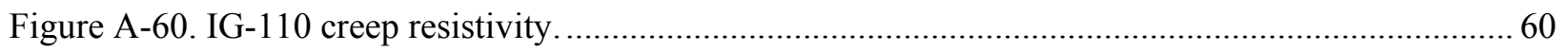

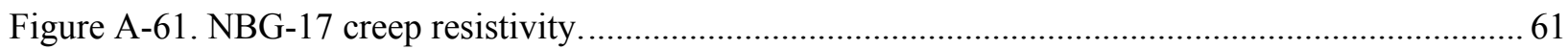

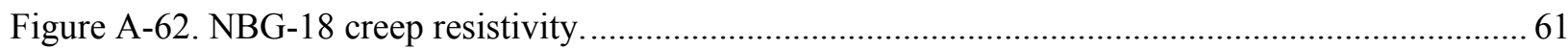




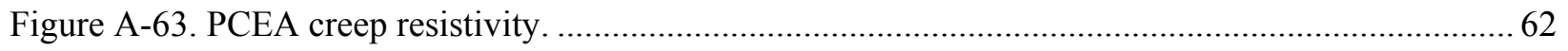

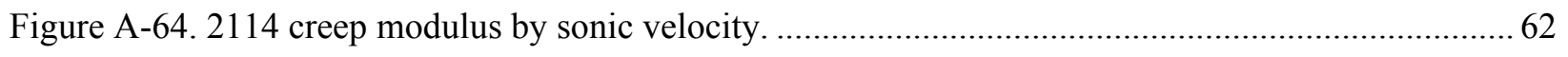

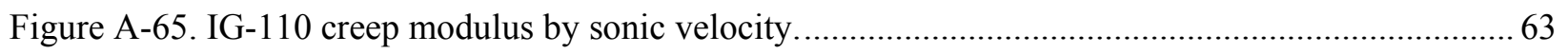

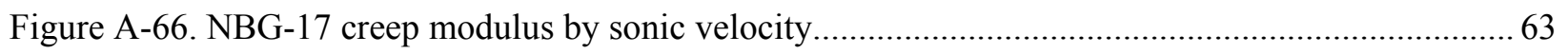

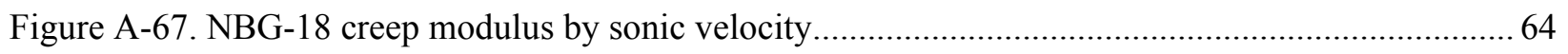

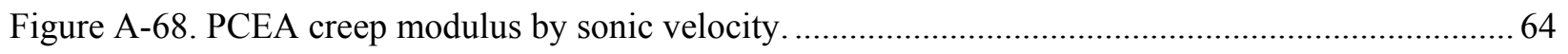

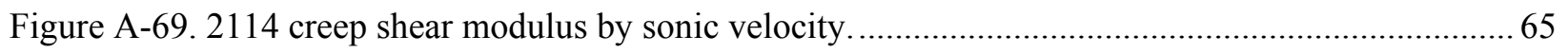

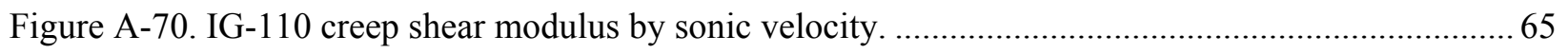

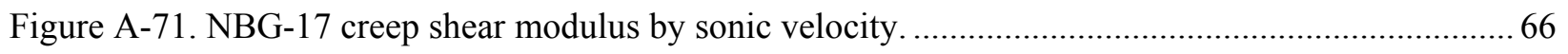

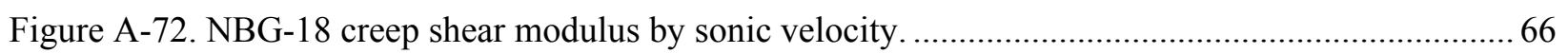

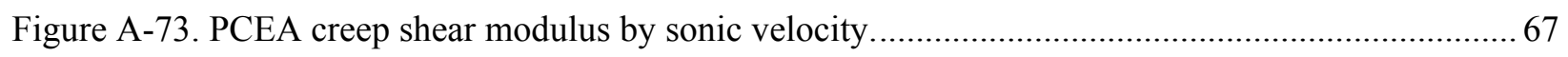

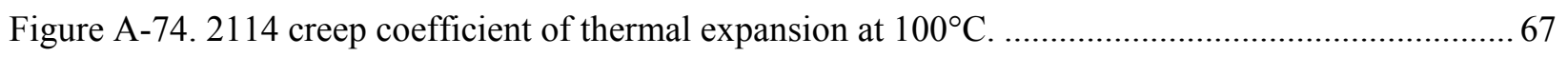

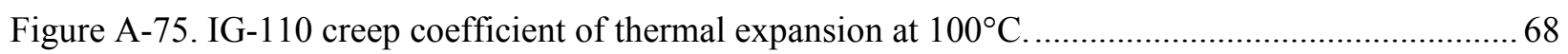

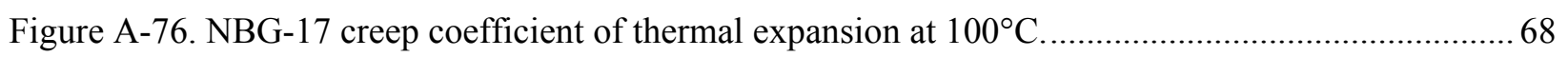

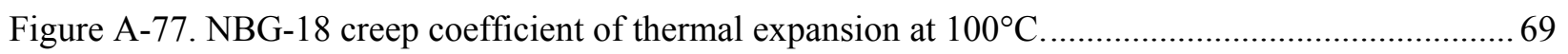

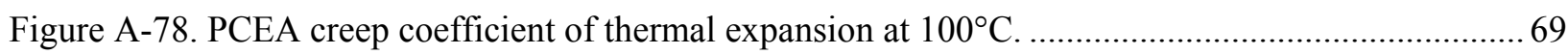

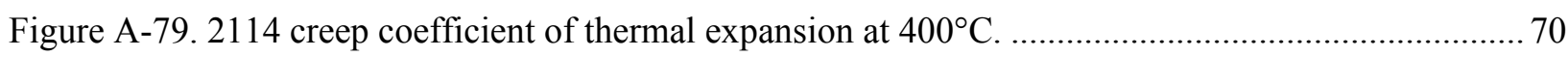

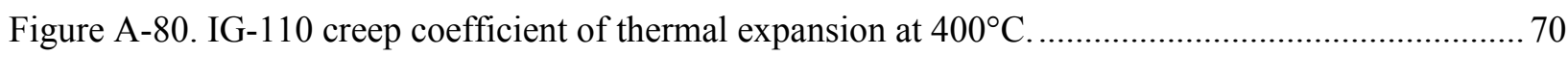

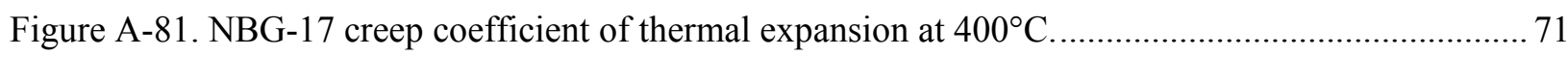

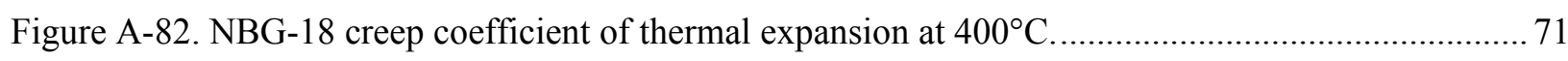

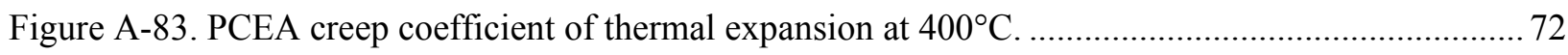

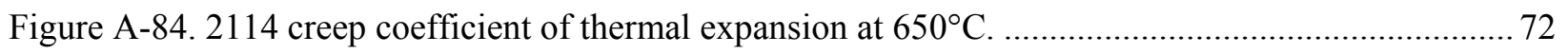

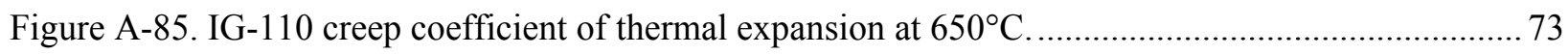

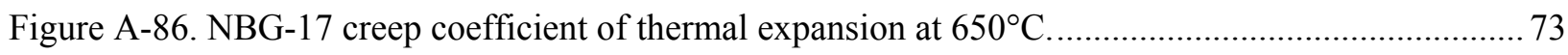

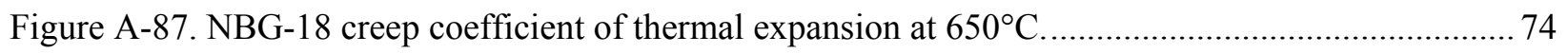

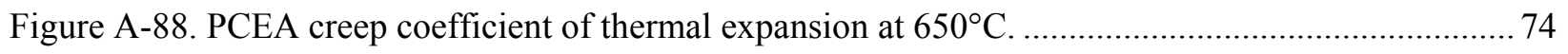

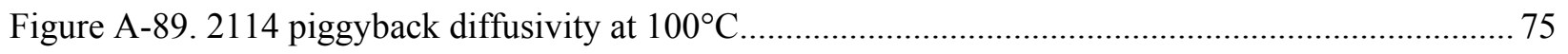

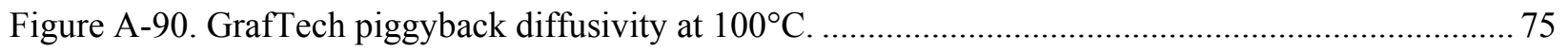

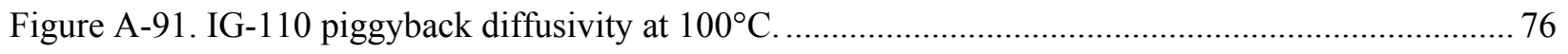

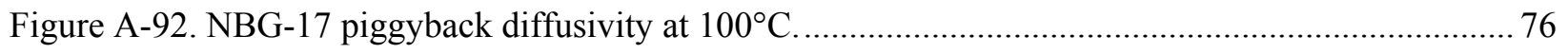

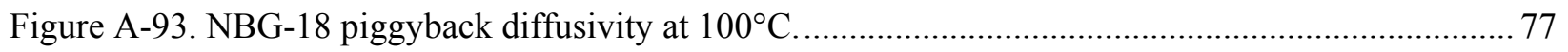

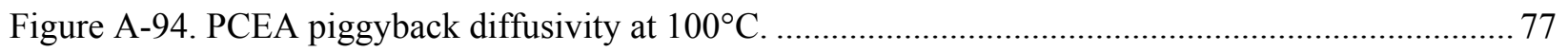

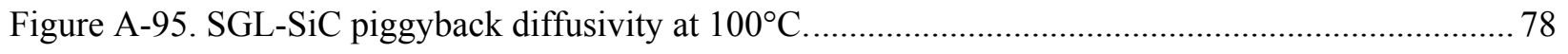

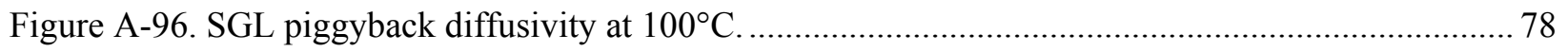

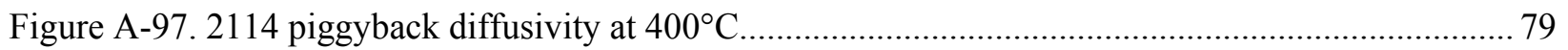




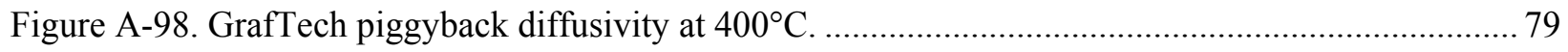

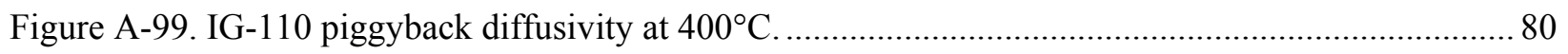

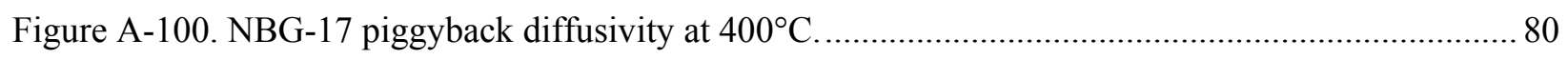

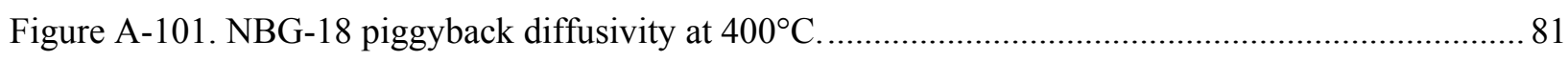

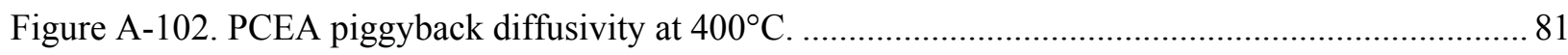

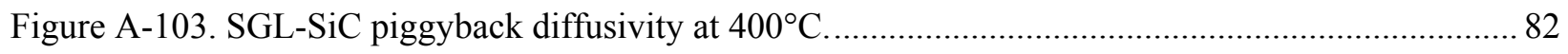

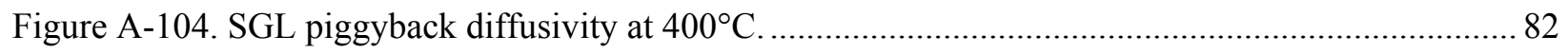

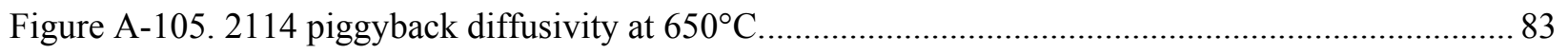

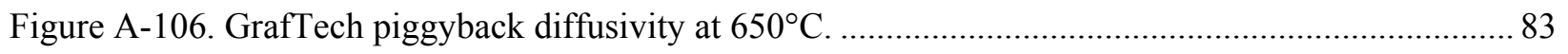

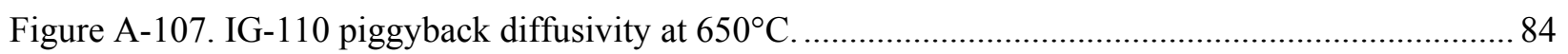

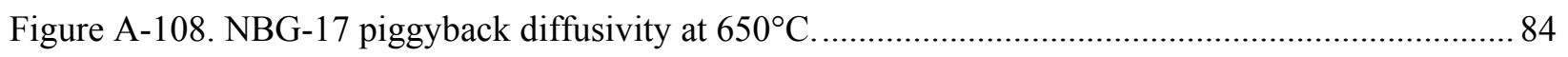

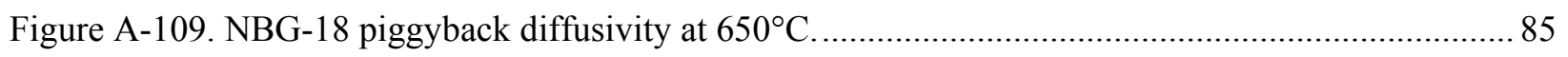

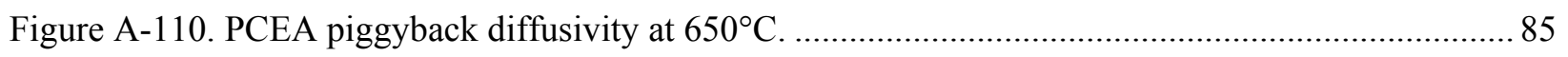

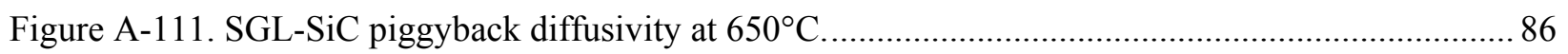

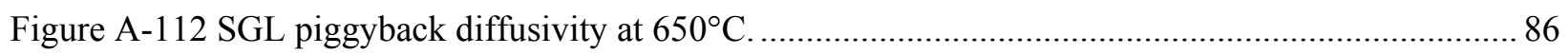

TABLES

Table 1. Major, minor, alternate, and experimental graphite grades within the AGC-3 capsule................9

Table 2. Number of irradiated creep and piggyback specimens of the major grades in the AGC-3

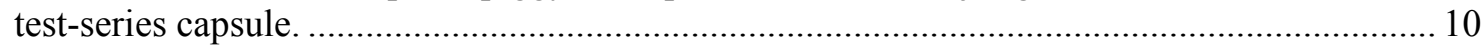

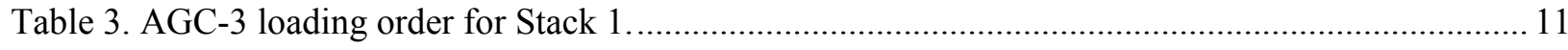

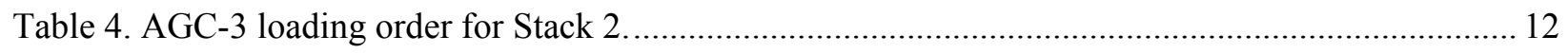

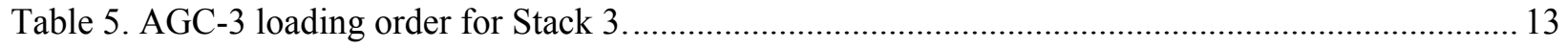

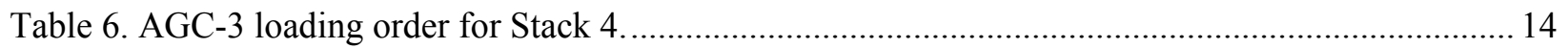

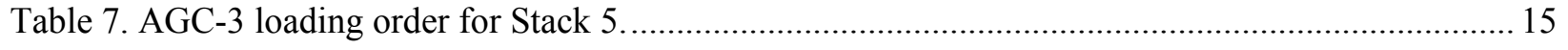

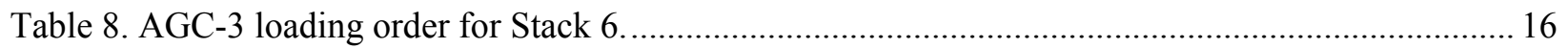

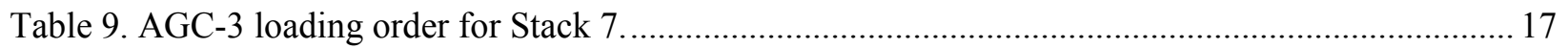

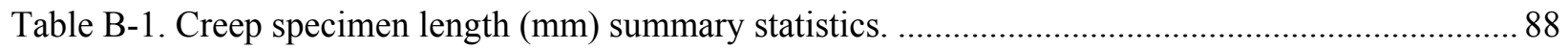

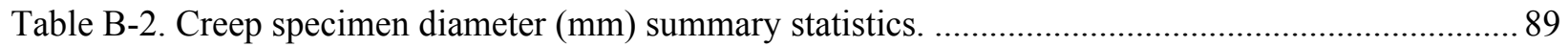

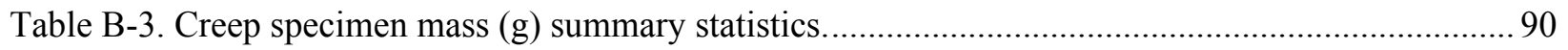

Table B-4. Creep specimen density $\left(\mathrm{g} / \mathrm{cm}^{3}\right)$ summary statistics..................................................... 91

Table B-5. Creep specimen coefficient of thermal expansion $(1 / \mathrm{k})$ summary statistics at $100^{\circ} \mathrm{C} \ldots \ldots \ldots \ldots . . . .92$

Table B-6. Creep specimen coefficient of thermal expansion $(1 / \mathrm{k})$ summary statistics at $400^{\circ} \mathrm{C} \ldots \ldots \ldots \ldots . . . .93$

Table B-7. Creep specimen coefficient of thermal expansion $(1 / \mathrm{k})$ summary statistics at $650^{\circ} \mathrm{C} \ldots \ldots \ldots \ldots . . . .94$

Table B-8. Creep specimen Young's modulus (GPa) by sonic resonance summary statistics.................. 95 
Table B-9. Creep specimen resistivity ( $\mu \Omega-m)$ summary statistics. .96

Table B-10. Creep specimen Young's modulus (GPa) by sonic velocity summary statistics. 97

Table B-11. Creep specimen shear modulus (GPa) by sonic velocity summary statistics. 98

Table B-12. Piggyback specimen length ( $\mathrm{mm}$ ) summary statistics. 99

Table B-13. Piggyback specimen diameter ( $\mathrm{mm})$ summary statistics. 100

Table B-14. Piggyback specimen mass (g) summary statistics. 101

Table B-15. Piggyback specimen density $\left(\mathrm{g} / \mathrm{cm}^{3}\right)$ summary statistics. 102

Table B-16. Piggyback specimen diffusivity $\left(\mathrm{mm}^{2} / \mathrm{sec}\right)$ at $100^{\circ} \mathrm{C}$ summary statistics. 103

Table B-17. Piggyback specimen diffusivity $\left(\mathrm{mm}^{2} / \mathrm{sec}\right)$ at $400^{\circ} \mathrm{C}$ summary statistics. 104

Table B-18. Piggyback specimen diffusivity $\left(\mathrm{mm}^{2} / \mathrm{sec}\right)$ at $650^{\circ} \mathrm{C}$ summary statistics. 105 


\section{ABBREVIATIONS}

AG against-grain

AGC advanced graphite creep

ASTM American Society for Testing and Materials

ATR Advanced Test Reactor

COV coefficient of variance

CTE coefficient of thermal expansion

HOPG highly ordered pyrolitic graphite

HTR high-temperature reactor

HTV high temperature vessel

INL Idaho National Laboratory

IQR interquartile range

MSR molten salt reactor

PB pebble bed

PIE post-irradiation examination

SGL SIGRI GmbH Great Lakes

WG with-grain 


\section{AGC-3 Specimen Post-Irradiation Examination Data Package Report}

\section{INTRODUCTION}

The Advanced Reactor Technologies Graphite Research and Development Program is conducting an extensive graphite irradiation program to provide data to assist in licensing of a high-temperature reactor (HTR) design. In past applications, graphite has been used effectively as a structural and moderator material in both research and commercial high-temperature gas-cooled reactor designs. ${ }^{1,2}$ Nuclear graphite H-451, used previously in the United States for nuclear reactor graphite components, is no longer available. New nuclear graphite grades have been developed and are considered suitable candidates for new HTR designs. To support the design and licensing of HTR core components within a commercial reactor, a complete properties database must be developed for these current grades of graphite. Quantitative data on in-service material performance is required for the physical, mechanical, and thermal properties of each graphite grade with a specific emphasis on data accounting for the life-limiting effects of irradiation creep. Further details on the research and development activities and associated rationale required to qualify nuclear-grade graphite for use within the HTR are documented in the graphite technology development plan. ${ }^{3}$

Based on experience with previous graphite core components, the phenomenon of irradiation-induced creep within the graphite has been shown to be a critical parameter in determining the total useful lifetime of graphite components. Irradiation-induced creep occurs under the simultaneous application of high temperatures, neutron irradiation, and applied stresses within the graphite components. A second, much more significant, internal stress is experienced within the graphite components due to irradiation-induced dimensional changes. These induced stresses result from neutron irradiation causing physical changes in the graphite structure, first shrinking it and then expanding it, with increasing neutron dose. This disparity in material volume change can induce significant internal stresses within graphite components. Irradiation-induced creep relaxes these large internal stresses, thus reducing the risk of crack formation and component failure. Obviously, higher irradiation creep levels tend to relieve more internal stress, thus allowing the components longer useful lifetimes within the core. Determining the irradiation creep rates of nuclear graphite grades is critical for determining the useful lifetime of graphite components and is a major component of the advanced graphite creep (AGC) experiment.

The overall AGC experiment is determining the in-service behavior of new graphite grades for use in HTRs. This test series is examining the properties and behaviors of nuclear-grade graphite over a large range of irradiation temperatures, moderate fluence levels, and applied stresses that are expected to induce physical property changes and irradiation creep strains within HTR graphite components. There are six irradiation capsules that will be irradiated in a large flux trap of the Advanced Test Reactor (ATR) at Idaho National Laboratory (INL). The AGC irradiation conditions are similar to the anticipated environment within a high-temperature core design. Each irradiation capsule contains over 400 graphite specimens that are characterized before and after irradiation to determine the irradiation-induced material property changes and life-limiting irradiation creep rate for each graphite grade.

The data and information produced in this report and the referenced documents within were generated under the approved quality assurance programs for the respective organizations including INL and Oak Ridge National Laboratory in compliance with the applicable NQA-1 requirements. ${ }^{4}$ It is anticipated that all data will be robust enough to stand up to a review by the American Society of Mechanical Engineers and Nuclear Regulatory Commission as support for an eventual graphite reactor design selection. 


\section{ADVANCED GRAPHITE CREEP EXPERIMENT}

The AGC test series is designed to provide data necessary to assist in determining the safe operating envelope of graphite core components for an HTR by measuring the irradiated material property changes and the behavior of several new nuclear graphite grades over a large range of temperatures, moderate neutron fluence, and mechanical compressive loads. The experiment consists of five interrelated stages: pre-irradiation characterization of the graphite specimens, as-run irradiation reports for each test series (designated as six separate irradiation test train capsules), capsule disassembly, post-irradiation examination (PIE) testing, and analysis of the graphite specimens. Separate reports for each distinct stage are prepared after each individual activity is completed.

The pre-irradiation examination report details the total number of graphite grades and individual specimens, specimen loading configuration designed to expose all specimens to the entire range of irradiation conditions, and pre-irradiation material property testing data and results. The as-run irradiation report will detail the irradiation history of each capsule while in the reactor, noting any changes from the technical and functional specifications for each specific test-series capsule and identifying the possible improvements to the next test-series capsule design. The disassembly report details specimen recovery from the irradiation capsule, noting any damage to the specimens and providing an inventory of recovered specimens for PIE testing. The PIE data report (this report) details the changes in specimen dimensional measurements as well as irradiated material properties upon exposure to neutron irradiation. Finally, the PIE analysis report will analyze the irradiation results reported in the data package reports, using the irradiation conditions recorded in the as-run irradiation report. The PIE analysis report(s) determines the irradiation-induced creep rates for the major grades of graphite and assesses any changes to the material properties in all graphite grades. The PIE analysis report(s) interprets the irradiation behavior of graphite to assist in determining a credible, safe operating envelope for graphite core components in an HTR design and licensing application. This report is an AGC PIE data report and provides the results and data from post-irradiation testing for AGC-3 specimens. An abridged statistical analysis is performed here along with a limited comparison to the pre- and post-irradiation data. In this way, the consistency and soundness of the data is initially tested. A more detailed analysis of trends in the AGC-3 PIE data will be reported in the subsequent AGC-3 analysis report(s).

\subsection{Design Parameters of AGC Experiment}

The AGC test series is designed to measure changes in key thermal, physical, and mechanical material properties over the anticipated range of HTR operating conditions. By comparing the material properties of each specimen before and after irradiation, the experiment generates quantitative material property change data and irradiation creep data that will be used to predict the in-service behavior and operating performance of the current nuclear graphite grades for HTR designs. Specific emphasis is placed on data that account for the life-limiting effects of irradiation creep on graphite components and the effects creep may have on key irradiated material properties of several candidate graphite grades for use in an HTR design.

The critical component of the experiment is the irradiation test series, which irradiates the graphite specimens after pre-irradiation examination characterization has been completed. The AGC test series is comprised of six planned irradiation test trains that are irradiated in ATR in a large flux trap, as described in the graphite technology development plan. ${ }^{3}$ The test series exposes test specimens of select nuclear graphite grades to temperatures and the initial range of the expected lifetime irradiation dose that are expected within an HTR design. Specifically, graphite specimens will be exposed to a fast neutron dose ranging from 1 to $7 \mathrm{dpa}$ and temperatures of 600,800 , and $1100^{\circ} \mathrm{C}$, as shown in Figure 1. The first and second AGC capsules, AGC-1 and AGC-2, were designed to be irradiated within ATR's south flux trap. All other AGC capsules are to be irradiated within ATR's east flux trap. ${ }^{5}$ Generally, irradiations within the south flux trap require approximately 175 effective full-power days to provide a nominal fast neutron dose range (in graphite) of approximately 0.5 to $3.5 \mathrm{dpa}$. For those capsules requiring a large dose range 
of approximately 3.5 to $7.0 \mathrm{dpa}$, the capsule is irradiated for twice as long, approximately 350 effective full-power days.

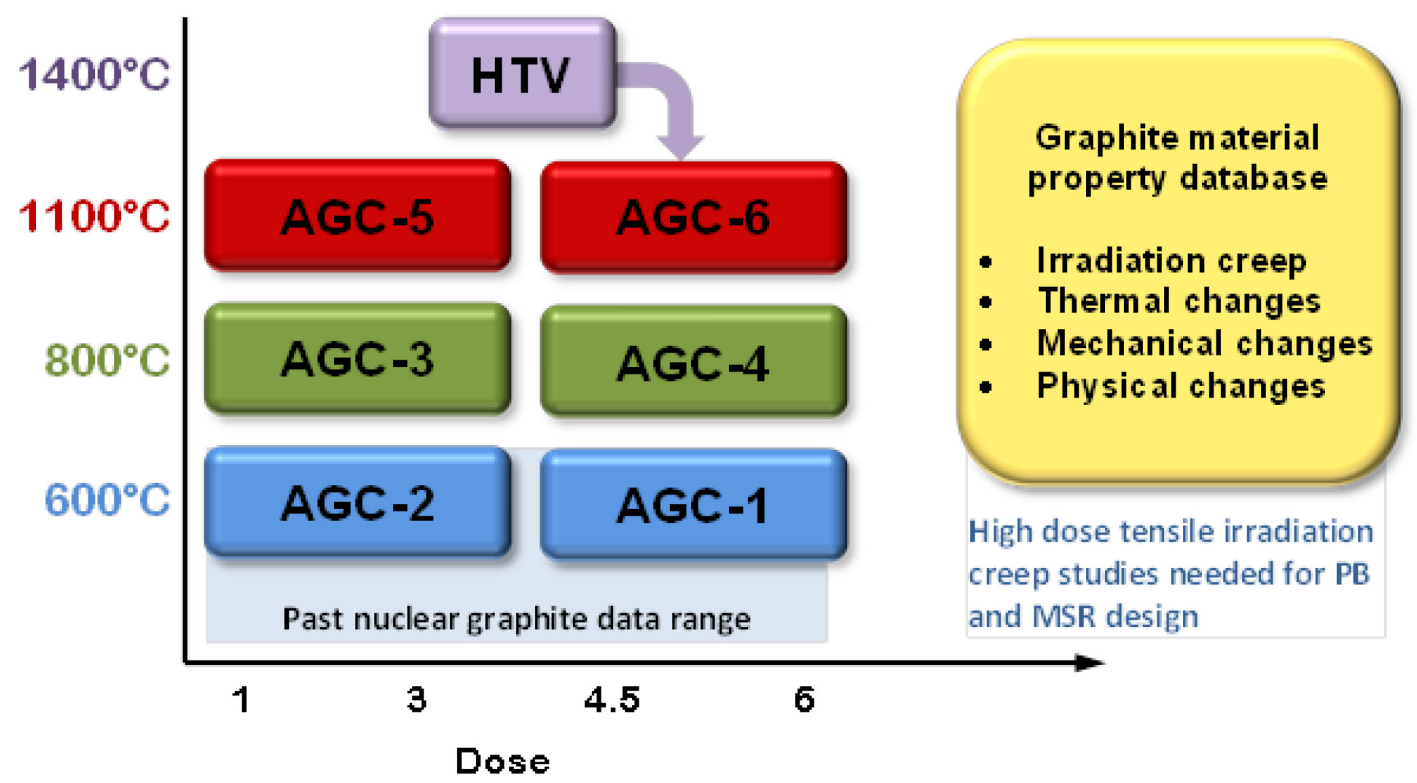

Figure 1. Irradiation dose and temperature parameters for the AGC experiment (MSR is molten salt reactor, HTV is high temperature vessel, and $\mathrm{PB}$ is pebble bed).

In addition to determining the irradiation-induced changes to the material properties of selected nuclear graphite grades, the AGC experiment dedicates a significant amount of scope to determining rates of irradiation-induced creep for different nuclear graphite grades. The traditional method for measuring irradiation-induced creep is to apply a significant mechanical load (inducing a mechanical stress within the graphite) to half the specimens during irradiation while leaving the remaining half of the specimens unloaded (unstressed). ${ }^{6,7}$ The resulting difference in dimensional change between the loaded and unloaded specimens (assuming that temperature and dose levels are the same) provides the amount of irradiation-induced strain for each "matched pair" of graphite specimens. From this strain level, a creep rate for each graphite grade can be calculated as a function of dose if both specimens were irradiated at the same constant temperature and similar dose level. Thus, each capsule is designed to be irradiated at a constant temperature, allowing only the dose and applied mechanical load to vary within the test train of each test-series capsule. With all graphite specimens at a constant temperature, only the applied stress level and dose will affect the calculated creep rate of each graphite grade within a test-series capsule.

The AGC experiment is designed to measure the constant creep strain rate (secondary creep) of the various grades. The experiment assumes that the induced creep strain for all specimens is within the secondary creep regime and therefore behaves linearly with respect to received neutron dose. ${ }^{3}$ This assumption is valid provided the specimens do not go beyond their turnaround dose where creep strain can no longer be expected to be linear with irradiation dose (the onset of tertiary creep). Once the specimens begin to reach turnaround, the creep strain response becomes non-linear with received dose. To ensure specimens remain within the constant linear creep strain regime within AGC-5 and AGC-6 (the highest temperature and dose) test trains, a high-temperature irradiation vessel (HTV) will be used to measure the dimensional changes of the graphite grades at a high temperature $\left(1400^{\circ} \mathrm{C}\right)$ and moderate dose (4.5 dpa). Results from this high-temperature dimensional change study will be used in the AGC-5 and AGC-6 designs, which constitute the upper bounds of the AGC experiment (see Figure 1). In addition, if any graphite grade achieves turnaround within the high-temperature irradiation vessel, it will be considered to be outside the upper temperature bounds of the AGC experiment and will be eliminated from the AGC-6 test train. 
While the effects from applied mechanical stresses and neutron dose can be determined within each irradiation capsule, the temperature dependency of any irradiation-induced material property changes within the graphite grades is achieved by comparing the measured values of the specimens between irradiation capsules. Since each test train is irradiated at a constant temperature $\left(600,800\right.$, or $\left.1100^{\circ} \mathrm{C}\right)$, the temperature-induced/enhanced material property changes must be determined by comparing specimens in different capsules exposed to similar dose and applied mechanical load levels. All AGC capsules are designed to have the same specimen stacking patterns. Thus, if specimens of identical graphite grades are located in similar positions within each capsule, a similar dose and load level will be imposed on a consistent grade of graphite. Maintaining consistent specimen positions for each grade within the six different capsules will allow for the determination of temperature-induced changes for irradiation creep and material properties across the AGC experiment.

\subsection{AGC Graphite Grades and Specimen Dimensions}

The AGC experiment is designed to ascertain the irradiation behavior of currently available nuclear graphite grades within the anticipated operating parameters of an HTR design. By exposing a variety of nuclear graphite grades representing the range of fabrication parameters (e.g., grain size, fabrication processes, and raw source material) to the expected operating conditions for a moderate HTR design (600 to $1100^{\circ} \mathrm{C}$ and 0.5 to $7 \mathrm{dpa}$ dose), a comprehensive understanding of the irradiation response and behavior of graphite components in general can be achieved. This will limit the need for additional research in the future if the current graphite grades are altered (i.e., new raw material sources are used) or new grades are used in future reactors.

The AGC experiment uses a variety of current graphite grades to envelope the major fabrication parameters believed to be responsible for the irradiation behavior of nuclear graphite. ${ }^{1}$ This range of fabrication parameters is represented by AGC major grades, which were deemed to be production-ready grades that could be used in current or future HTR designs. Major graphite grades are one type of sample within the AGC irradiation capsule. In addition, four other sample types are designated within the AGC experiment. The five AGC sample types are categorized as follows ${ }^{8}$ :

1. Major grades (irradiation creep and control specimens). These graphite grades are current reactor candidates for the core structures of an HTR design. Historical, or reference grades, are considered major grades as well. Due to their fabrication maturity and consistency, HTR core components are most likely to be formed from these major grades and are thus expected to receive reasonably large neutron doses in their lifetime. Only major grade specimens were used to determine the critical irradiation-induced creep strain rate.

2. Minor grades (6mm tall, button-shaped piggyback specimens). These grades are HTR-relevant grades that are not yet production ready or are most likely to be used in low-neutron-dose regions of the core (e.g., the permanent structure of the prismatic-block HTR design).

3. Alternate grades (piggyback specimens). Grades that current HTR vendors have identified as being of interest as alternate graphite grades for certain components within the reactor.

4. Experimental grades (piggyback specimens). These graphite grades are included in AGC to assess the viability of new graphite grades whose manufacturing processes and raw materials are such that they may offer superior irradiation stability. Additionally, other carbonaceous materials such as fuel compact matrix materials, carbon-carbon composites, silicon-carbide composites, or other experimental materials that could offer superior performance within the extreme environment of an HTR core are included.

5. Single crystal graphite (piggyback specimens). Samples of highly ordered pyrolytic graphite (HOPG) are included in all AGC capsules to assess the fundamental irradiation response of single crystal graphite. These specimens offer specific dimensional change behavior of graphite, which is particularly significant to the behavior of polycrystalline (polygranular) graphite grades. 
To provide all necessary material property tests in the AGC experiment, each test-series capsule contains two primary specimens: (1) "creep" specimens, providing irradiation creep-rate value as well as mechanical properties; and (2) "piggyback" specimens, providing thermal material property changes to the graphite. Creep specimens are fabricated only from major grade graphite types. ${ }^{2}$ Piggyback specimens are fabricated from major, minor, and experimental grade graphite types. The piggyback specimens are not mechanically loaded and are subjected only to neutron irradiation at high operating temperatures to assess the effects of a reactor environment on the specific graphite grade.

All specimens are $12.4 \mathrm{~mm}$ in diameter, with the larger creep specimens having a nominal length of $25.4 \mathrm{~mm}$ and the piggyback specimens having a nominal length of $6.3 \mathrm{~mm}$. ${ }^{9}$ Small graphite containers that are $12.4 \mathrm{~mm}$ in diameter by $6 \mathrm{~mm}$ long contain the thin wafer HOPG specimens, while 12.7-mm-long containers hold the MLRF specimens (experimental silicon-carbide coated graphite specimens from SGL Group being irradiated in AGC-3 capsule only). The large creep specimens provide a means to acquire dimensional/volume change, elastic modulus, thermal expansion, and electrical resistivity measurements. However, these creep specimens are not suitable for thermal diffusivity measurements because of their length. The small piggyback specimens permitted only dimensional measurements, density, and thermal diffusivity testing to be performed. Together, both types of specimens provide the changes in material properties for stressed and unstressed graphite grades.

\subsection{General AGC Test Train Design}

All AGC test trains and irradiation capsules have the same general physical configuration to provide consistent dose and applied mechanical stresses on specimens of similar graphite grades. While there are key machining and structural differences between capsules to change the irradiation temperature for the different capsules, the majority of the AGC design is identical for all capsules. A schematic of the AGC-3 test train is shown in Figure 2.,

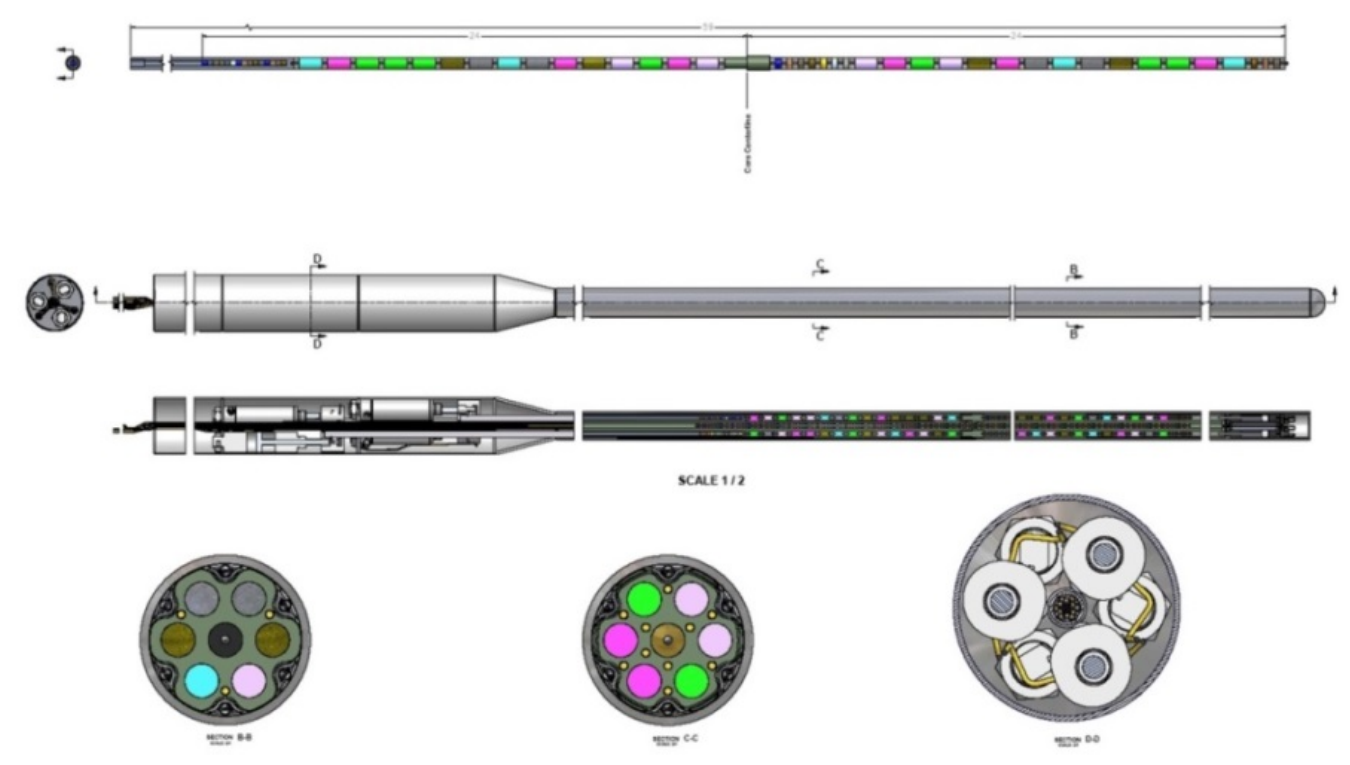

Figure 2. The AGC-3 creep capsule.

All irradiation capsules have six channels located on the outer perimeter of the graphite specimen holder body and a center channel. All channels are $12.9 \mathrm{~mm}(0.51 \mathrm{in}$.) in diameter and are designed to hold all types of AGC specimens. The upper (top) half the outer channels has had mechanical loads applied to the specimens. However, the lower (bottom) half for these channels has had no mechanical load applied to the specimens in these locations. Due to the neutron flux profile in ATR, matched pairs 
with similar neutron fluence and temperatures are achieved by pre-ordering the specimen axial locations. Specimens in the upper half of the channels were stressed by the applied mechanical load while their matched pair received a similar dose in an unstressed state. Three stress levels-13.8, 17.2, and $20.7 \mathrm{MPa}$ $(2.0,2.5$, and $3.0 \mathrm{ksi})$ nominal - are applied in all AGC capsules to provide a known stress upon the graphite specimens during irradiation. These induced stress levels are high enough to produce irradiation-induced creep strain with the graphite specimens. However, the AGC-3 capsule encountered a high gas leak rate $(5.6 \mathrm{~L} / \mathrm{min}$ system leak rate versus the average rate of $1.0 \mathrm{~L} / \mathrm{min}$ for the AGC-1 and AGC-2 experiments) in the compressive load control system, with the significant increase attributed primarily to the portion of the system providing the load on Stack 4. Therefore, a compressive load was not placed on Stack 4 until the source and future consequences of the leak were evaluated. In addition, a compressive load was not placed on Stack 1 (diametrically opposite and load pair companion to Stack 4) to prevent eccentrically loading the graphite specimen holder, which could possibly result in damaging the holder. The compressive loads on Stacks 2 and 5 were reduced from 17.3 to $13.8 \mathrm{MPa}$ on December 5, 2012, to maximize the range of stack loading from the experiment if Stacks 1 and 4 were not able to have compressive loads.

Since the compressive loads have to remain constant throughout the irradiation, there were two major concerns: (1) the leak rate may increase to the point that the load could not be maintained, and (2) sufficient helium may not be obtainable to overcome the leak rate due to a national shortage of helium. Data from the inlet and outlet system flow meters indicated that the source of the leak was internal to the test train, most probably within the pneumatic ram for Stack 4. After discussions with the vendor and reviewing data taken during preassembly testing of the pneumatic rams, it was decided to test the system to determine the stability of the leak rate. The desired loads were imposed on Stacks 1 and 4 on Tuesday, December 11, 2012, and the leak rate was monitored until Monday, December 17, 2012. The leak rate was extremely stable with essentially no perceptible change over the 6-day period. This result indicated that the leak was most likely located in a metallic component (such as a fitting) and should remain very stable throughout the irradiation. Sufficient helium was located to support maintaining the load on the stacks for the duration of Cycle 152B. The compression gas was switched from helium to argon at the end of Cycle 152B. With the gas shortage issue resolved, and the determination that the leak rate was stable, it was concluded that loads could successfully be applied to Stacks 1 and 4 for the duration of the AGC-3 experiment.

A compressive load of $13.8 \mathrm{MPa}$ was applied to Stacks 1 and 4 for the duration of the experiment. Stacks 2 and 5 remained at $13.8 \mathrm{MPa}$ for the duration of the experiment so that the load applied to these stacks would be constant. Therefore, four stacks were loaded to $13.8 \mathrm{MPa}$ for the experiment and two stacks were loaded to $20.7 \mathrm{MPa}$ (Stacks 3 and 6). ${ }^{12}$

Temperature values within all AGC capsules are calculated based upon thermocouple readings at select positions within the capsule. Specimen temperature is calculated with a finite element model that has been calibrated to predict the known thermocouple readings in the capsule. Dose levels are calculated using Monte Carlo N-Particle Transport Code models and operating conditions in the ATR core and are corroborated from flux wire data.

\subsection{Establishing Specimen Dose}

To achieve the desired irradiation dose levels and applied mechanical loads to specific specimens, an exact specimen loading order is critical. Because irradiation creep is usually determined by the difference in dimensional change occurring within specimens that have an applied load and those that do not, these matched-pair specimens are assumed to have the same irradiation dose and irradiation temperature values. The AGC test train designs use the symmetric flux profile generated within ATR to achieve these similar irradiation conditions for matched pairs. 
Other considerations that went into the capsule design included the size of each creep specimen, need for periodically placed spacers containing flux wires, and space requirements in the top of the stacks for the pneumatic push rods. The core flux mid-plane, in relation to the capsule arrangement, was established so that the reactor neutron flux field could be correlated to the physical elevations and positions in the capsule to yield accurate matched-pair irradiation dose levels (see Figure 3).

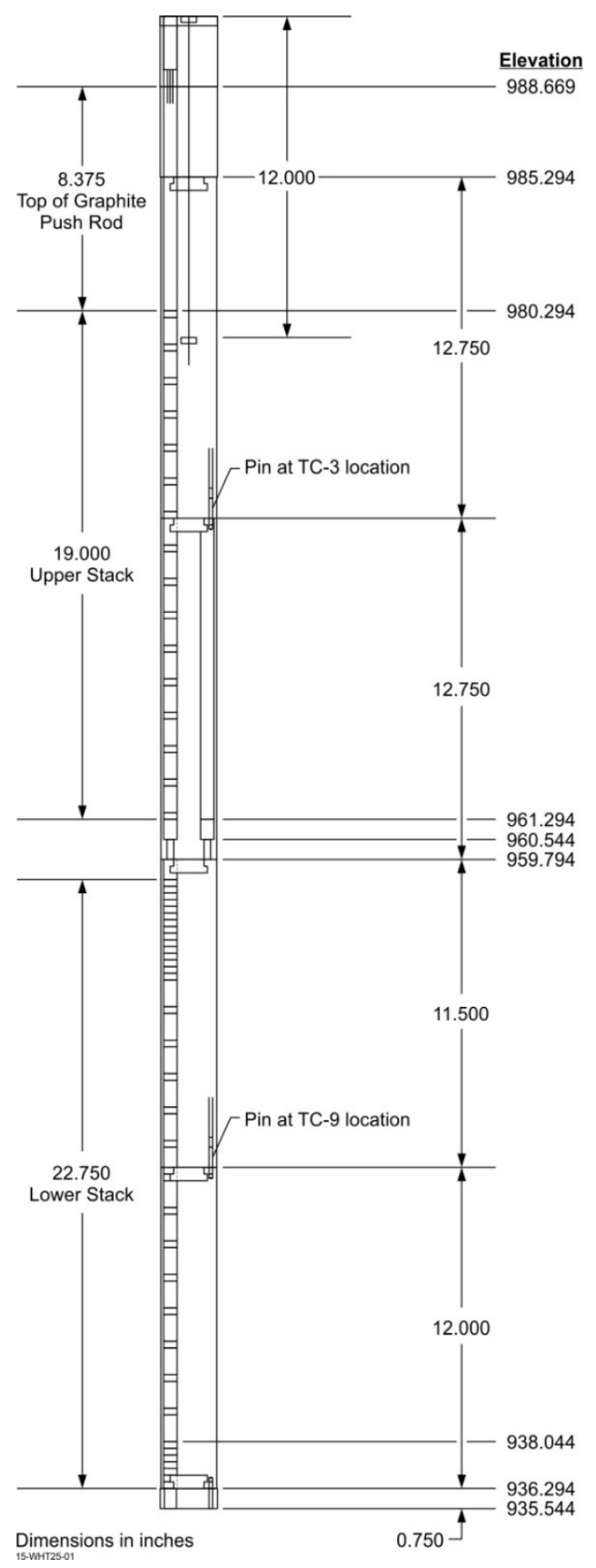

Figure 3. Elevation sketch of the AGC capsule. 
Irradiation dose values, as a function of distance from the reactor core centerline, are calculated from the total calculated fluence using standard conversion factors for carbon in a fast neutron irradiation field $(\mathrm{E}>0.1 \mathrm{MeV}){ }^{13}$ There is a neutron flux gradient across the capsule thickness requiring the capsule to be rotated 180 degrees at the irradiation duration mid-point. This rotation results in a uniform neutron-fluence profile for all stacks, regardless of their position within the capsule.

As described in previous reports, ${ }^{8}$ the ATR neutron flux profile is not completely symmetrical along the vertical axis. Thus, to produce matched-pair specimens that have similar dose profiles both above and below the core mid-plane, an offset position from the mid-plane is required. It was determined that an offset distance of $1.25 \mathrm{in}$. from the core mid-plane for the bottom creep specimens produces the closest dose matches between specimens.

\subsection{Physical Positions of Creep Specimens in the Stacks}

Once the specimen-position offset is established for the bottom half of the specimens, the number of total creep specimens for each grade of graphite is determined. It should be noted that the specimen stacking order for subsequent AGC irradiation capsules was changed from that initially established for the AGC-1 test train. In the initial AGC capsule design, AGC-1 used 0.25-in.-long NBG-25 graphite spacers between all creep specimens to separate them from each other. It was determined that this was not necessary, and the 0.25 -in.-long NBG-25 graphite spacers were eliminated. Eliminating the spacers increased the total number of creep specimens in the AGC capsules. In particular, the number of AGC-3 specimens was increased to 222 total specimens (36 matched pairs in each outer perimeter channel, plus two extra 2114 specimens in each of the first three channels). This allowed more specimens per graphite grade to be irradiated within the AGC-3 capsule.

Because any two opposing stacks are at similar applied stress levels, the specimen loading order can be shifted between the two stacks, allowing the same grade of graphite to be mechanically loaded over a broader neutron dose range, as shown in Figure 4. Assuming that both stacks will have the same applied stress level, receive similar dose levels per position, and have a constant temperature allows this shifting of the specimens and, consequently, a more uniform, smoother dose profile for each graphite grade.

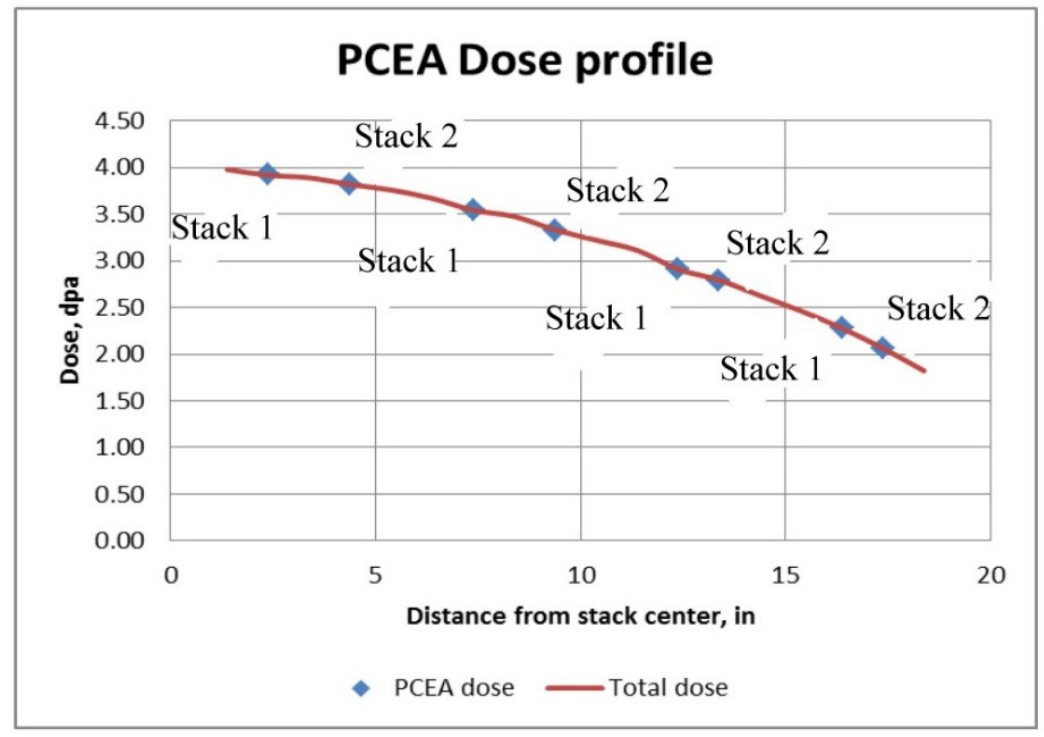

Figure 4. A typical dose profile for creep graphite specimens using similar applied stress levels in matched stacks. 
A final consideration when establishing the specimen loading positions is the grain orientation of the specimens. For extruded graphite grades, the against-grain (AG) and with-grain (WG) directions are obviously perpendicular and parallel to the extrusion direction, respectively. Isomolded grades have little to no grain direction, but these specimens were nonetheless machined at two distinct orientations. However, in the case of the vibration-molded graphites (i.e., NBG-17 and NBG-18), there are actually two WG directions and one $\mathrm{AG}$ direction as a consequence of the fabrication process. The total number of WG and AG specimens is dependent upon the particular AGC capsule pair (i.e., AGC-1 and AGC-2 have the same number of specimens with similar orientation).

Once these considerations are accounted for, the dose-level profiles are determined for each graphite grade within each channel stack. It should be noted that due to the elimination of the majority of the NBG-25 spacers from the AGC-1 design, the dose-level profiles for each graphite grade have been altered for the succeeding AGC capsules. ${ }^{13}$ However, the changes are modest, allowing nearly direct comparison between AGC-1 and the subsequent AGC capsules.

\section{AGC-3 TEST TRAIN CAPSULE}

The AGC-3 capsule was irradiated in ATR beginning with Cycle 152B on November 27, 2012, and ending with ATR Cycle 155B on April 12, 2014. ${ }^{12}$ Between Cycles 154B and 155A, the AGC-3 experiment capsule was rotated 180 degrees to evenly distribute the radiation dose. Estimates of AGC-3 dose, average temperature, and stress conditions are summarized in this report. Specific individual dose levels, temperature ranges, and stress conditions for all specimens contained within the irradiation capsule will be reported in a subsequent AGC-3 analysis report. AGC-3 design documents and drawings pertinent to the AGC-3 graphite specimens have been reported in the previous AGC-3 graphite pre-irradiation data analysis report. ${ }^{14}$ The technical and functional requirements for the AGC-3 test train are given in TFR791.5

\subsection{AGC-3 Graphite Grades and Changes to Dimensions}

Graphite grades used in AGC-3 were categorized as follows:

1. Major graphite grades: 2114, IG-110, NBG-17, NBG-18, and PCEA

2. Minor graphite grades: None

3. Alternate grades: PCIB

4. Experimental grades - Four experimental grades were irradiated in the AGC-3 capsule:

a. MLRF (Hemispherical shaped samples of SGL's NBG-17 grade coated with silicon carbide - $\mathrm{SiC})$

b. SGL/SGL-SiC (Piggyback button-shaped samples of SGL's NBG-17 grade coated and uncoated with silicon carbide)

c. TS (Piggyback button-shaped samples of a new experimental graphite grade from GrafTech, Inc.)

d. PCIB-MG (Piggyback button-shaped samples of a special experimental formulation of GrafTech, Inc.'s PCIB graphite grade)

5. Single crystal graphite: HOPG.

A more complete description of all of the graphite specimens included in the AGC-3 capsule is given in Table $1 .{ }^{14}$

Table 1. Major, minor, alternate, and experimental graphite grades within the AGC-3 capsule.

\begin{tabular}{|l|l|l|l|} 
Graphite Grade & Forming Method & Intended Purpose & AGC Code Designation \\
\hline
\end{tabular}


Table 1. (continued).

\begin{tabular}{|l|l|l|c|}
\hline \multicolumn{1}{|c|}{ Graphite Grade } & \multicolumn{1}{|c|}{ Forming Method } & \multicolumn{1}{c|}{ Intended Purpose } & AGC Code Designation \\
\hline NBG-17 & Vibrational molded & $\begin{array}{l}\text { AREVA Next Generation } \\
\text { Nuclear Plant design }\end{array}$ & A \\
\hline NBG-18 & Vibrational molded & $\begin{array}{l}\text { Pebble-Bed Modular Reactor (not } \\
\text { currently being pursued) }\end{array}$ & B \\
\hline PCEA & Extruded & $\begin{array}{l}\text { AREVA Next Generation } \\
\text { Nuclear Plant design }\end{array}$ & D \\
\hline IG-110 & Isostatically pressed & $\begin{array}{l}\text { HTR-Pebble-Bed Module } \\
\text { (China) }\end{array}$ & E \\
\hline HOPG & Vapor deposited & Fundamental studies & CAN101 - CAN117 \\
\hline 2114 & Isostatically pressed & Candidate graphite & T \\
\hline PCIB & Isostatically pressed & Alternative candidate grades & P \\
\hline GrafTech & Isostatically pressed & $\begin{array}{l}\text { Alternate/experiment candidate } \\
\text { grades TS and PCIB-MG }\end{array}$ & S1-S20 \\
\hline SGL & Vibrational molded & SiC coating experiments & A-H \\
\hline SGL-SiC & Vibrational molded & SiC coating experiments & CAN121 - CAN129 \\
\hline MLRF & Vibrational molded & SiC coating experiments & \\
\hline
\end{tabular}

\subsection{AGC-3 Specimen Stack Positions}

The final loading configuration for the outer channel/stacks was determined for each graphite grade to optimize the number of specimens for each grade, create a smooth irradiation profile for the creep and piggyback specimens, and assure the proper position of creep specimens to create the matched pairs. The graphite grades irradiated within AGC-3 differed slightly with the graphite grades in AGC-1 and AGC-2. H-451 and IG-430 were completely removed and replaced with 2114. Table 2 lists the total number of specimens irradiated per major graphite grade.

Table 2. Number of irradiated creep and piggyback specimens of the major grades in the AGC-3 test-series capsule.

\begin{tabular}{|l|c|c|c|}
\hline \multicolumn{1}{|c|}{ Graphite Grade } & Creep Specimens & Piggyback Specimens & Total \\
\hline 2114 & 48 & 24 & 72 \\
\hline IG-110 & 42 & 29 & 71 \\
\hline NBG-17 & 36 & 30 & 66 \\
\hline NBG-18 & 48 & 20 & 68 \\
\hline PCEA & 48 & 29 & 77 \\
\hline & 222 & 132 & 354 \\
\hline
\end{tabular}

The final loading configuration for the AGC-3 capsule is shown in Table 3 through Table $9 .{ }^{15}$ These tables also include the specimens' accumulated elevation within the capsule, channel number, and nominal load imposed on the specimens. 
Table 3. AGC-3 loading order for Stack 1.

\begin{tabular}{|c|c|c|c|c|c|c|c|}
\hline Channel & Housing & Loading Order & $\begin{array}{c}\text { Specimen } \\
\text { ID } \\
\end{array}$ & Description & $\begin{array}{l}\text { Accumulative } \\
\text { Eevation (in) }\end{array}$ & Grade & $\begin{array}{c}\text { Nominal } \\
\text { Load (KSI) } \\
\end{array}$ \\
\hline 1 & Upper & 23 & AP3001 & Stressed creep & 44.000 & NBG-17 & 2 \\
\hline 1 & Upper & 22 & $1 \mathrm{~J}$ & Flux Monitor & 43.000 & - & 2 \\
\hline 1 & Upper & 21 & DW3001 & Stressed creep & 42.750 & PCEA & 2 \\
\hline 1 & Upper & 20 & BW3001 & Stressed creep & 41.750 & NBG-18 & 2 \\
\hline 1 & Upper & 19 & EW3001 & Stressed creep & 40.750 & IG-110 & 2 \\
\hline 1 & Upper & 18 & TW3001 & Stressed creep & 39.750 & 2114 & 2 \\
\hline 1 & Upper & 17 & DW3004 & Stressed creep & 38.750 & PCEA & 2 \\
\hline 1 & Upper & 16 & $\mathrm{Y} 1$ & Flux Monitor & 37.750 & - & 2 \\
\hline 1 & Upper & 15 & BР3002 & Stressed creep & 37.500 & NBG-18 & 2 \\
\hline 1 & Upper & 14 & TW3004 & Stressed creep & 36.500 & 2114 & 2 \\
\hline 1 & Upper & 13 & EW3004 & Stressed creep & 35.500 & IG-110 & 2 \\
\hline 1 & Upper & 12 & DW3103 & Stressed creep & 34.500 & PCEA & 2 \\
\hline 1 & Upper & 11 & BW3101 & Stressed creep & 33.500 & NBG-18 & 2 \\
\hline 1 & Upper & 10 & TW3705 & Stressed creep & 32.500 & 2114 & 2 \\
\hline 1 & Upper & 9 & DA & Flux Monitor & 31.500 & - & 2 \\
\hline 1 & Upper & 8 & AP3301 & Stressed creep & 31.250 & NBG-17 & 2 \\
\hline 1 & Upper & 7 & EW3103 & Stressed creep & 30.250 & IG-110 & 2 \\
\hline 1 & Upper & 6 & DW3203 & Stressed creep & 29.250 & PCEA & 2 \\
\hline 1 & Upper & 5 & BL3001 & Stressed creep & 28.250 & NBG-18 & 2 \\
\hline 1 & Upper & 4 & TW3010 & Stressed creep & 27.250 & 2114 & 2 \\
\hline 1 & Upper & 3 & $1 \mathrm{~L}$ & Flux Monitor & 26.250 & - & 2 \\
\hline 1 & Upper & 2 & AW3103 & Stressed creep & 26.000 & NBG-17 & 2 \\
\hline 1 & Lower & 29 & TW3605 & Unstressed control & 22.500 & 2114 & 0 \\
\hline 1 & Lower & 28 & $200-9$ & Piggyback & 21.500 & GrafTech-200 & 0 \\
\hline 1 & Lower & 27 & AW3104 & Unstressed control & 21.250 & NBG-17 & 0 \\
\hline 1 & Lower & 26 & $1 \mathrm{U}$ & Flux Monitor & 20.250 & - & 0 \\
\hline 1 & Lower & 25 & TW3103 & Unstressed control & 20.000 & 2114 & 0 \\
\hline 1 & Lower & 24 & BL3004 & Unstressed control & 19.000 & NBG-18 & 0 \\
\hline 1 & Lower & 23 & DW3302 & Unstressed control & 18.000 & PCEA & 0 \\
\hline 1 & Lower & 22 & EW3202 & Unstressed control & 17.000 & IG-110 & 0 \\
\hline 1 & Lower & 21 & AP3004 & Unstressed control & 16.000 & NBG-17 & 0 \\
\hline 1 & Lower & 20 & AL3804 & Piggyback & 15.000 & NBG-17 & 0 \\
\hline 1 & Lower & 19 & TW3107 & Unstressed control & 14.750 & 2114 & 0 \\
\hline 1 & Lower & 18 & BW3501 & Unstressed control & 13.750 & NBG-18 & 0 \\
\hline 1 & Lower & 17 & DW3401 & Unstressed control & 12.750 & PCEA & 0 \\
\hline 1 & Lower & 16 & EW3301 & Unstressed control & 11.750 & IG-110 & 0 \\
\hline 1 & Lower & 15 & TW3201 & Unstressed control & 10.750 & 2114 & 0 \\
\hline 1 & Lower & 14 & BP3005 & Unstressed control & 9.750 & NBG-18 & 0 \\
\hline 1 & Lower & 13 & $\mathrm{H} 7$ & Flux Monitor & 8.750 & - & 0 \\
\hline 1 & Lower & 12 & DW3404 & Unstressed control & 8.500 & PCEA & 0 \\
\hline 1 & Lower & 11 & TW3402 & Unstressed control & 7.500 & 2114 & 0 \\
\hline 1 & Lower & 10 & EW3304 & Unstressed control & 6.500 & IG-110 & 0 \\
\hline 1 & Lower & 9 & BW3301 & Unstressed control & 5.500 & NBG-18 & 0 \\
\hline 1 & Lower & 8 & DW3504 & Unstressed control & 4.500 & PCEA & 0 \\
\hline 1 & Lower & 7 & F7 & Flux Monitor & 3.500 & - & 0 \\
\hline 1 & Lower & 6 & AP3202 & Unstressed control & 3.250 & NBG-17 & 0 \\
\hline 1 & Lower & 5 & TW3608 & Unstressed control & 2.250 & 2114 & 0 \\
\hline 1 & Lower & 4 & $325-12$ & Piggyback & 1.250 & GrafTech-325 & 0 \\
\hline 1 & Lower & 3 & $200-12$ & Piggyback & 1.000 & GrafTech-200 & 0 \\
\hline 1 & Lower & 2 & AL3805 & Piggyback & 0.750 & NBG-17 & 0 \\
\hline
\end{tabular}


Table 4. AGC-3 loading order for Stack 2.

\begin{tabular}{|c|c|c|c|c|c|c|c|}
\hline Channel & Housing & Loading Order & $\begin{array}{c}\text { Specimen } \\
\text { ID } \\
\end{array}$ & Description & $\begin{array}{l}\text { Accumulative } \\
\text { Elevation (in) }\end{array}$ & Grade & $\begin{array}{c}\text { Nominal } \\
\text { Load (KSI) }\end{array}$ \\
\hline 2 & Upper & 23 & AP3002 & Stressed creep & 44.000 & NBG-17 & 2.5 \\
\hline 2 & Upper & 22 & EA-SP1 & Piggyback Spacer & 43.000 & IG-110 & 2.5 \\
\hline 2 & Upper & 21 & DW3002 & Stressed creep & 42.750 & PCEA & 2.5 \\
\hline 2 & Upper & 20 & BW3002 & Stressed creep & 41.750 & NBG-18 & 2.5 \\
\hline 2 & Upper & 19 & EW3802 & Stressed creep & 40.750 & IG-110 & 2.5 \\
\hline 2 & Upper & 18 & TW3002 & Stressed creep & 39.750 & 2114 & 2.5 \\
\hline 2 & Upper & 17 & DW3101 & Stressed creep & 38.750 & PCEA & 2.5 \\
\hline 2 & Upper & 16 & 2B & Flux Monitor & 37.750 & - & 2.5 \\
\hline 2 & Upper & 15 & BP3003 & Stressed creep & 37.500 & NBG-18 & 2.5 \\
\hline 2 & Upper & 14 & TW3005 & Stressed creep & 36.500 & 2114 & 2.5 \\
\hline 2 & Upper & 13 & EW3101 & Stressed creep & 35.500 & IG-110 & 2.5 \\
\hline 2 & Upper & 12 & DW3201 & Stressed creep & 34.500 & PCEA & 2.5 \\
\hline 2 & Upper & 11 & BW3402 & Stressed creep & 33.500 & NBG-18 & 2.5 \\
\hline 2 & Upper & 10 & TW3008 & Stressed creep & 32.500 & 2114 & 2.5 \\
\hline 2 & Upper & 9 & EA-SP2 & Piggyback Spacer & 31.500 & IG-110 & 2.5 \\
\hline 2 & Upper & 8 & AP3302 & Stressed creep & 31.250 & NBG-17 & 2.5 \\
\hline 2 & Upper & 7 & EW3104 & Stressed creep & 30.250 & IG-110 & 2.5 \\
\hline 2 & Upper & 6 & DW3204 & Stressed creep & 29.250 & PCEA & 2.5 \\
\hline 2 & Upper & 5 & BL3002 & Stressed creep & 28.250 & NBG-18 & 2.5 \\
\hline 2 & Upper & 4 & TW3101 & Stressed creep & 27.250 & 2114 & 2.5 \\
\hline 2 & Upper & 3 & FA & Flux Monitor & 26.250 & - & 2.5 \\
\hline 2 & Upper & 2 & AW3201 & Stressed creep & 26.000 & NBG-17 & 2.5 \\
\hline 2 & Lower & 29 & TW3606 & Unstressed control & 22.500 & 2114 & 0 \\
\hline 2 & Lower & 28 & $200-10$ & Piggyback & 21.500 & GrafTech-200 & 0 \\
\hline 2 & Lower & 27 & AW3202 & Unstressed control & 21.250 & NBG-17 & 0 \\
\hline 2 & Lower & 26 & EA3609 & Piggyback & 20.250 & IG-110 & 0 \\
\hline 2 & Lower & 25 & TW3105 & Unstressed control & 20.000 & 2114 & 0 \\
\hline 2 & Lower & 24 & BL3101 & Unstressed control & 19.000 & NBG-18 & 0 \\
\hline 2 & Lower & 23 & DW3303 & Unstressed control & 18.000 & PCEA & 0 \\
\hline 2 & Lower & 22 & EW3203 & Unstressed control & 17.000 & IG-110 & 0 \\
\hline 2 & Lower & 21 & AP3101 & Unstressed control & 16.000 & NBG-17 & 0 \\
\hline 2 & Lower & 20 & EA3610 & Piggyback & 15.000 & IG-110 & 0 \\
\hline 2 & Lower & 19 & TW3108 & Unstressed control & 14.750 & 2114 & 0 \\
\hline 2 & Lower & 18 & BW3202 & Unstressed control & 13.750 & NBG-18 & 0 \\
\hline 2 & Lower & 17 & DW3402 & Unstressed control & 12.750 & PCEA & 0 \\
\hline 2 & Lower & 16 & EW3302 & Unstressed control & 11.750 & IG-110 & 0 \\
\hline 2 & Lower & 15 & TW3202 & Unstressed control & 10.750 & 2114 & 0 \\
\hline 2 & Lower & 14 & BP3101 & Unstressed control & 9.750 & NBG-18 & 0 \\
\hline 2 & Lower & 13 & 70 & Flux Monitor & 8.750 & - & 0 \\
\hline 2 & Lower & 12 & DW3501 & Unstressed control & 8.500 & PCEA & 0 \\
\hline 2 & Lower & 11 & TW3403 & Unstressed control & 7.500 & 2114 & 0 \\
\hline 2 & Lower & 10 & EW3401 & Unstressed control & 6.500 & IG-110 & 0 \\
\hline 2 & Lower & 9 & BW3503 & Unstressed control & 5.500 & NBG-18 & 0 \\
\hline 2 & Lower & 8 & DW3601 & Unstressed control & 4.500 & PCEA & 0 \\
\hline 2 & Lower & 7 & EA3611 & Piggyback & 3.500 & IG-110 & 0 \\
\hline 2 & Lower & 6 & AP3203 & Unstressed control & 3.250 & NBG-17 & 0 \\
\hline 2 & Lower & 5 & TW3609 & Unstressed control & 2.250 & 2114 & 0 \\
\hline 2 & Lower & 4 & $325-13$ & Piggyback & 1.250 & GrafTech-325 & 0 \\
\hline 2 & Lower & 3 & $200-13$ & Piggyback & 1.000 & GrafTech-200 & 0 \\
\hline 2 & Lower & 2 & AL3806 & Piggyback & 0.750 & NBG-17 & 0 \\
\hline
\end{tabular}


Table 5. AGC-3 loading order for Stack 3.

\begin{tabular}{|c|c|c|c|c|c|c|c|}
\hline Channel & Housing & Loading Order & $\begin{array}{c}\text { Specimen } \\
\text { ID } \\
\end{array}$ & Description & $\begin{array}{l}\text { Accumulative } \\
\text { Elevation (in) }\end{array}$ & Grade & $\begin{array}{c}\text { Nominal } \\
\text { Load (KSI) }\end{array}$ \\
\hline 3 & Upper & 23 & AP3003 & Stressed creep & 44.000 & NBG-17 & 3 \\
\hline 3 & Upper & 22 & EW-SP1 & Piggyback Spacer & 43.000 & IG-110 & 3 \\
\hline 3 & Upper & 21 & DW3003 & Stressed creep & 42.750 & PCEA & 3 \\
\hline 3 & Upper & 20 & BW3401 & Stressed creep & 41.750 & NBG-18 & 3 \\
\hline 3 & Upper & 19 & EW3003 & Stressed creep & 40.750 & IG-110 & 3 \\
\hline 3 & Upper & 18 & TW3003 & Stressed creep & 39.750 & 2114 & 3 \\
\hline 3 & Upper & 17 & DW3102 & Stressed creep & 38.750 & PCEA & 3 \\
\hline 3 & Upper & 16 & $\mathrm{AF}$ & Flux Monitor & 37.750 & - & 3 \\
\hline 3 & Upper & 15 & BP3004 & Stressed creep & 37.500 & NBG-18 & 3 \\
\hline 3 & Upper & 14 & TW3006 & Stressed creep & 36.500 & 2114 & 3 \\
\hline 3 & Upper & 13 & EW3801 & Stressed creep & 35.500 & IG-110 & 3 \\
\hline 3 & Upper & 12 & DW3202 & Stressed creep & 34.500 & PCEA & 3 \\
\hline 3 & Upper & 11 & BW3103 & Stressed creep & 33.500 & NBG-18 & 3 \\
\hline 3 & Upper & 10 & TW3009 & Stressed creep & 32.500 & 2114 & 3 \\
\hline 3 & Upper & 9 & EW-SP2 & Piggyback Spacer & 31.500 & IG-110 & 3 \\
\hline 3 & Upper & 8 & AP3303 & Stressed creep & 31.250 & NBG-17 & 3 \\
\hline 3 & Upper & 7 & EW3201 & Stressed creep & 30.250 & IG-110 & 3 \\
\hline 3 & Upper & 6 & DW3301 & Stressed creep & 29.250 & PCEA & 3 \\
\hline 3 & Upper & 5 & BL3003 & Stressed creep & 28.250 & NBG-18 & 3 \\
\hline 3 & Upper & 4 & TW3102 & Stressed creep & 27.250 & 2114 & 3 \\
\hline 3 & Upper & 3 & $8 \mathrm{I}$ & Flux Monitor & 26.250 & - & 3 \\
\hline 3 & Upper & 2 & AW 3203 & Stressed creep & 26.000 & NBG-17 & 3 \\
\hline 3 & Lower & 29 & TW3607 & Unstressed control & 22.500 & 2114 & 0 \\
\hline 3 & Lower & 28 & $200-11$ & Piggyback & 21.500 & GrafTech-200 & 0 \\
\hline 3 & Lower & 27 & AW3204 & Unstressed control & 21.250 & NBG-17 & 0 \\
\hline 3 & Lower & 26 & EW4607 & Piggyback & 20.250 & IG-110 & 0 \\
\hline 3 & Lower & 25 & TW3106 & Unstressed control & 20.000 & 2114 & 0 \\
\hline 3 & Lower & 24 & BL3102 & Unstressed control & 19.000 & NBG-18 & 0 \\
\hline 3 & Lower & 23 & DW3304 & Unstressed control & 18.000 & PCEA & 0 \\
\hline 3 & Lower & 22 & EW3204 & Unstressed control & 17.000 & IG-110 & 0 \\
\hline 3 & Lower & 21 & AP3102 & Unstressed control & 16.000 & NBG-17 & 0 \\
\hline 3 & Lower & 20 & EW4608 & Piggyback & 15.000 & IG-110 & 0 \\
\hline 3 & Lower & 19 & TW3109 & Unstressed control & 14.750 & 2114 & 0 \\
\hline 3 & Lower & 18 & BW3502 & Unstressed control & 13.750 & NBG-18 & 0 \\
\hline 3 & Lower & 17 & DW3403 & Unstressed control & 12.750 & PCEA & 0 \\
\hline 3 & Lower & 16 & EW3303 & Unstressed control & 11.750 & IG-110 & 0 \\
\hline 3 & Lower & 15 & TW3704 & Unstressed control & 10.750 & 2114 & 0 \\
\hline 3 & Lower & 14 & $\mathrm{BP} 3102$ & Unstressed control & 9.750 & NBG-18 & 0 \\
\hline 3 & Lower & 13 & XA & Flux Monitor & 8.750 & - & 0 \\
\hline 3 & Lower & 12 & DW3502 & Unstressed control & 8.500 & PCEA & 0 \\
\hline 3 & Lower & 11 & TW3404 & Unstressed control & 7.500 & 2114 & 0 \\
\hline 3 & Lower & 10 & EW3402 & Unstressed control & 6.500 & IG-110 & 0 \\
\hline 3 & Lower & 9 & BW3303 & Unstressed control & 5.500 & NBG-18 & 0 \\
\hline 3 & Lower & 8 & DW3602 & Unstressed control & 4.500 & PCEA & 0 \\
\hline 3 & Lower & 7 & EW4609 & Piggyback & 3.500 & IG-110 & 0 \\
\hline 3 & Lower & 6 & AP3204 & Unstressed control & 3.250 & NBG-17 & 0 \\
\hline 3 & Lower & 5 & TW3610 & Unstressed control & 2.250 & 2114 & 0 \\
\hline 3 & Lower & 4 & $325-14$ & Piggyback & 1.250 & GrafTech-325 & 0 \\
\hline 3 & Lower & 3 & $200-14$ & Piggyback & 1.000 & GrafTech-200 & 0 \\
\hline 3 & Lower & 2 & AL3807 & Piggyback & 0.750 & NBG-17 & 0 \\
\hline
\end{tabular}


Table 6. AGC-3 loading order for Stack 4.

\begin{tabular}{|c|c|c|c|c|c|c|c|}
\hline Channel & Housing & Loading Order & $\begin{array}{c}\text { Specimen } \\
\text { ID }\end{array}$ & Description & $\begin{array}{l}\text { Accumulative } \\
\text { Elevation (in) }\end{array}$ & Grade & \begin{tabular}{|c|} 
Nominal \\
Load (KSI)
\end{tabular} \\
\hline 4 & Upper & 23 & EW 3601 & Stressed creep & 44.000 & IG-110 & 2 \\
\hline 4 & Upper & 22 & $7 \mathrm{~A}$ & Flux Monitor & 43.000 & - & 2 \\
\hline 4 & Upper & 21 & TW3703 & Stressed creep & 42.750 & 2114 & 2 \\
\hline 4 & Upper & 20 & DA3001 & Stressed creep & 41.750 & PCEA & 2 \\
\hline 4 & Upper & 19 & BP3103 & Stressed creep & 40.750 & NBG-18 & 2 \\
\hline 4 & Upper & 18 & AL3202 & Stressed creep & 39.750 & NBG-17 & 2 \\
\hline 4 & Upper & 17 & EW3604 & Stressed creep & 38.750 & IG-110 & 2 \\
\hline 4 & Upper & 16 & $1 \mathrm{H}$ & Flux Monitor & 37.750 & - & 2 \\
\hline 4 & Upper & 15 & DW3801 & Stressed creep & 37.500 & PCEA & 2 \\
\hline 4 & Upper & 14 & BL3103 & Stressed creep & 36.500 & NBG-18 & 2 \\
\hline 4 & Upper & 13 & TW3405 & Stressed creep & 35.500 & 2114 & 2 \\
\hline 4 & Upper & 12 & AW3001 & Stressed creep & 34.500 & NBG-17 & 2 \\
\hline 4 & Upper & 11 & EA3001 & Stressed creep & 33.500 & IG-110 & 2 \\
\hline 4 & Upper & 10 & DA3203 & Stressed creep & 32.500 & PCEA & 2 \\
\hline 4 & Upper & 9 & YA & Flux Monitor & 31.500 & - & 2 \\
\hline 4 & Upper & 8 & BP3202 & Stressed creep & 31.250 & NBG-18 & 2 \\
\hline 4 & Upper & 7 & TW3408 & Stressed creep & 30.250 & 2114 & 2 \\
\hline 4 & Upper & 6 & AP3304 & Stressed creep & 29.250 & NBG-17 & 2 \\
\hline 4 & Upper & 5 & EA3004 & Stressed creep & 28.250 & IG-110 & 2 \\
\hline 4 & Upper & 4 & DW3603 & Stressed creep & 27.250 & PCEA & 2 \\
\hline 4 & Upper & 3 & $1 \mathrm{C}$ & Flux Monitor & 26.250 & - & 2 \\
\hline 4 & Upper & 2 & BP3301 & Stressed creep & 26.000 & NBG-18 & 2 \\
\hline 4 & Lower & 35 & AW3810 & Piggyback & 22.500 & NBG-17 & 0 \\
\hline 4 & Lower & 34 & EW4601 & Piggyback & 22.250 & IG-110 & 0 \\
\hline 4 & Lower & 33 & TW3821 & Piggyback & 22.000 & 2114 & 0 \\
\hline 4 & Lower & 32 & $325-9$ & Piggyback & 21.750 & GrafTech-325 & 0 \\
\hline 4 & Lower & 31 & P3-07 & Piggyback & 21.500 & PCIB & 0 \\
\hline 4 & Lower & 30 & BP3304 & Unstressed control & 21.250 & NBG-18 & 0 \\
\hline 4 & Lower & 29 & R7 & Flux Monitor & 20.250 & - & 0 \\
\hline 4 & Lower & 28 & DW3702 & Unstressed control & 20.000 & PCEA & 0 \\
\hline 4 & Lower & 27 & EA3103 & Unstressed control & 19.000 & IG-110 & 0 \\
\hline 4 & Lower & 26 & AP3403 & Unstressed control & 18.000 & NBG-17 & 0 \\
\hline 4 & Lower & 25 & TW3501 & Unstressed control & 17.000 & 2114 & 0 \\
\hline 4 & Lower & 24 & BP3603 & Unstressed control & 16.000 & NBG-18 & 0 \\
\hline 4 & Lower & 23 & TW3904 & Piggyback & 15.000 & 2114 & 0 \\
\hline 4 & Lower & 22 & DA3302 & Unstressed control & 14.750 & PCEA & 0 \\
\hline 4 & Lower & 21 & EA3202 & Unstressed control & 13.750 & IG-110 & 0 \\
\hline 4 & Lower & 20 & AW3004 & Unstressed control & 12.750 & NBG-17 & 0 \\
\hline 4 & Lower & 19 & TW3504 & Unstressed control & 11.750 & 2114 & 0 \\
\hline 4 & Lower & 18 & BL3201 & Unstressed control & 10.750 & NBG-18 & 0 \\
\hline 4 & Lower & 17 & DW 3803 & Unstressed control & 9.750 & PCEA & 0 \\
\hline 4 & Lower & 16 & 10 & Flux Monitor & 8.750 & - & 0 \\
\hline 4 & Lower & 15 & EW3403 & Unstressed control & 8.500 & IG-110 & 0 \\
\hline 4 & Lower & 14 & AL3301 & Unstressed control & 7.500 & NBG-17 & 0 \\
\hline 4 & Lower & 13 & BP3801 & Unstressed control & 6.500 & NBG-18 & 0 \\
\hline 4 & Lower & 12 & DA3403 & Unstressed control & 5.500 & PCEA & 0 \\
\hline 4 & Lower & 11 & TW3507 & Unstressed control & 4.500 & 2114 & 0 \\
\hline 4 & Lower & 10 & JA & Flux Monitor & 3.500 & - & 0 \\
\hline 4 & Lower & 9 & EW3502 & Unstressed control & 3.250 & IG-110 & 0 \\
\hline 4 & Lower & 8 & BL3601 & Piggyback & 2.250 & NBG-18 & 0 \\
\hline 4 & Lower & 7 & AL3801 & Piggyback & 2.000 & NBG-17 & 0 \\
\hline 4 & Lower & 6 & EW4509 & Piggyback & 1.750 & IG-110 & 0 \\
\hline 4 & Lower & 5 & AL3904 & Piggyback & 1.500 & NBG-17 & 0 \\
\hline 4 & Lower & 4 & DW4511 & Piggyback & 1.250 & PCEA & 0 \\
\hline 4 & Lower & 3 & DA3510 & Piggyback & 1.000 & PCEA & 0 \\
\hline 4 & Lower & 2 & TW3827 & Piggyback & 0.750 & 2114 & 0 \\
\hline
\end{tabular}


Table 7. AGC-3 loading order for Stack 5.

\begin{tabular}{|c|c|c|c|c|c|c|c|}
\hline Channel & Housing & Loading Order & $\begin{array}{c}\text { Specimen } \\
\text { ID }\end{array}$ & Description & $\begin{array}{l}\text { Accumulative } \\
\text { Elevation (in) } \\
\end{array}$ & Grade & \begin{tabular}{|c|} 
Nominal \\
Load (KSI) \\
\end{tabular} \\
\hline 5 & Upper & 23 & EW 3602 & Stressed creep & 44.000 & IG-110 & 2.5 \\
\hline 5 & Upper & 22 & DA-SP1 & Piggyback Spacer & 44.000 & PCEA & 2.5 \\
\hline 5 & Upper & 21 & TW3702 & Stressed creep & 42.750 & 2114 & 2.5 \\
\hline 5 & Upper & 20 & DA3003 & Stressed creep & 41.750 & PCEA & 2.5 \\
\hline 5 & Upper & 19 & BP3104 & Stressed creep & 40.750 & NBG-18 & 2.5 \\
\hline 5 & Upper & 18 & AL3203 & Stressed creep & 39.750 & NBG-17 & 2.5 \\
\hline 5 & Upper & 17 & EW3701 & Stressed creep & 38.750 & IG-110 & 2.5 \\
\hline 5 & Upper & 16 & $\mathrm{~J} 7$ & Flux Monitor & 37.750 & - & 2.5 \\
\hline 5 & Upper & 15 & DW3804 & Stressed creep & 37.500 & PCEA & 2.5 \\
\hline 5 & Upper & 14 & BL3104 & Stressed creep & 36.500 & NBG-18 & 2.5 \\
\hline 5 & Upper & 13 & TW3406 & Stressed creep & 35.500 & 2114 & 2.5 \\
\hline 5 & Upper & 12 & AW3002 & Stressed creep & 34.500 & NBG-17 & 2.5 \\
\hline 5 & Upper & 11 & EA3002 & Stressed creep & 33.500 & IG-110 & 2.5 \\
\hline 5 & Upper & 10 & DA3204 & Stressed creep & 32.500 & PCEA & 2.5 \\
\hline 5 & Upper & 9 & DA-SP2 & Piggyback Spacer & 31.500 & PCEA & 2.5 \\
\hline 5 & Upper & 8 & BP3204 & Stressed creep & 31.250 & NBG-18 & 2.5 \\
\hline 5 & Upper & 7 & TW3409 & Stressed creep & 30.250 & 2114 & 2.5 \\
\hline 5 & Upper & 6 & AP3401 & Stressed creep & 29.250 & NBG-17 & 2.5 \\
\hline 5 & Upper & 5 & EA3101 & Stressed creep & 28.250 & IG-110 & 2.5 \\
\hline 5 & Upper & 4 & DW3604 & Stressed creep & 27.250 & PCEA & 2.5 \\
\hline 5 & Upper & 3 & O7 & Flux Monitor & 26.250 & - & 2.5 \\
\hline 5 & Upper & 2 & BP3302 & Stressed creep & 26.000 & NBG-18 & 2.5 \\
\hline 5 & Lower & 35 & AW3811 & Piggyback & 22.500 & NBG-17 & 0 \\
\hline 5 & Lower & 34 & EW 4602 & Piggyback & 22.250 & IG-110 & 0 \\
\hline 5 & Lower & 33 & TW3822 & Piggyback & 22.000 & 2114 & 0 \\
\hline 5 & Lower & 32 & $325-10$ & Piggyback & 21.750 & GrafTech-325 & 0 \\
\hline 5 & Lower & 31 & P3-08 & Piggyback & 21.500 & PCIB & 0 \\
\hline 5 & Lower & 30 & BP3601 & Unstressed control & 21.250 & NBG-18 & 0 \\
\hline 5 & Lower & 29 & DA3603 & Piggyback & 20.250 & PCEA & 0 \\
\hline 5 & Lower & 28 & DW3703 & Unstressed control & 20.000 & PCEA & 0 \\
\hline 5 & Lower & 27 & EA3104 & Unstressed control & 19.000 & IG-110 & 0 \\
\hline 5 & Lower & 26 & AP3404 & Unstressed control & 18.000 & NBG-17 & 0 \\
\hline 5 & Lower & 25 & TW3502 & Unstressed control & 17.000 & 2114 & 0 \\
\hline 5 & Lower & 24 & BP3604 & Unstressed control & 16.000 & NBG-18 & 0 \\
\hline 5 & Lower & 23 & DA3604 & Piggyback & 15.000 & PCEA & 0 \\
\hline 5 & Lower & 22 & DA3303 & Unstressed control & 14.750 & PCEA & 0 \\
\hline 5 & Lower & 21 & EA3203 & Unstressed control & 13.750 & IG-110 & 0 \\
\hline 5 & Lower & 20 & AW3101 & Unstressed control & 12.750 & NBG-17 & 0 \\
\hline 5 & Lower & 19 & TW3505 & Unstressed control & 11.750 & 2114 & 0 \\
\hline 5 & Lower & 18 & BL3202 & Unstressed control & 10.750 & NBG-18 & 0 \\
\hline 5 & Lower & 17 & DW 3901 & Unstressed control & 9.750 & PCEA & 0 \\
\hline 5 & Lower & 16 & $\mathrm{Y} 2$ & Flux Monitor & 8.750 & - & 0 \\
\hline 5 & Lower & 15 & EW3704 & Unstressed control & 8.500 & IG-110 & 0 \\
\hline 5 & Lower & 14 & AL3101 & Unstressed control & 7.500 & NBG-17 & 0 \\
\hline 5 & Lower & 13 & BP3702 & Unstressed control & 6.500 & NBG-18 & 0 \\
\hline 5 & Lower & 12 & DA3404 & Unstressed control & 5.500 & PCEA & 0 \\
\hline 5 & Lower & 11 & TW3508 & Unstressed control & 4.500 & 2114 & 0 \\
\hline 5 & Lower & 10 & DA3605 & Piggyback & 3.500 & PCEA & 0 \\
\hline 5 & Lower & 9 & EW 3503 & Unstressed control & 3.250 & IG-110 & 0 \\
\hline 5 & Lower & 8 & BL3602 & Piggyback & 2.250 & NBG-18 & 0 \\
\hline 5 & Lower & 7 & AL3802 & Piggyback & 2.000 & NBG-17 & 0 \\
\hline 5 & Lower & 6 & EW4510 & Piggyback & 1.750 & IG-110 & 0 \\
\hline 5 & Lower & 5 & AW3902 & Piggyback & 1.500 & NBG-17 & 0 \\
\hline 5 & Lower & 4 & DW4512 & Piggyback & 1.250 & PCEA & 0 \\
\hline 5 & Lower & 3 & DA3511 & Piggyback & 1.000 & PCEA & 0 \\
\hline 5 & Lower & 2 & TW3828 & Piggyback & 0.750 & 2114 & 0 \\
\hline
\end{tabular}


Table 8. AGC-3 loading order for Stack 6.

\begin{tabular}{|c|c|c|c|c|c|c|c|}
\hline Channel & Housing & Loading Order & $\begin{array}{c}\text { Specimen } \\
\text { ID }\end{array}$ & Description & $\begin{array}{l}\text { Accumulative } \\
\text { Eevation (in) } \\
\end{array}$ & Grade & \begin{tabular}{|c|} 
Nominal \\
Load (KSI)
\end{tabular} \\
\hline 6 & Upper & 23 & EW 3603 & Stressed creep & 44.000 & IG-110 & 3 \\
\hline 6 & Upper & 22 & DA-SP3 & Piggyback Spacer & 43.000 & PCEA & 3 \\
\hline 6 & Upper & 21 & TW3602 & Stressed creep & 42.750 & 2114 & 3 \\
\hline 6 & Upper & 20 & DA3004 & Stressed creep & 41.750 & PCEA & 3 \\
\hline 6 & Upper & 19 & BP3201 & Stressed creep & 40.750 & NBG-18 & 3 \\
\hline 6 & Upper & 18 & AL3204 & Stressed creep & 39.750 & NBG-17 & 3 \\
\hline 6 & Upper & 17 & EW3702 & Stressed creep & 38.750 & IG-110 & 3 \\
\hline 6 & Upper & 16 & $\mathrm{AU}$ & Flux Monitor & 37.750 & - & 3 \\
\hline 6 & Upper & 15 & DW3902 & Stressed creep & 37.500 & PCEA & 3 \\
\hline 6 & Upper & 14 & BL3204 & Stressed creep & 36.500 & NBG-18 & 3 \\
\hline 6 & Upper & 13 & TW3407 & Stressed creep & 35.500 & 2114 & 3 \\
\hline 6 & Upper & 12 & AW3003 & Stressed creep & 34.500 & NBG-17 & 3 \\
\hline 6 & Upper & 11 & EA3003 & Stressed creep & 33.500 & IG-110 & 3 \\
\hline 6 & Upper & 10 & DA3301 & Stressed creep & 32.500 & PCEA & 3 \\
\hline 6 & Upper & 9 & DA-SP4 & Piggyback Spacer & 31.500 & PCEA & 3 \\
\hline 6 & Upper & 8 & BP3205 & Stressed creep & 31.250 & NBG-18 & 3 \\
\hline 6 & Upper & 7 & TW3410 & Stressed creep & 30.250 & 2114 & 3 \\
\hline 6 & Upper & 6 & AP3402 & Stressed creep & 29.250 & NBG-17 & 3 \\
\hline 6 & Upper & 5 & EA3301 & Stressed creep & 28.250 & IG-110 & 3 \\
\hline 6 & Upper & 4 & DW3701 & Stressed creep & 27.250 & PCEA & 3 \\
\hline 6 & Upper & 3 & 1D & Flux Monitor & 26.250 & - & 3 \\
\hline 6 & Upper & 2 & BP3303 & Stressed creep & 26.000 & NBG-18 & 3 \\
\hline 6 & Lower & 35 & AW 3812 & Piggyback & 22.500 & NBG-17 & 0 \\
\hline 6 & Lower & 34 & EW4603 & Piggyback & 22.250 & IG-110 & 0 \\
\hline 6 & Lower & 33 & TW3823 & Piggyback & 22.000 & 2114 & 0 \\
\hline 6 & Lower & 32 & $325-11$ & Piggyback & 21.750 & GrafTech-325 & 0 \\
\hline 6 & Lower & 31 & P3-09 & Piggyback & 21.500 & PCIB & 0 \\
\hline 6 & Lower & 30 & BP3602 & Unstressed control & 21.250 & NBG-18 & 0 \\
\hline 6 & Lower & 29 & DA3608 & Piggyback & 20.250 & PCEA & 0 \\
\hline 6 & Lower & 28 & DW3704 & Unstressed control & 20.000 & PCEA & 0 \\
\hline 6 & Lower & 27 & EA3201 & Unstressed control & 19.000 & IG-110 & 0 \\
\hline 6 & Lower & 26 & AP3103 & Unstressed control & 18.000 & NBG-17 & 0 \\
\hline 6 & Lower & 25 & TW3503 & Unstressed control & 17.000 & 2114 & 0 \\
\hline 6 & Lower & 24 & BP3605 & Unstressed control & 16.000 & NBG-18 & 0 \\
\hline 6 & Lower & 23 & DA3607 & Piggyback & 15.000 & PCEA & 0 \\
\hline 6 & Lower & 22 & DA3401 & Unstressed control & 14.750 & PCEA & 0 \\
\hline 6 & Lower & 21 & EA3204 & Unstressed control & 13.750 & IG-110 & 0 \\
\hline 6 & Lower & 20 & AW3102 & Unstressed control & 12.750 & NBG-17 & 0 \\
\hline 6 & Lower & 19 & TW3506 & Unstressed control & 11.750 & 2114 & 0 \\
\hline 6 & Lower & 18 & BL3203 & Unstressed control & 10.750 & NBG-18 & 0 \\
\hline 6 & Lower & 17 & DW3903 & Unstressed control & 9.750 & PCEA & 0 \\
\hline 6 & Lower & 16 & $\mathrm{AH}$ & Flux Monitor & 8.750 & - & 0 \\
\hline 6 & Lower & 15 & EW3501 & Unstressed control & 8.500 & IG-110 & 0 \\
\hline 6 & Lower & 14 & AL3103 & Unstressed control & 7.500 & NBG-17 & 0 \\
\hline 6 & Lower & 13 & BP3703 & Unstressed control & 6.500 & NBG-18 & 0 \\
\hline 6 & Lower & 12 & DA3104 & Unstressed control & 5.500 & PCEA & 0 \\
\hline 6 & Lower & 11 & TW3509 & Unstressed control & 4.500 & 2114 & 0 \\
\hline 6 & Lower & 10 & DA3606 & Piggyback & 3.500 & PCEA & 0 \\
\hline 6 & Lower & 9 & EW3504 & Unstressed control & 3.250 & IG-110 & 0 \\
\hline 6 & Lower & 8 & BL3603 & Piggyback & 2.250 & NBG-18 & 0 \\
\hline 6 & Lower & 7 & AL3803 & Piggyback & 2.000 & NBG-17 & 0 \\
\hline 6 & Lower & 6 & EW4511 & Piggyback & 1.750 & IG-110 & 0 \\
\hline 6 & Lower & 5 & AW3903 & Piggyback & 1.500 & NBG-17 & 0 \\
\hline 6 & Lower & 4 & DW4601 & Piggyback & 1.250 & PCEA & 0 \\
\hline 6 & Lower & 3 & DA3512 & Piggyback & 1.000 & PCEA & 0 \\
\hline 6 & Lower & 2 & TW3829 & Piggyback & 0.750 & 2114 & 0 \\
\hline
\end{tabular}


Table 9. AGC-3 loading order for Stack 7.

\begin{tabular}{|c|c|c|c|c|c|c|c|}
\hline Channel & Housing & Loading Order & $\begin{array}{c}\text { Specimen } \\
\text { ID }\end{array}$ & Description & $\begin{array}{l}\text { Accumulative } \\
\text { Elevation (in) }\end{array}$ & Grade & $\begin{array}{c}\text { Nominal } \\
\text { Load (KSI) }\end{array}$ \\
\hline 7 & Center & 161 & BP3401 & Piggyback & 42.500 & NBG-18 & 0 \\
\hline 7 & Center & 160 & AP3501 & Piggyback & 42.250 & NBG-17 & 0 \\
\hline 7 & Center & 159 & EA3504 & Piggyback & 42.000 & IG-110 & 0 \\
\hline 7 & Center & 158 & TW3801 & Piggyback & 41.750 & 2114 & 0 \\
\hline 7 & Center & 157 & DA3501 & Piggyback & 41.500 & PCEA & 0 \\
\hline 7 & Center & 156 & CAN101 & CAN & 41.250 & HOPG & 0 \\
\hline 7 & Center & 155 & CAN129 & CAN & 41.000 & MLRF & 0 \\
\hline 7 & Center & 154 & $324-1$ & Piggyback & 40.500 & GrafTech-324 & 0 \\
\hline 7 & Center & 153 & $328-1$ & Piggyback & 40.250 & GrafTech-328 & 0 \\
\hline 7 & Center & 152 & BW4002 & Piggyback & 40.000 & NBG-18 & 0 \\
\hline 7 & Center & 151 & AW3801 & Piggyback & 39.750 & NBG-17 & 0 \\
\hline 7 & Center & 150 & EW4501 & Piggyback & 39.500 & IG-110 & 0 \\
\hline 7 & Center & 149 & TW3802 & Piggyback & 39.250 & 2114 & 0 \\
\hline 7 & Center & 148 & DW4502 & Piggyback & 39.000 & PCEA & 0 \\
\hline 7 & Center & 147 & CAN102 & CAN & 38.750 & HOPG & 0 \\
\hline 7 & Center & 146 & $\mathrm{~A}$ & Piggyback & 38.500 & SGL-SiC & 0 \\
\hline 7 & Center & 145 & S1 & Piggyback & 38.250 & SGL & 0 \\
\hline 7 & Center & 144 & $325-1$ & Piggyback & 38.000 & GrafTech-325 & 0 \\
\hline 7 & Center & 143 & $200-1$ & Piggyback & 37.750 & GrafTech-200 & 0 \\
\hline 7 & Center & 142 & BP3502 & Piggyback & 37.500 & NBG-18 & 0 \\
\hline 7 & Center & 141 & AP3502 & Piggyback & 37.250 & NBG-17 & 0 \\
\hline 7 & Center & 140 & EA3505 & Piggyback & 37.000 & IG-110 & 0 \\
\hline 7 & Center & 139 & TW3803 & Piggyback & 36.750 & 2114 & 0 \\
\hline 7 & Center & 138 & DA3502 & Piggyback & 36.500 & PCEA & 0 \\
\hline 7 & Center & 137 & CAN103 & CAN & 36.250 & HOPG & 0 \\
\hline 7 & Center & 136 & CAN121 & CAN & 36.000 & MLRF & 0 \\
\hline 7 & Center & 135 & $324-2$ & Piggyback & 35.500 & GrafTech-324 & 0 \\
\hline 7 & Center & 134 & $328-2$ & Piggyback & 35.250 & GrafTech-328 & 0 \\
\hline 7 & Center & 133 & BW4003 & Piggyback & 35.000 & NBG-18 & 0 \\
\hline 7 & Center & 132 & AW3802 & Piggyback & 34.750 & NBG-17 & 0 \\
\hline 7 & Center & 131 & EW4502 & Piggyback & 34.500 & IG-110 & 0 \\
\hline 7 & Center & 130 & TW3804 & Piggyback & 34.250 & 2114 & 0 \\
\hline 7 & Center & 129 & DW4503 & Piggyback & 34.000 & PCEA & 0 \\
\hline 7 & Center & 128 & CAN104 & CAN & 33.750 & HOPG & 0 \\
\hline 7 & Center & 127 & B & Piggyback & 33.500 & SGL-SiC & 0 \\
\hline 7 & Center & 126 & S2 & Piggyback & 33.250 & SGL & 0 \\
\hline 7 & Center & 125 & $325-2$ & Piggyback & 33.000 & GrafTech-325 & 0 \\
\hline 7 & Center & 124 & $200-2$ & Piggyback & 32.750 & GrafTech-200 & 0 \\
\hline 7 & Center & 123 & BP3403 & Piggyback & 32.500 & NBG-18 & 0 \\
\hline 7 & Center & 122 & AP3503 & Piggyback & 32.250 & NBG-17 & 0 \\
\hline 7 & Center & 121 & EA3506 & Piggyback & 32.000 & IG-110 & 0 \\
\hline 7 & Center & 120 & TW3805 & Piggyback & 31.750 & 2114 & 0 \\
\hline 7 & Center & 119 & DA3503 & Piggyback & 31.500 & PCEA & 0 \\
\hline 7 & Center & 118 & CAN105 & CAN & 31.250 & HOPG & 0 \\
\hline 7 & Center & 117 & CAN122 & CAN & 31.000 & MLRF & 0 \\
\hline 7 & Center & 116 & $324-3$ & Piggyback & 30.500 & GrafTech-324 & 0 \\
\hline 7 & Center & 115 & $328-3$ & Piggyback & 30.250 & GrafTech-328 & 0 \\
\hline 7 & Center & 114 & BW4004 & Piggyback & 30.000 & NBG-18 & 0 \\
\hline 7 & Center & 113 & AW3803 & Piggyback & 29.750 & NBG-17 & 0 \\
\hline 7 & Center & 112 & EW4503 & Piggyback & 29.500 & IG-110 & 0 \\
\hline 7 & Center & 111 & TW3806 & Piggyback & 29.250 & 2114 & 0 \\
\hline 7 & Center & 110 & DW4504 & Piggyback & 29.000 & PCEA & 0 \\
\hline 7 & Center & 109 & CAN106 & CAN & 28.750 & HOPG & 0 \\
\hline 7 & Center & 108 & $\mathrm{C}$ & Piggyback & 28.500 & SGL-SiC & 0 \\
\hline 7 & Center & 107 & S3 & Piggyback & 28.250 & SGL & 0 \\
\hline
\end{tabular}


Table 9. (continued).

\begin{tabular}{|c|c|c|c|c|c|c|c|}
\hline Channel & Housing & Loading Order & $\begin{array}{c}\text { Specimen } \\
\text { ID } \\
\end{array}$ & Description & $\begin{array}{l}\text { Accumulative } \\
\text { Elevation (in) }\end{array}$ & Grade & $\begin{array}{c}\text { Nominal } \\
\text { Load (KSI) }\end{array}$ \\
\hline 7 & Center & 106 & $325-3$ & Piggyback & 28.000 & GrafTech-325 & 0 \\
\hline 7 & Center & 105 & $200-3$ & Piggyback & 27.750 & GrafTech-200 & 0 \\
\hline 7 & Center & 104 & BP3404 & Piggyback & 27.500 & NBG-18 & 0 \\
\hline 7 & Center & 103 & AP3504 & Piggyback & 27.250 & NBG-17 & 0 \\
\hline 7 & Center & 102 & EA3507 & Piggyback & 27.000 & IG-110 & 0 \\
\hline 7 & Center & 101 & TW3807 & Piggyback & 26.750 & 2114 & 0 \\
\hline 7 & Center & 100 & DA3504 & Piggyback & 26.500 & PCEA & 0 \\
\hline 7 & Center & 99 & CAN107 & CAN & 26.250 & HOPG & 0 \\
\hline 7 & Center & 98 & CAN123 & CAN & 26.000 & MLRF & 0 \\
\hline 7 & Center & 97 & $324-4$ & Piggyback & 25.500 & GrafTech-324 & 0 \\
\hline 7 & Center & 96 & $328-4$ & Piggyback & 25.250 & GrafTech-328 & 0 \\
\hline 7 & Center & 95 & BW 4005 & Piggyback & 25.000 & NBG-18 & 0 \\
\hline 7 & Center & 94 & AW3804 & Piggyback & 24.750 & NBG-17 & 0 \\
\hline 7 & Center & 93 & EW4504 & Piggyback & 24.500 & IG-110 & 0 \\
\hline 7 & Center & 92 & TW 3808 & Piggyback & 24.250 & 2114 & 0 \\
\hline 7 & Center & 91 & DW4505 & Piggyback & 24.000 & PCEA & 0 \\
\hline 7 & Center & 90 & CAN108 & CAN & 23.750 & HOPG & 0 \\
\hline 7 & Center & 89 & $\mathrm{D}$ & Piggyback & 23.500 & SGL-SiC & 0 \\
\hline 7 & Center & 88 & S4 & Piggyback & 23.250 & SGL & 0 \\
\hline 7 & Center & 87 & $325-4$ & Piggyback & 23.000 & GrafTech-325 & 0 \\
\hline 7 & Center & 86 & $200-4$ & Piggyback & 22.750 & GrafTech-200 & 0 \\
\hline 7 & Center & 85 & BР3405 & Piggyback & 22.500 & NBG-18 & 0 \\
\hline 7 & Center & 84 & AP3505 & Piggyback & 22.250 & NBG-17 & 0 \\
\hline 7 & Center & 83 & EA3508 & Piggyback & 22.000 & IG-110 & 0 \\
\hline 7 & Center & 82 & TW3809 & Piggyback & 21.750 & 2114 & 0 \\
\hline 7 & Center & 81 & DA3505 & Piggyback & 21.500 & PCEA & 0 \\
\hline 7 & Center & 80 & CAN109 & CAN & 21.250 & HOPG & 0 \\
\hline 7 & Center & 79 & CAN124 & CAN & 21.000 & MLRF & 0 \\
\hline 7 & Center & 78 & $324-5$ & Piggyback & 20.500 & GrafTech-324 & 0 \\
\hline 7 & Center & 77 & $328-5$ & Piggyback & 20.250 & GrafTech-328 & 0 \\
\hline 7 & Center & 76 & BW 4006 & Piggyback & 20.000 & NBG-18 & 0 \\
\hline 7 & Center & 75 & AW3805 & Piggyback & 19.750 & NBG-17 & 0 \\
\hline 7 & Center & 74 & EW4505 & Piggyback & 19.500 & IG-110 & 0 \\
\hline 7 & Center & 73 & TW3810 & Piggyback & 19.250 & 2114 & 0 \\
\hline 7 & Center & 72 & DW4506 & Piggyback & 19.000 & PCEA & 0 \\
\hline 7 & Center & 71 & CAN110 & CAN & 18.750 & HOPG & 0 \\
\hline 7 & Center & 70 & $\mathrm{E}$ & Piggyback & 18.500 & SGL-SiC & 0 \\
\hline 7 & Center & 69 & S5 & Piggyback & 18.250 & SGL & 0 \\
\hline 7 & Center & 68 & $325-5$ & Piggyback & 18.000 & GrafTech-325 & 0 \\
\hline 7 & Center & 67 & $200-5$ & Piggyback & 17.750 & GrafTech-200 & 0 \\
\hline 7 & Center & 66 & BP3406 & Piggyback & 17.500 & NBG-18 & 0 \\
\hline 7 & Center & 65 & AP3506 & Piggyback & 17.250 & NBG-17 & 0 \\
\hline 7 & Center & 64 & EA3509 & Piggyback & 17.000 & IG-110 & 0 \\
\hline 7 & Center & 63 & TW3811 & Piggyback & 16.750 & 2114 & 0 \\
\hline 7 & Center & 62 & DA3506 & Piggyback & 16.500 & PCEA & 0 \\
\hline 7 & Center & 61 & CAN111 & CAN & 16.250 & HOPG & 0 \\
\hline 7 & Center & 60 & CAN125 & CAN & 16.000 & MLRF & 0 \\
\hline 7 & Center & 59 & $324-6$ & Piggyback & 15.500 & GrafTech-324 & 0 \\
\hline 7 & Center & 58 & $328-6$ & Piggyback & 15.250 & GrafTech-328 & 0 \\
\hline 7 & Center & 57 & BW4007 & Piggyback & 15.000 & NBG-18 & 0 \\
\hline 7 & Center & 56 & AW3806 & Piggyback & 14.750 & NBG-17 & 0 \\
\hline 7 & Center & 55 & EW4506 & Piggyback & 14.500 & IG-110 & 0 \\
\hline 7 & Center & 54 & TW3812 & Piggyback & 14.250 & 2114 & 0 \\
\hline 7 & Center & 53 & DW4507 & Piggyback & 14.000 & PCEA & 0 \\
\hline 7 & Center & 52 & CAN112 & CAN & 13.750 & HOPG & 0 \\
\hline
\end{tabular}


Table 9. (continued).

\begin{tabular}{|c|c|c|c|c|c|c|c|}
\hline Channel & Housing & Loading Order & $\begin{array}{c}\text { Specimen } \\
\text { ID } \\
\end{array}$ & Des cription & $\begin{array}{l}\text { Accumulative } \\
\text { Elevation (in) }\end{array}$ & Grade & $\begin{array}{c}\text { Nominal } \\
\text { Load (KSI) }\end{array}$ \\
\hline 7 & Center & 51 & $\mathrm{~F}$ & Piggyback & 13.500 & SGL-SiC & 0 \\
\hline 7 & Center & 50 & S6 & Piggyback & 13.250 & SGL & 0 \\
\hline 7 & Center & 49 & $325-6$ & Piggyback & 13.000 & GrafTech-325 & 0 \\
\hline 7 & Center & 48 & $200-6$ & Piggyback & 12.750 & GrafTech-200 & 0 \\
\hline 7 & Center & 47 & BP3407 & Piggyback & 12.500 & NBG-18 & 0 \\
\hline 7 & Center & 46 & AP3507 & Piggyback & 12.250 & NBG-17 & 0 \\
\hline 7 & Center & 45 & EA3510 & Piggyback & 12.000 & IG-110 & 0 \\
\hline 7 & Center & 44 & TW3813 & Piggyback & 11.750 & 2114 & 0 \\
\hline 7 & Center & 43 & DA3507 & Piggyback & 11.500 & PCEA & 0 \\
\hline 7 & Center & 42 & CAN113 & CAN & 11.250 & HOPG & 0 \\
\hline 7 & Center & 41 & CAN126 & CAN & 11.000 & MLRF & 0 \\
\hline 7 & Center & 40 & $324-7$ & Piggyback & 10.500 & GrafTech-324 & 0 \\
\hline 7 & Center & 39 & $328-7$ & Piggyback & 10.250 & GrafTech-328 & 0 \\
\hline 7 & Center & 38 & BW4101 & Piggyback & 10.000 & NBG-18 & 0 \\
\hline 7 & Center & 37 & AW3808 & Piggyback & 9.750 & NBG-17 & 0 \\
\hline 7 & Center & 36 & EW4507 & Piggyback & 9.500 & IG-110 & 0 \\
\hline 7 & Center & 35 & TW3814 & Piggyback & 9.250 & 2114 & 0 \\
\hline 7 & Center & 34 & DW4508 & Piggyback & 9.000 & PCEA & 0 \\
\hline 7 & Center & 33 & CAN114 & CAN & 8.750 & HOPG & 0 \\
\hline 7 & Center & 32 & G & Piggyback & 8.500 & SGL-SiC & 0 \\
\hline 7 & Center & 31 & S7 & Piggyback & 8.250 & SGL & 0 \\
\hline 7 & Center & 30 & $325-7$ & Piggyback & 8.000 & GrafTech-325 & 0 \\
\hline 7 & Center & 29 & $200-7$ & Piggyback & 7.750 & GrafTech-200 & 0 \\
\hline 7 & Center & 28 & BP3408 & Piggyback & 7.500 & NBG-18 & 0 \\
\hline 7 & Center & 27 & AP3508 & Piggyback & 7.250 & NBG-17 & 0 \\
\hline 7 & Center & 26 & EA3511 & Piggyback & 7.000 & IG-110 & 0 \\
\hline 7 & Center & 25 & TW3815 & Piggyback & 6.750 & 2114 & 0 \\
\hline 7 & Center & 24 & DA3508 & Piggyback & 6.500 & PCEA & 0 \\
\hline 7 & Center & 23 & CAN115 & CAN & 6.250 & HOPG & 0 \\
\hline 7 & Center & 22 & CAN127 & CAN & 6.000 & MLRF & 0 \\
\hline 7 & Center & 21 & $324-8$ & Piggyback & 5.500 & GrafTech-324 & 0 \\
\hline 7 & Center & 20 & $328-8$ & Piggyback & 5.250 & GrafTech-328 & 0 \\
\hline 7 & Center & 19 & BW4102 & Piggyback & 5.000 & NBG-18 & 0 \\
\hline 7 & Center & 18 & AW3809 & Piggyback & 4.750 & NBG-17 & 0 \\
\hline 7 & Center & 17 & EW4508 & Piggyback & 4.500 & IG-110 & 0 \\
\hline 7 & Center & 16 & TW3816 & Piggyback & 4.250 & 2114 & 0 \\
\hline 7 & Center & 15 & DW4509 & Piggyback & 4.000 & PCEA & 0 \\
\hline 7 & Center & 14 & CAN116 & CAN & 3.750 & HOPG & 0 \\
\hline 7 & Center & 13 & $\mathrm{H}$ & Piggyback & 3.500 & SGL-SiC & 0 \\
\hline 7 & Center & 12 & S8 & Piggyback & 3.250 & SGL & 0 \\
\hline 7 & Center & 11 & $325-8$ & Piggyback & 3.000 & GrafTech-325 & 0 \\
\hline 7 & Center & 10 & 200-8 & Piggyback & 2.750 & GrafTech-200 & 0 \\
\hline 7 & Center & 9 & BP3409 & Piggyback & 2.500 & NBG-18 & 0 \\
\hline 7 & Center & 8 & AP3509 & Piggyback & 2.250 & NBG-17 & 0 \\
\hline 7 & Center & 7 & EA3512 & Piggyback & 2.000 & IG-110 & 0 \\
\hline 7 & Center & 6 & TW3817 & Piggyback & 1.750 & 2114 & 0 \\
\hline 7 & Center & 5 & DA3509 & Piggyback & 1.500 & PCEA & 0 \\
\hline 7 & Center & 4 & CAN117 & CAN & 1.250 & HOPG & 0 \\
\hline 7 & Center & 3 & CAN128 & CAN & 1.000 & MLRF & 0 \\
\hline 7 & Center & 2 & $324-9$ & Piggyback & 0.500 & GrafTech-324 & 0 \\
\hline 7 & Center & 1 & $328-9$ & Piggyback & 0.250 & GrafTech-328 & 0 \\
\hline
\end{tabular}


Following irradiation in ATR at INL, the AGC-3 capsule was disassembled. ${ }^{16}$ All specimens recovered from disassembly were visually inspected and physically measured within the INL Carbon Characterization Laboratory before storage within the irradiated graphite storage vault. It should be noted that one 2114 specimen (TW3405) and two NBG-17 specimens (BL3103 and BP3302) were lost during AGC-3 disassembly activities. After accounting for all recovered specimens from the AGC-3 capsule, PIE and testing were performed for each specimen in the INL Carbon Characterization Laboratory.

\section{TESTING}

A significant level of preparation was needed to meet the NQA-1 quality requirements prior to actual material property testing. An approved characterization plan was developed that was dependent upon the two graphite specimen geometries and on the material properties to be measured. ${ }^{17,18}$ In general, all testing was performed through American Society for Testing and Materials (ASTM) approved standards; however, due to the small size of the graphite specimens, some methods required modification and/or variation of the testing standards. Details of these testing standard variations, along with equipment calibration, personnel training on testing methodology, and data acquisition, are specified in the characterization plans.

Thermal diffusivity, coefficient of thermal expansion (CTE), electrical resistivity, elastic modulus, mass, and dimensional measurements were performed on the AGC-3 irradiated specimens. These measurements were performed per the AGC-3 graphite specimen post-irradiation characterization plan. ${ }^{18}$ This plan describes in detail the measurement techniques, equipment, and standards used to gather the data presented here.

Data gathered for the characterization of AGC-3 specimens are contained in the appendixes of this report. Appendix A contains plots of the individual data points for each specimen. Shown by the dashed lines in each plot are the upper and lower limits of the interquartile range (IQR). These limits are established by either the least or greatest value in the data or by multiplying the IQR by 1.5 and adding or subtracting this value from the third and first quartile. Any datum value outside of these established limits is considered a suspected outlier of the established pattern and may indicate a mistaken measurement test or calculated value. Any sample exhibiting a measured data point outside of the established pattern is reassessed, including re-testing the specific material property value, to ascertain whether the sample was tested correctly. It is important to note that the analysis of these outlying values are not meant to determine the changes due to irradiation (i.e., variations resulting from different grades, received dose, temperature, orientation, and/or applied stress). A complete analysis addressing the irradiation conditions will be provided in a future data analysis report.

These outlying values are examined in the context of the entire data set, including pre-irradiation data. Other statistical parameters are calculated and presented in the tables of Appendix B. The mean, standard deviation, and coefficient of variance (COV) are all calculated for the various measurement data sets and graphite types. Upper and lower limits displayed in the tables of Appendix B are the IQR limits described above. Raw, tabulated data can be found in the Nuclear Data Management and Analysis System Database, including parameters specified by the applicable ASTM standard (e.g., dates, performer identifier, and laboratory conditions).

There are many ways to compare the data presented here. In doing so, the validity of the test data is exercised and scrutinized. First, the data sets are evaluated independently, using the statistical analysis described above. Additionally, a limited comparison of pre- and post-irradiation values is made for each graphite grade to show the effects of irradiation and applied stress (where applicable). Note that preirradiation properties were measured using the same techniques, equipment, and standards per the AGC-3 Graphite Specimen Pre-Irradiation Characterization Plan. ${ }^{17}$ Pre-irradiation data for the AGC-3 specimens can be found in the AGC-3 Graphite Pre-Irradiation Data Analysis Report. ${ }^{14}$ These initial comparisons 
provide an initial examination of the data for trends and correlations that are intuitive and logical. In this way, the physical and thermal post-irradiation property measurements are vetted.

The data presented in this report include testing from all irradiated AGC-3 graphite specimens. Variables of irradiation, grain orientation, and temperature are not considered for any property measurement in Figure 5 through Figure 9 or for the figures in appendix A. The data are presented simply to illustrate the measured material property trends for the major graphite grades in AGC-3. It should be noted that the averaged data shows significant spread across all material property measurements. This is expected since the data includes measurements from all samples and does not differentiate between the effects of irradiation dose, temperature variations, graphite grades, orientation, or the other factors being tested in the AGC Experiment. A more detailed analysis taking all test variables into consideration will be reported in the subsequent AGC-3 data analysis report(s).

\subsection{Dimensions, Mass, and Density}

Specimens are weighed and dimensionally measured at room temperature. ${ }^{18}$ Plots of the measured dimensions, mass, and densities for all AGC-3 irradiated specimens are shown in Appendix A, Figure A-1 through Figure A-53. Prior to irradiation, the freshly machined surfaces produced consistent dimensional measurements with a COV of less than $0.05 \%$ for all specimens. Following irradiation, the surfaces are more irregular and inconsistent. This resulted in the creep specimens dimensional COVs increasing between 0.23 and $0.96 \%$ (see Appendix B, Table B-1 and Table B-2). Distributions in the pre- and post-irradiation mass data were similar with no difference in mass observed between pre- and post-irradiation measurements outside of the measurement uncertainty (see Appendix B, Table B-1).

Figure 5 shows the overall volume change for the irradiated specimens as a function of graphite grade and applied stress. Detailed volume dependency on irradiation dose and irradiation temperature will be addressed in the subsequent AGC-3 data analysis report. As expected, all graphite types experienced an overall shrinkage due to neutron irradiation. Shrinkage for all graphite types increased as the specimen stress increased. This is consistent with trends observed in the literature. ${ }^{6,7}$

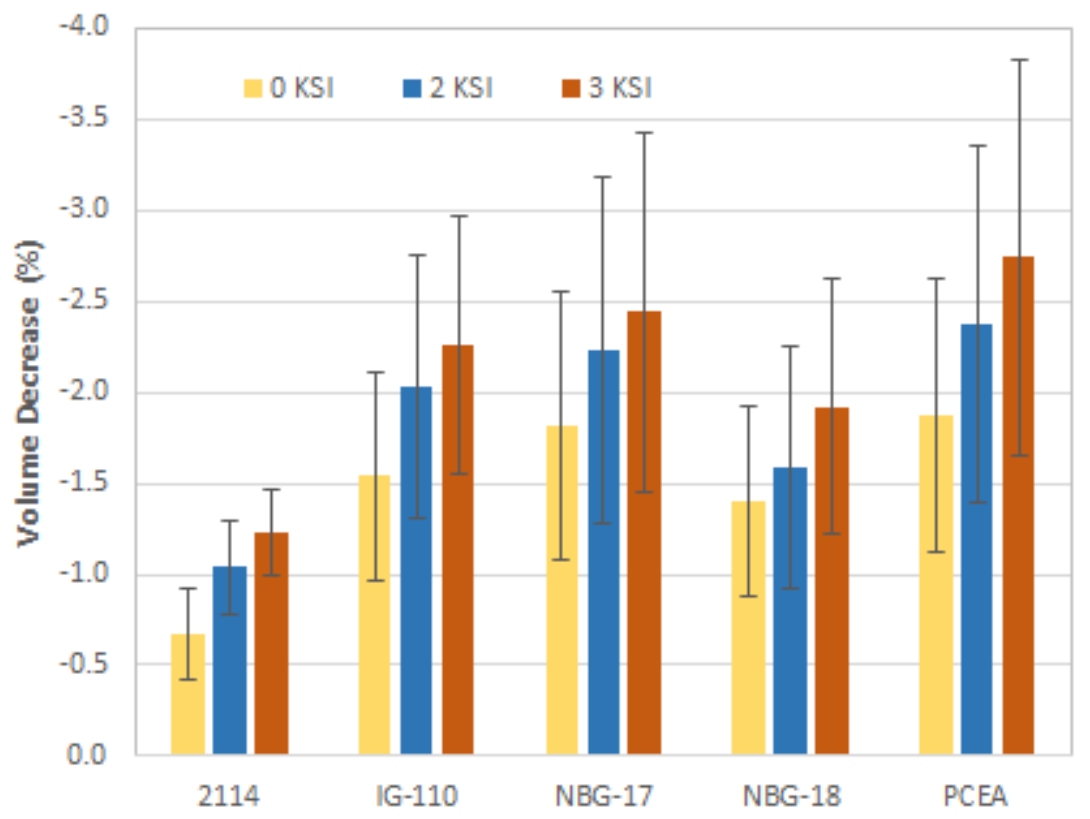

Figure 5. Volume decrease due to irradiation creep for five major grades of graphite.

Figure 6 shows an increase in density for all graphite grades that is a result of a reduction in volume with no change in mass. The greatest change in density occurs for the specimens that experience applied 
stresses. These specimens undergo a greater volume reduction while the unstressed condition results in less volume change from irradiation shrinkage only. The COV for density values of irradiated specimens of the individual graphite types was below 1.5\% (see Appendix B, Table B-4). Detailed density analysis and trends will be addressed in the subsequent AGC-3 data analysis report.

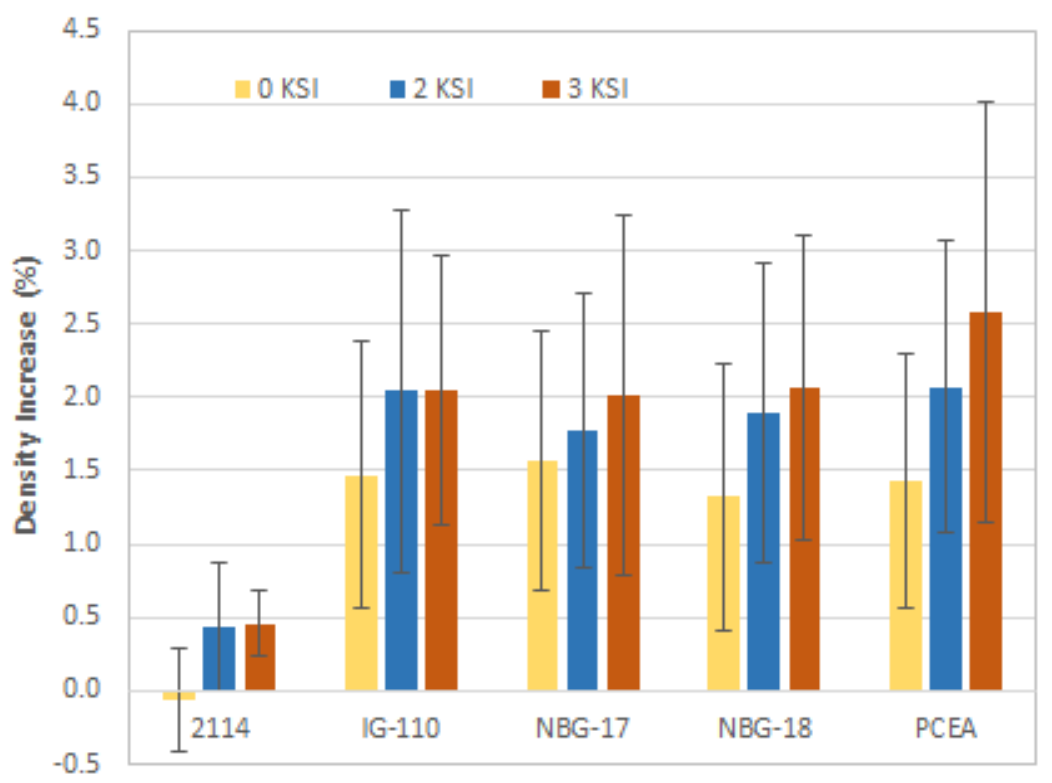

Figure 6. Density increase due to irradiation volume shrinkage for five major grades of graphite and three stress conditions. Error bars represent one standard deviation in the percent density increase.

\subsection{Elastic Modulus}

Elastic properties were measured with two dynamic nondestructive testing techniques at room temperature. ${ }^{19,20,21,22}$ In the fundamental frequency testing technique, Young's modulus is derived from the natural frequency of the creep specimens oscilating in the flexural mode. Due to the geometry of the specimens, the shear modulus cannot be determined using this technique. However, both Young's modulus and shear modulus can be determined using the sonic velocity technique. In this case, an ultrasonic longitudinal or shear wave is sent through the specimen. The time it takes for this wave to pass through the specimen and the length of the specimen are used to determine the sonic velocity. Young's modulus and shear modulus can then be calculated from this time-of-flight measurement.

Young's modulus, determined by measurement of fundamental frequency, is plotted in Appendix A, Figure A-54 through Figure A-58, and the statistical data are contained in Appendix B, Table B-8. Statistically, these data are well-behaved, with the IQR analysis showing no significant outliers. Appendix A, Figure A-64 through Figure A-73, contain plots of Young's and shear moduli determined from the measurement of sonic velocity. Statistical parameters are shown in Appendix B, Table B-10 and Table B-11, for Young's and shear moduli, respectively, and again the IQR analysis does not reveal any inconsistency or significant outliers. The spread in all modulus data is reasonable with the COV approximately $5 \%$.

It should be noted that for AGC-3 specimens, the dynamic Young's modulus values determined by sonic velocity testing techniques are generally 2 to $3 \mathrm{GPa}$ higher than the measurements obtained by the fundamental frequency testing technique (Appendix A, Figure A-64 through Figure A-73). This difference between modulus measurements has been noted for a number of years and was finally addressed in the latest version of the sonic velocity standard (ASTM 769-09). ${ }^{19}$ In this latest ASTM standard version, the Young's modulus value is calculated from the time-of-flight measurement using a correction factor designated as the Poisson's factor $\left(\mathrm{C}_{\mathrm{v}}\right)$, which is normally valued at 0.9 . Calculating the 
modulus using the Poisson's factor effectively lowers the value by $10 \%$, bringing the measured sonic velocity values to values arrived at by the fundamental frequency test method.

However, AGC-3 pre-irradiation testing was performed under the previous ASTM sonic velocity standard, ASTM 769-98 (reapproved 2005), ${ }^{20}$ which does not use the Poisson's factor to calculate the modulus values. The AGC-3 characterization plan (PLN-4888) specifies that the testing standards used to measure the material properties for the graphite specimens must be the same version before and after irradiation. ${ }^{18}$ Using the same ASTM test method version assures the unirradiated and irradiated measurements will be consistent and comparable without testing method bias.

Since only the measured data is being corrected by the Poisson's factor, and not the actual testing technique itself, the pre- and post-irradiation AGC-3 sonic velocity data can be recalculated.

Recalculating the data will be considered in the subsequent AGC-3 data analysis report to provide a more accurate modulus value from the sonic velocity testing method.

While the absolute Young's modulus values between sonic velocity and fundamental frequency may be different for the AGC-3 measurements, when making relative comparisons between pre- and post-irradiation measurements, the difference is consistent between the two techniques. Dynamic Young's modulus generally increases when pre- and post-irradiation Young's modulus values (as a percentage) are compared. This increase is shown to be similar for the fundamental frequency and sonic velocity testing techniques (see Figure 7 and Figure 8). Detailed Young's modulus dependency on irradiation dose and irradiation temperature will be addressed in the subsequent AGC-3 data analysis report.

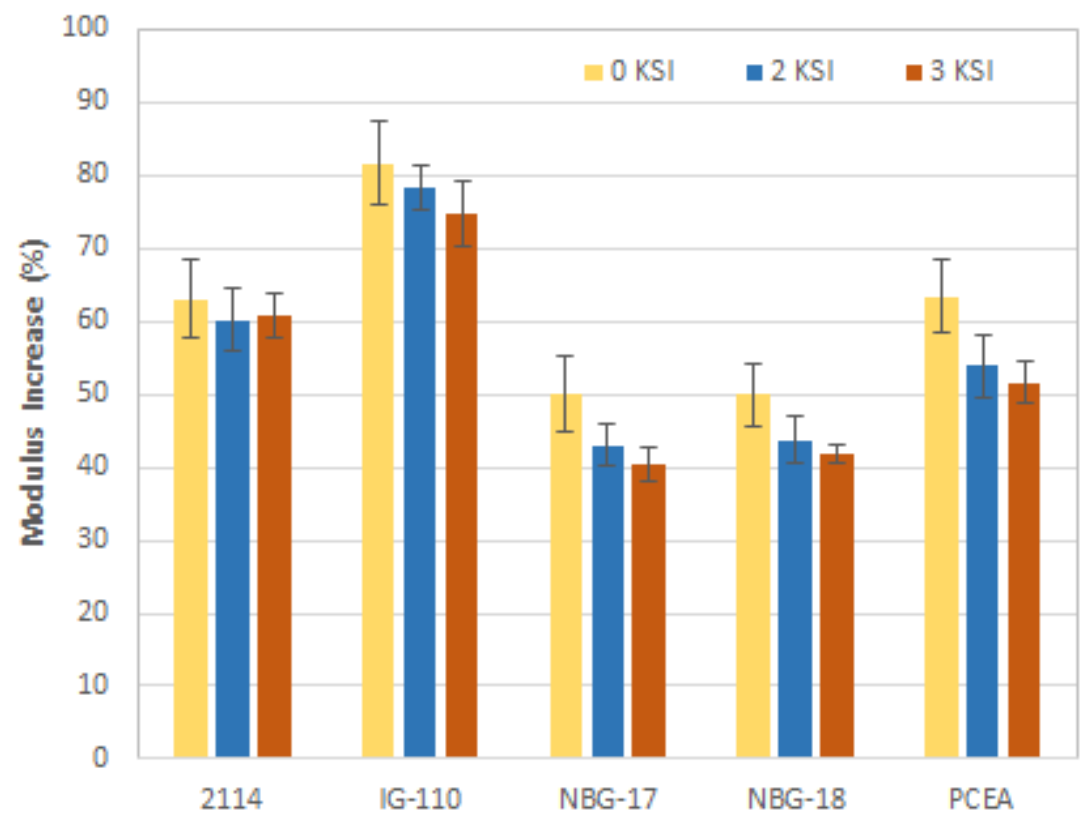

Figure 7. Young's modulus derived from the measurement of fundamental frequency for five grades of graphite and three different stress conditions. 


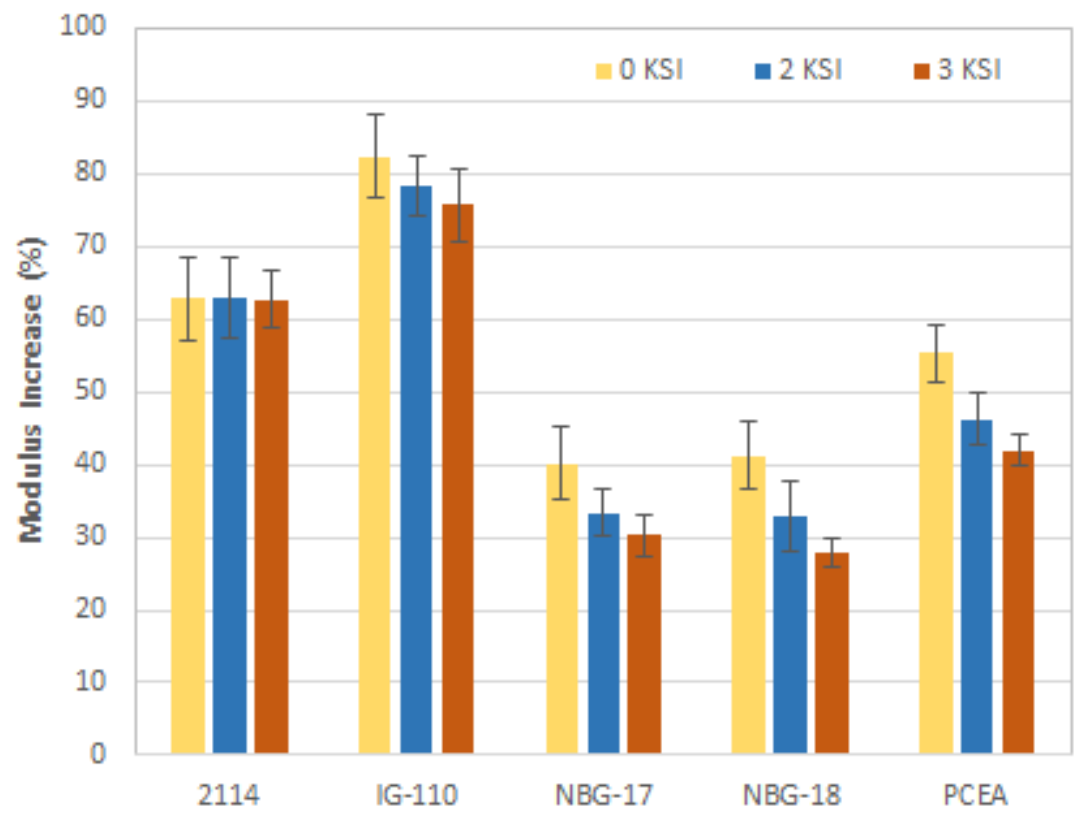

Figure 8. Young's modulus derived from the measurement of ultrasonic velocity for five grades of graphite and three different stress conditions.

\subsection{Resistivity}

Plots of electrical resistivity are shown in Appendix A, Figure A-59 through Figure A-63, for graphite grades of 2114, IG-110, NBG-17, NBG-18, and PCEA. Resistivity measurements were performed on the longer creep specimens only. ${ }^{18}$ Statistical parameters can be found in Appendix B, Table B-9. The resistivity data are well behaved with only one 2114 specimen outlier and one PCEA specimen outlier. A closer look at the resistance measurements showed that these specimens had consistent, but either high or low resistance values. Since these measurements were stable, the final resistivity values are included in the data. Overall, the COV of the resistivity measurements ranged from 2.3 to $3.6 \%$.

Specimen resistivity is measured at room temperature using a four-point testing method. A constant current is passed through the long axis of the specimen, and the voltage is measured at a fixed distance along the specimen axis. Resistivity is calculated from these values and the specimen geometry. Figure 9 shows the percent increase of the specimens' resistivity. Detailed electrical resistivity analysis, including irradiation dose and irradiation temperature effects, will be addressed in the subsequent AGC-3 data analysis report. 


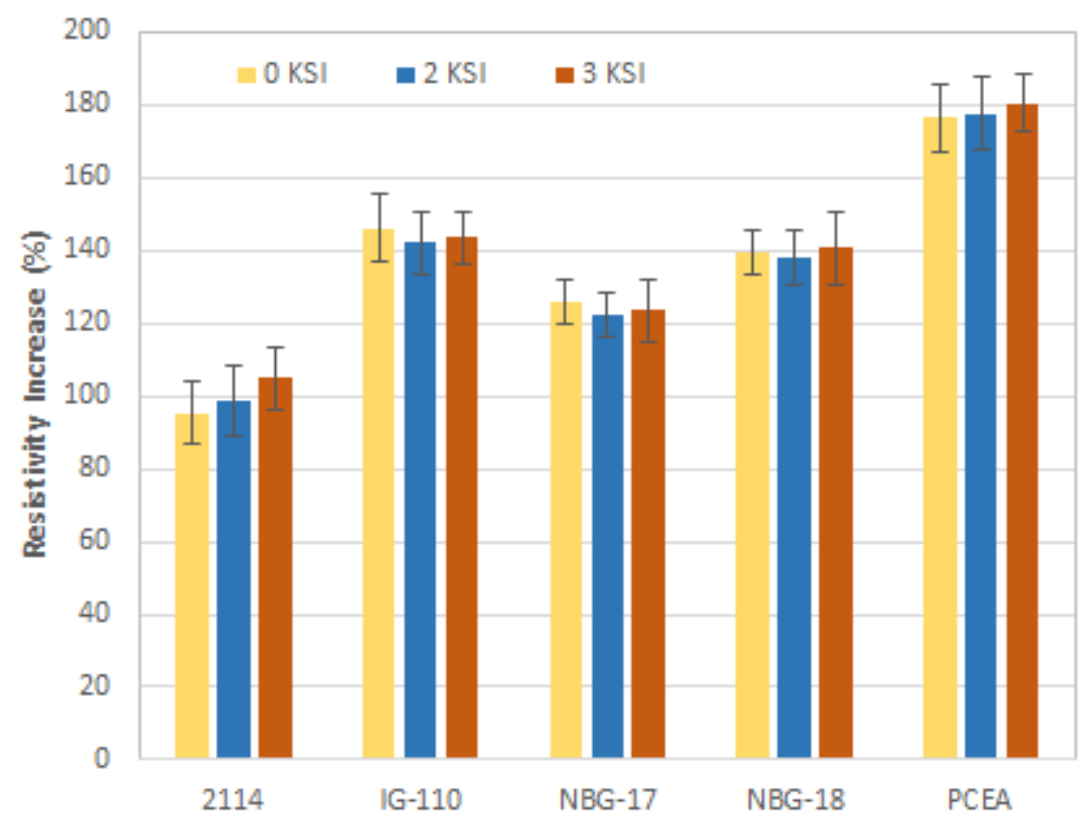

Figure 9. Electrical resistivity for five grades of graphite and three different stress conditions.

\subsection{Thermal Diffusivity}

Thermal diffusivity was measured using a laser flash technique. ${ }^{18}$ Because annealing of irradiation damage begins to take place at temperatures above the irradiation temperature, measurements of thermal diffusivity were limited to $650^{\circ} \mathrm{C}$ (about $170^{\circ} \mathrm{C}$ below the average AGC-3 specimen irradiation temperature).

Plots of thermal diffusivity are shown in Appendix A, Figure A-89 through Figure A-112. Discrete temperatures of 100,400 , and $650^{\circ} \mathrm{C}$ were statistically evaluated. Appendix B, Table B-16 through Table B-18, contain values of the mean, standard deviation, and COV. Considering the complexities associated with measuring the thermal diffusivity of irradiated specimens, the COVs are reasonable, ranging between approximately $1 \%$ and approximately $12 \%$. There were however, four specimens (three 2114 and one NBG-18) that fell outside of the IQR limits (see Appendix A, Figure A-89, Figure A-93, Figure A-97, Figure A-101, Figure A-105, and Figure A-109). The data from these outliers were consistently higher across all of the measurement temperatures than the other specimens within their same grade. In order to validate the measurements of these outliers, they were re-measured and compared with their initial measurements. The results were virtually the same. Therefore, there is no reason, at this time, to suspect that the initial measurements are incorrect and these data outside the IQR limits are maintained with the complete data set.

Figure 10 shows the average diffusivity of all specimens of a particular type of graphite over the measurement temperature range. The plot shows that the greatest change in diffusivity occurs at the lower measurement temperatures. All graphite grades follow this similar trend. Detailed diffusivity dependency analysis, including irradiation dose and irradiation temperature dependency, will be addressed in the subsequent AGC-3 data analysis report. 


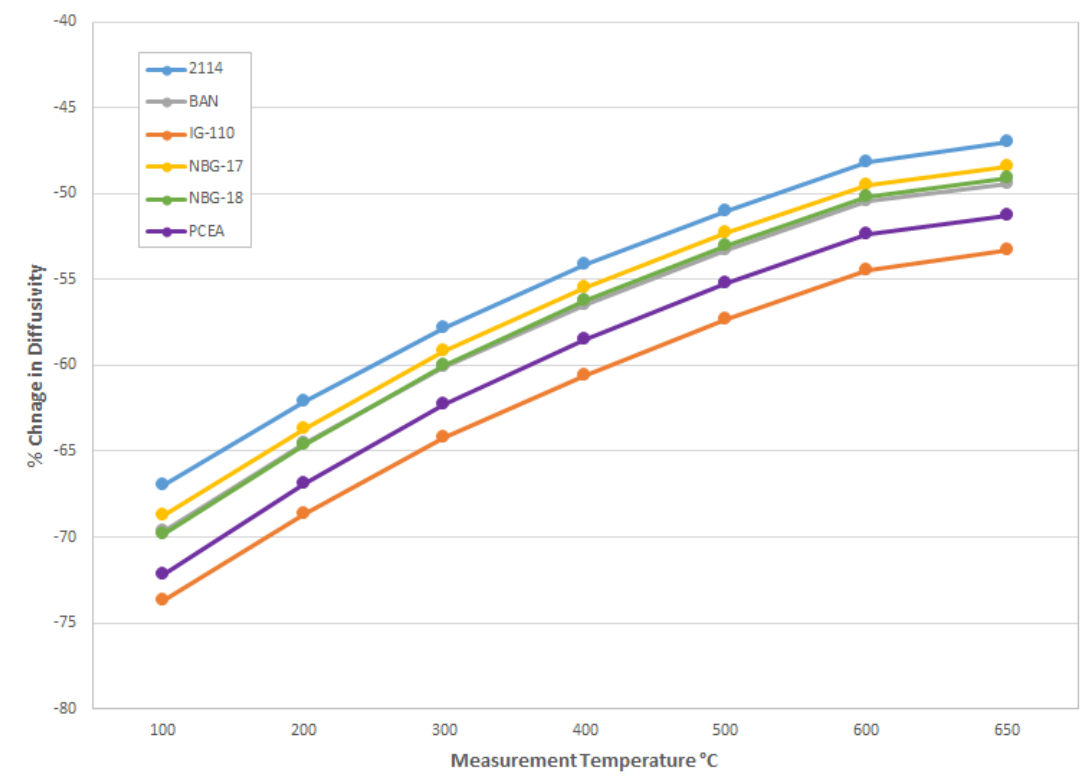

Figure 10. Percent change in diffusivity as a function of measurement temperature for six grades of graphite.

\subsection{Coefficient of Thermal Expansion}

CTE was measured using a linear dilatometer technique. ${ }^{18}$ Because annealing of irradiation damage begins to take place at temperatures above the irradiation temperature, measurements of thermal expansion were limited to $650^{\circ} \mathrm{C}$ (about $170^{\circ} \mathrm{C}$ below the average AGC-3 specimen irradiation temperature).

Mean CTE data are plotted in Appendix A, Figure A-74 through Figure A-88. A statistical evaluation of the CTE data was performed at three discrete temperatures (i.e., 100,400 , and $650^{\circ} \mathrm{C}$ ) for each graphite type. Again, the dashed lines in these plots indicate the upper and lower IQR limits. There are no outliers to consider.

Appendix B, Table B-5 through Table B-7, list the mean, standard deviation, and COV values for data evaluated at the discrete temperatures. As shown, COV values range from approximately 8 to $12 \%$. This is a relatively large scatter to the data and will be evaluated further in the subsequent AGC-3 data analysis report.

Figure 11 shows the average change in CTE as a function of the measurement temperature for stressed and unstressed specimens of the five major graphite grades. Each data point is averaged over all specimen doses and irradiation temperatures for each graphite grade. Specimens that were mechanically loaded are averaged over stress values of 2 and $3 \mathrm{ksi}$. The measured CTE values for all stressed creep specimens (the dashed lines) are considerably higher than the unstressed control specimens of the same grade and will be analyzed further in the subsequent AGC-3 data analysis report. 


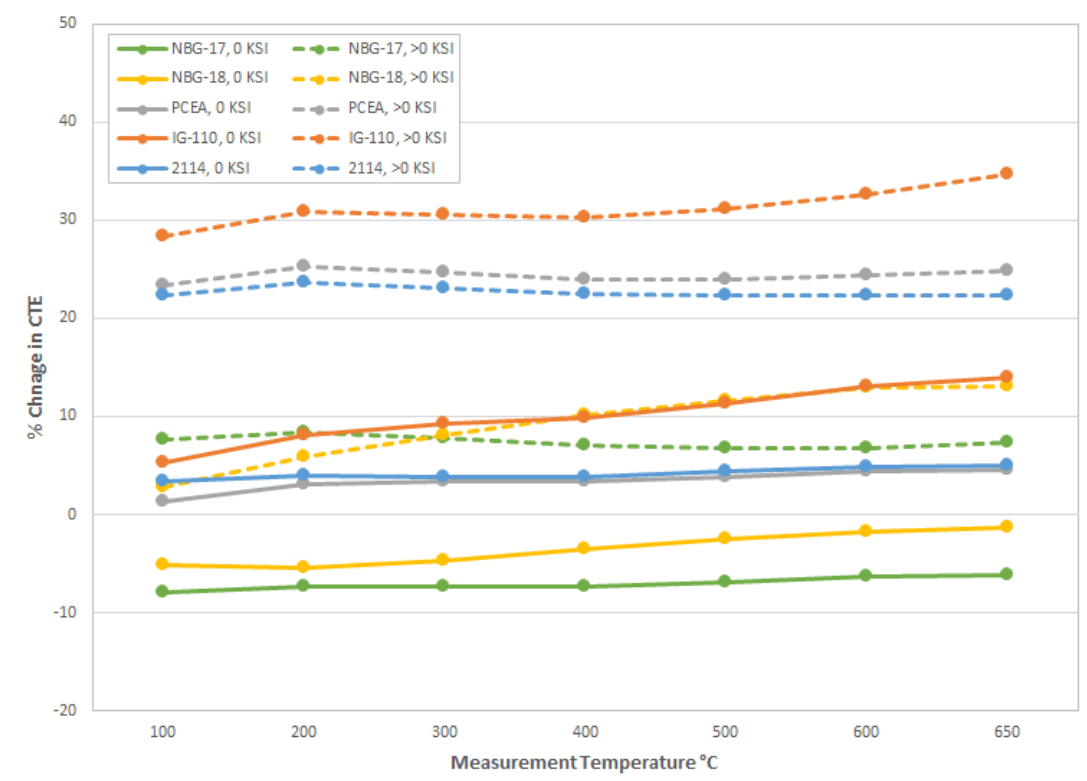

Figure 11. Percent change in CTE for six different grades of graphite as a function of temperature for stressed and unstressed conditions.

\section{REFERENCES}

1. Burchell, T., R. Bratton, and W. Windes, NGNP Graphite Selection and Acquisition Strategy, ORNL/TM-2007/153, Oak Ridge National Laboratory, September 2007.

2. Bratton, R. L. and T. D. Burchell, NGNP Graphite Testing and Qualification Specimen Selection Strategy, INL/EXT-05-00269, Idaho National Laboratory, May 2005.

3. PLN-2497, “Graphite Technology Development Plan,” Idaho National Laboratory, Rev. 1, October 2010.

4. NQA-1 2008/1a-2009, "Quality Assurance Requirements for Nuclear Facility Applications," American Society of Mechanical Engineers, May 2009.

5. TFR-791, "NGNP Advanced Graphite Capsule AGC-3 Experiment Test Train," Idaho National Laboratory, Rev. 1, June 2012.

6. Brocklehurst J. E. and R. G. Brown, "Constant stress irradiation creep experiments on graphite in Br-2," Carbon, Vol. 7, No. 4, August 1969.

7. Gray, W. J., "Constant stress irradiation-induced compressive creep of graphite at high fluences," Carbon, Vol. 11, No. 4, August 1973.

8. Burchell, T. and R. Bratton, Graphite Irradiation Creep Capsule AGC-1 Experimental Plan, ORNL/TM-2005/505, Oak Ridge National Laboratory, May 2005.

9. INL Drawing 601501, "ATR Advanced Graphite Capsule (AGC) AGC-3 Graphite Specimen Cutout Diagrams," Idaho National Laboratory, Rev. 4, July 2012.

10. INL Drawing 603520, "ATR Advanced Graphite Capsule (AGC-3) Test Train Facility Assembly," Idaho National Laboratory, Rev. 0, June 2012.

11. INL Drawing 603523, “ATR Advanced Graphite Capsule (AGC) Miscellaneous Graphite Component Assemblies and Details," Idaho National Laboratory, Rev. 1, March 2012. 
12. Hull, L., AGC-3 Experiment Irradiation Monitoring Data Qualification Final Report, INL/EXT-14-32425, Idaho National Laboratory, July 2014.

13. Parry, J. R., "Reactor Physics Projections for the AGC-3 Experiment Irradiated in the ATR East Flux Trap,” ECAR-1788, Idaho National Laboratory, Rev. 0, April 19, 2012.

14. Windes, W., D. Swank, D. Rohrbaugh, and J. Lord, AGC-3 Graphite Preirradiation Data Analysis Report, INL/EXT-13-30297, Idaho National Laboratory, September 2013.

15. WO 15970401, "Engineering Work Instructions for Assembling the AGC-3 Experiment," June 4, 2012.

16. Windes, W., P. Winston, W. D. Swank, AGC-3 Disassemble Report, INL/EXT-15-34675, Idaho National Laboratory, May 2015.

17. D. Swank, “AGC-3 Graphite Specimen Preirradiation Characterization Plan.” PLN-3858, Rev 0, June 2011.

18. D. Swank, "AGC-3 Graphite Specimen Postirradiation Characterization Plan,” PLN-4888, Rev. 0, May 2015.

19. ASTM 769-09, Standard Test Method for Sonic Velocity in Manufactured Carbon and Graphite Materials for Use in Obtaining Young's Modulus, American Society for Testing and Materials International, 2009.

20. ASTM-769-98 (reapproved 2005), Standard Test Method for Sonic Velocity in Manufactured Carbon and Graphite Materials for Use in Obtaining Young's Modulus, American Society for Testing and Materials International, 2005.

21. ASTM C747-93 (Reapproved 2010), "Standard Test Method of Moduli of Elasticity and Fundamental Frequencies of Carbon and Graphite Materials by Sonic Resonance."

22. ASTM C1259-08, "Dynamic Young's Modulus, Shear Modulus, and Poisson's Ratio for Advanced Ceramics by Impulse Excitation of Vibration." 
Appendix A

\section{Data Plots}




\section{Appendix A}

\section{Data Plots}

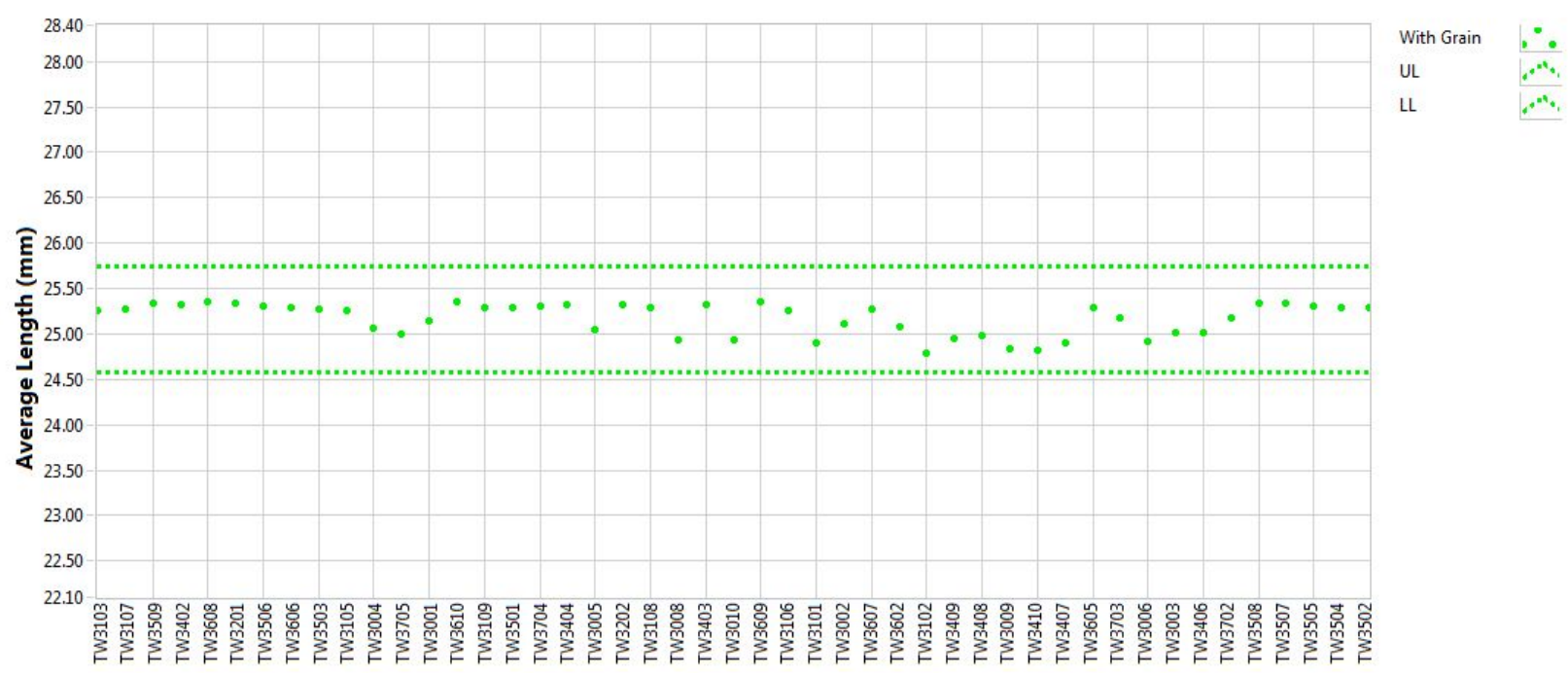

Figure A-1. 2114 creep length.

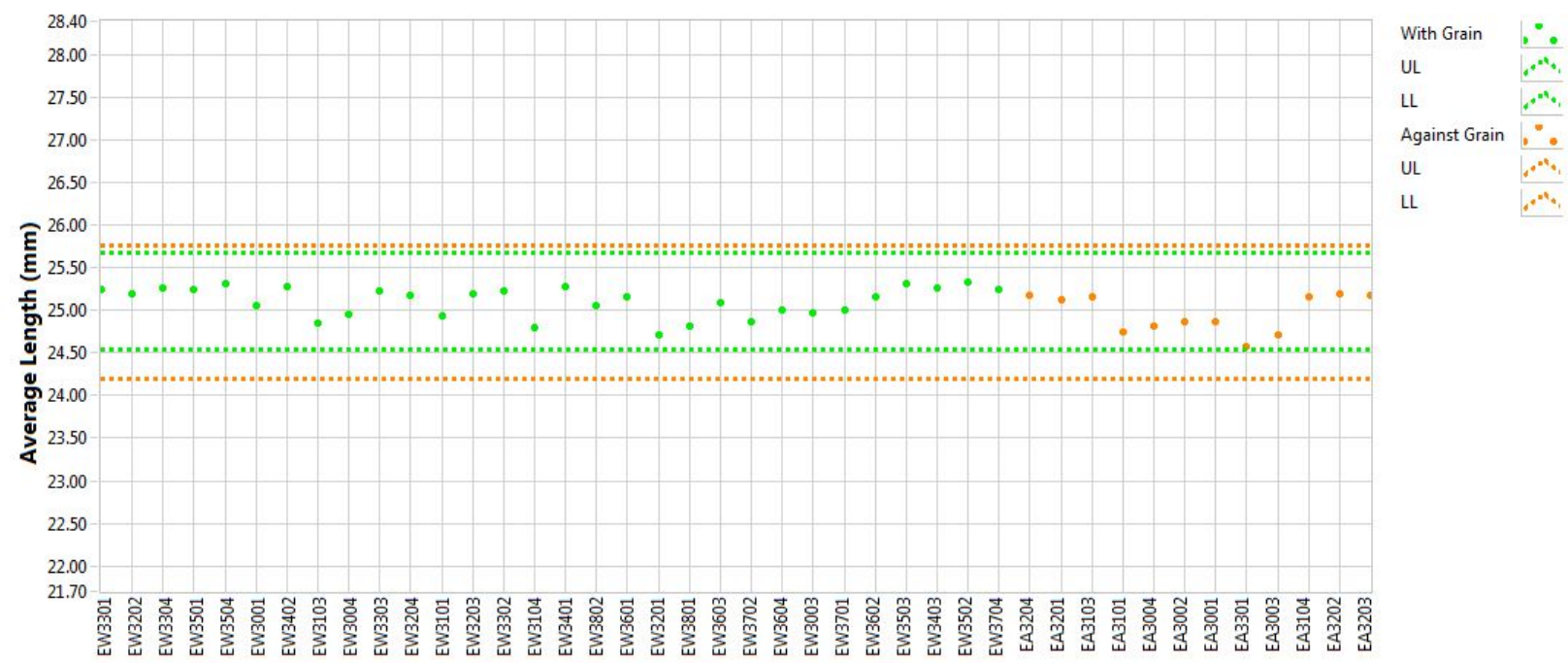

Figure A-2. IG-110 creep length. 


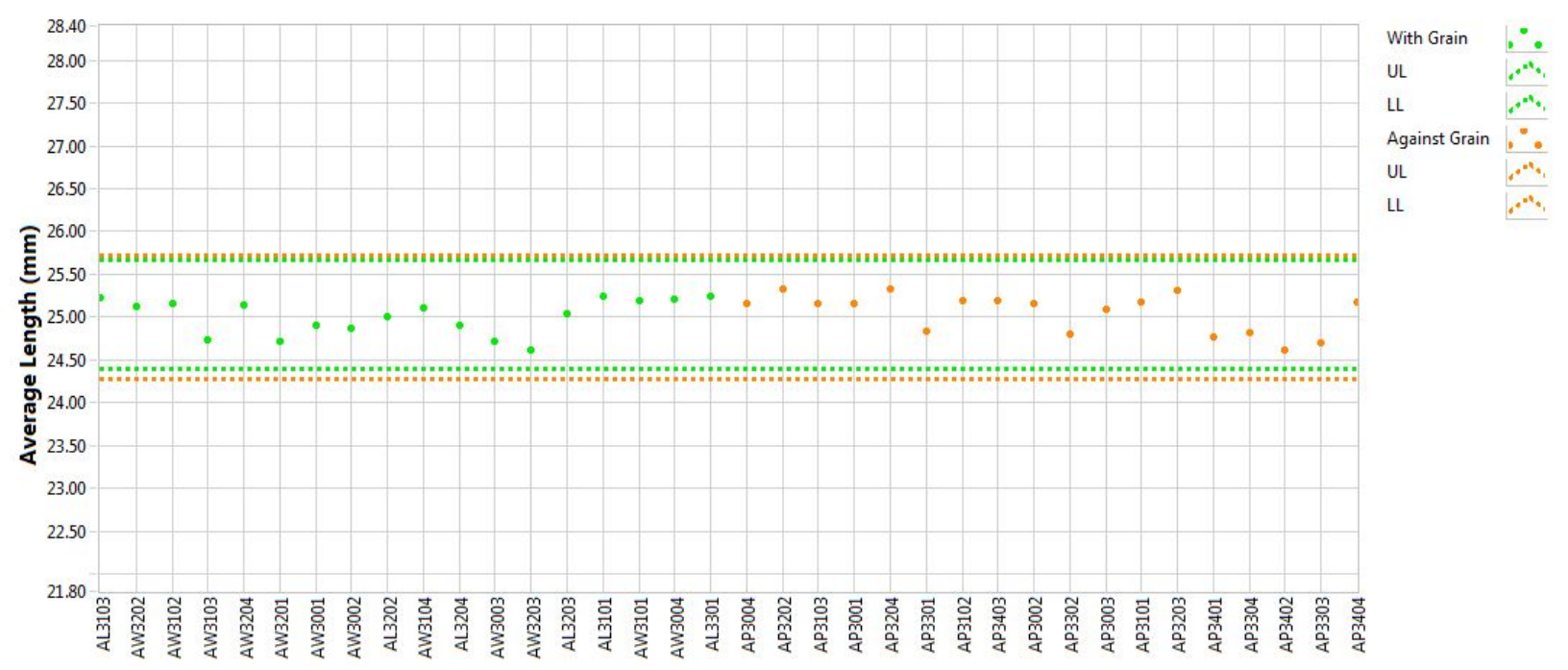

Figure A-3. NBG-17 creep length.

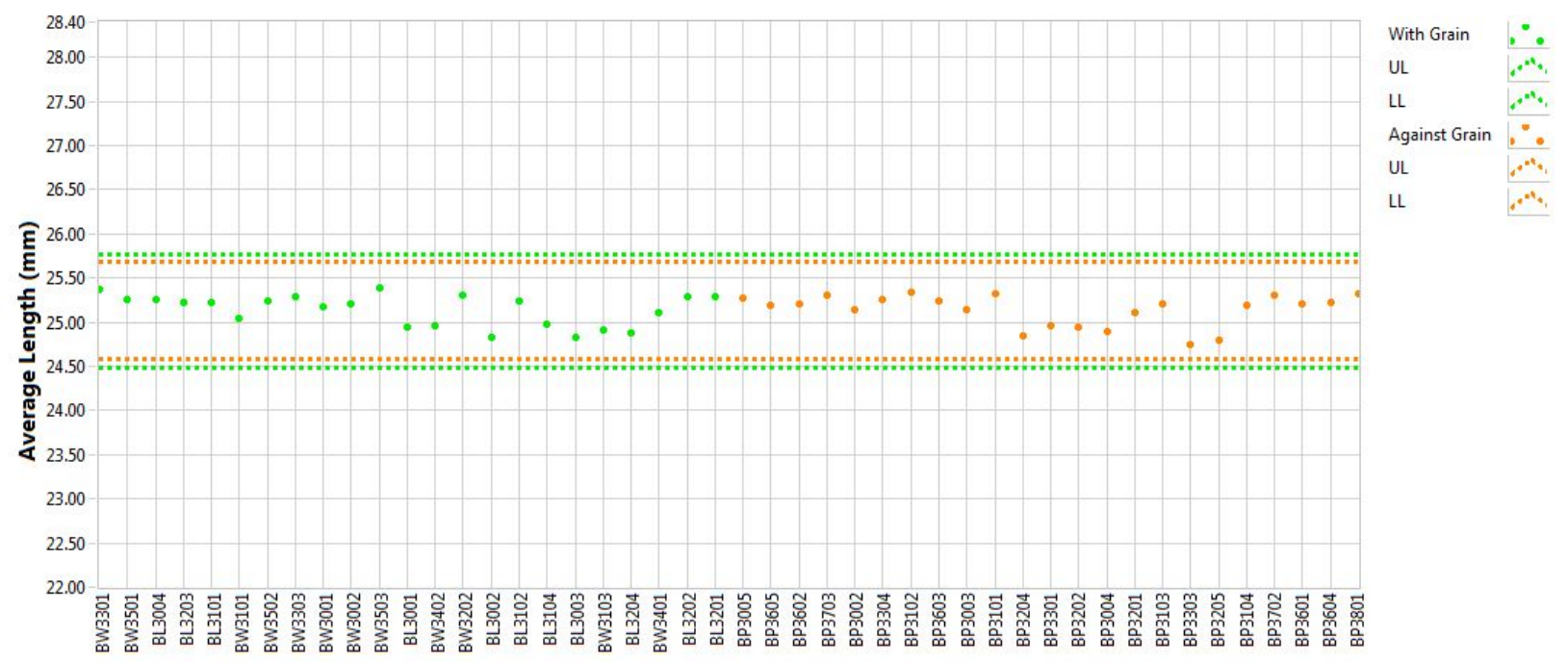

Figure A-4. NBG-18 creep length. 

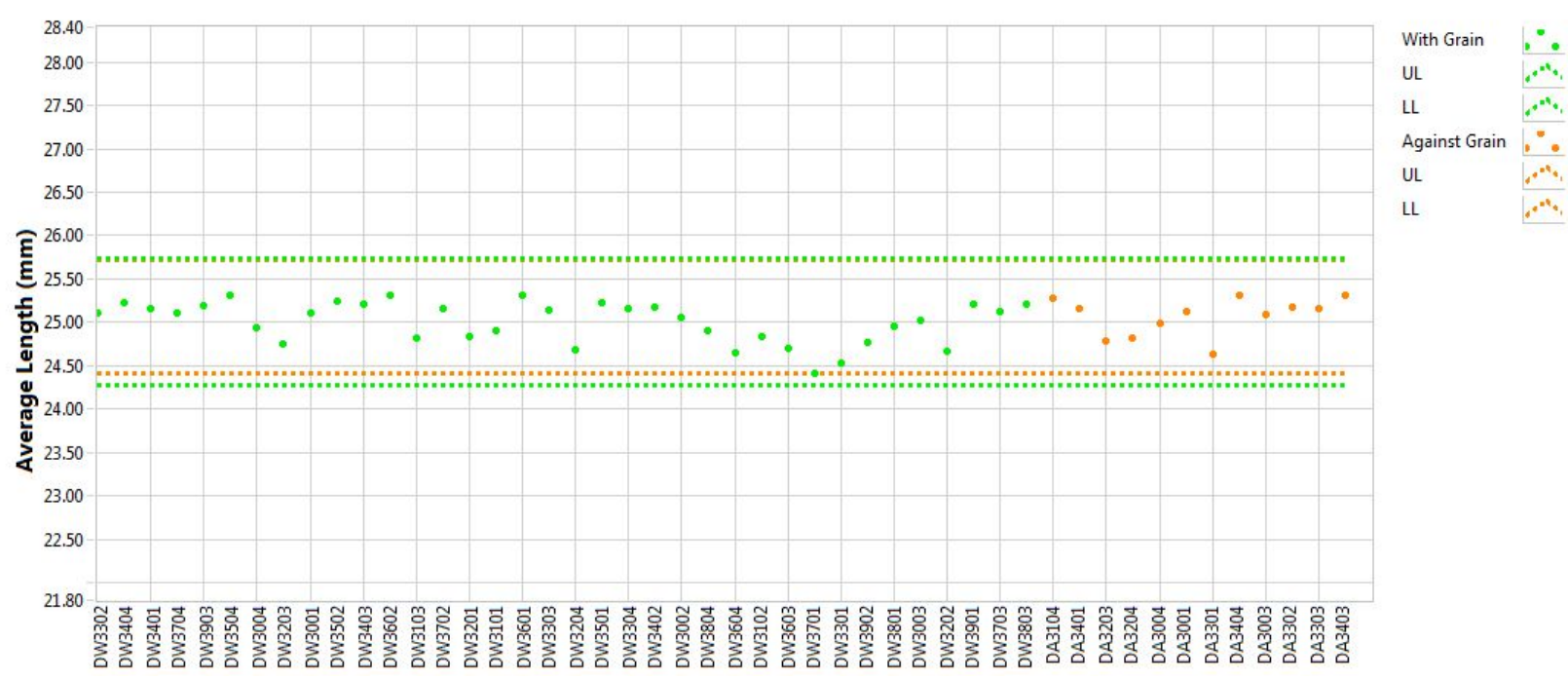

Figure A-5. PCEA creep length.

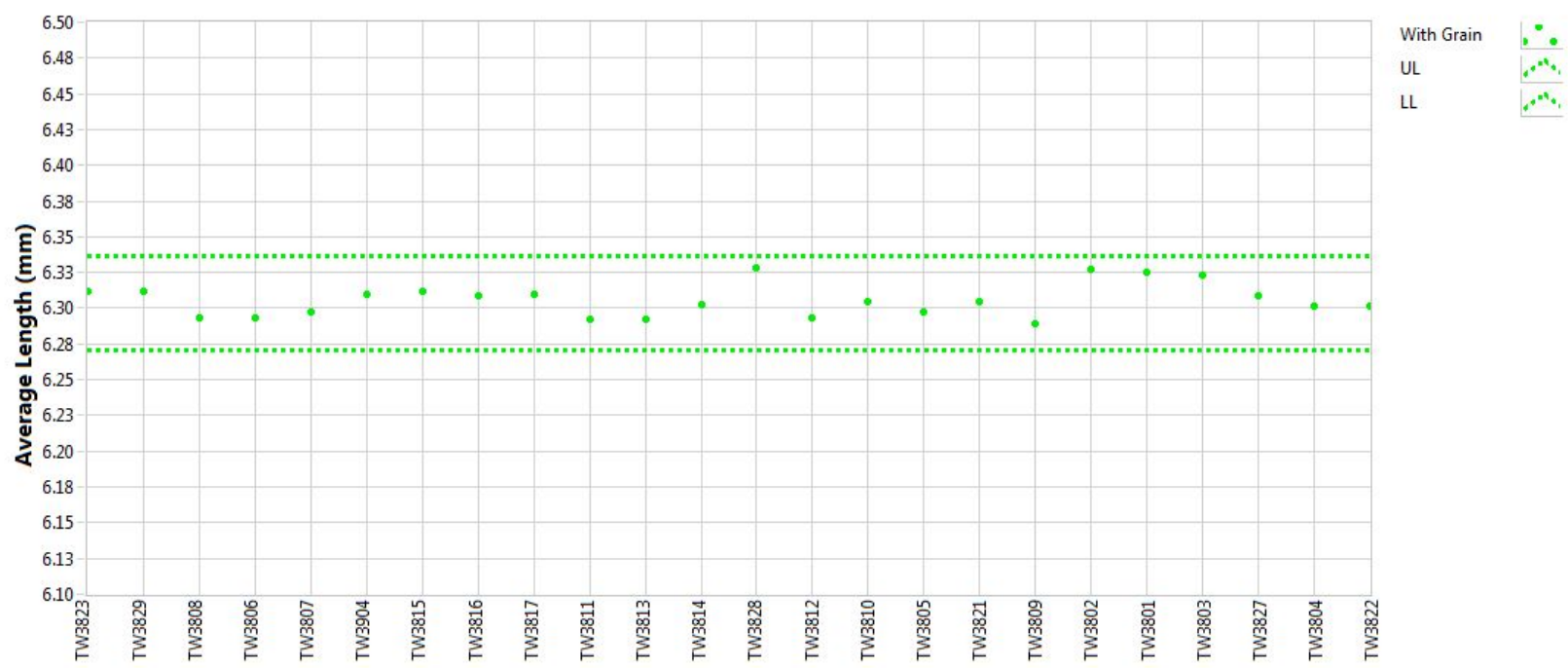

Figure A-6. 2114 piggyback length. 


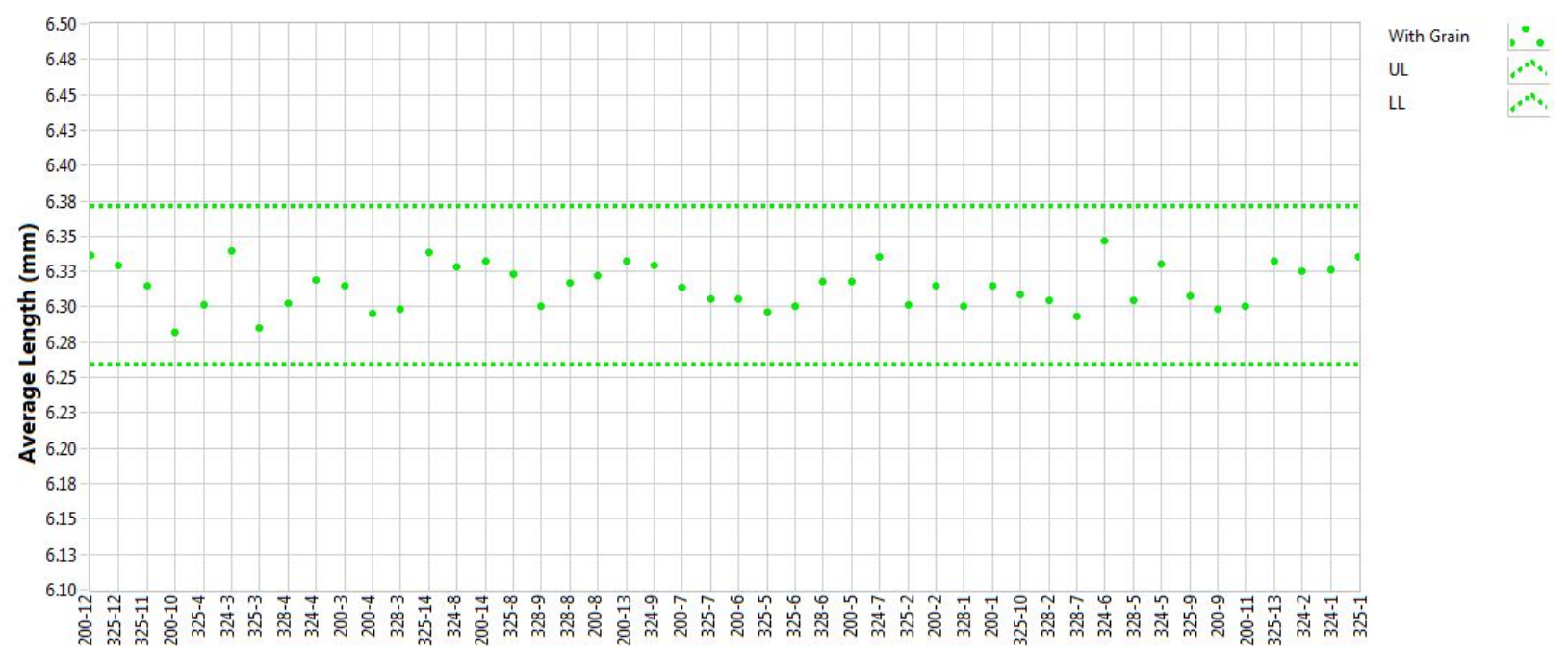

Figure A-7. GrafTech piggyback length.

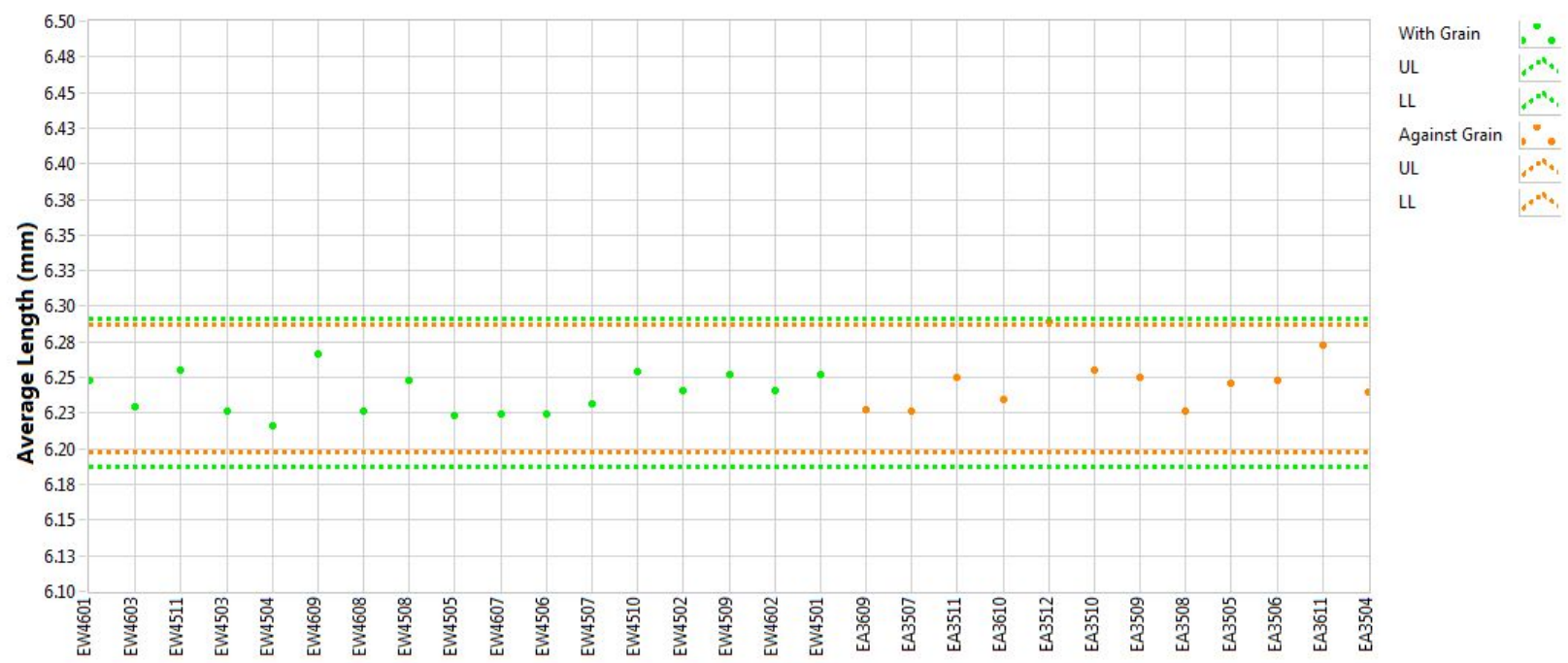

Figure A-8. IG-110 piggyback length. 


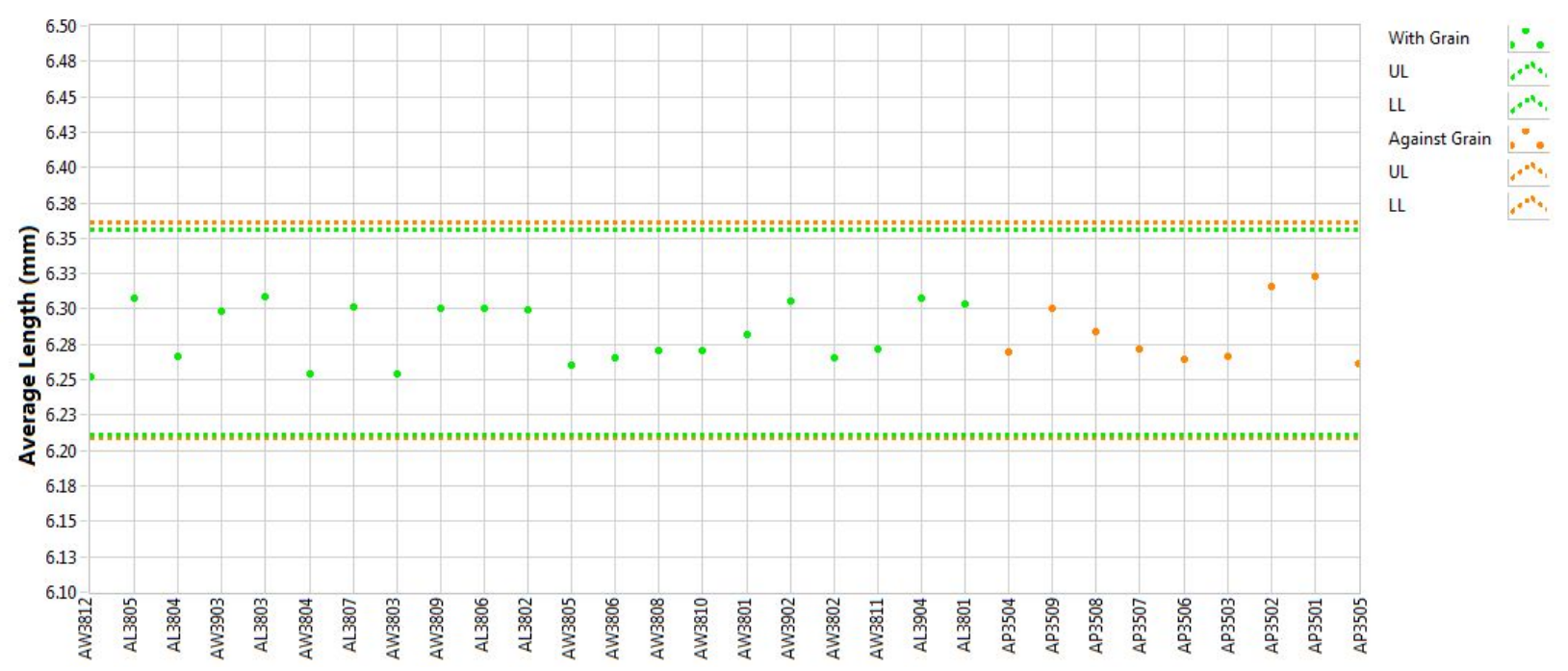

Figure A-9. NBG-17 piggyback length.

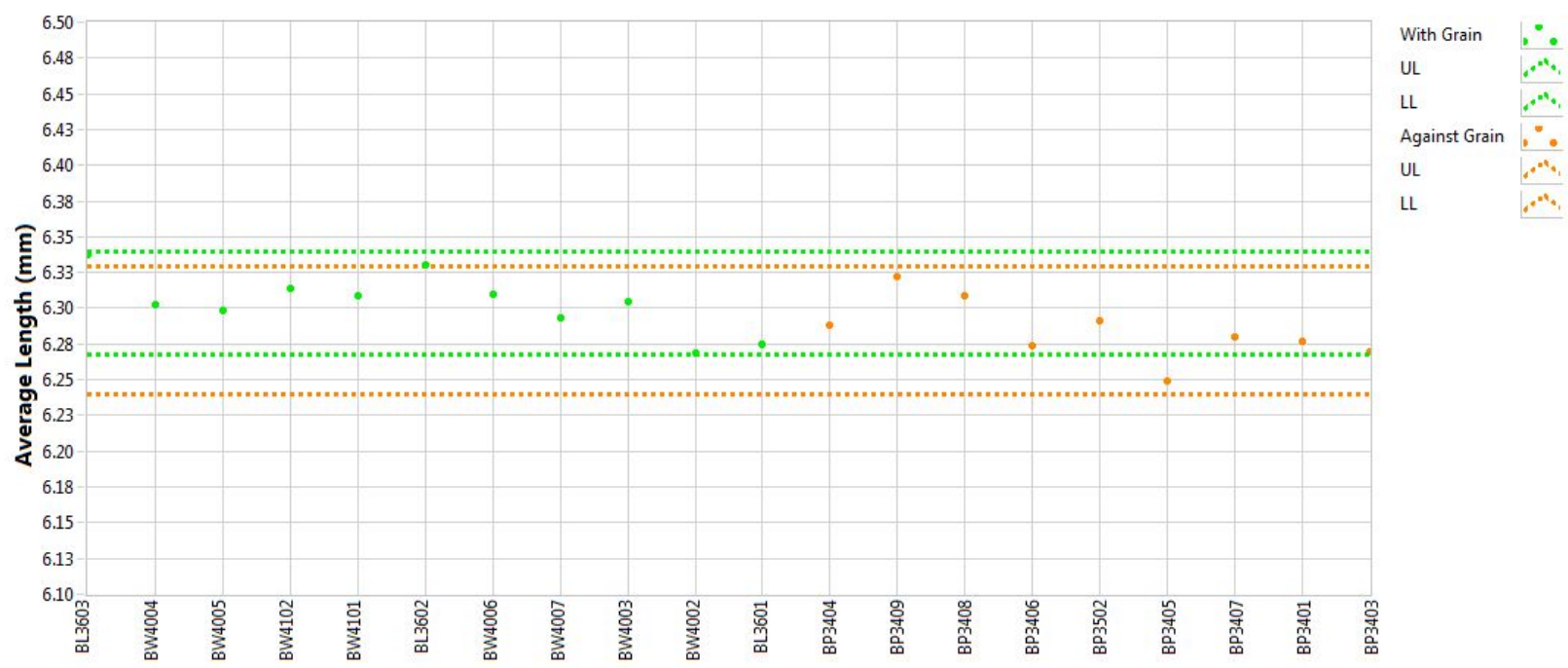

Figure A-10. NBG-18 piggyback length. 


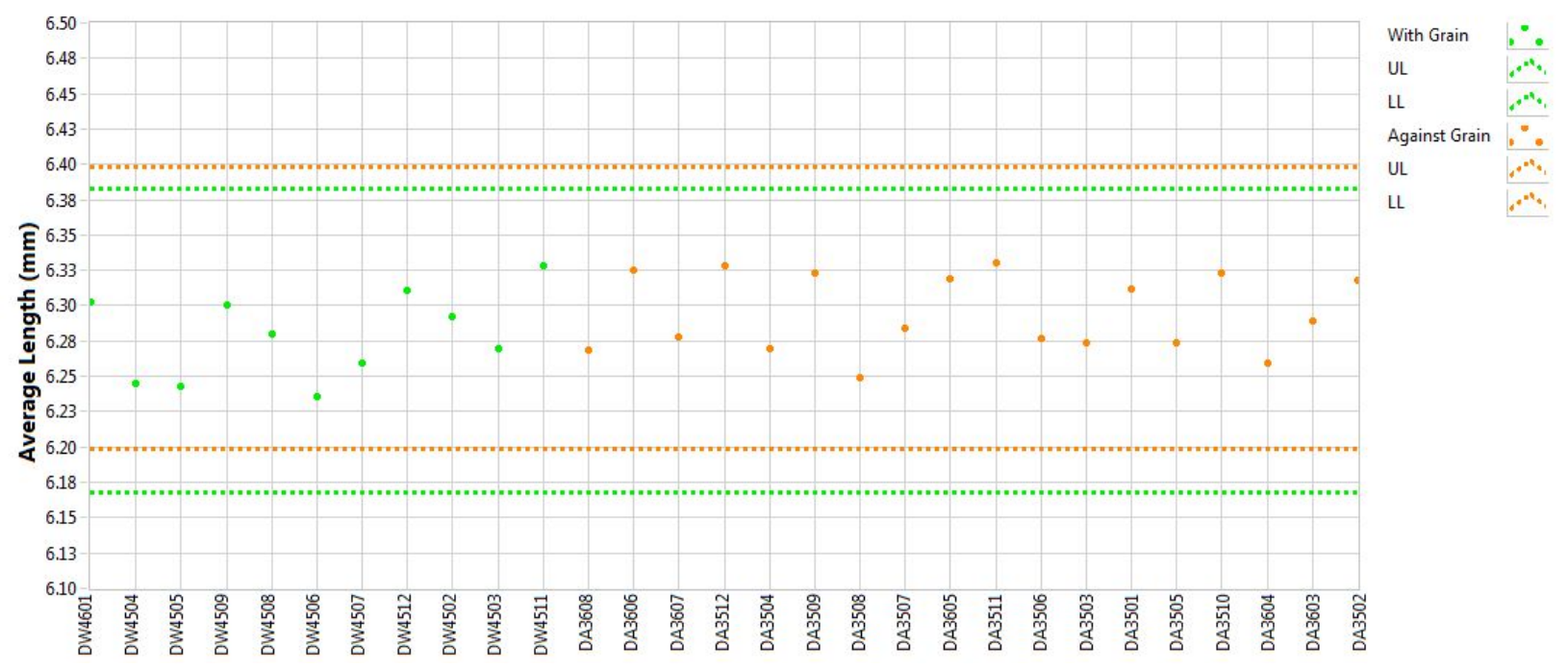

Figure A-11. PCEA piggyback length.

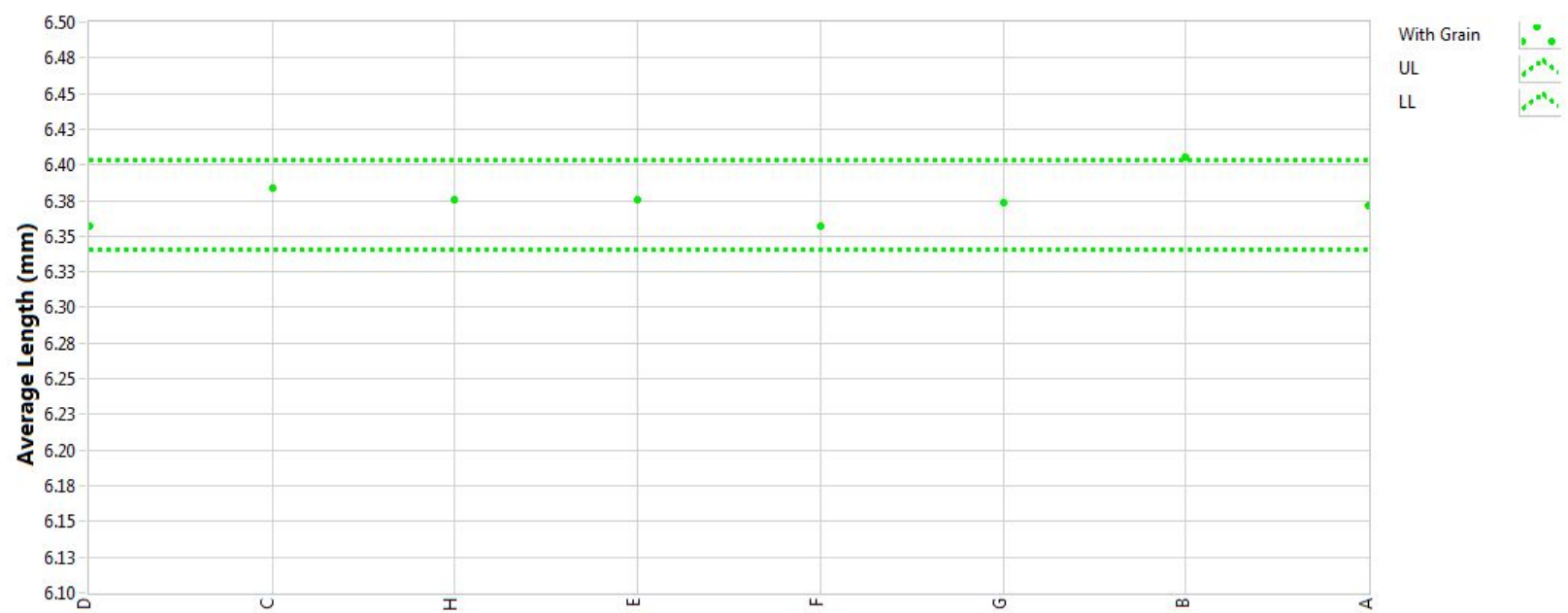

Figure A-12. SGL-SiC piggyback length. 


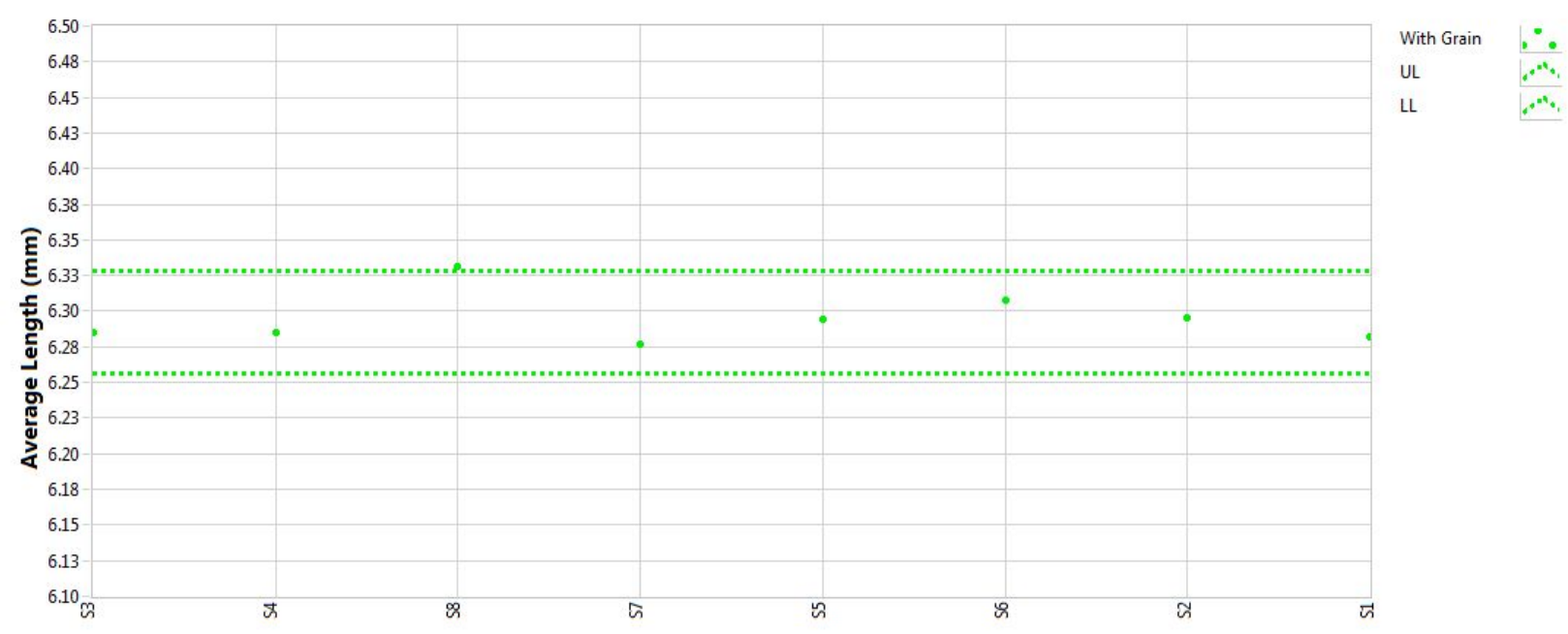

Figure A-13. SGL piggyback length.

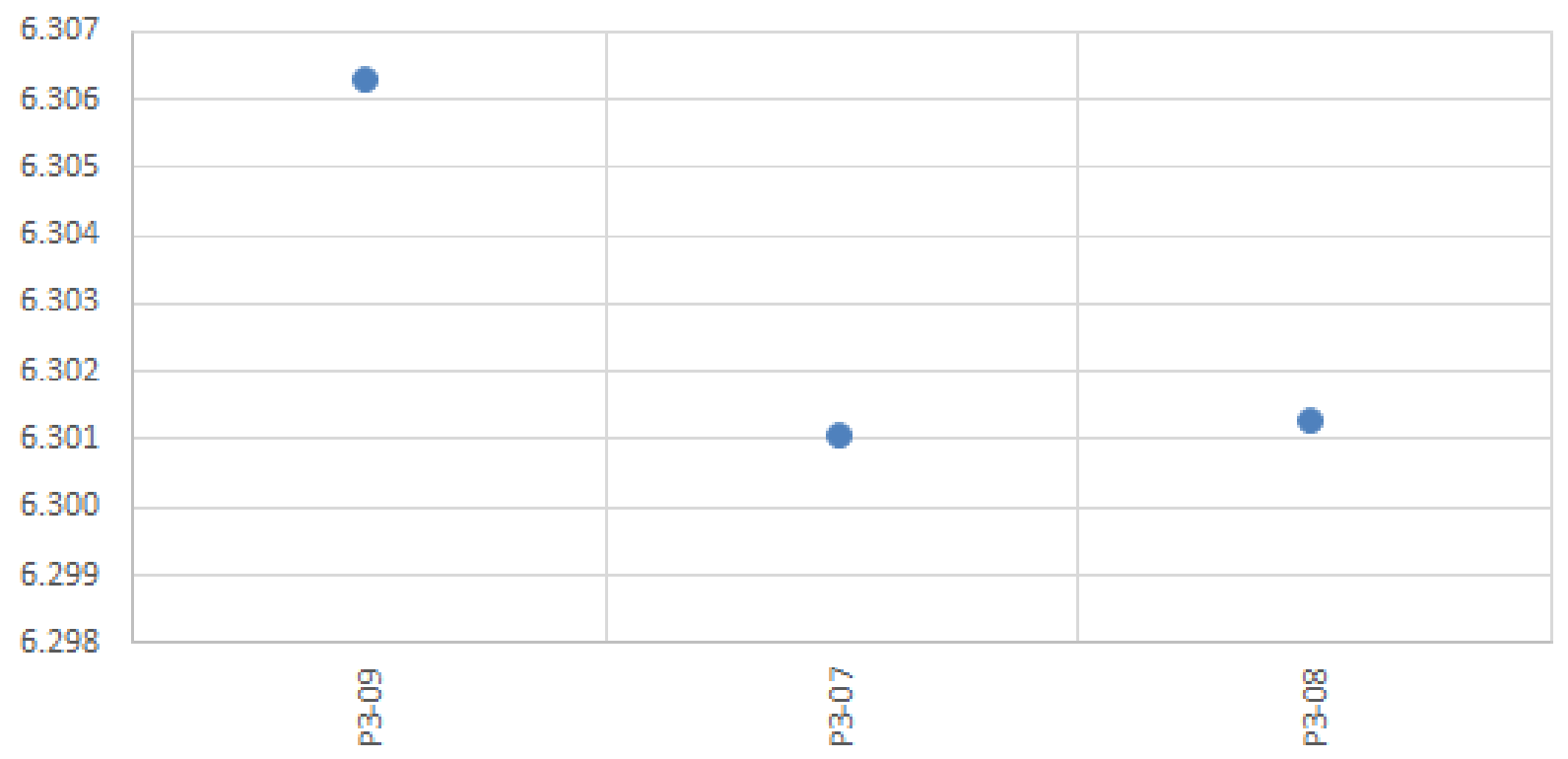

Figure A-14. PCIB piggyback length. 


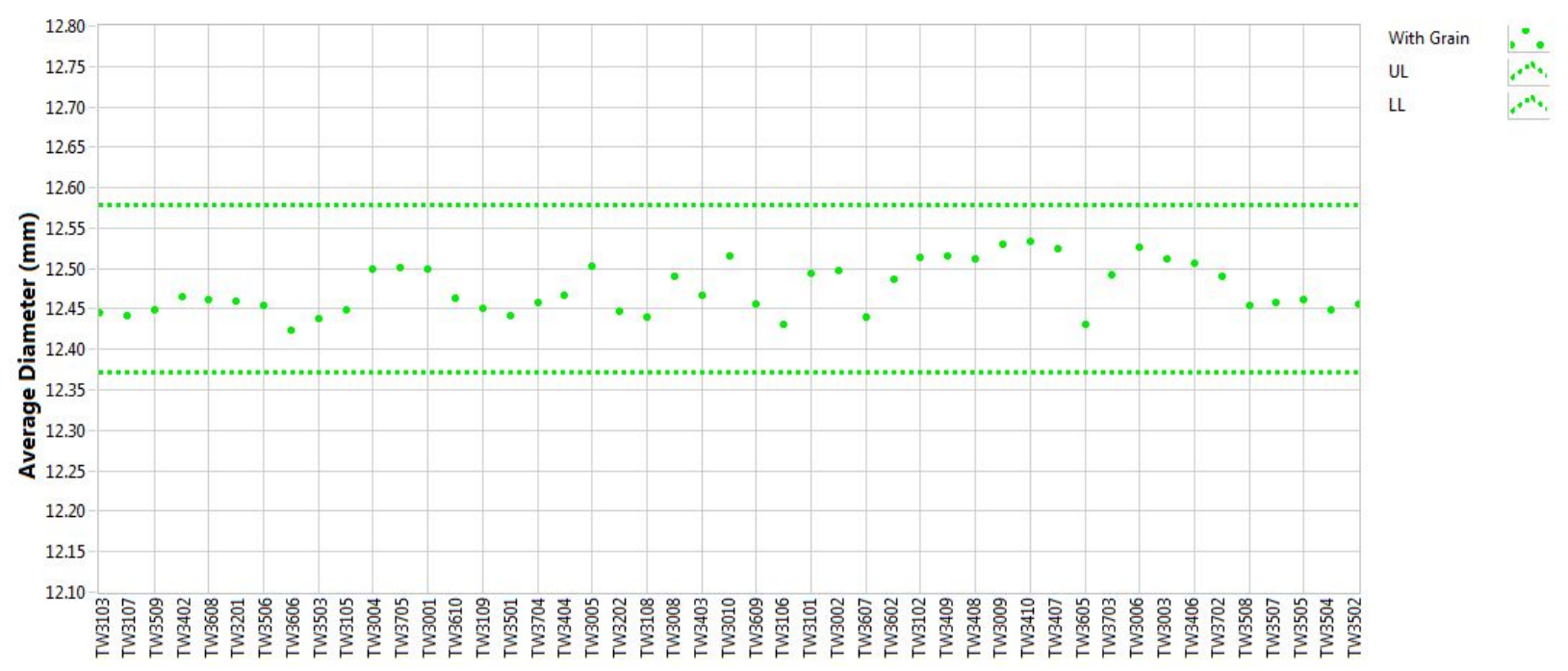

Figure A-15. 2114 creep diameter.

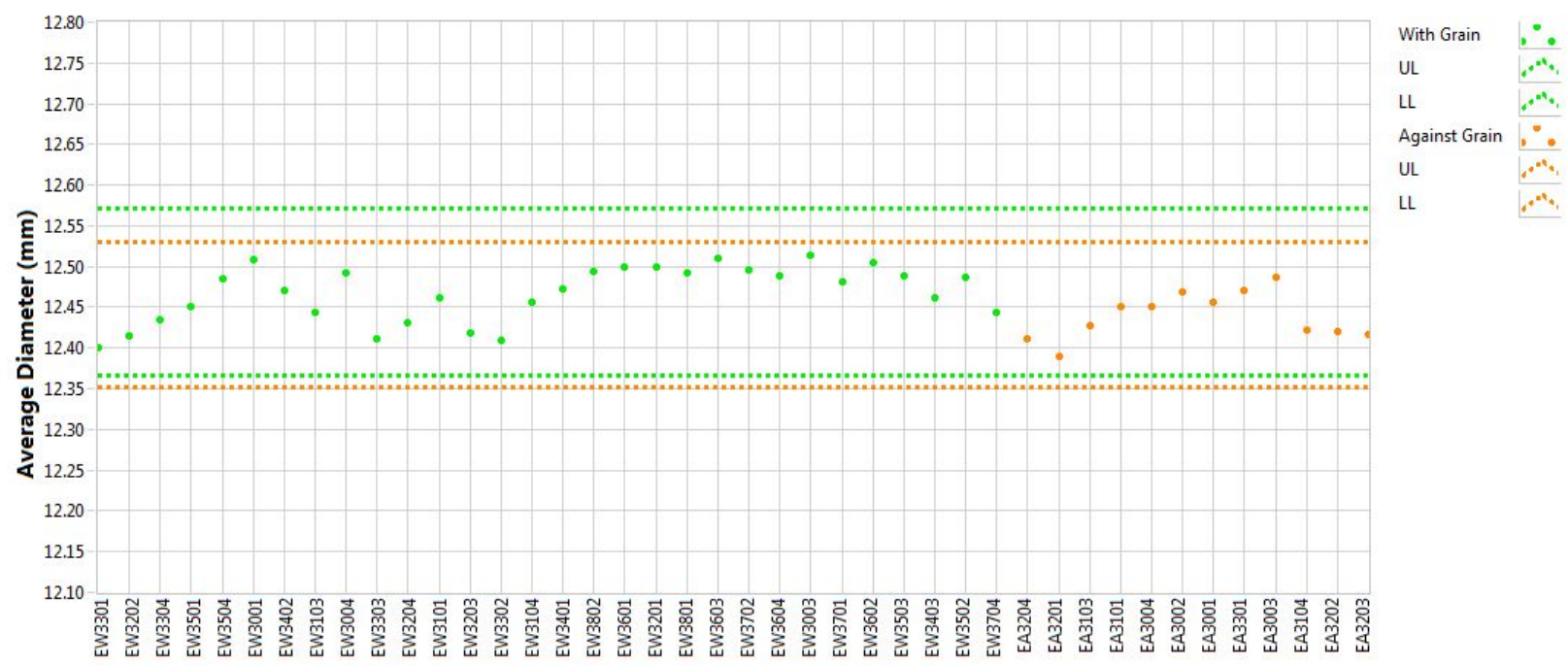

Figure A-16. IG-110 creep diameter. 


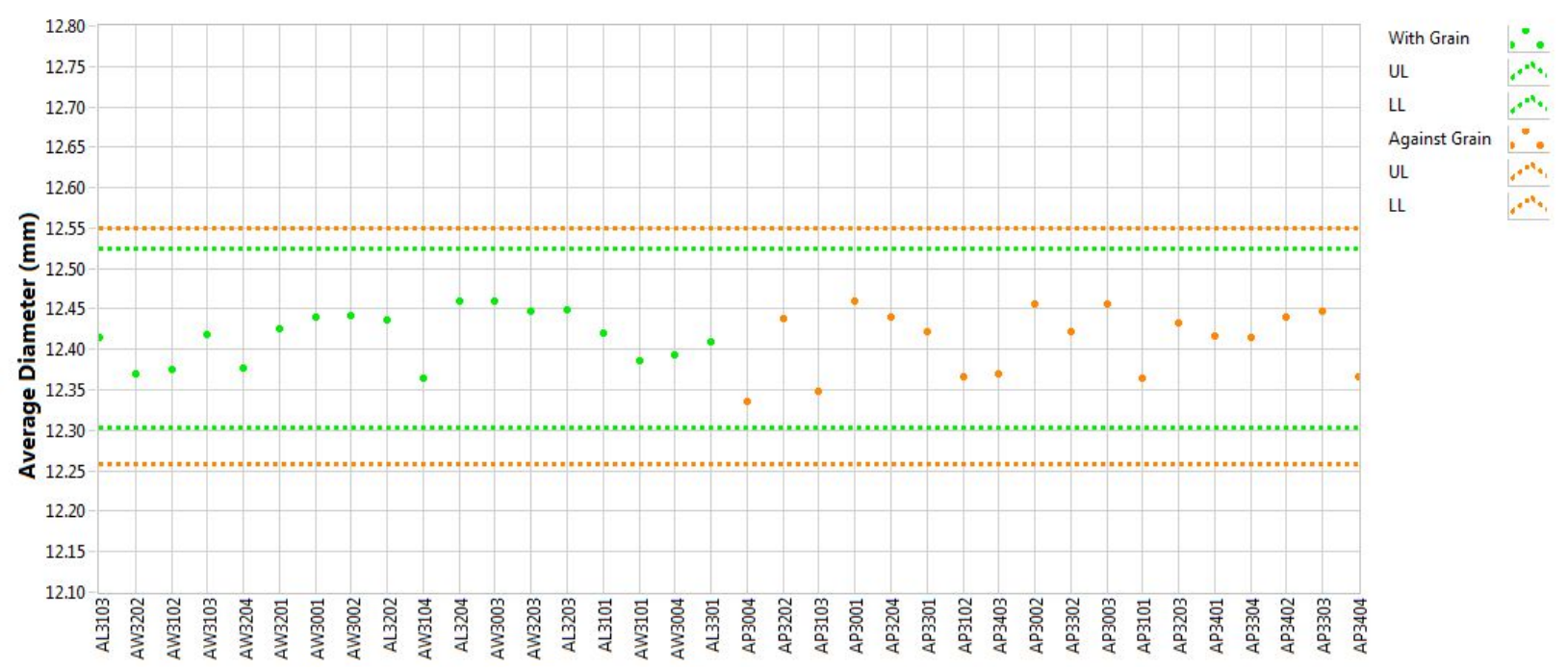

Figure A-17. NBG-17 creep diameter.

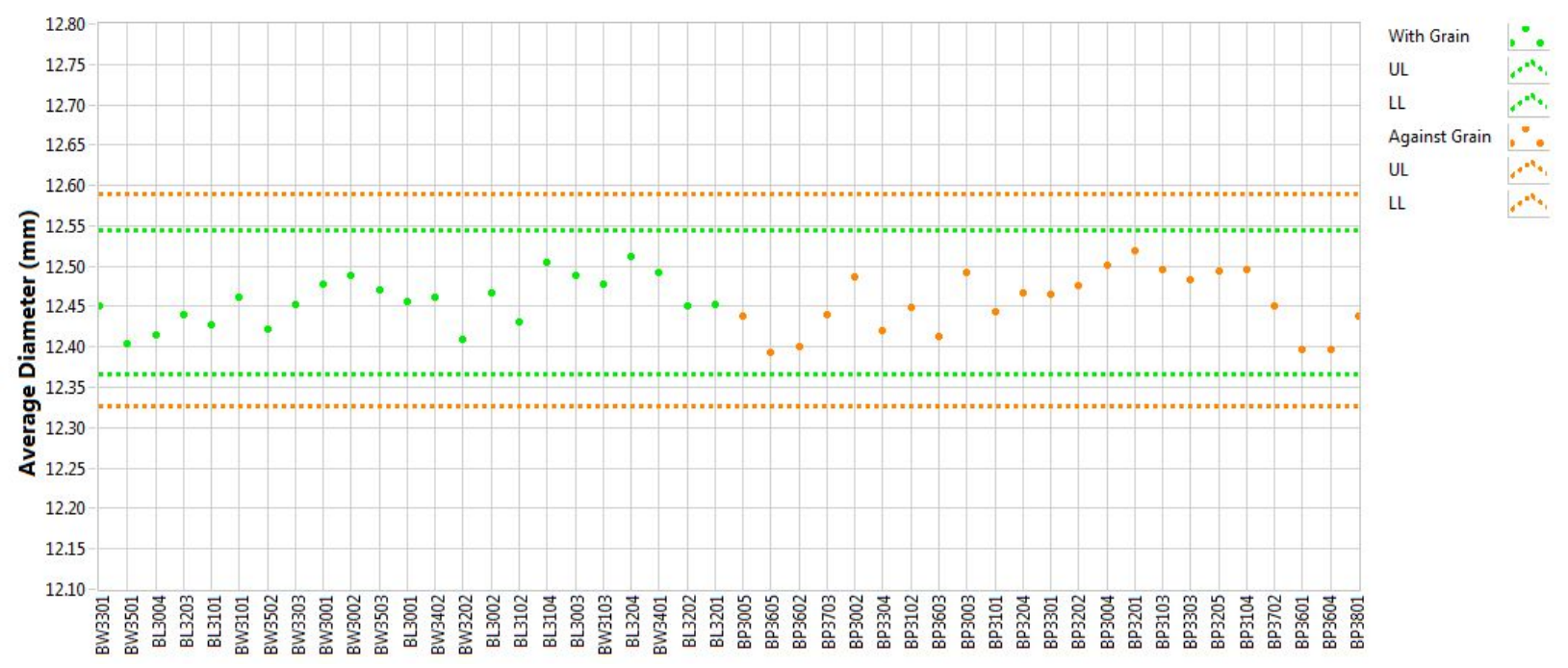

Figure A-18. NBG-18 creep diameter. 

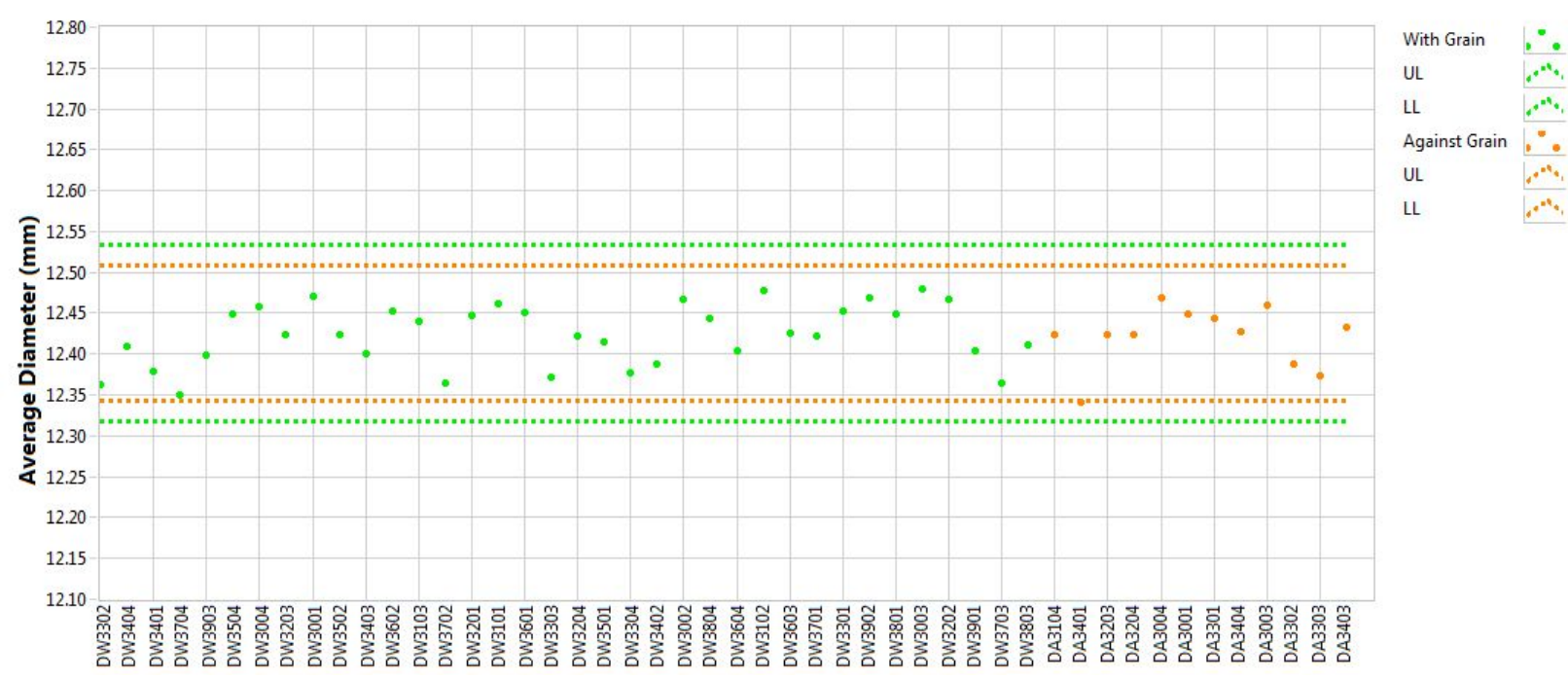

Figure A-19. PCEA creep diameter.

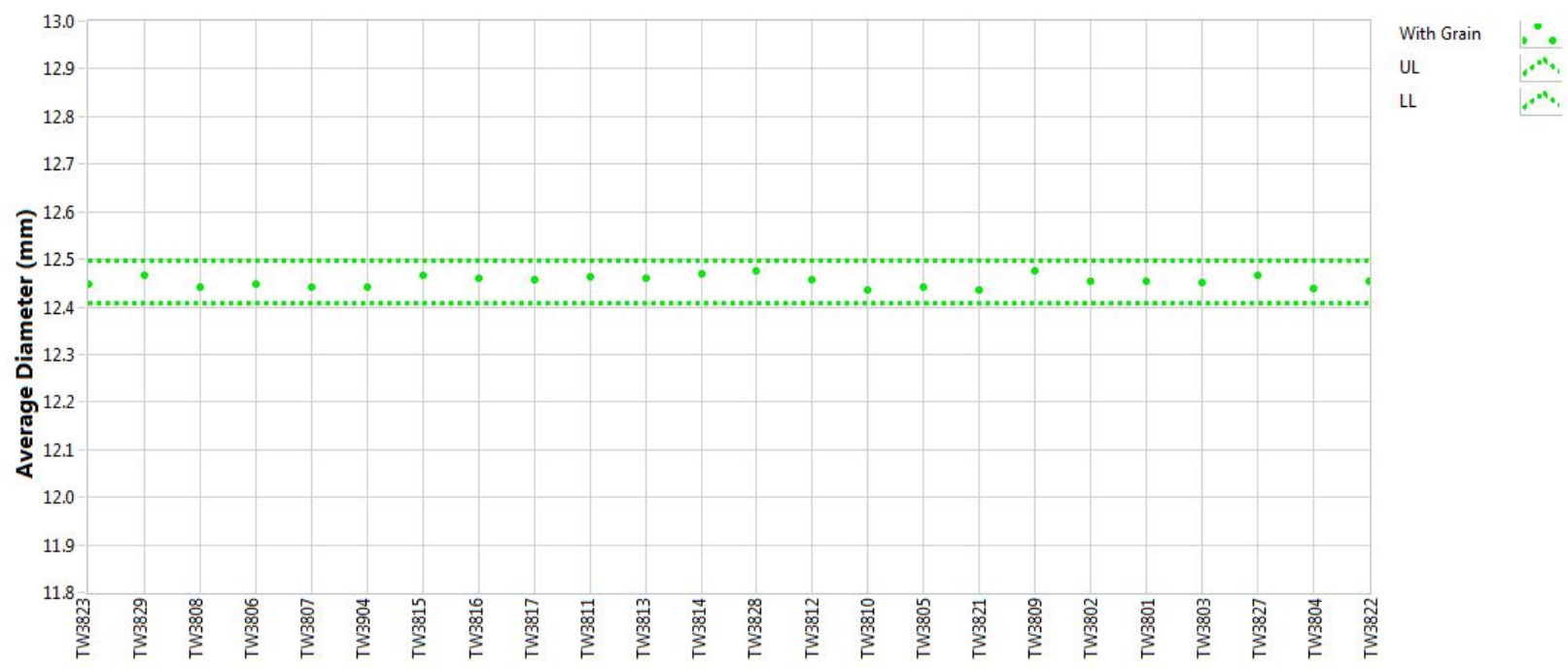

Figure A-20. 2114 piggyback diameter. 


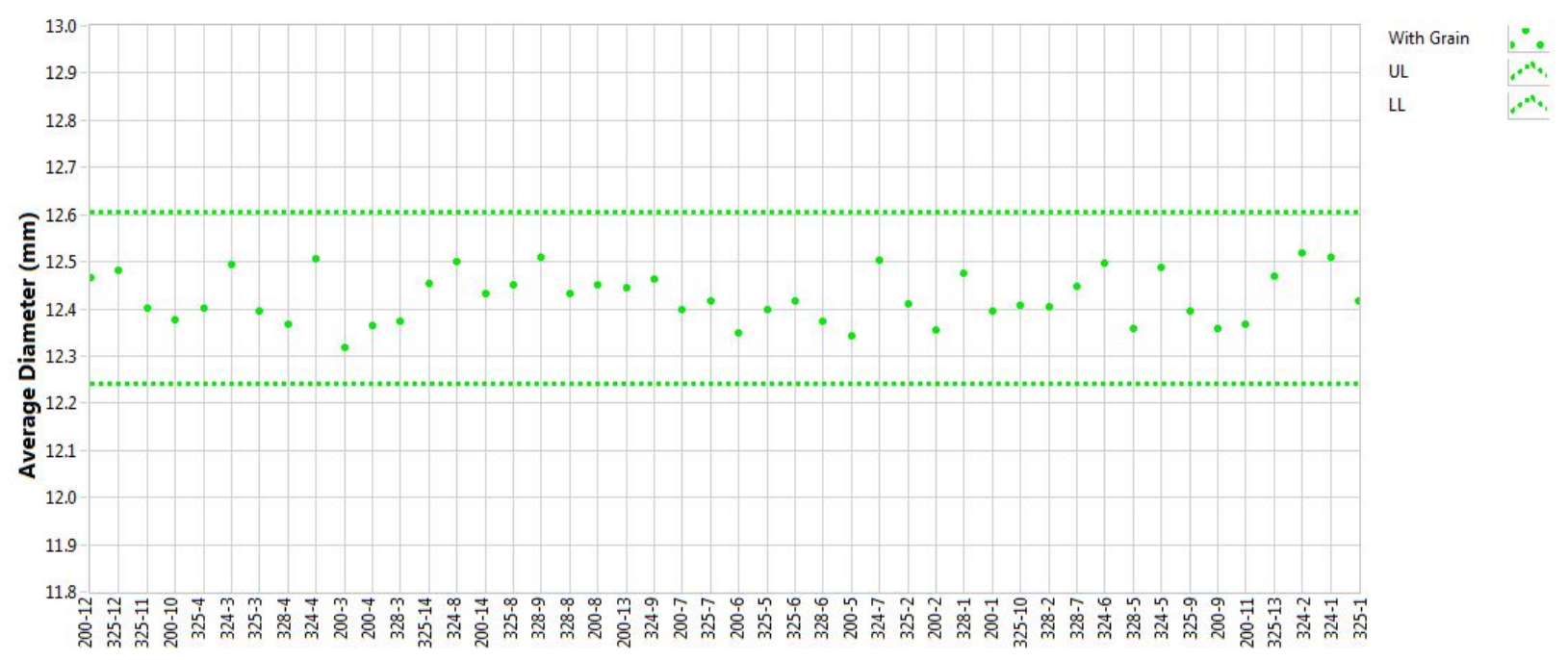

Figure A-21. GrafTech piggyback diameter.

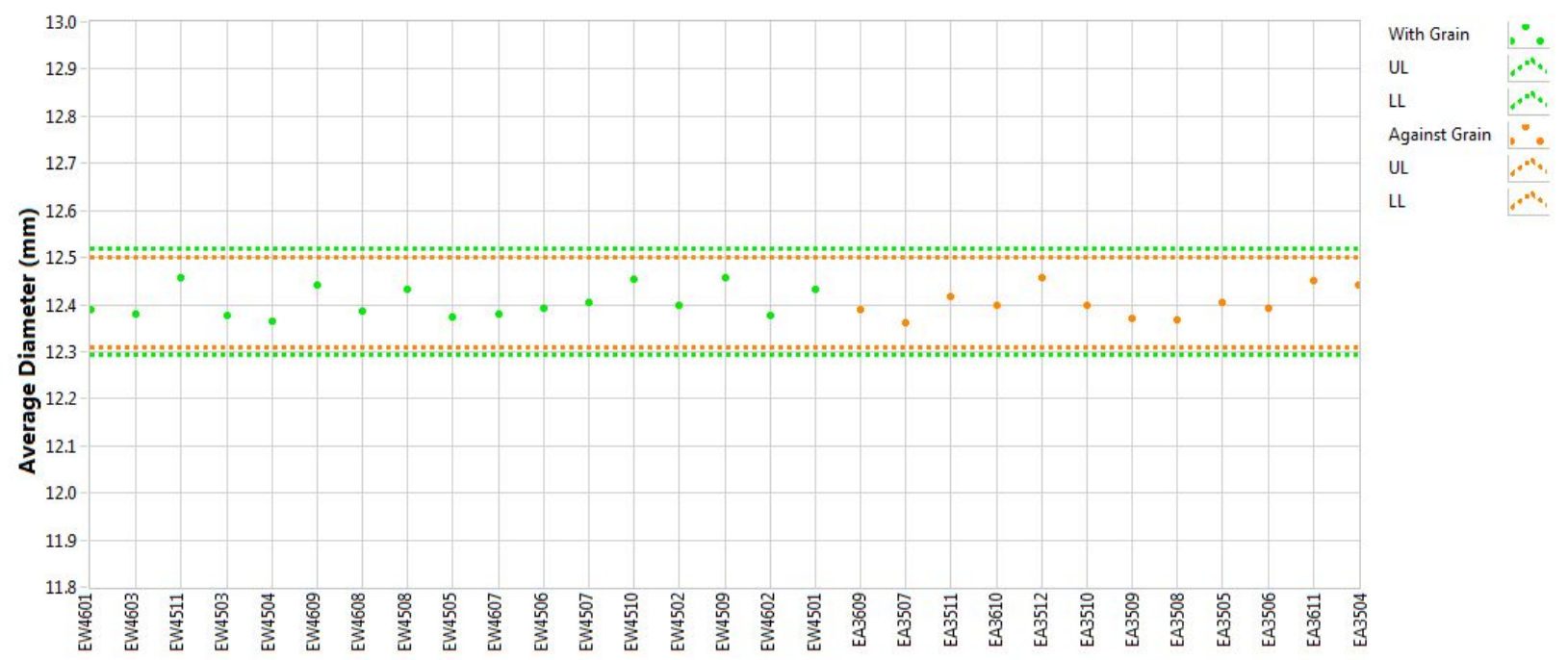

Figure A-22. IG-110 piggyback diameter. 


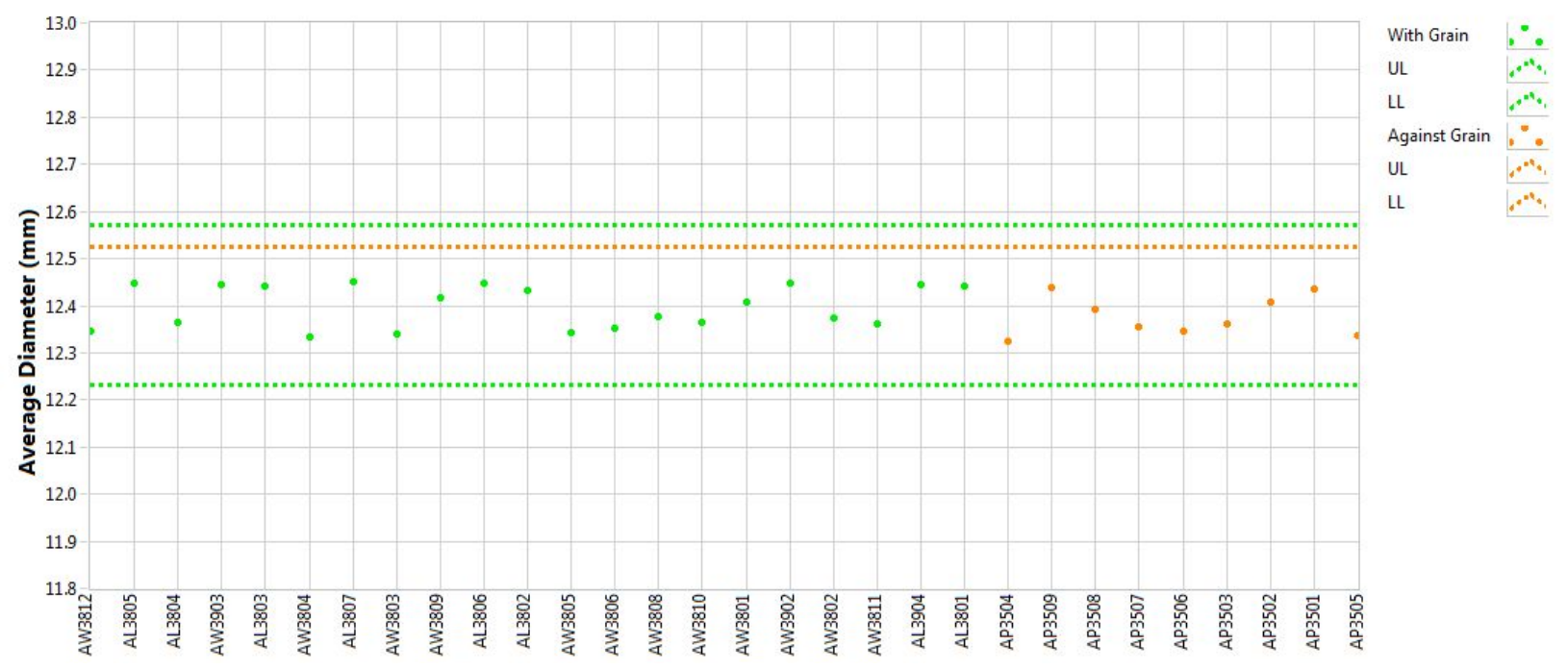

Figure A-23. NBG-17 piggyback diameter.

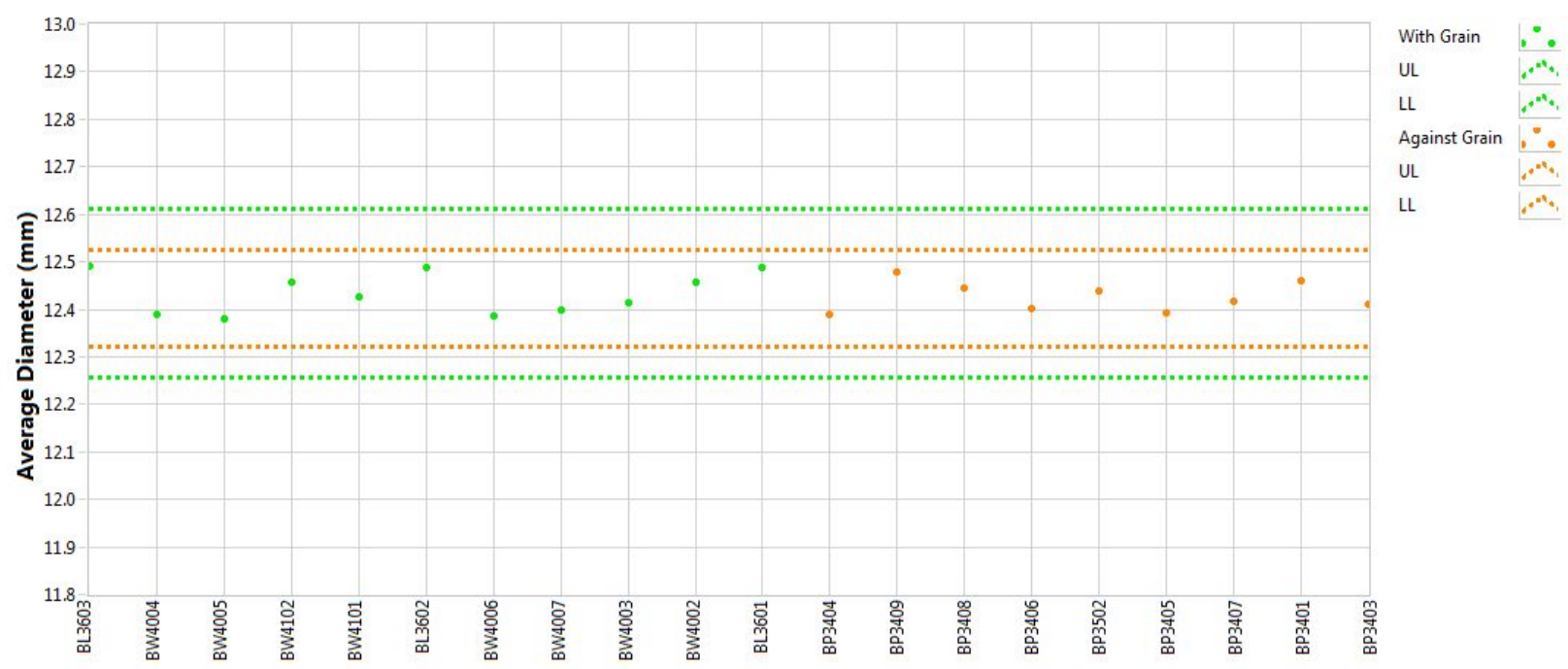

Figure A-24. NBG-18 piggyback diameter. 


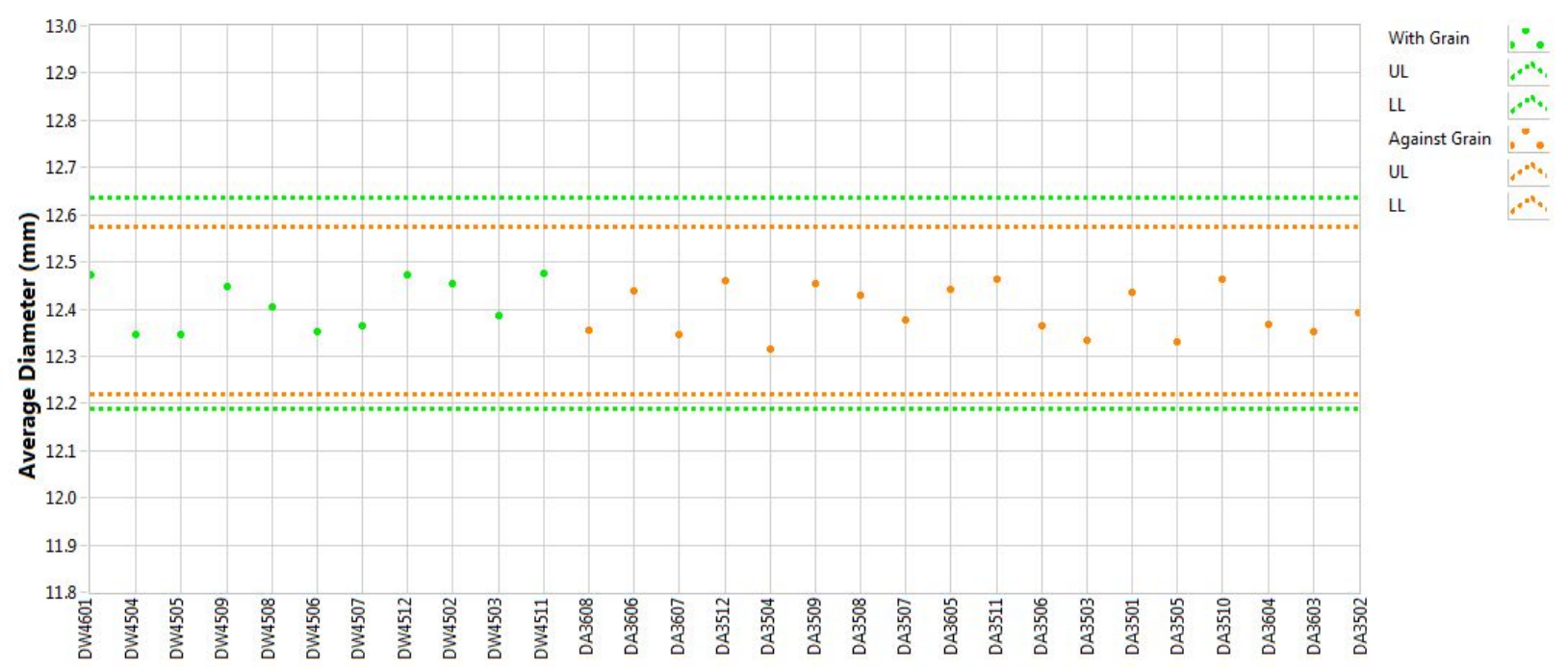

Figure A-25. PCEA piggyback diameter.

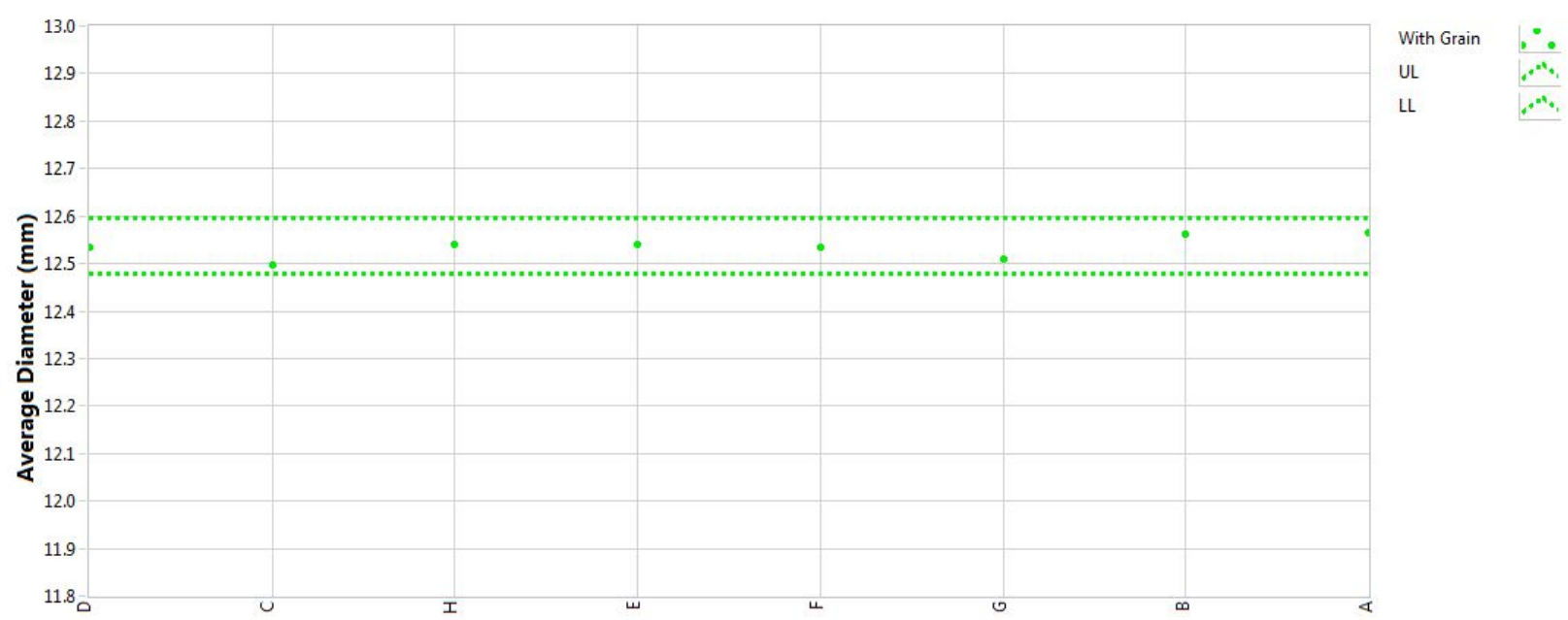

Figure A-26. SGL-SiC piggyback diameter. 


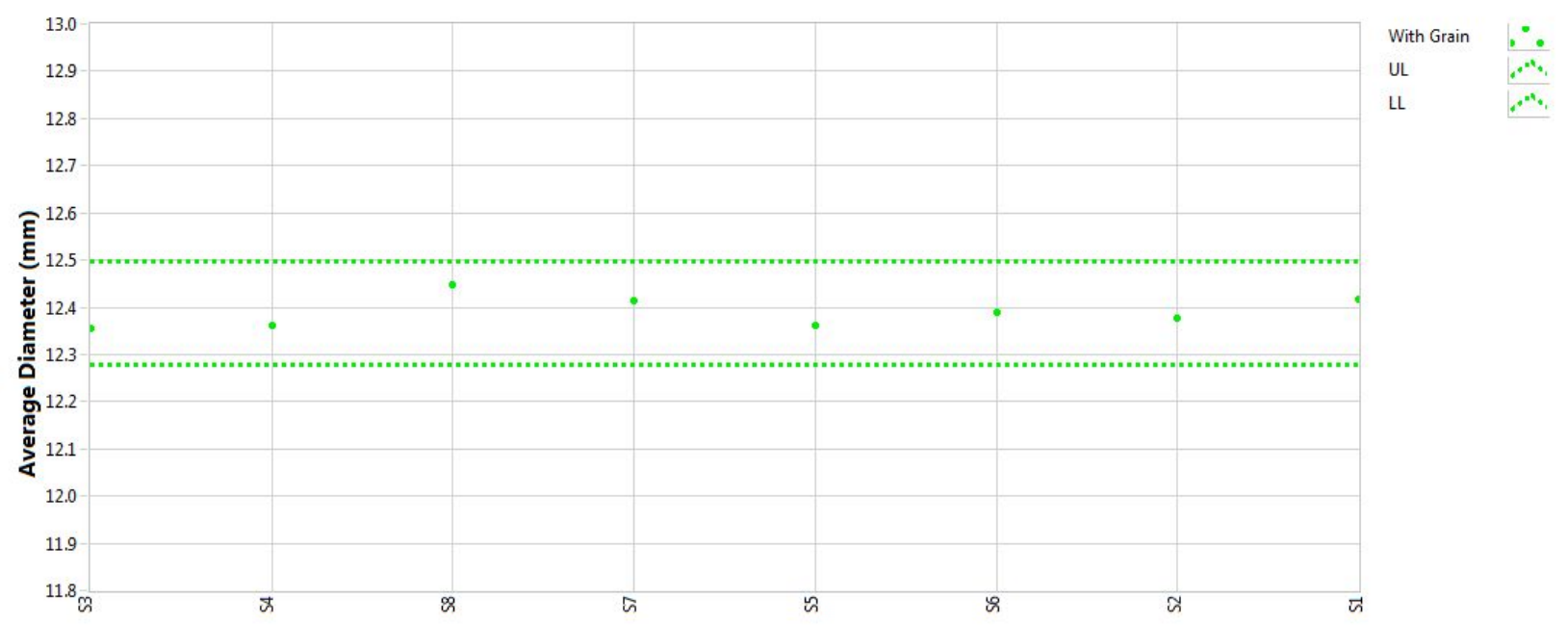

Figure A-27. SGL piggyback diameter.

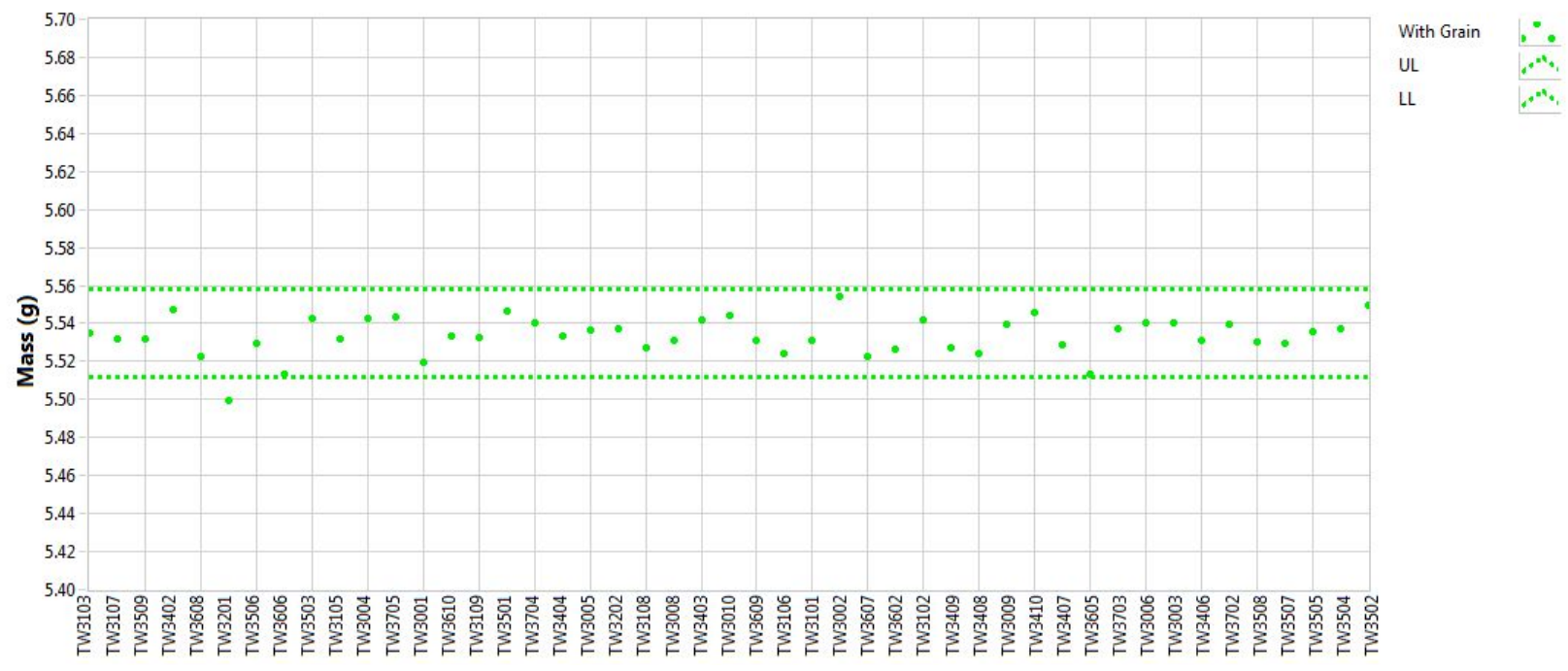

Figure A-28. 2114 creep mass. 


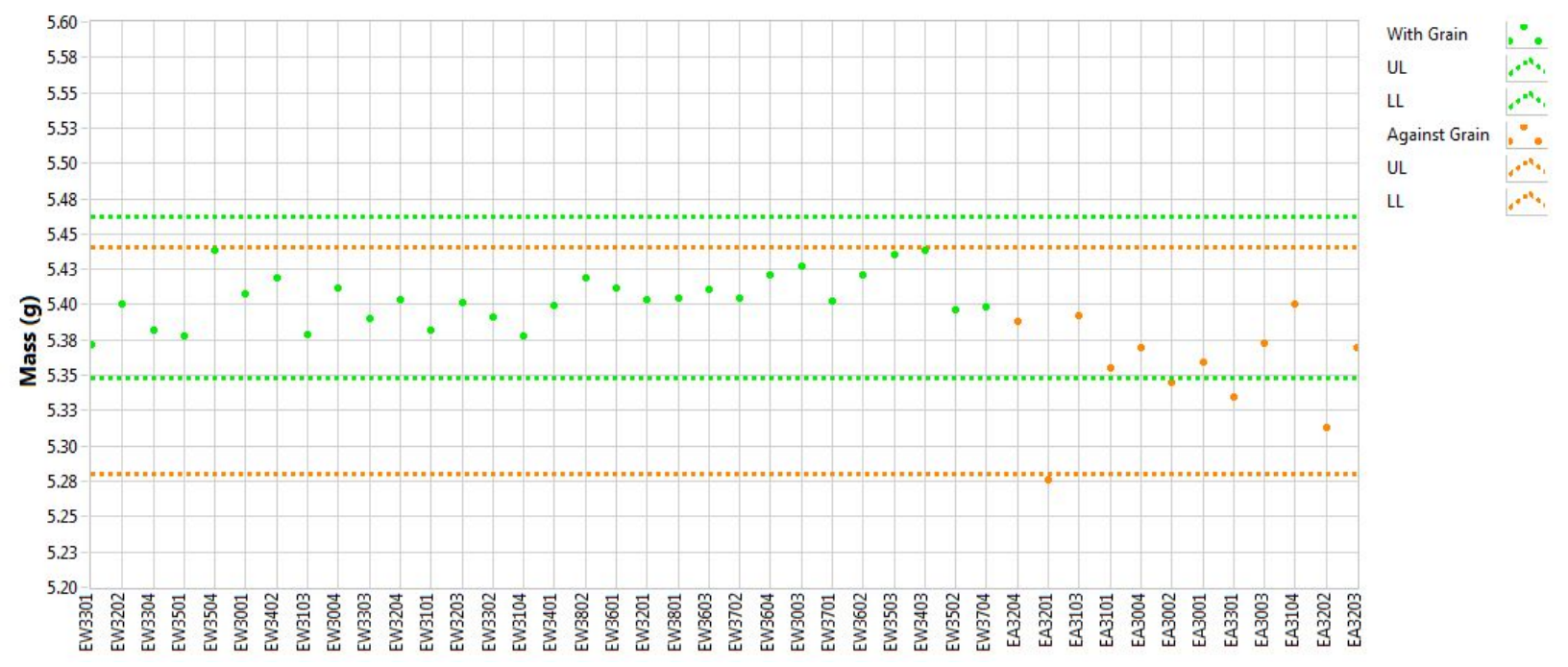

Figure A-29. IG-110 creep mass.

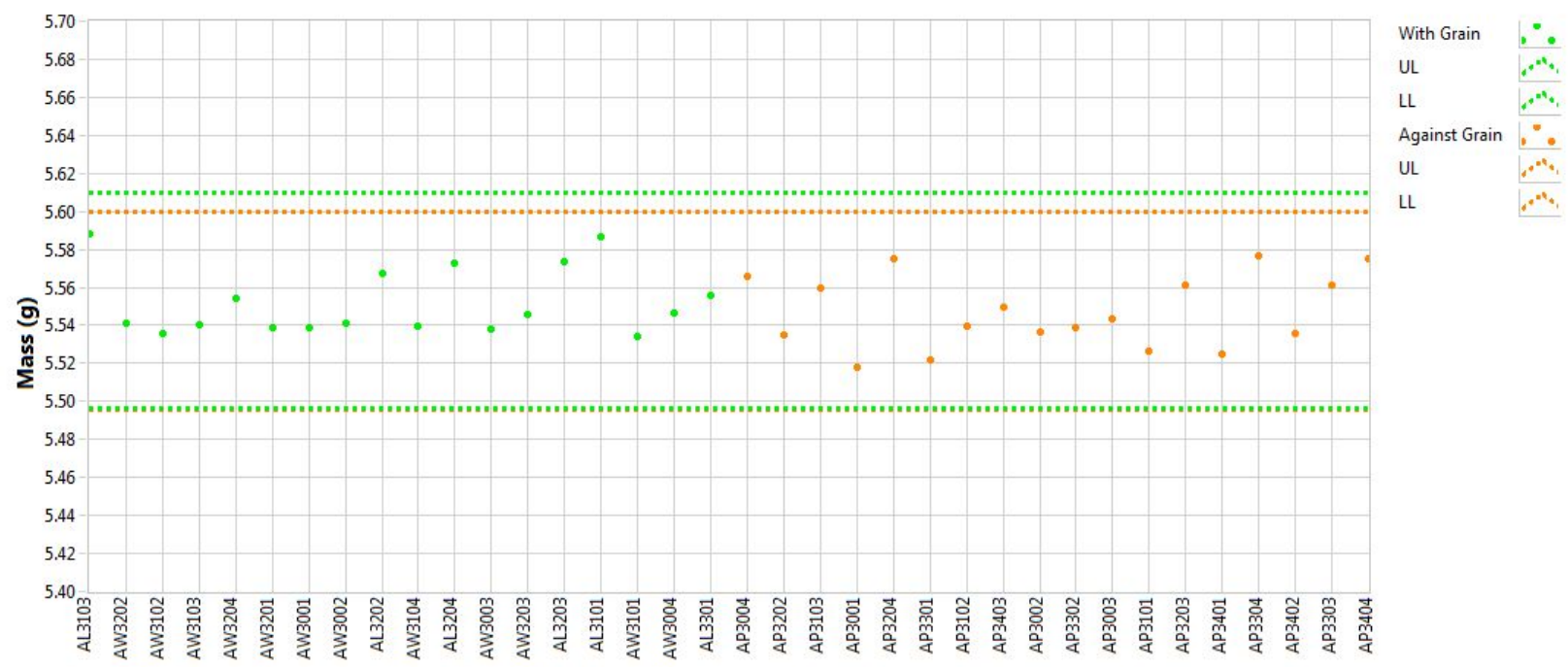

Figure A-30. NBG-17 creep mass. 


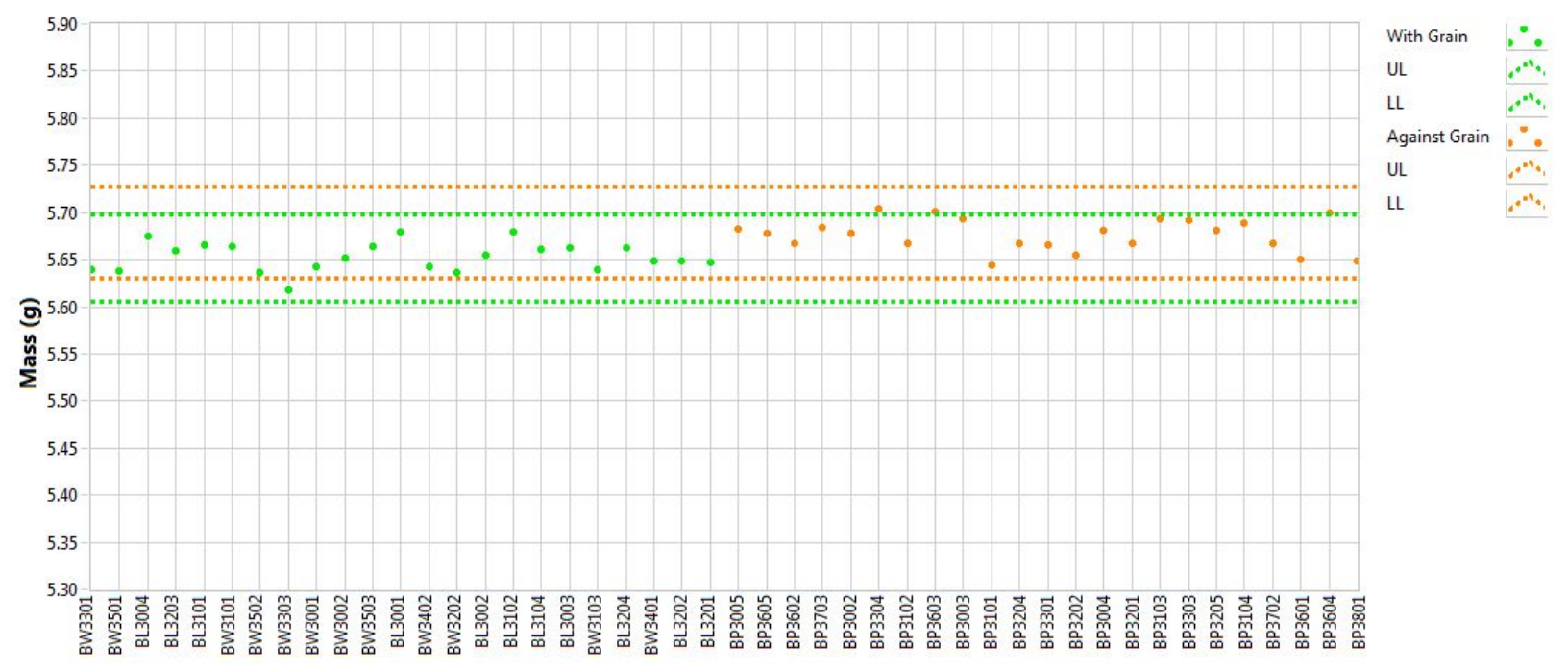

Figure A-31. NBG-18 creep mass.

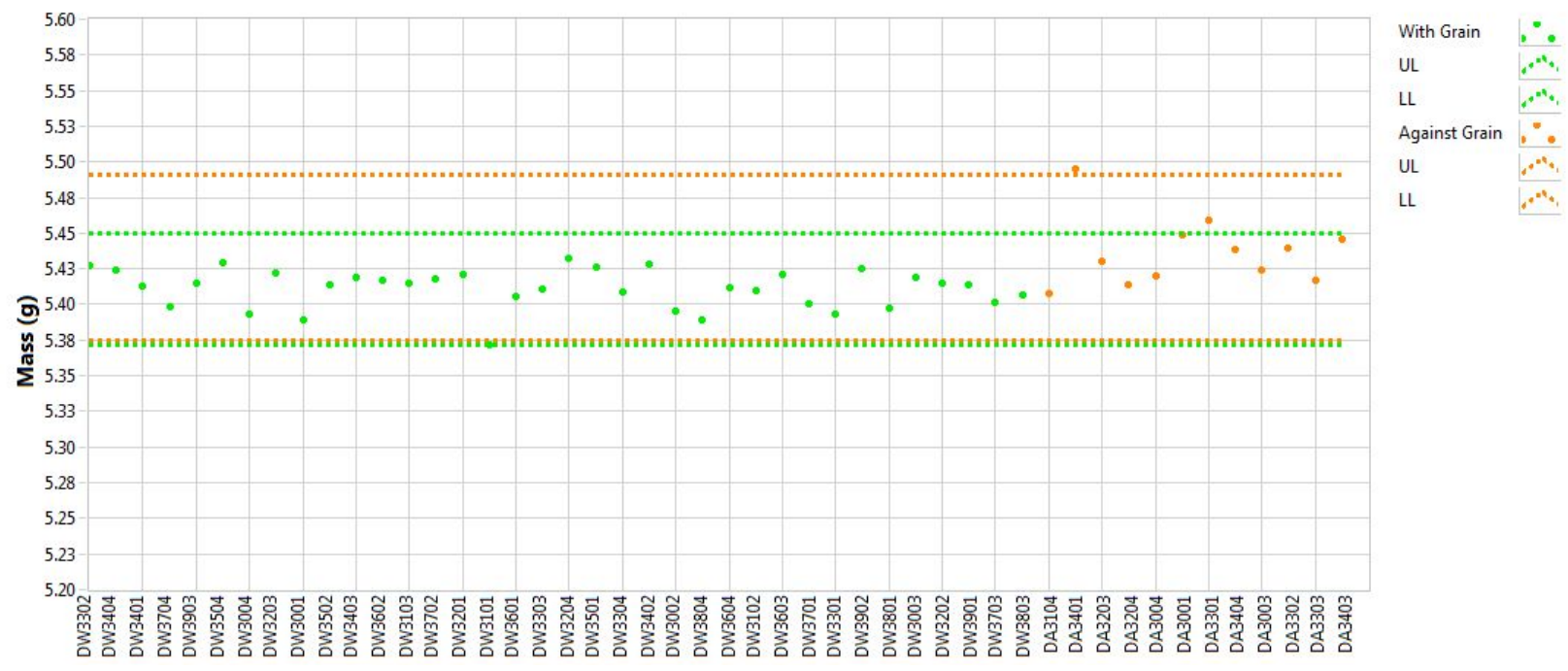

Figure A-32. PCEA creep mass. 


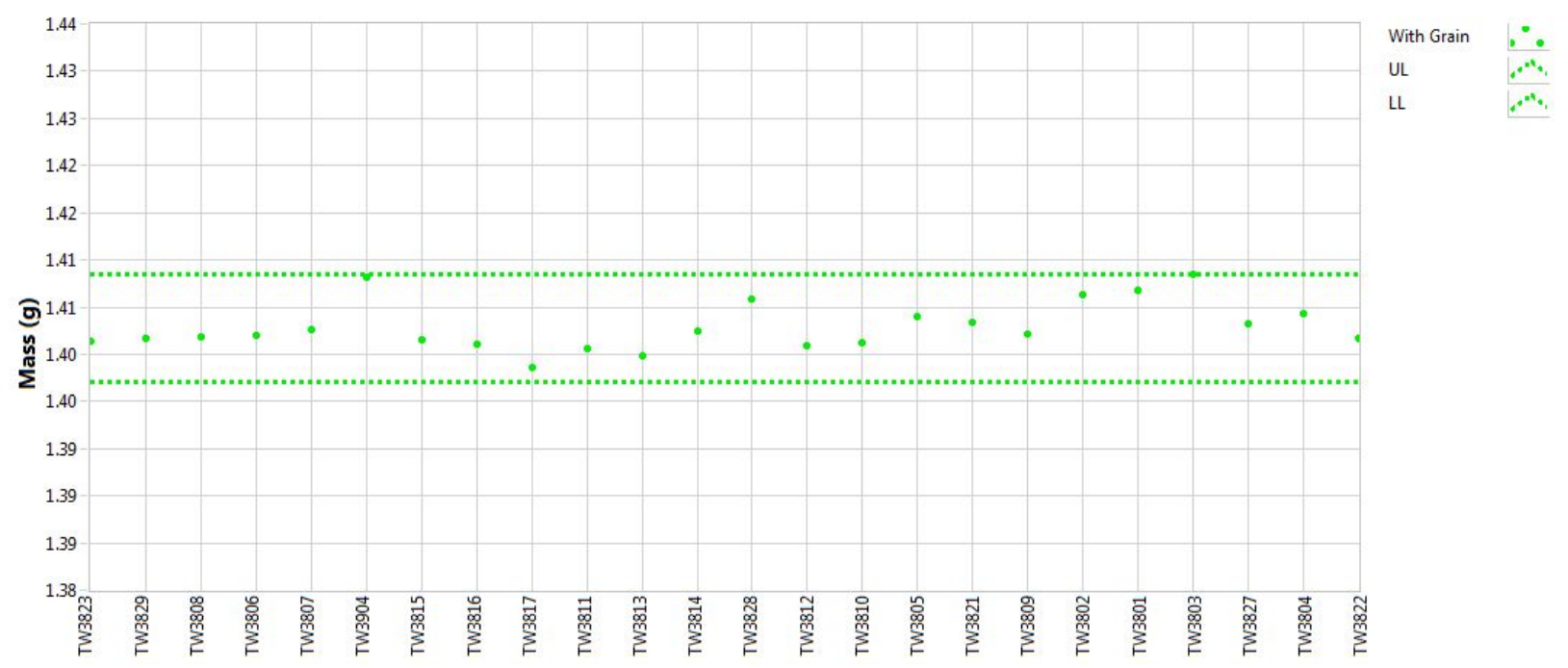

Figure A-33. 2114 piggyback mass.

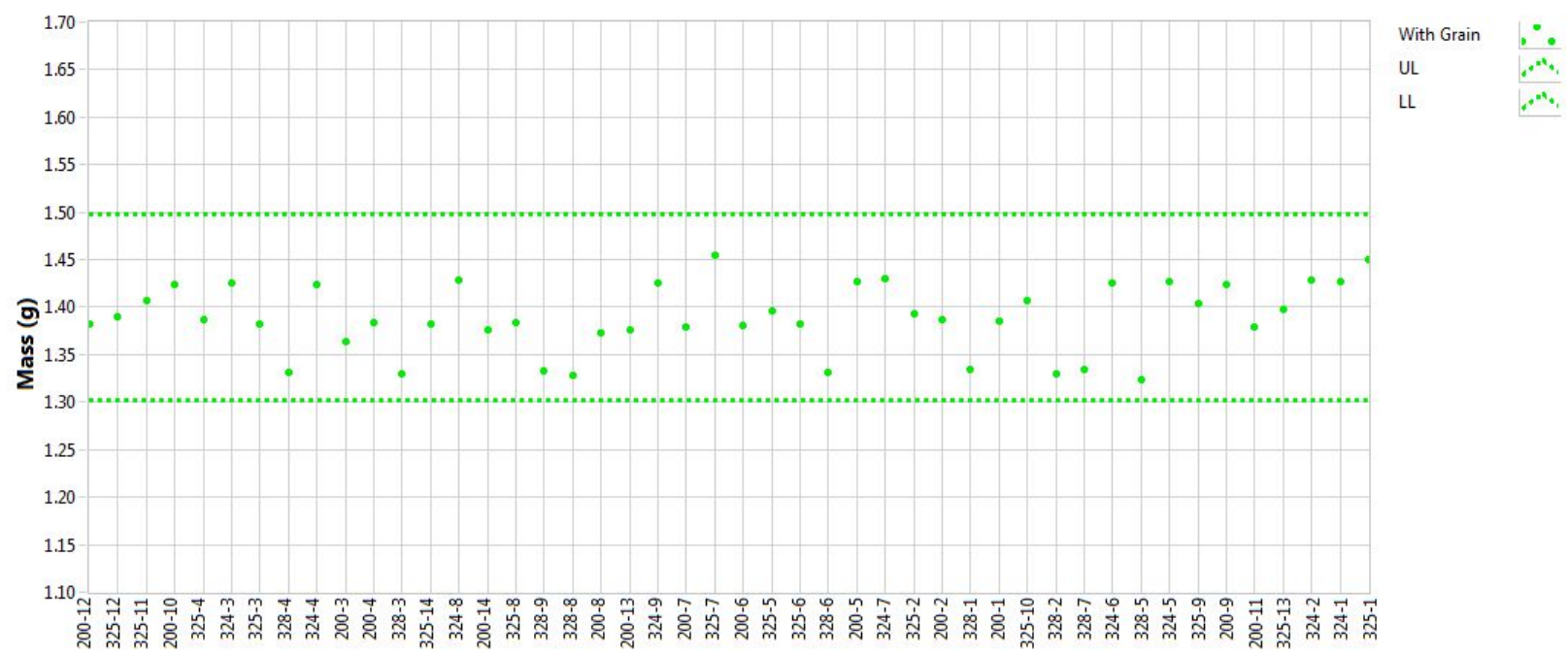

Figure A-34. GrafTech piggyback mass. 


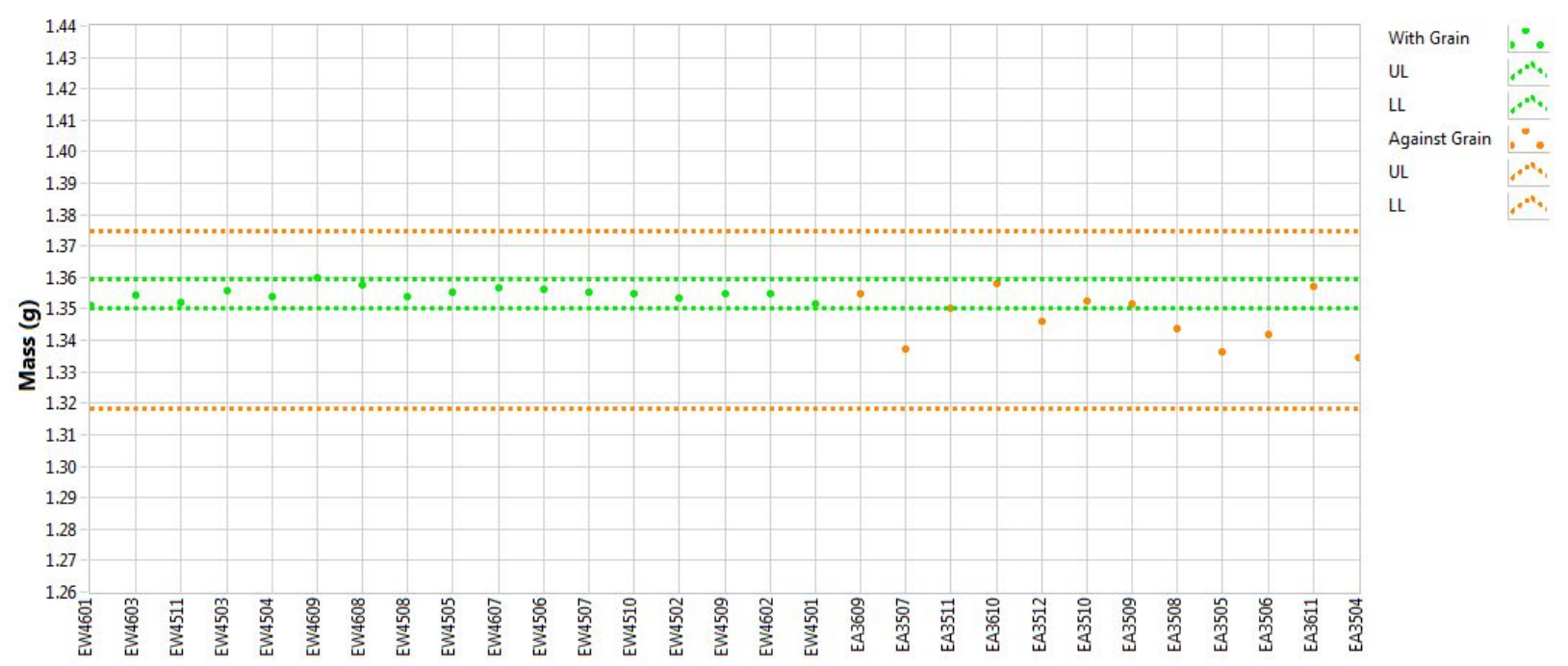

Figure A-35. IG-110 piggyback mass.

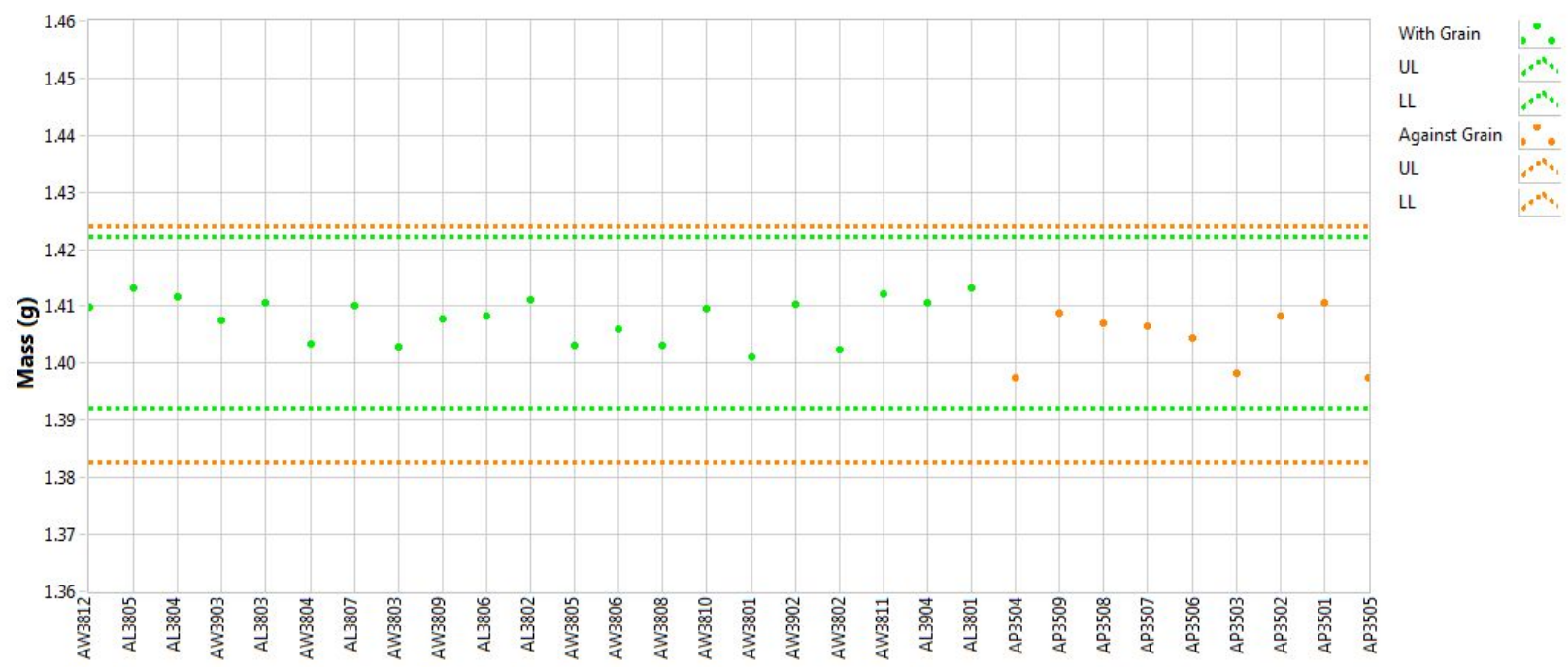

Figure A-36. NBG-17 piggyback mass. 


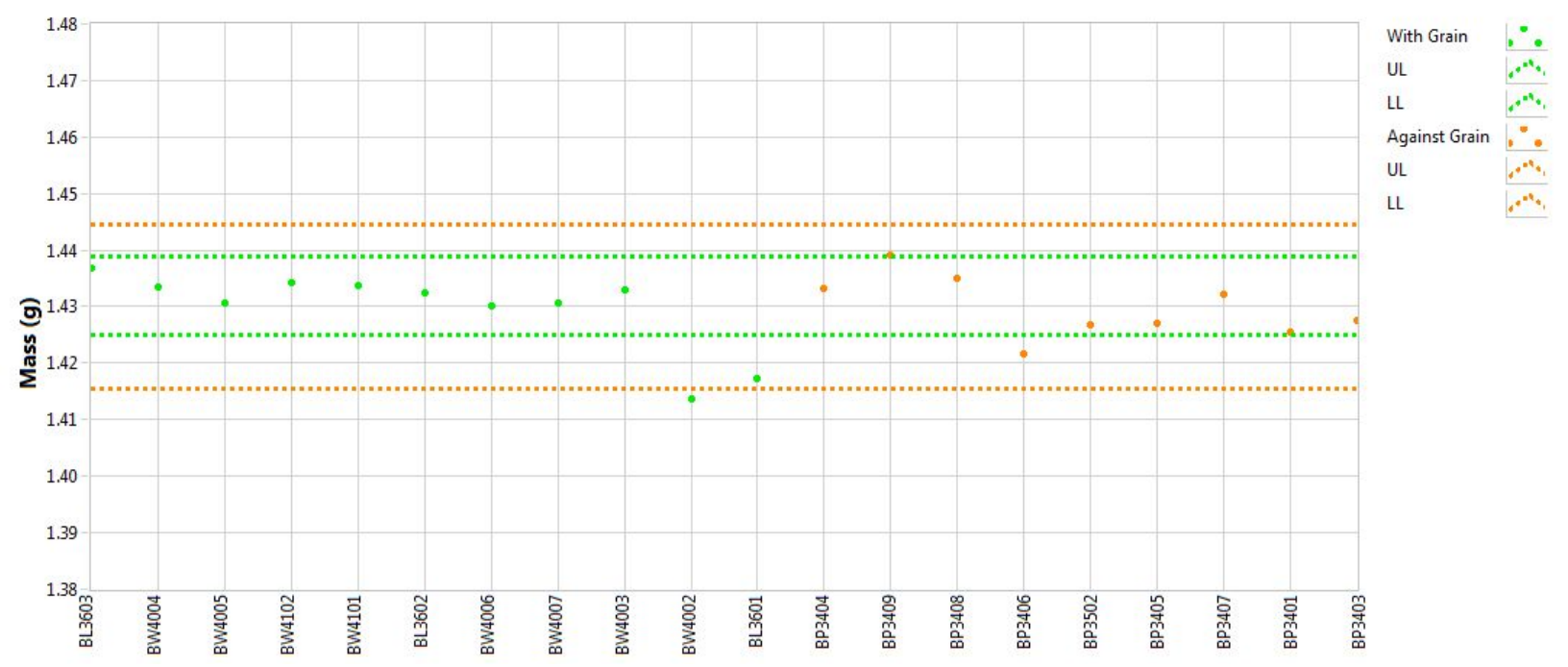

Figure A-37. NBG-18 piggyback mass.

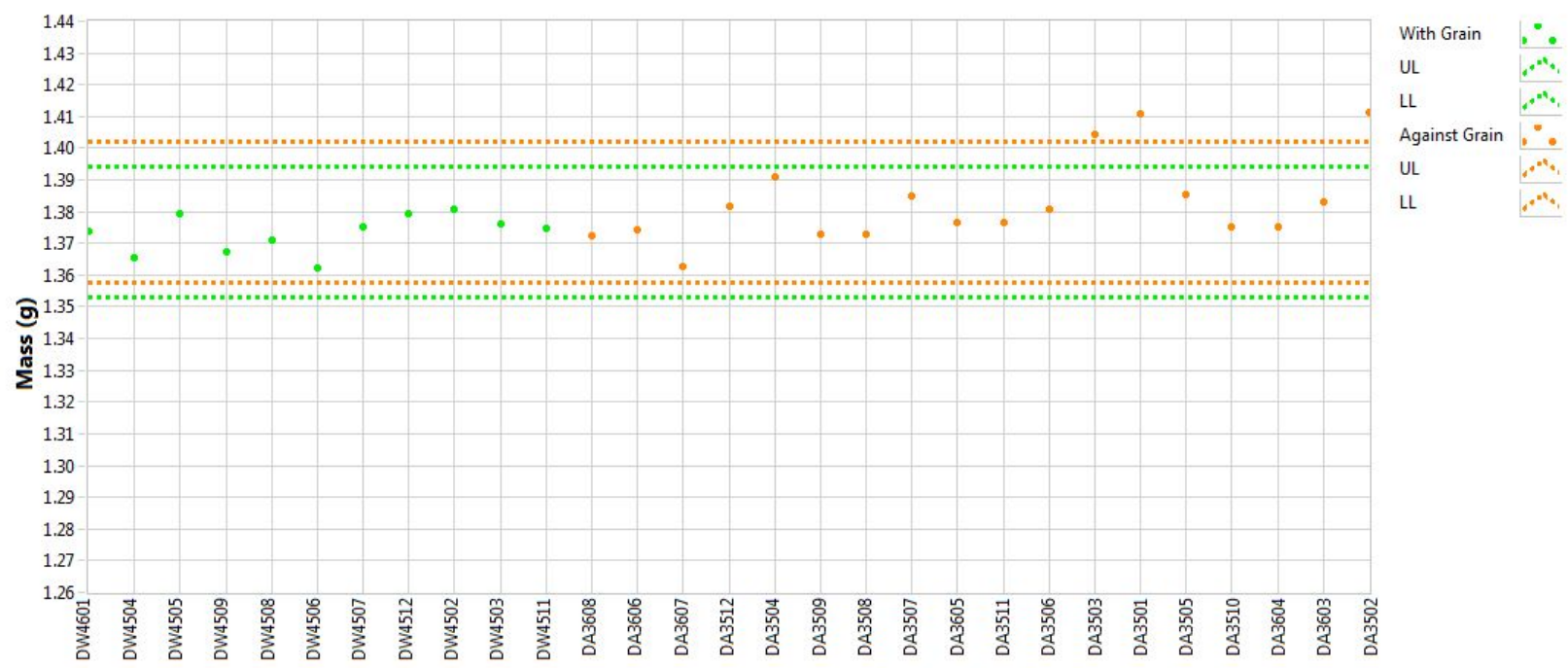

Figure A-38. PCEA piggyback mass. 


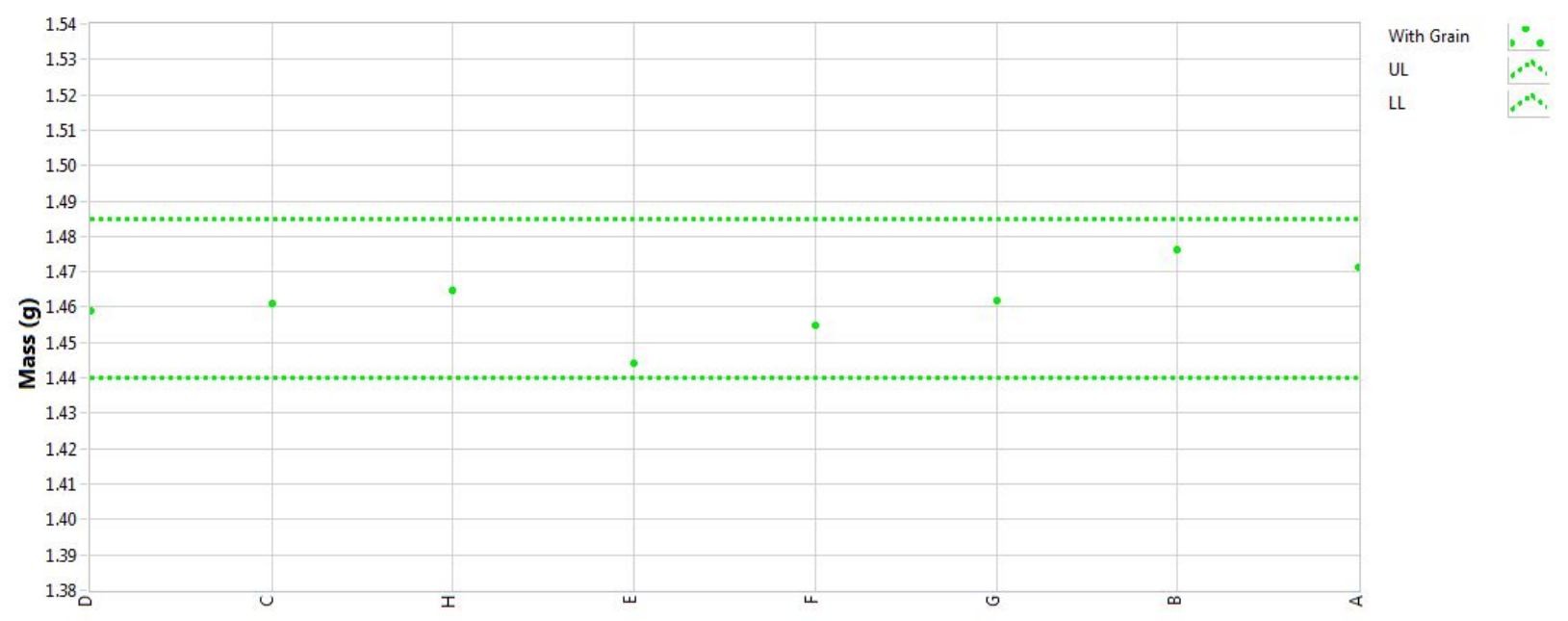

Figure A-39. SGL-SiC piggyback mass.

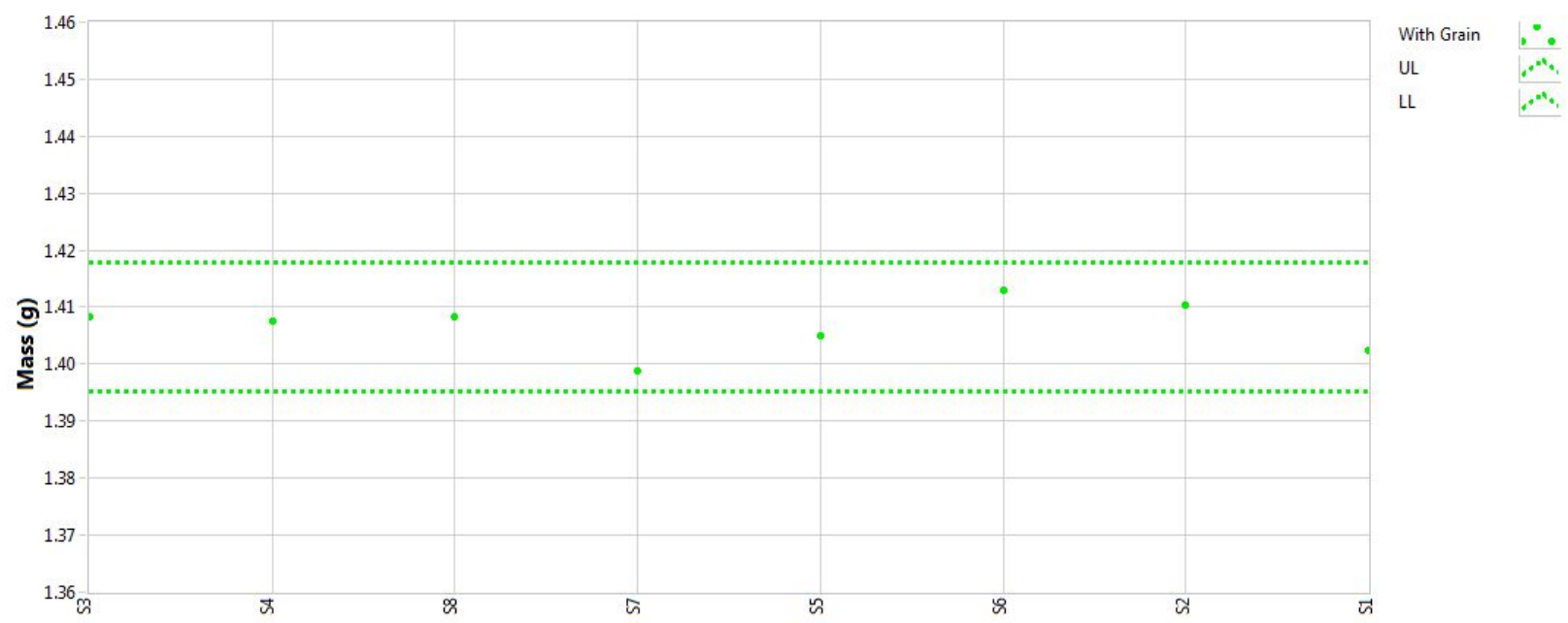

Figure A-40. SGL piggyback mass. 


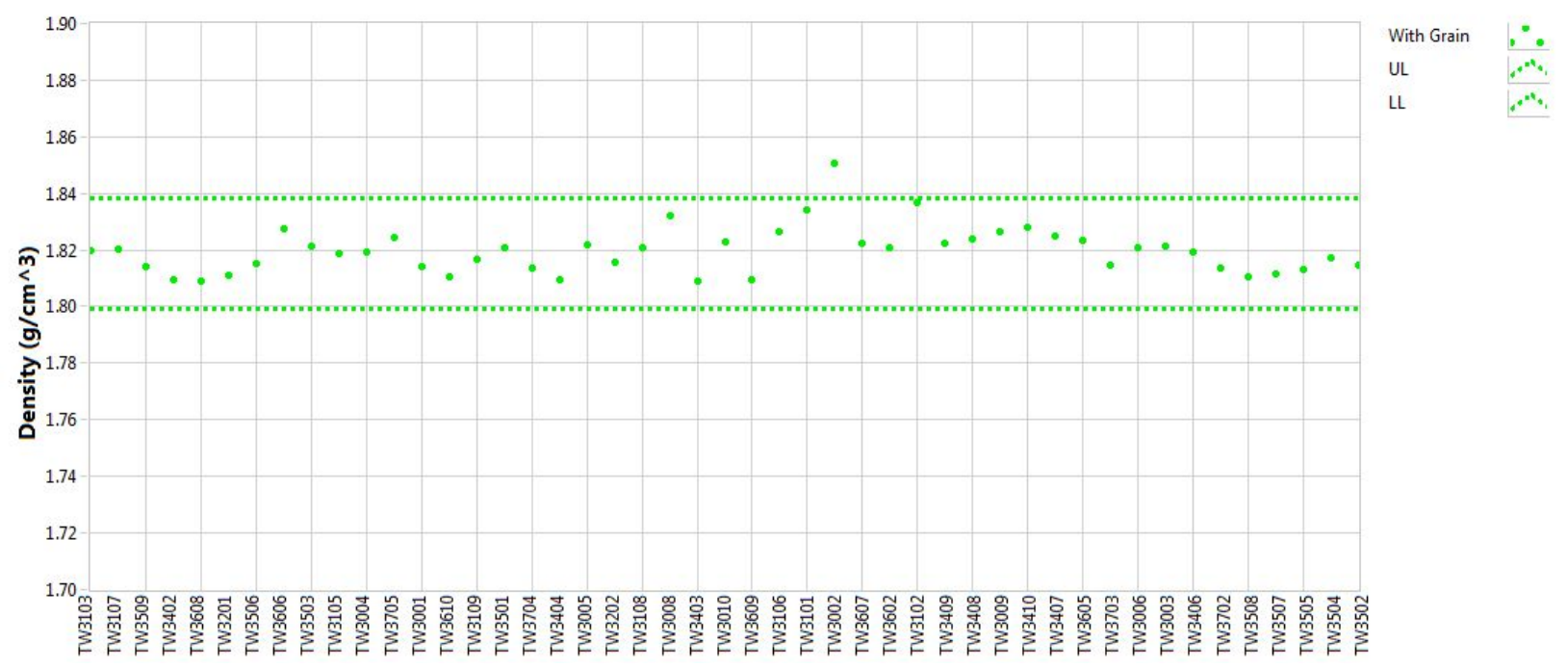

Figure A-41. 2114 creep density.

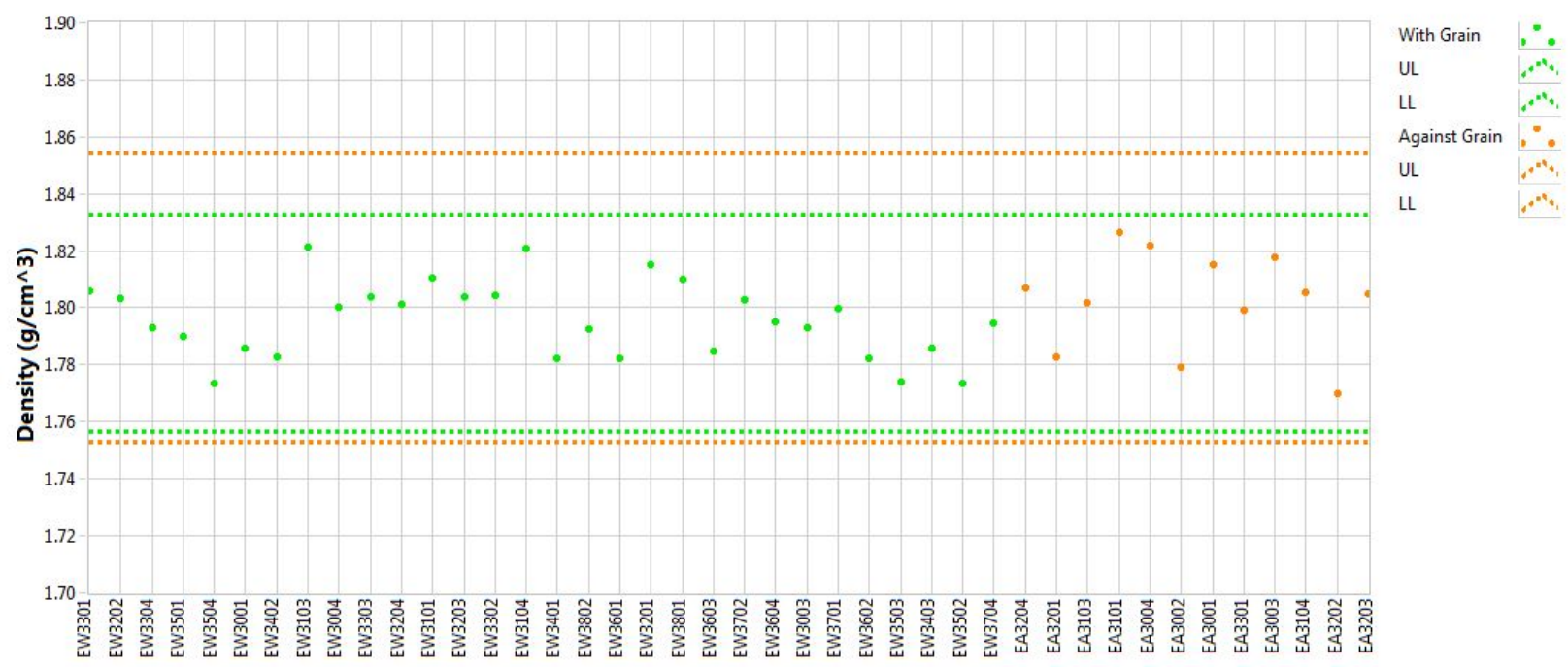

Figure A-42. IG-110 creep density. 


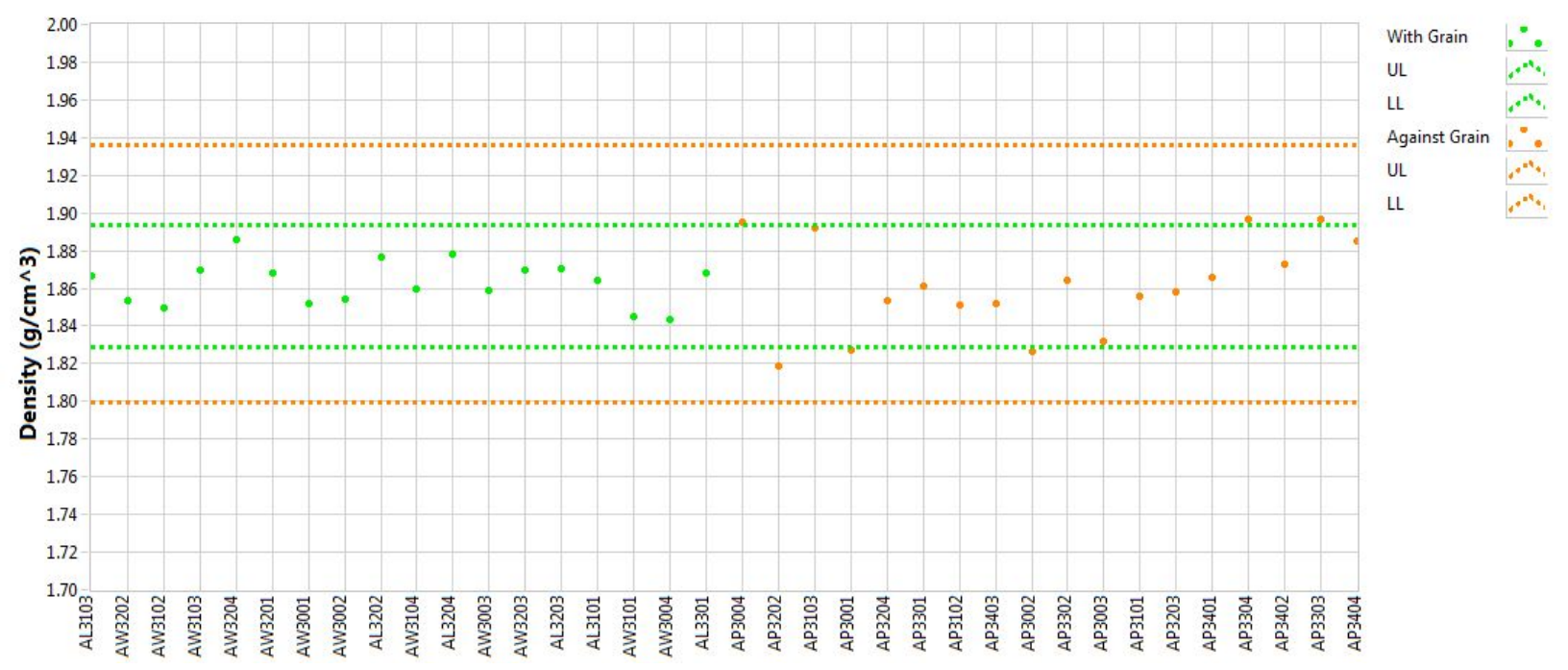

Figure A-43. NBG-17 creep density.

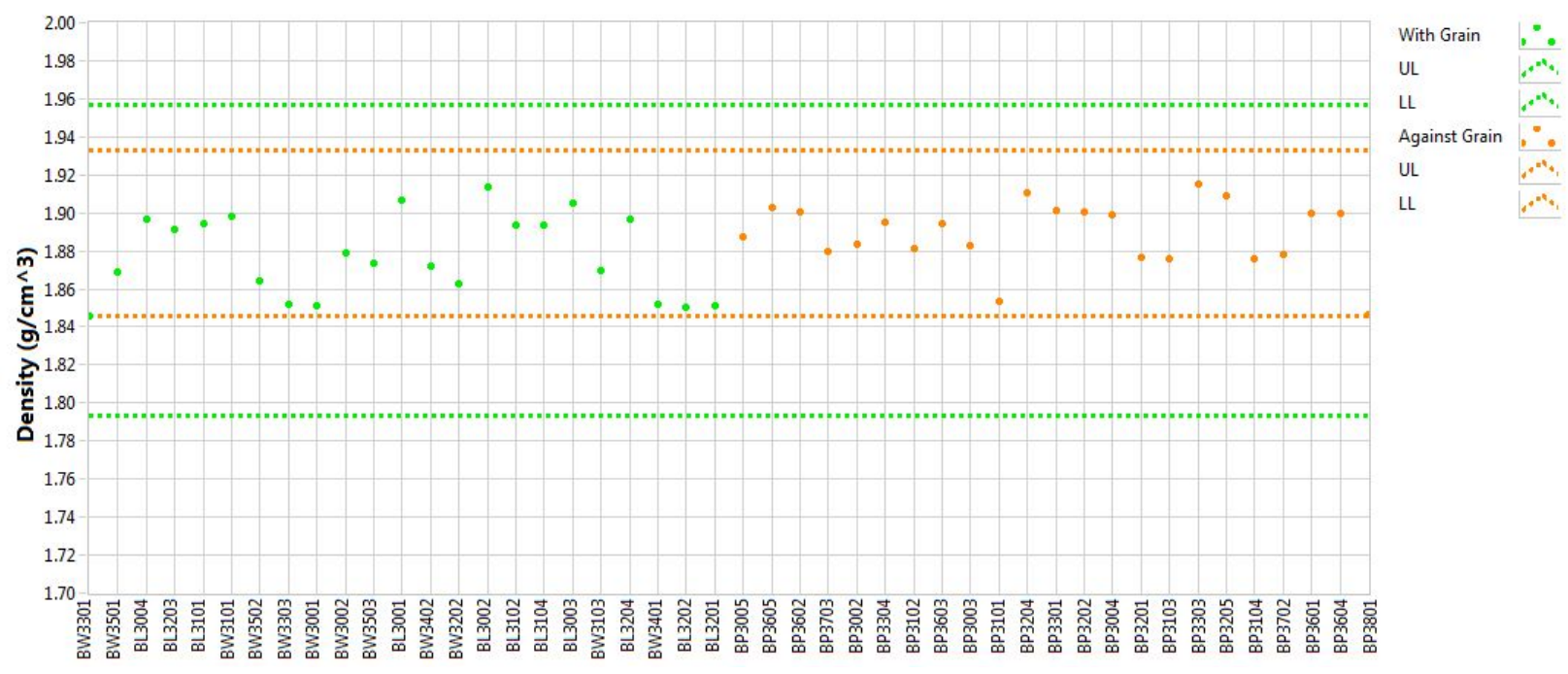

Figure A-44. NBG-18 creep density. 

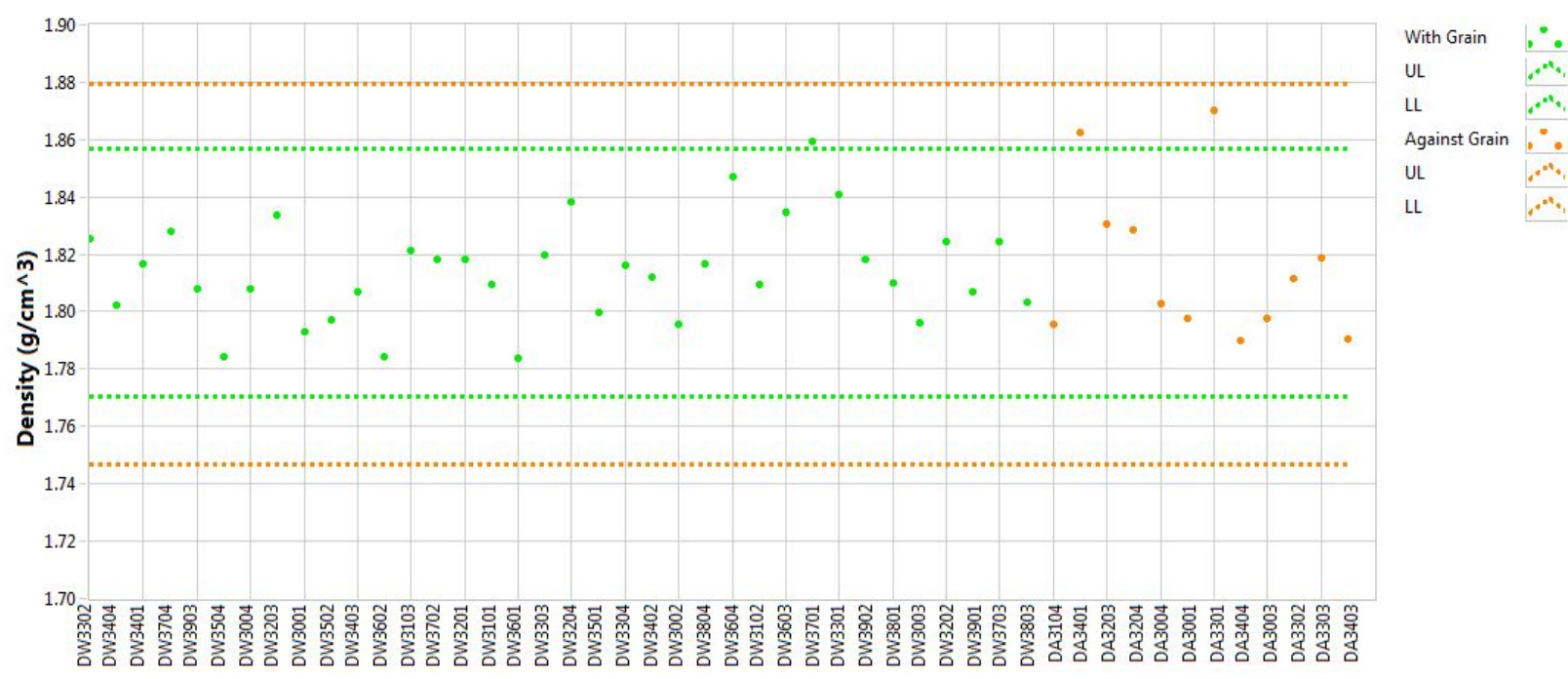

Figure A-45. PCEA creep density.

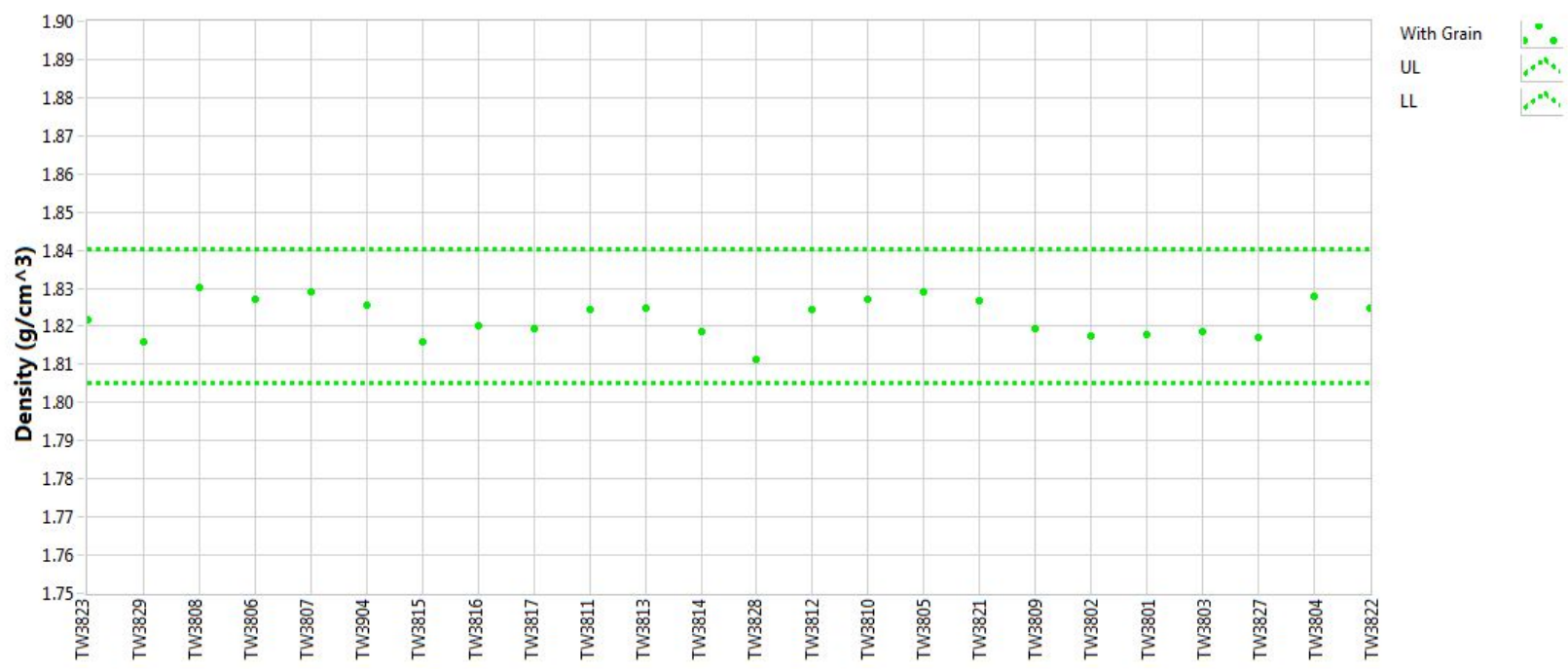

Figure A-46. 2114 piggyback density. 


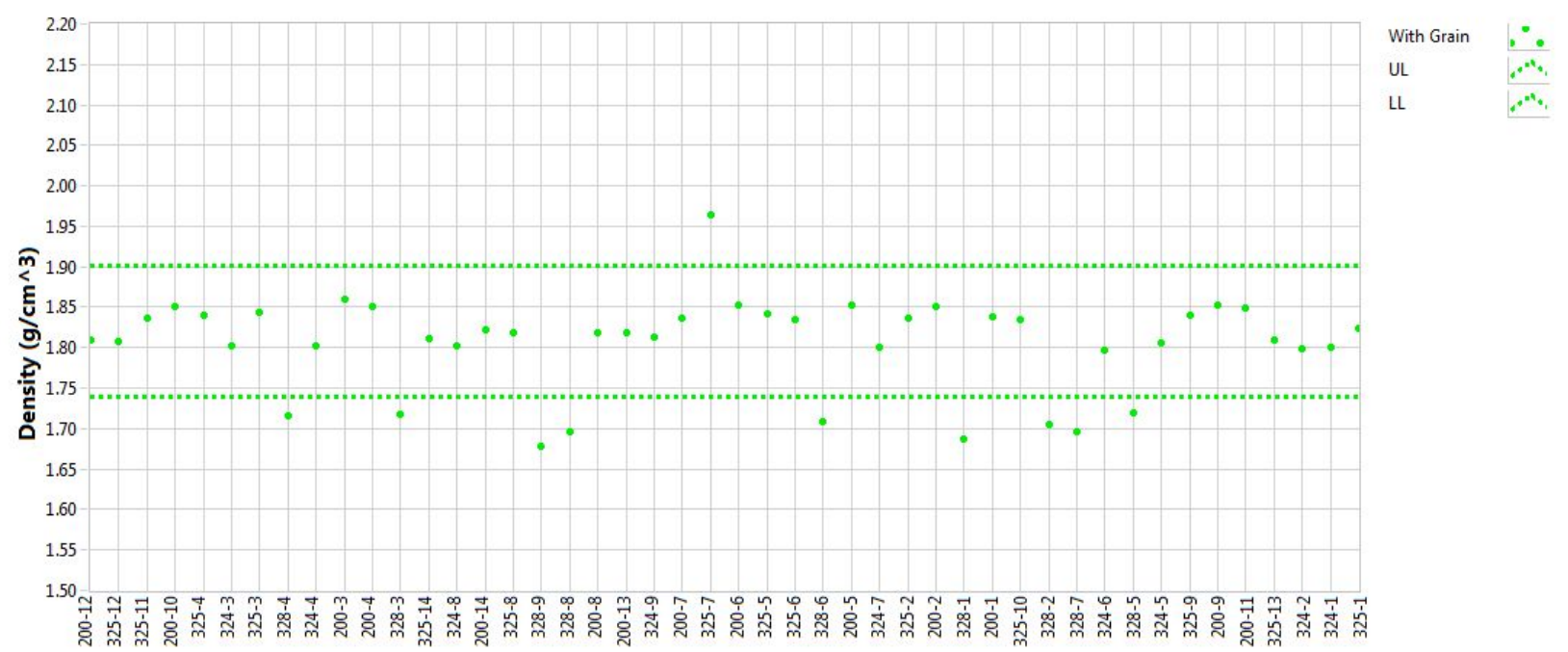

Figure A-47. GrafTech piggyback density.

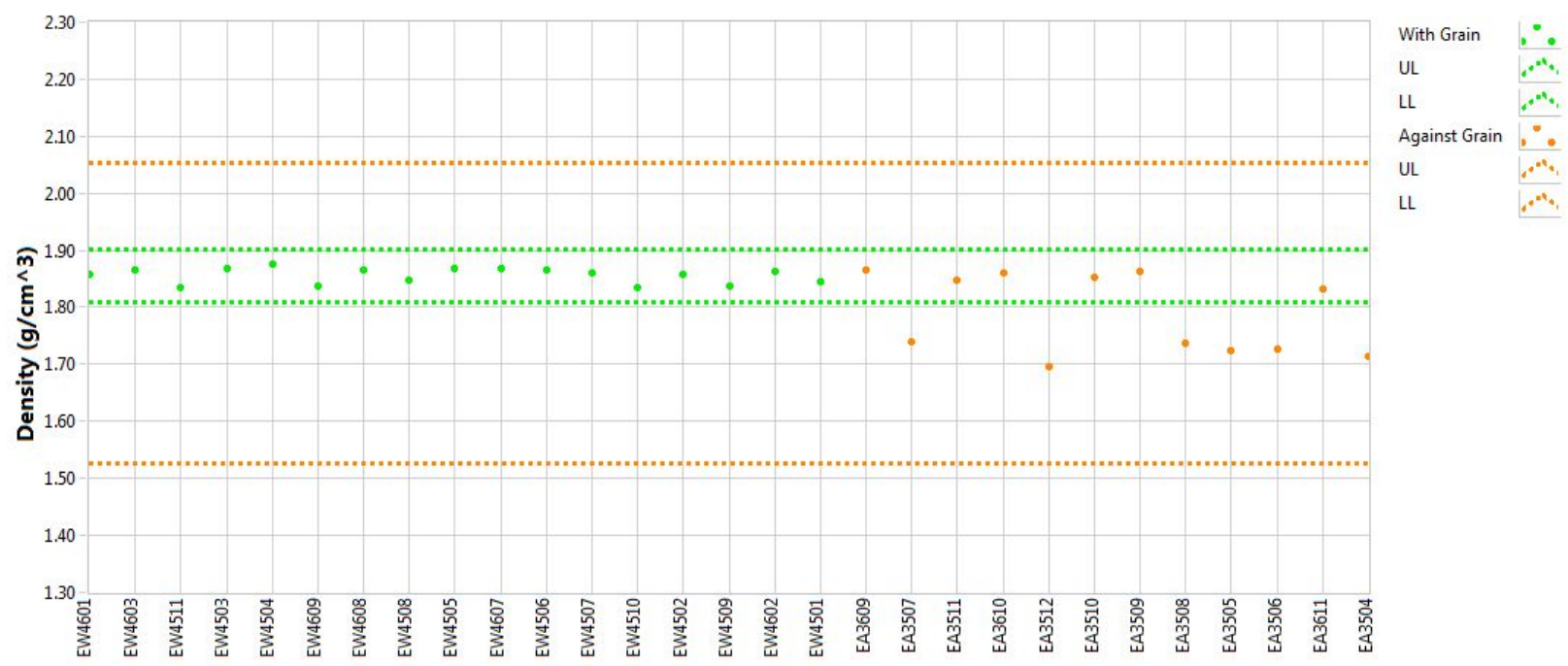

Figure A-48. IG-110 piggyback density. 


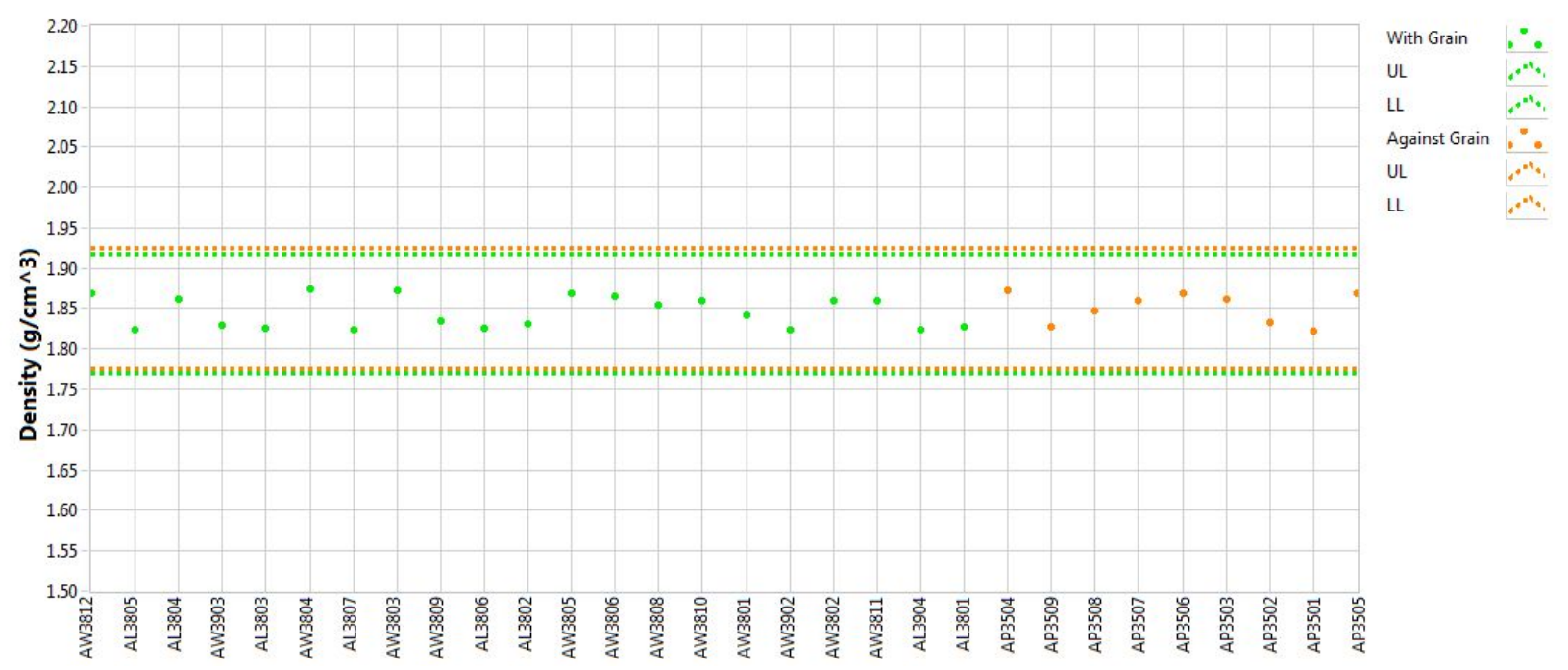

Figure A-49. NBG-17 piggyback density.

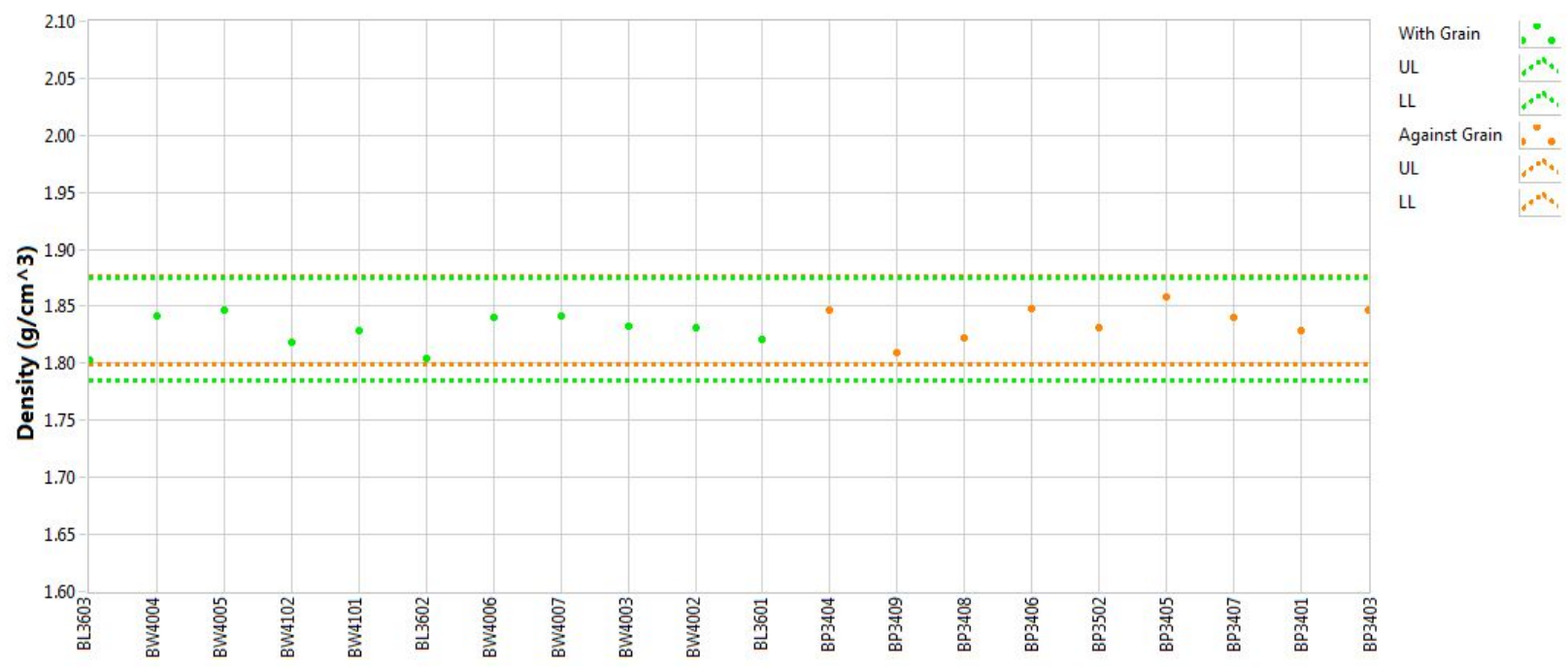

Figure A-50. NBG-18 piggyback density. 


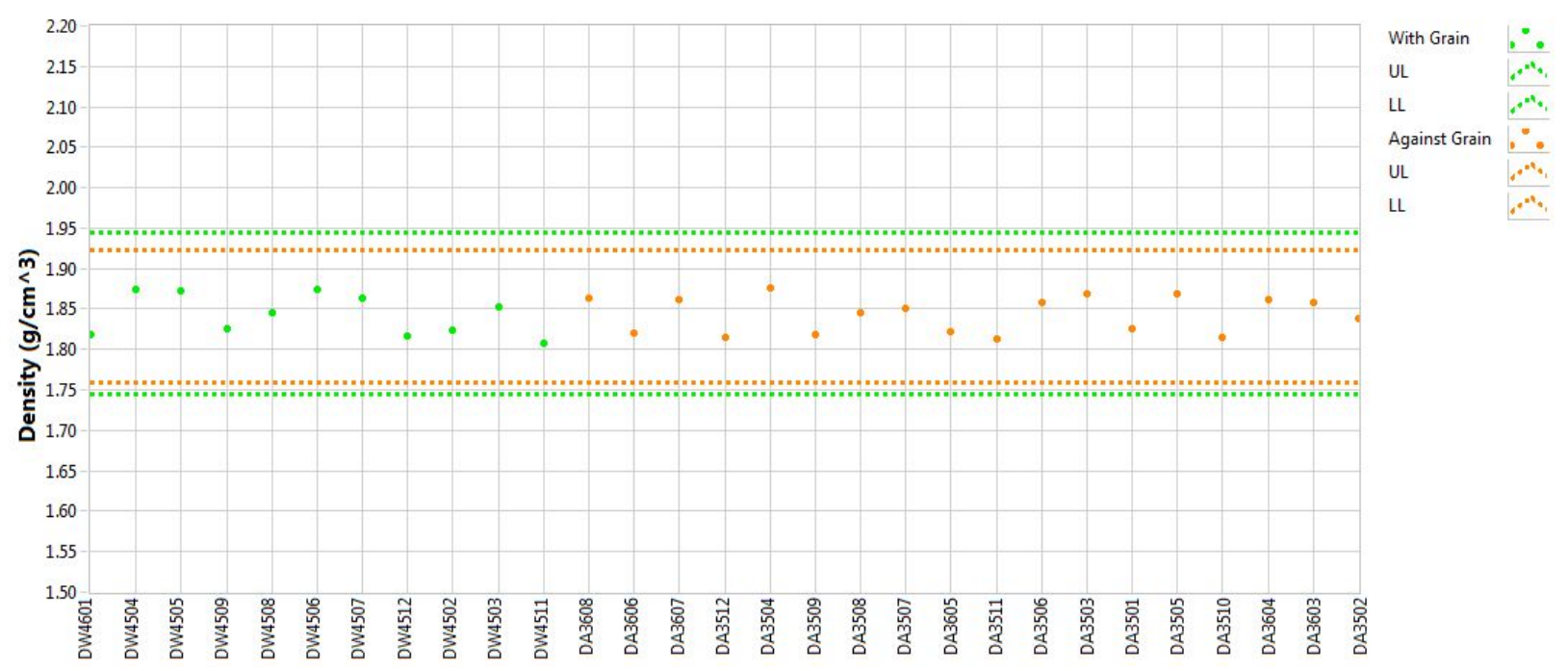

Figure A-51. PCEA piggyback density.

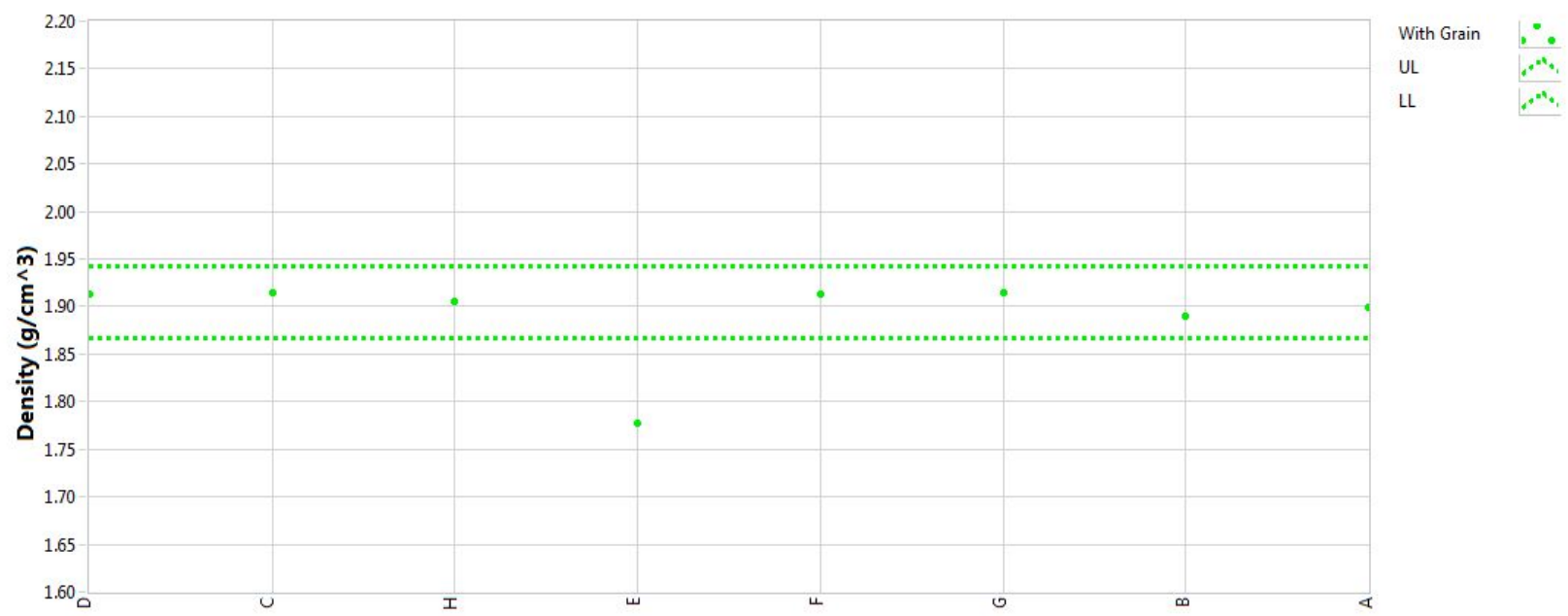

Figure A-52. SGL-SiC piggyback density. 


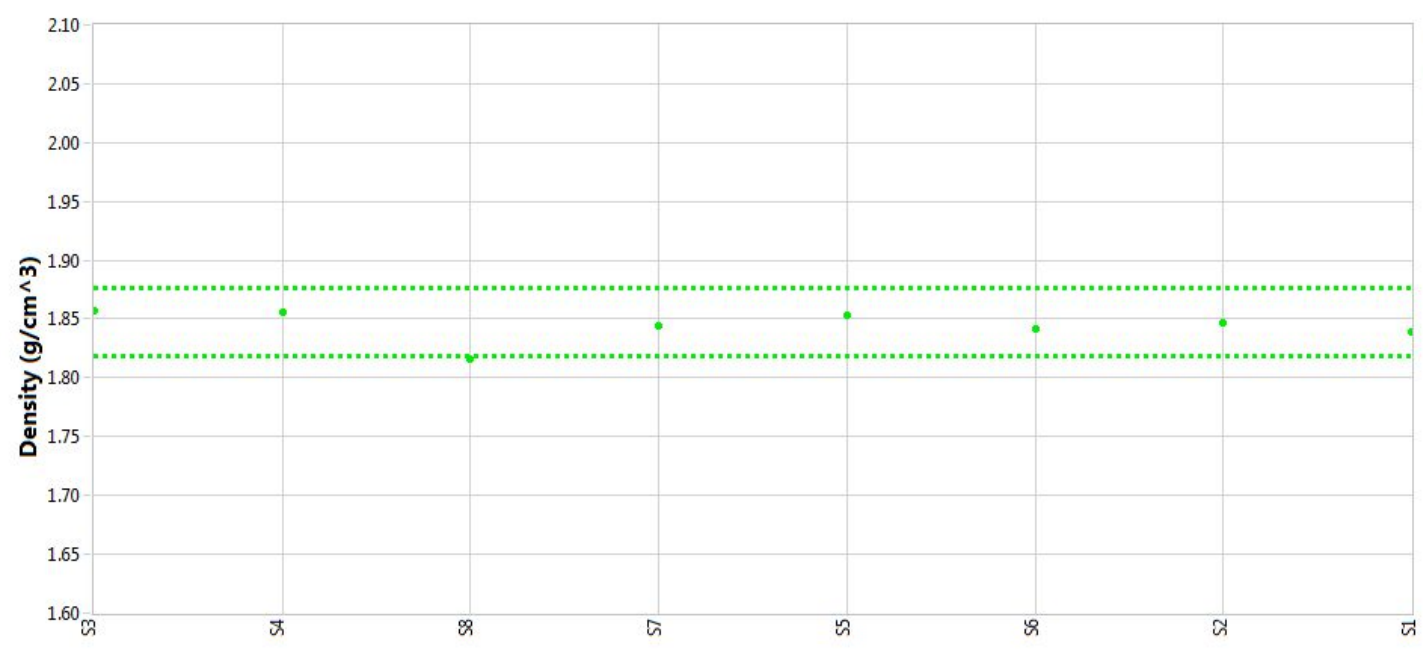

With Grain

Figure A-53. SGL piggyback density.

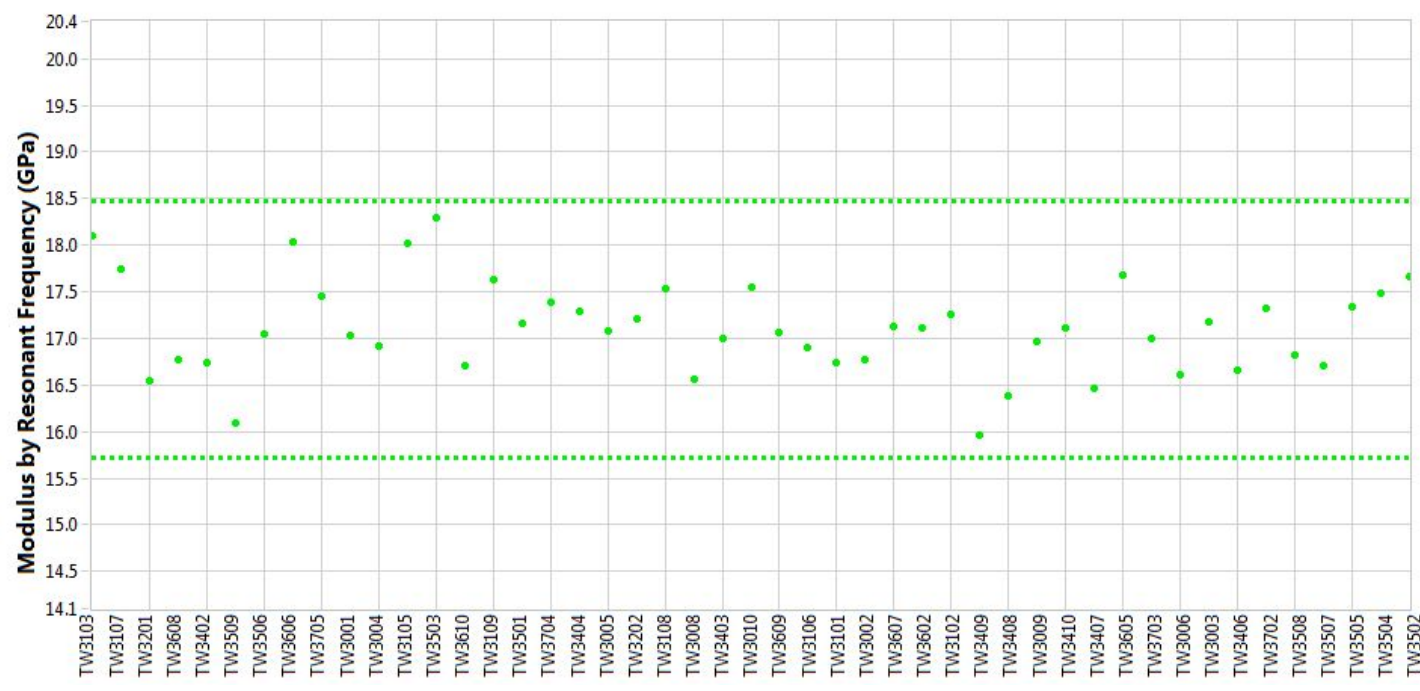

Figure A-54. 2114 creep modulus by resonant frequency. 


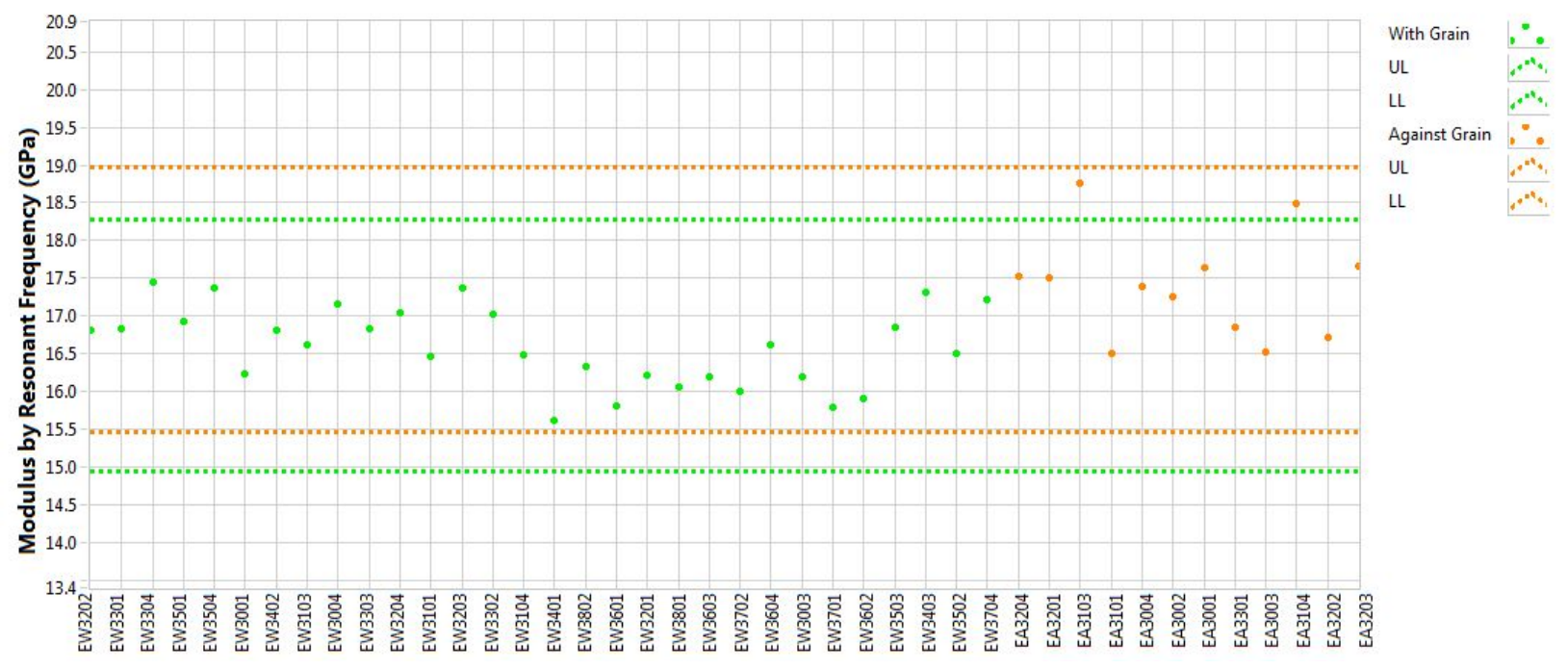

Figure A-55. IG-110 creep modulus by resonant frequency.

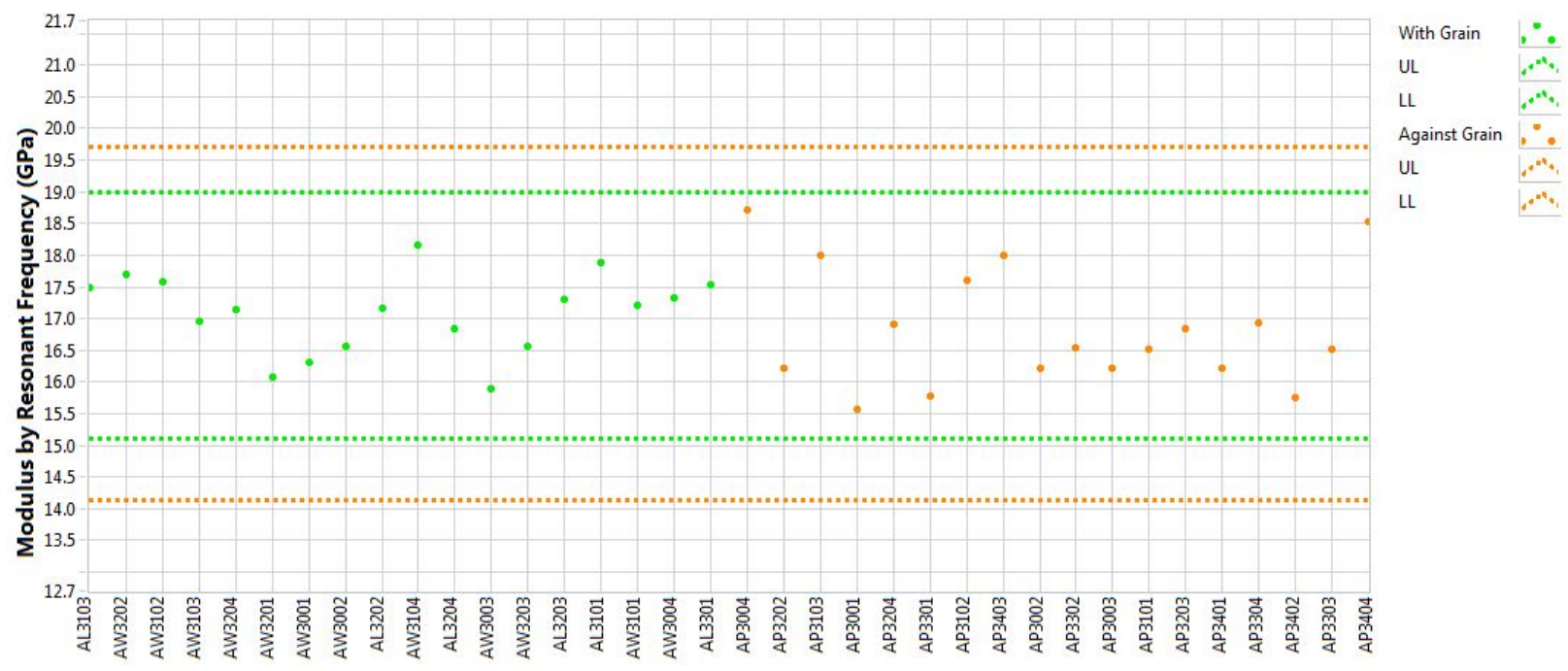

Figure A-56. NBG-17 creep modulus by resonant frequency. 


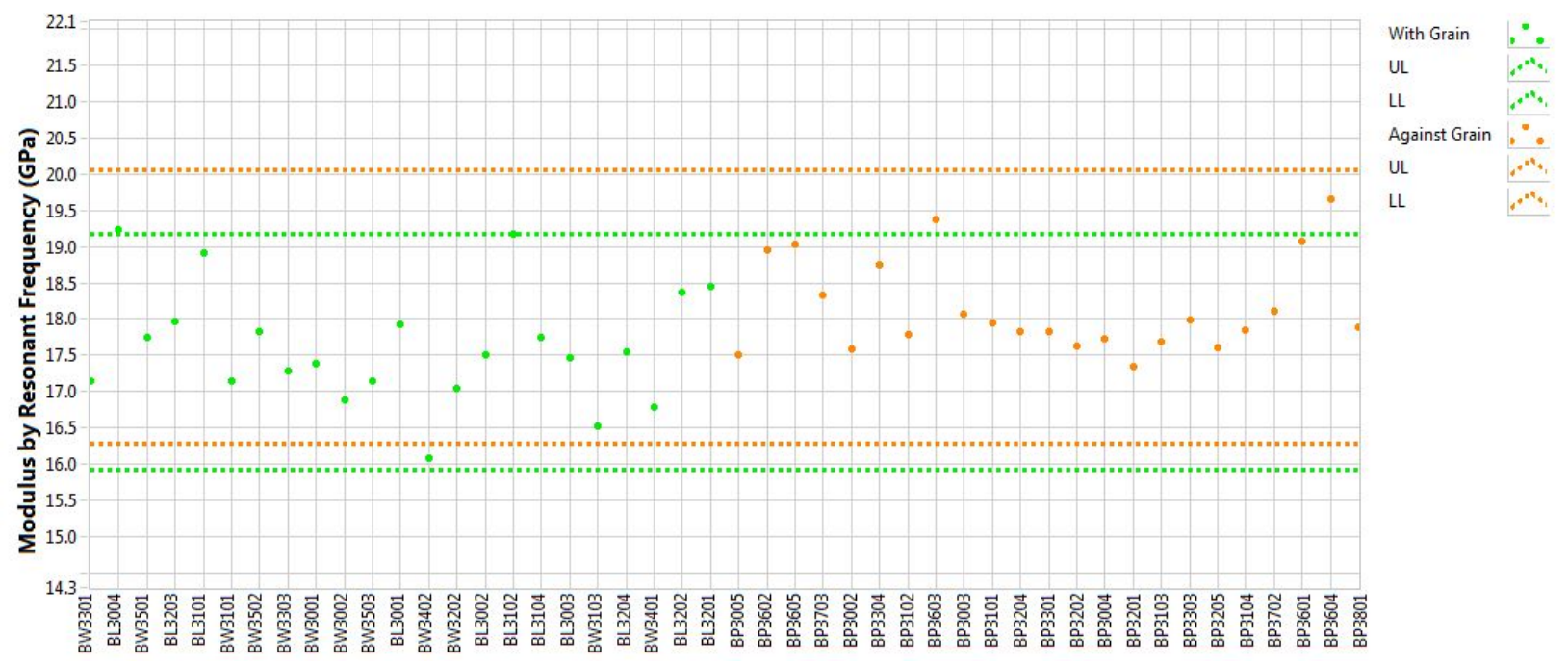

Figure A-57. NBG-18 creep modulus by resonant frequency.

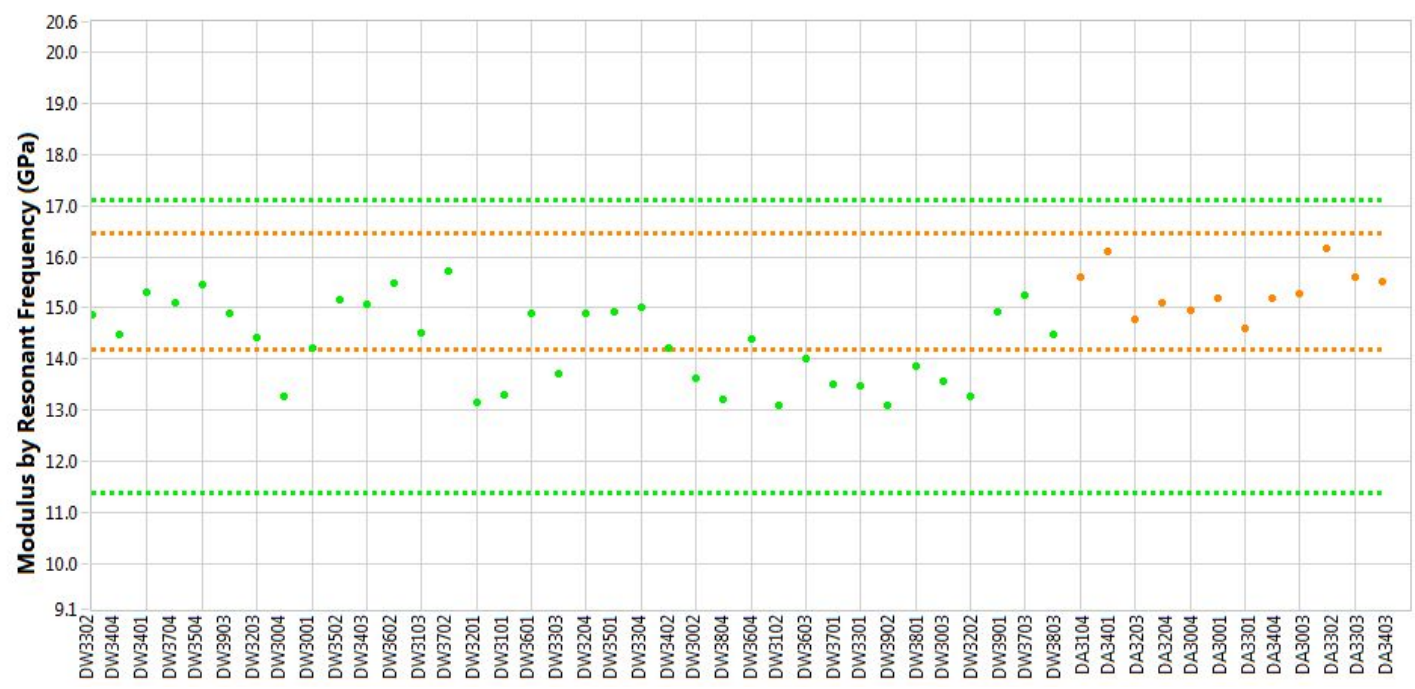

Figure A-58. PCEA creep modulus by resonant frequency. 

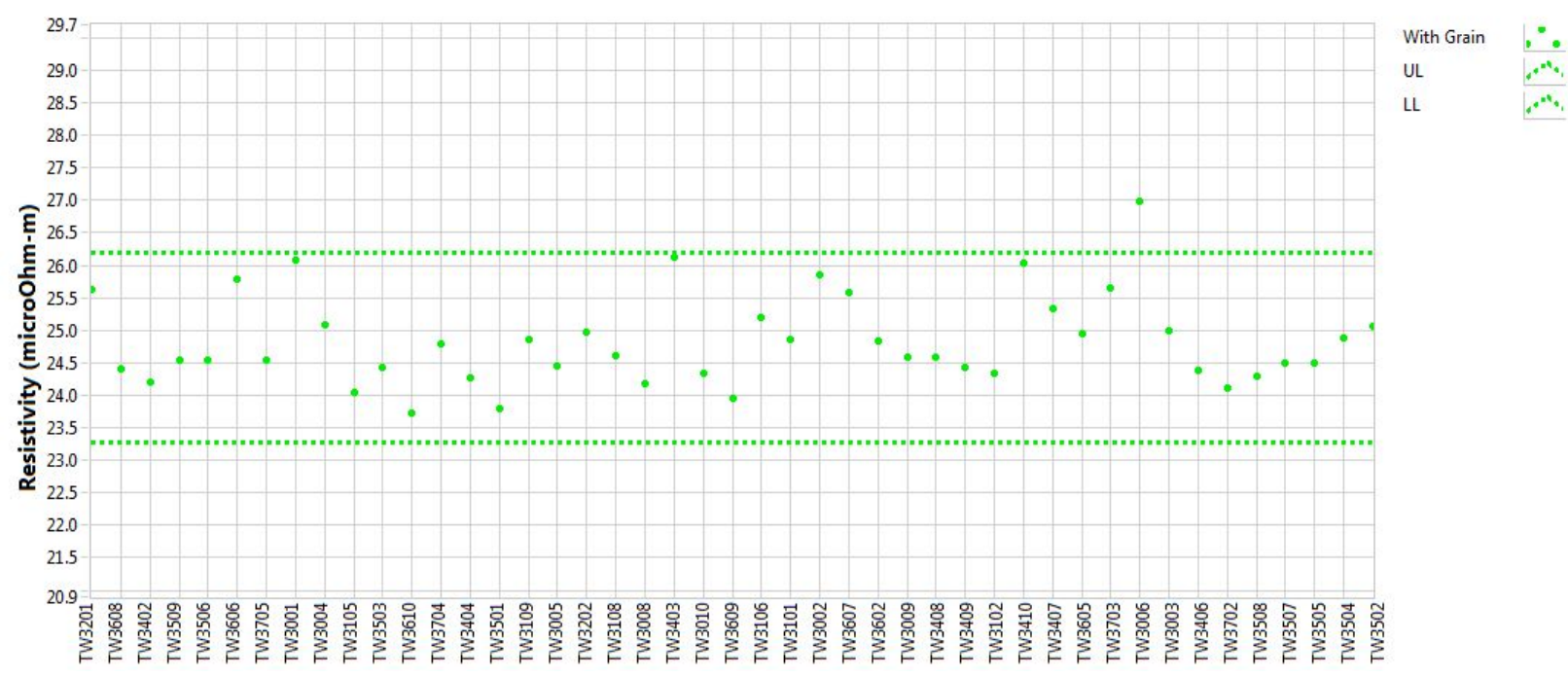

Figure A-59. 2114 creep resistivity.

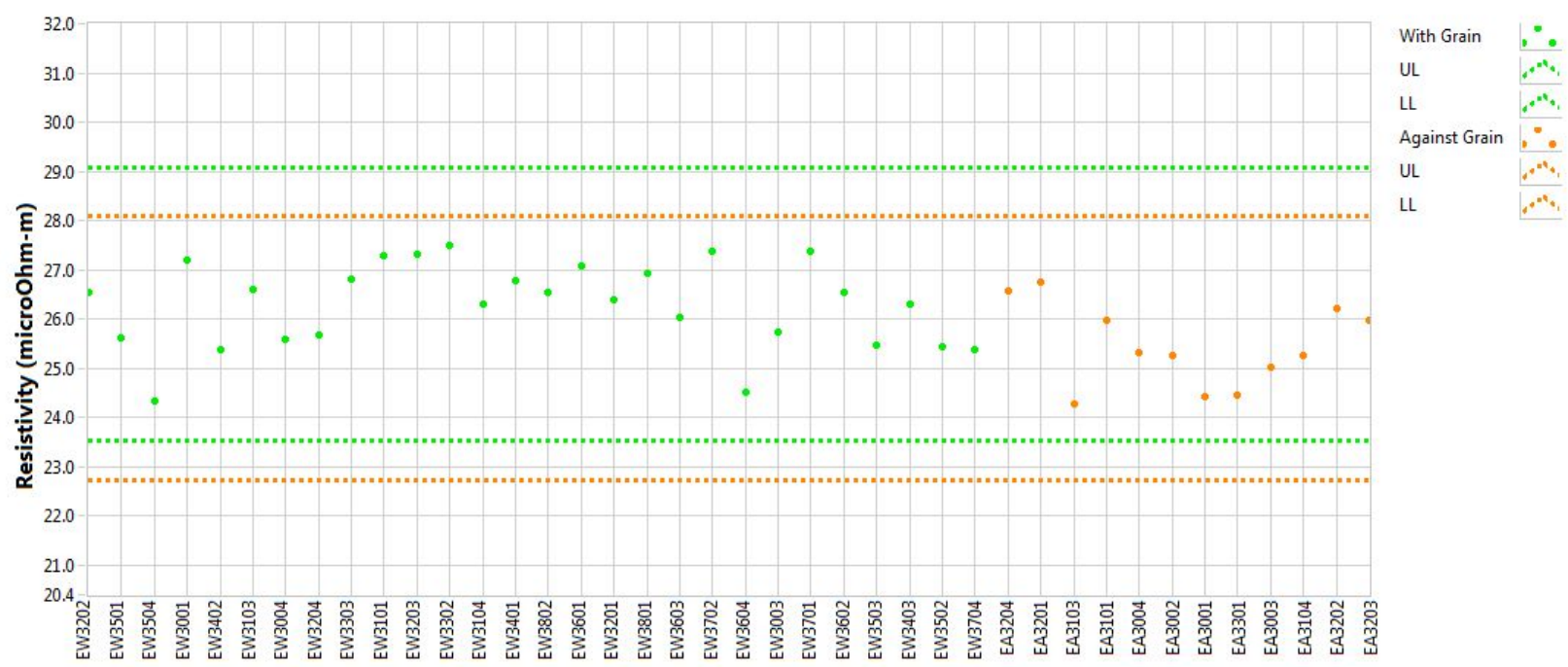

Figure A-60. IG-110 creep resistivity. 


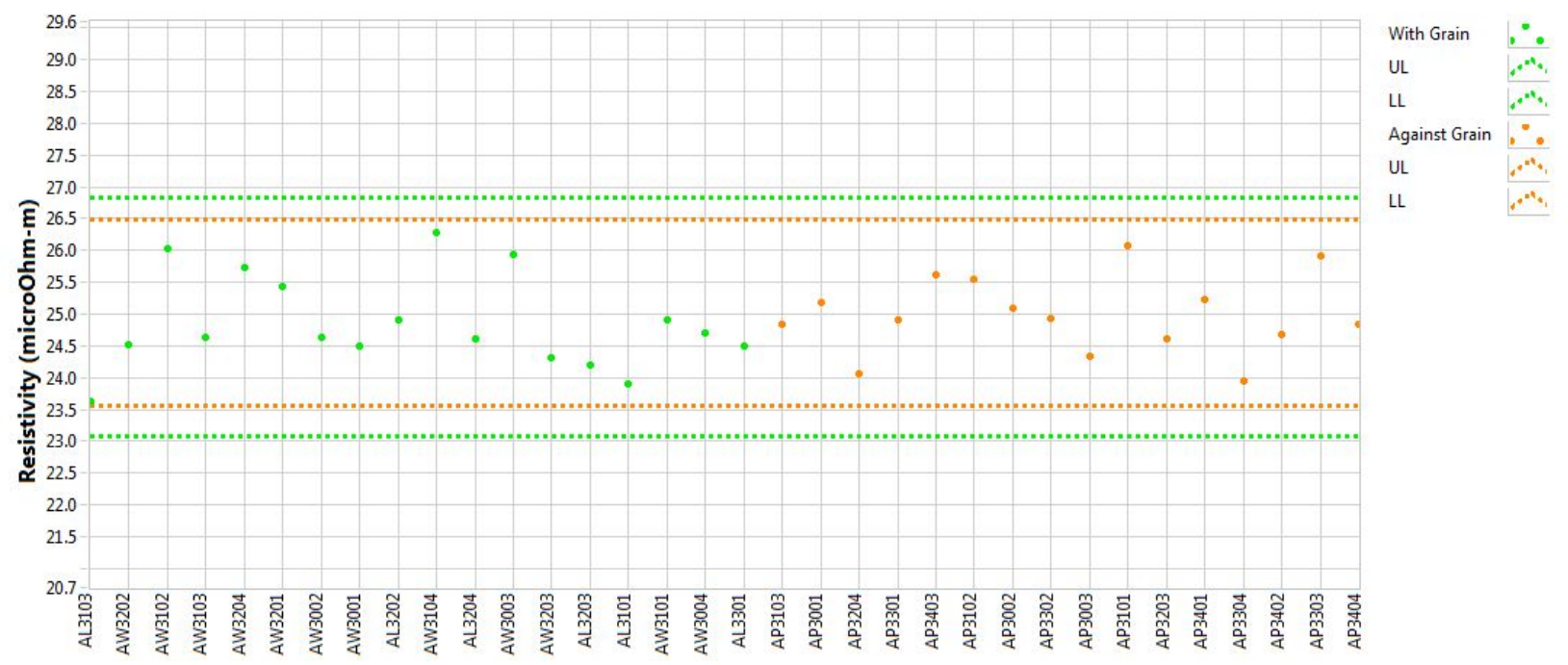

Figure A-61. NBG-17 creep resistivity.

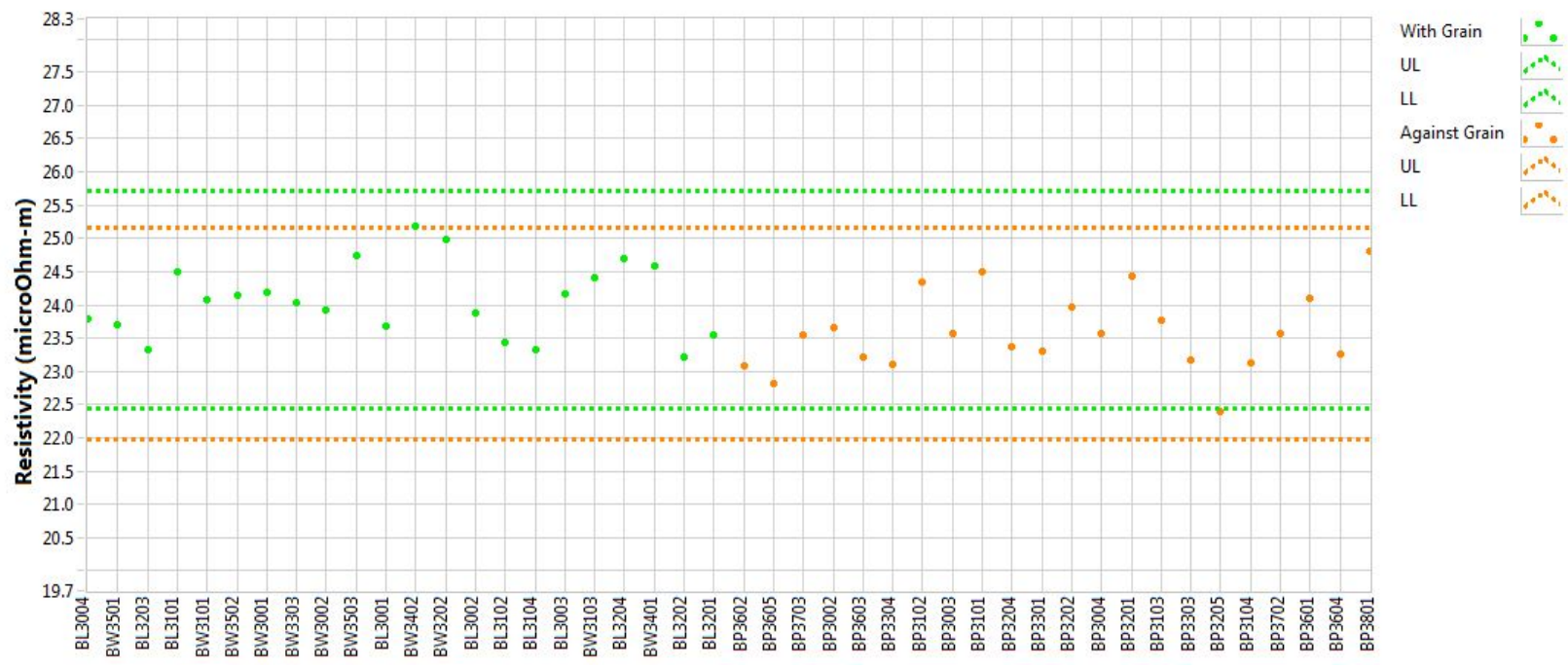

Figure A-62. NBG-18 creep resistivity. 


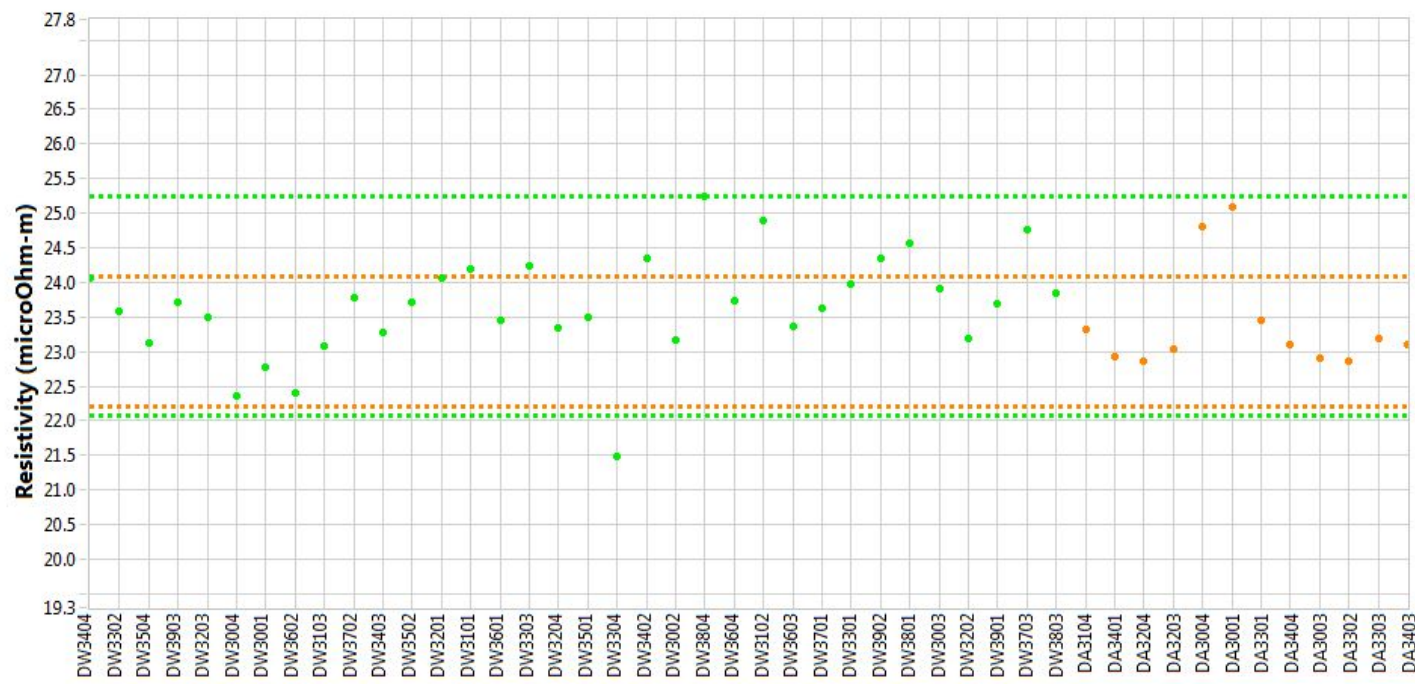

$\begin{array}{l:l}\text { With Grain } & \\ \text { UL } & \\ \text { LL } & \\ \text { Against Grain } \\ \text { UL }\end{array}$

Figure A-63. PCEA creep resistivity.

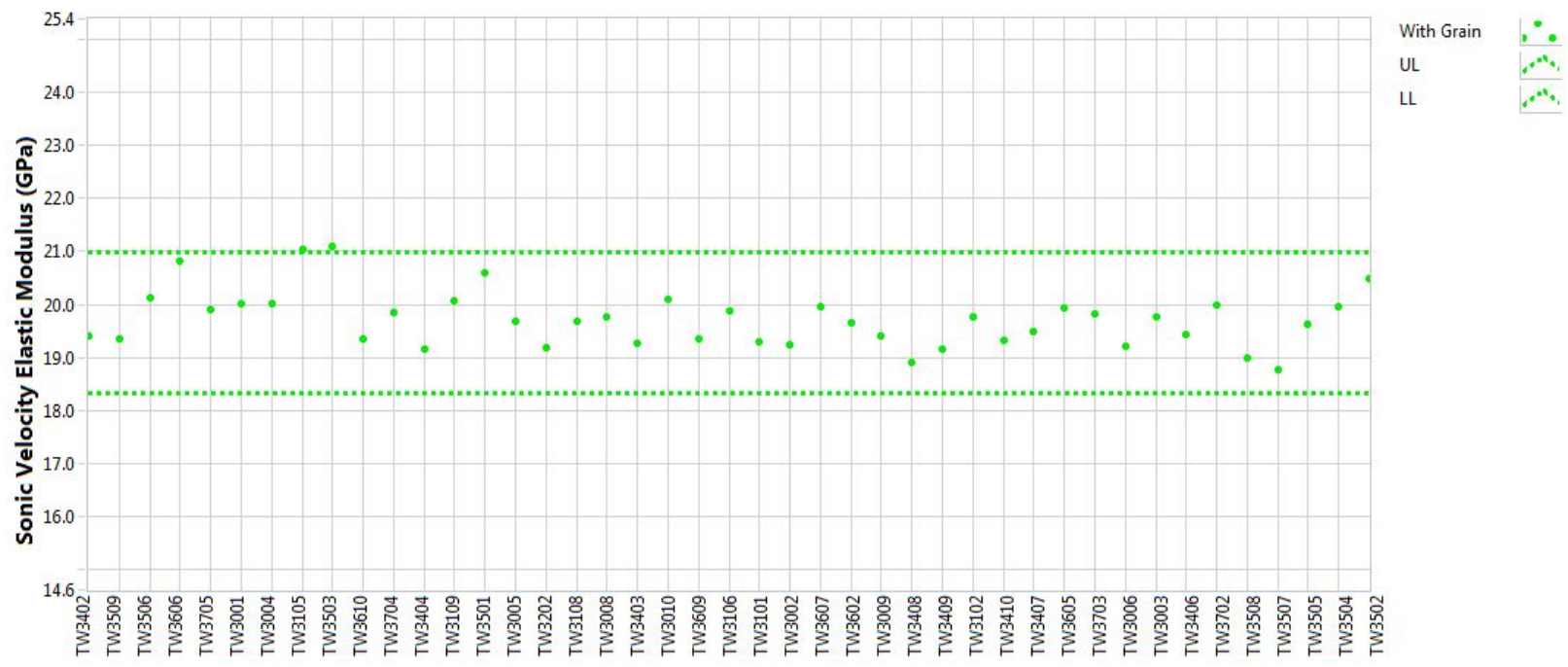

Figure A-64. 2114 creep modulus by sonic velocity. 


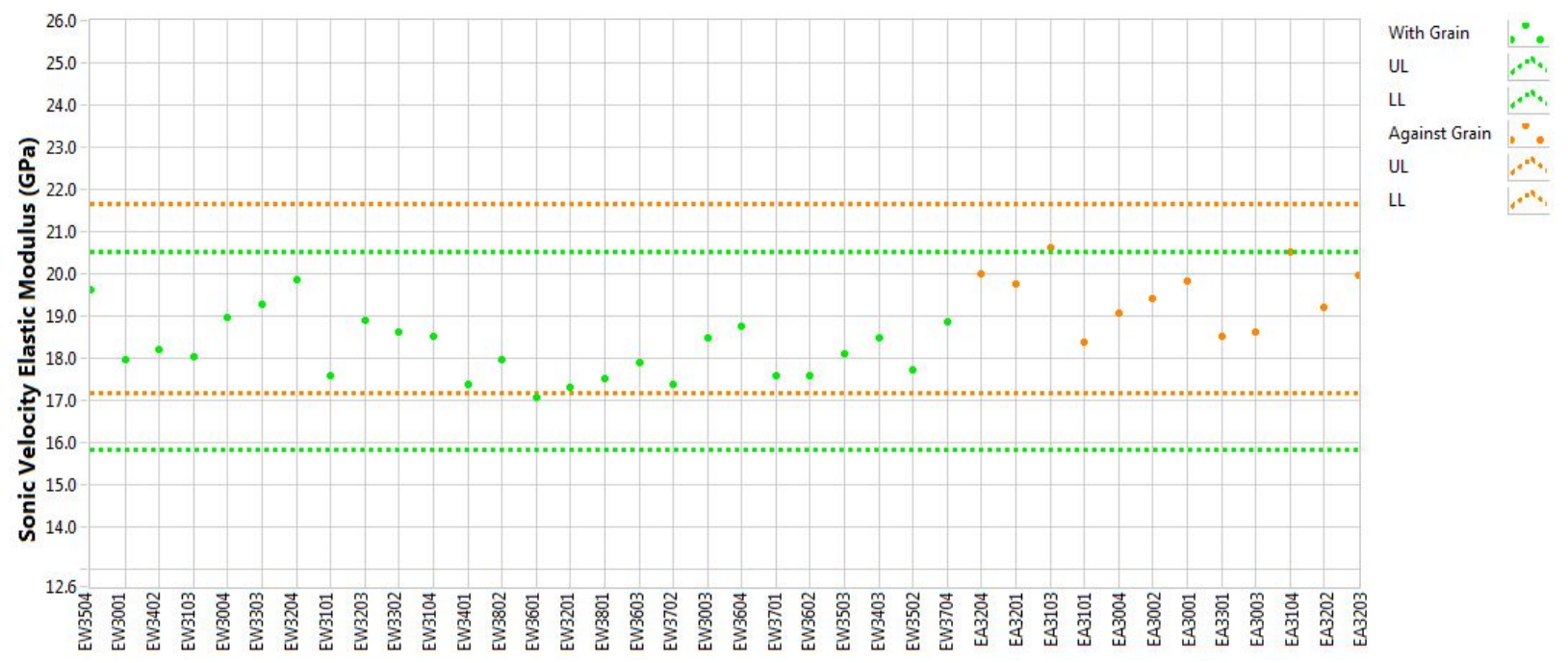

Figure A-65. IG-110 creep modulus by sonic velocity.

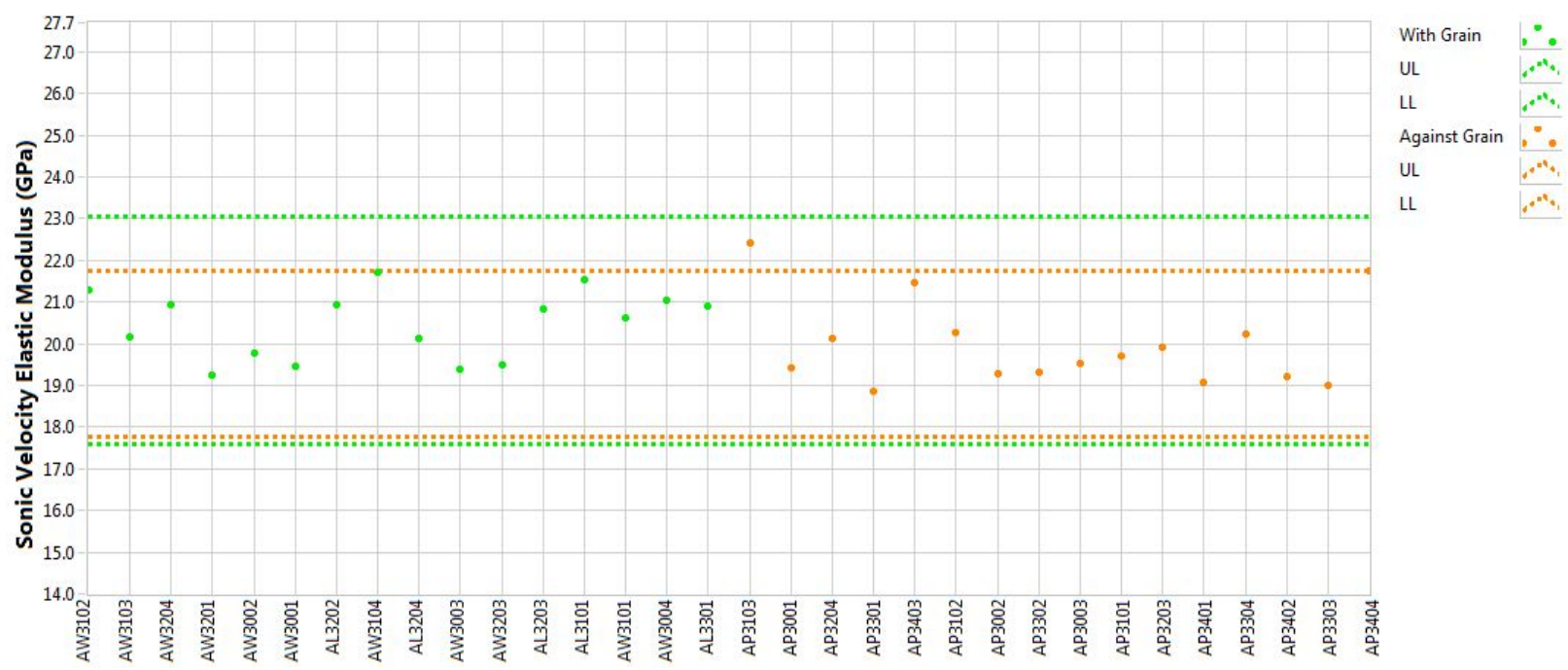

Figure A-66. NBG-17 creep modulus by sonic velocity. 


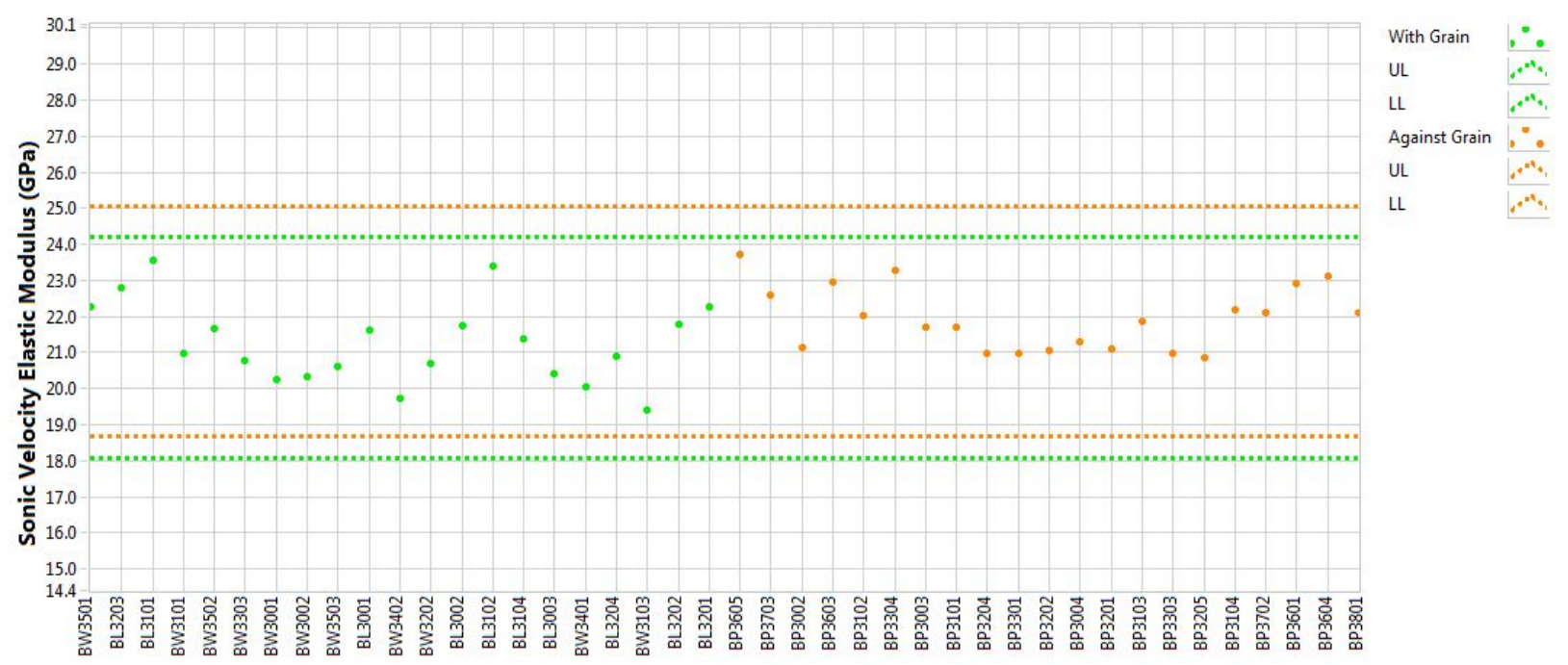

Figure A-67. NBG-18 creep modulus by sonic velocity.

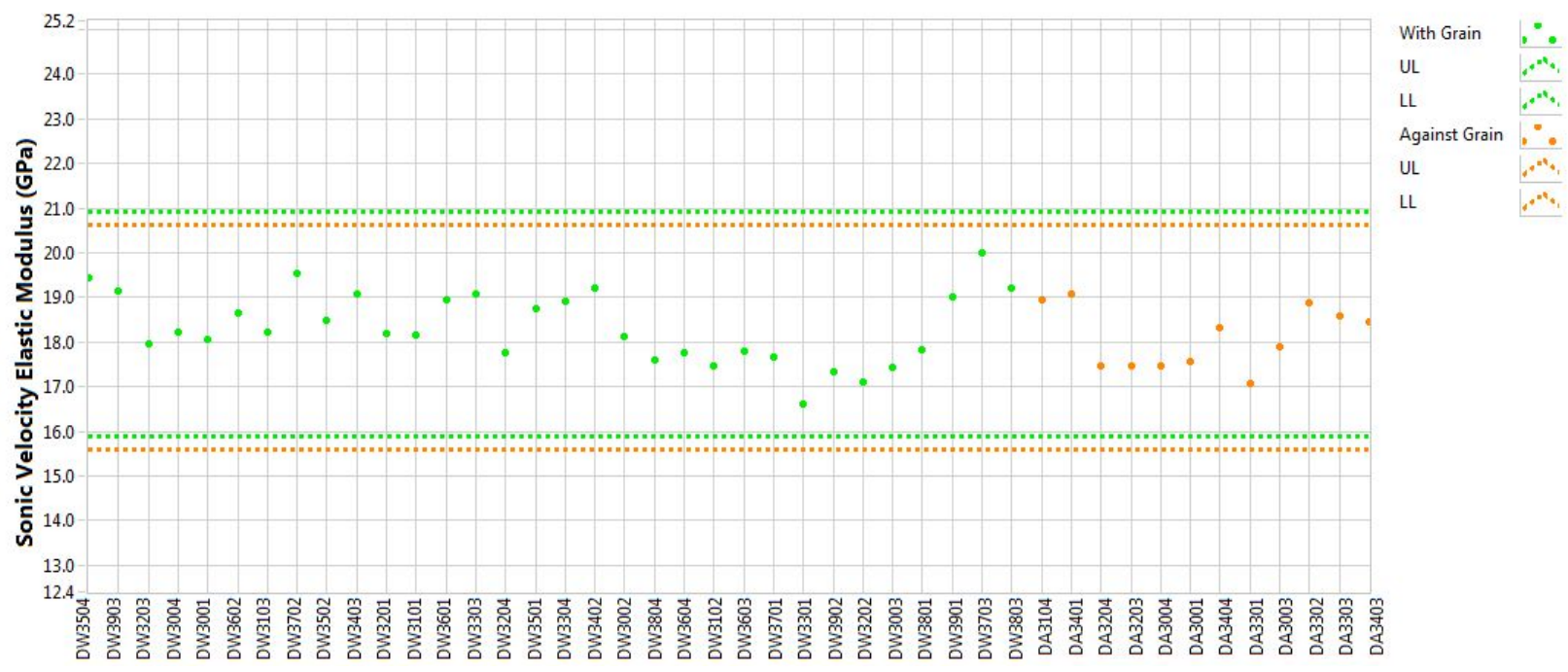

Figure A-68. PCEA creep modulus by sonic velocity. 


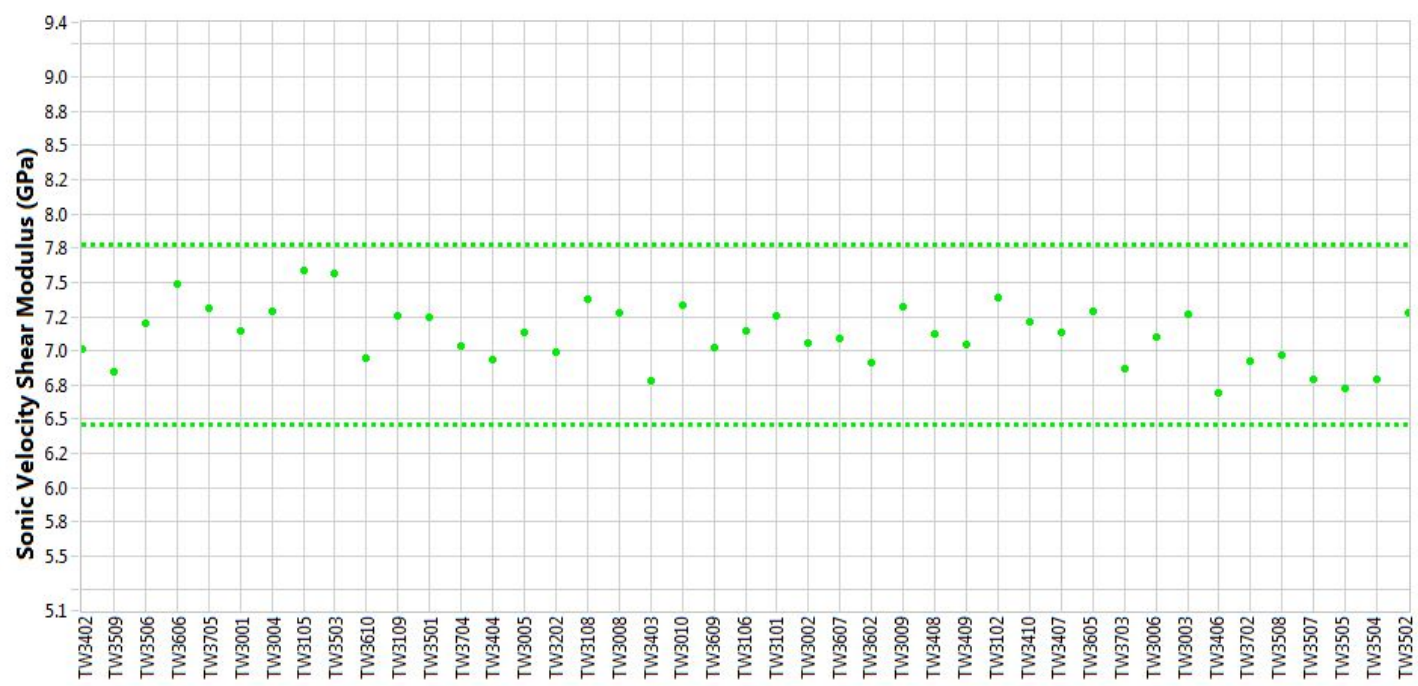

Figure A-69. 2114 creep shear modulus by sonic velocity.

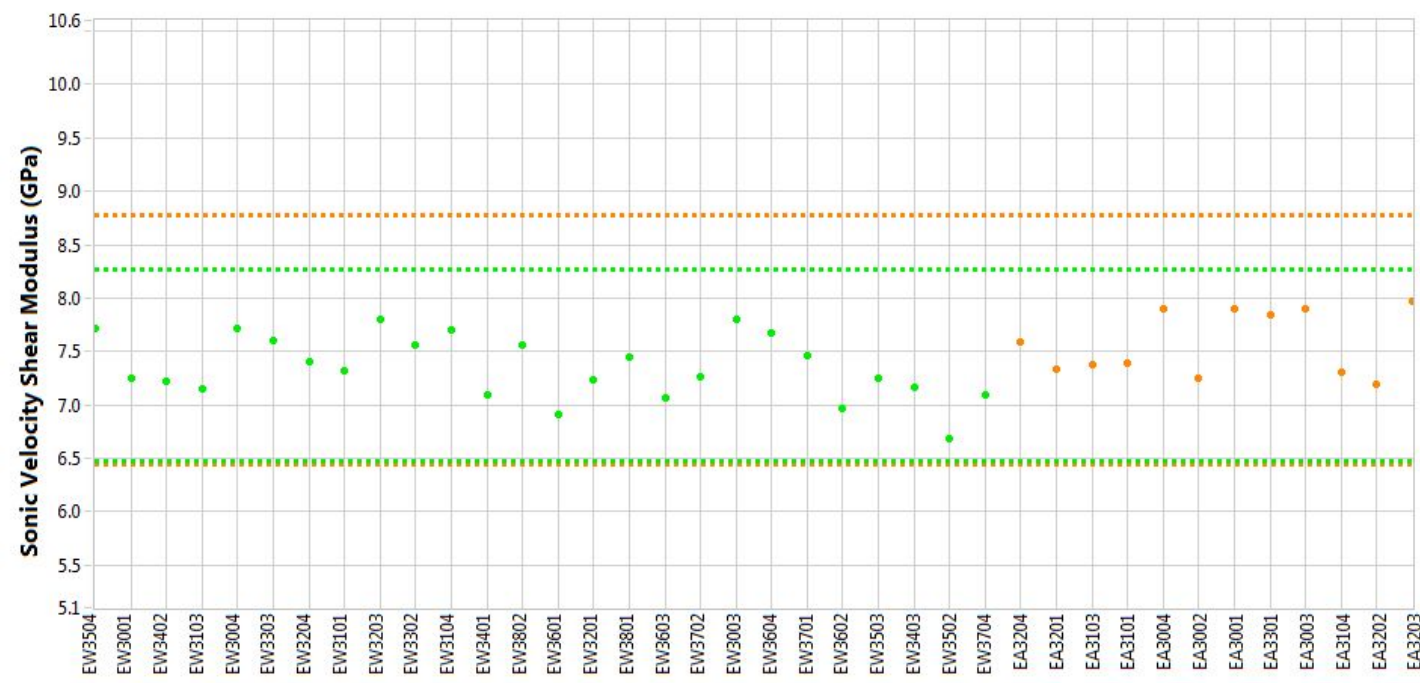

Figure A-70. IG-110 creep shear modulus by sonic velocity. 


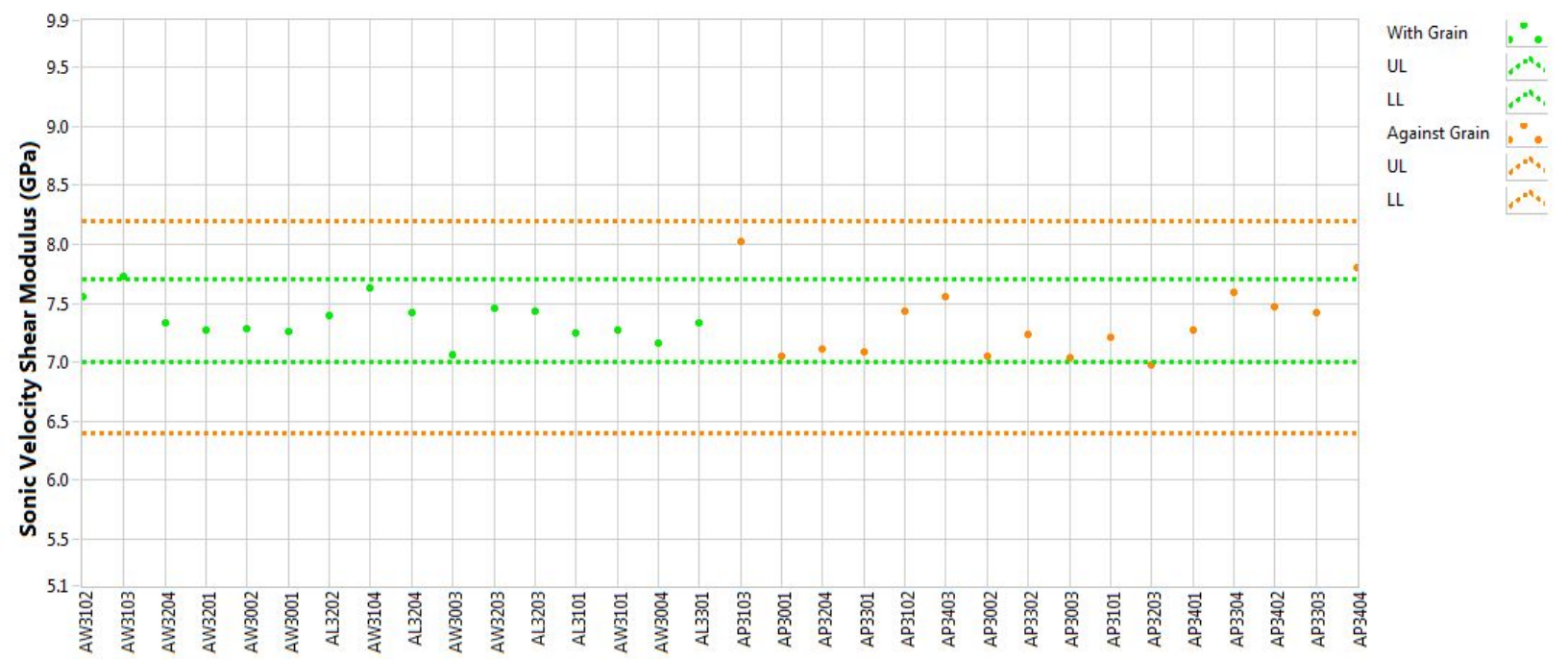

Figure A-71. NBG-17 creep shear modulus by sonic velocity.

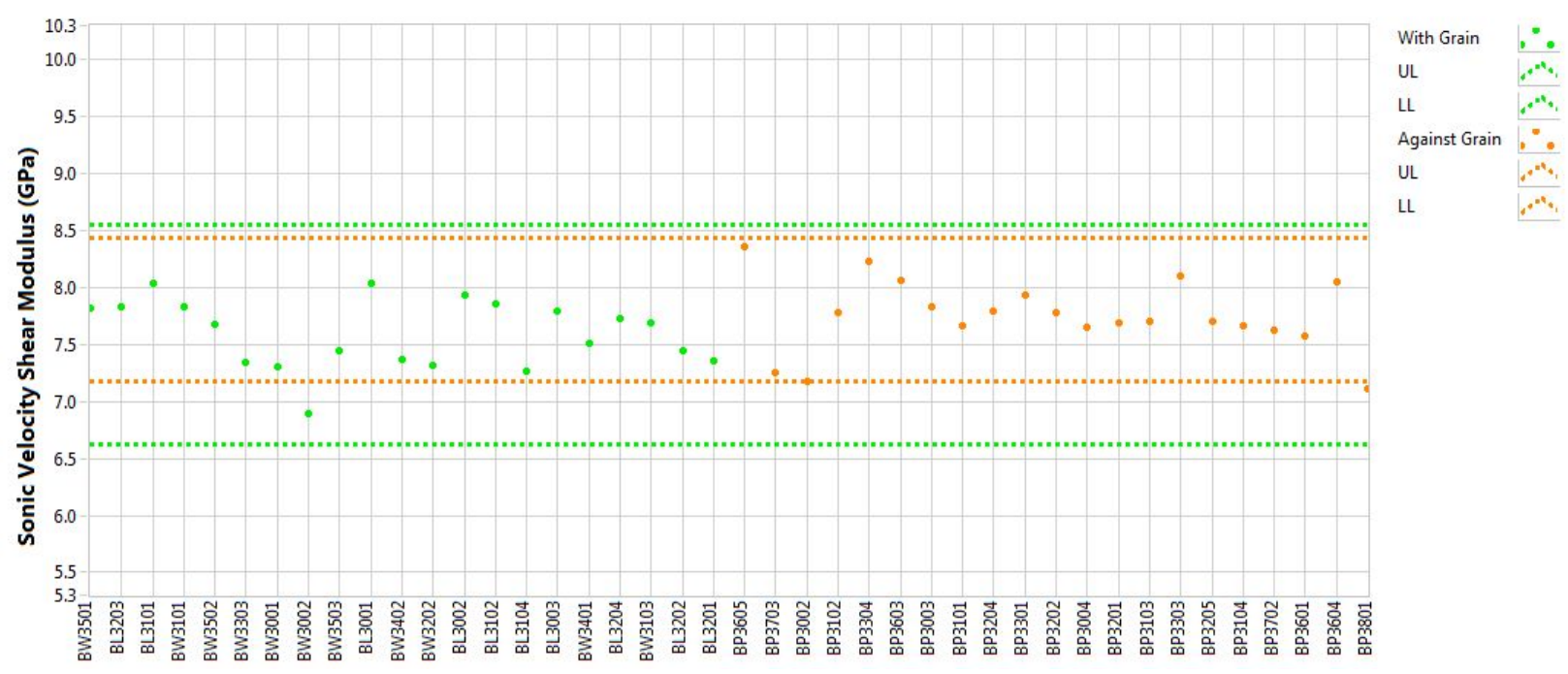

Figure A-72. NBG-18 creep shear modulus by sonic velocity. 


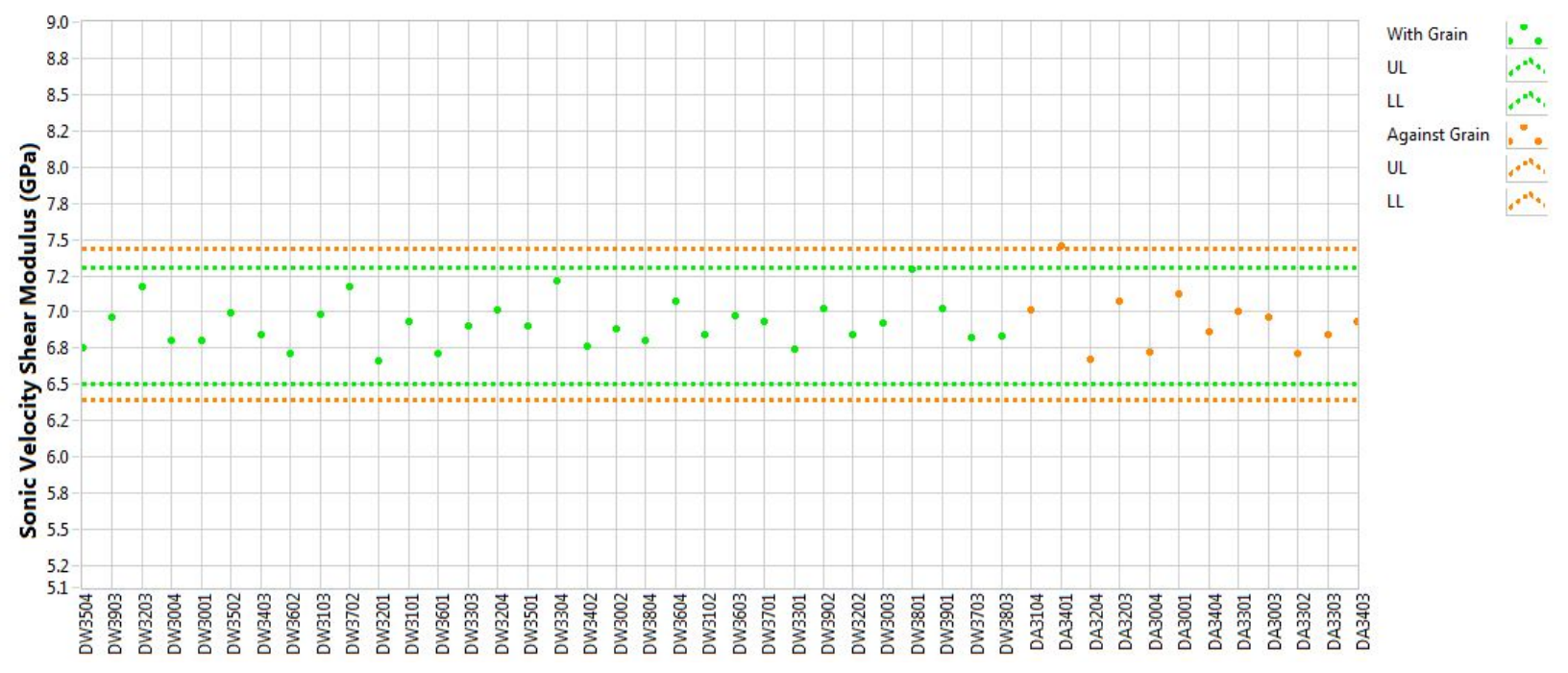

Figure A-73. PCEA creep shear modulus by sonic velocity.

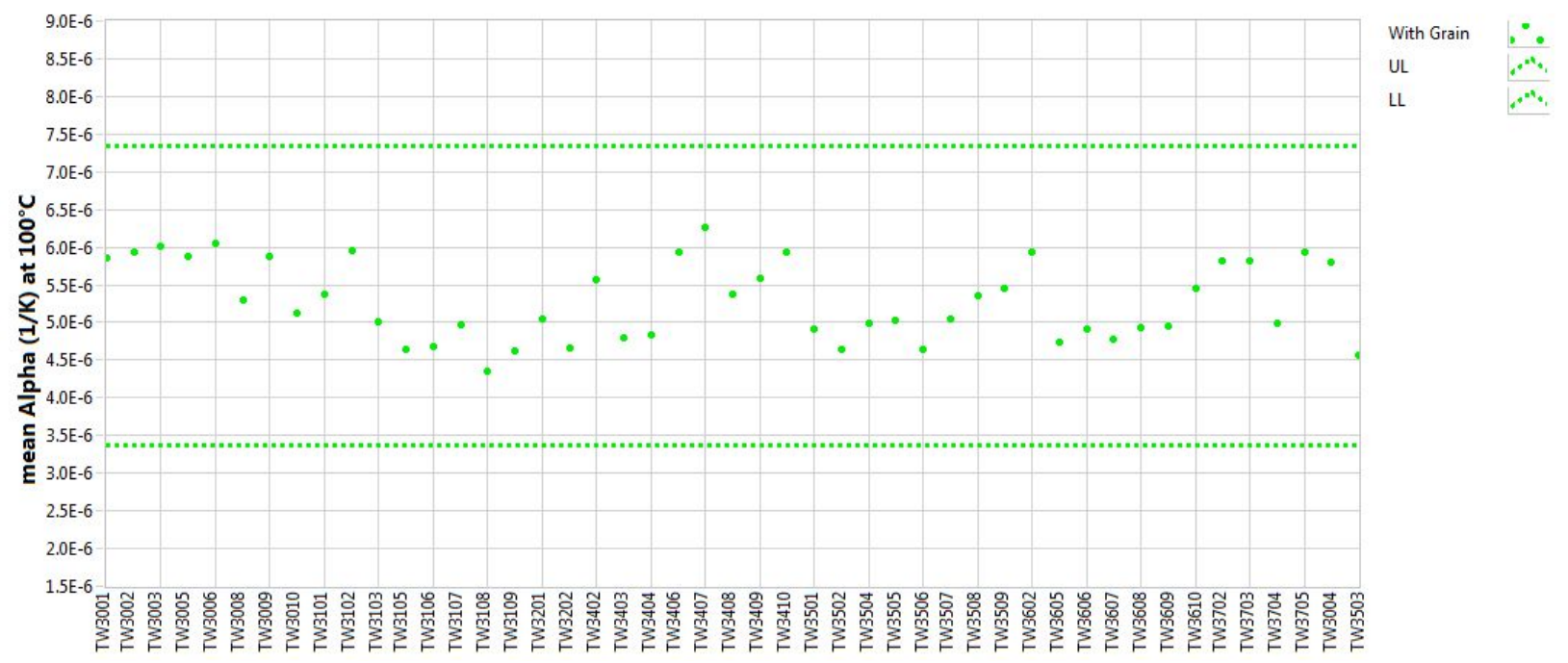

Figure A-74. 2114 creep coefficient of thermal expansion at $100^{\circ} \mathrm{C}$. 


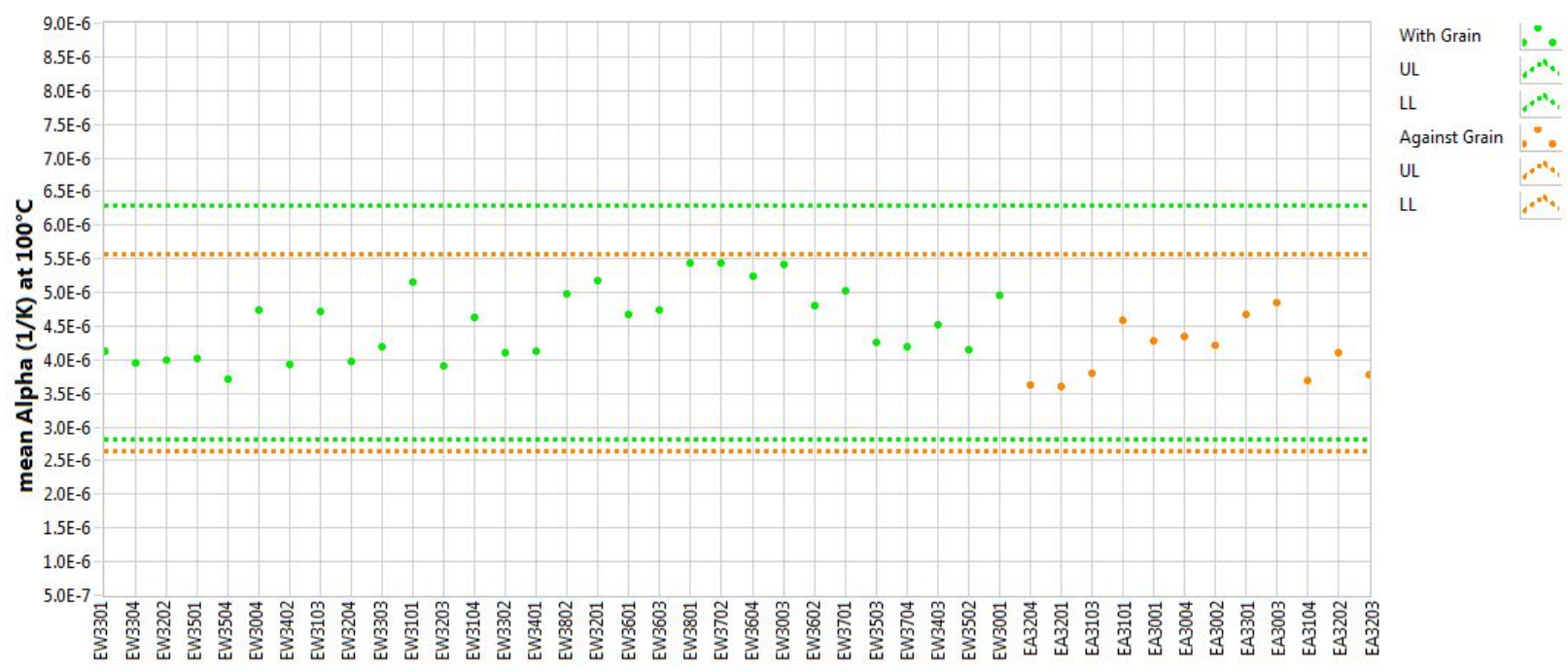

Figure A-75. IG-110 creep coefficient of thermal expansion at $100^{\circ} \mathrm{C}$.

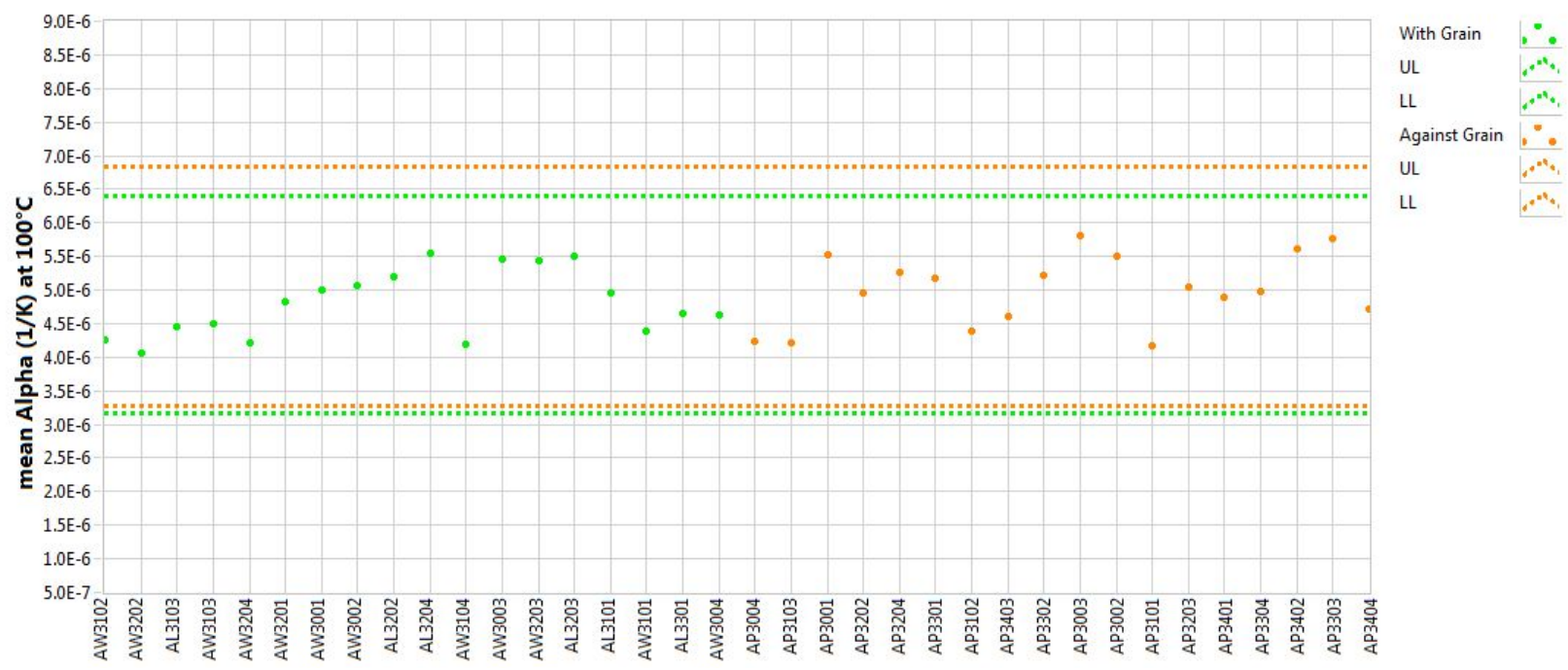

Figure A-76. NBG-17 creep coefficient of thermal expansion at $100^{\circ} \mathrm{C}$. 


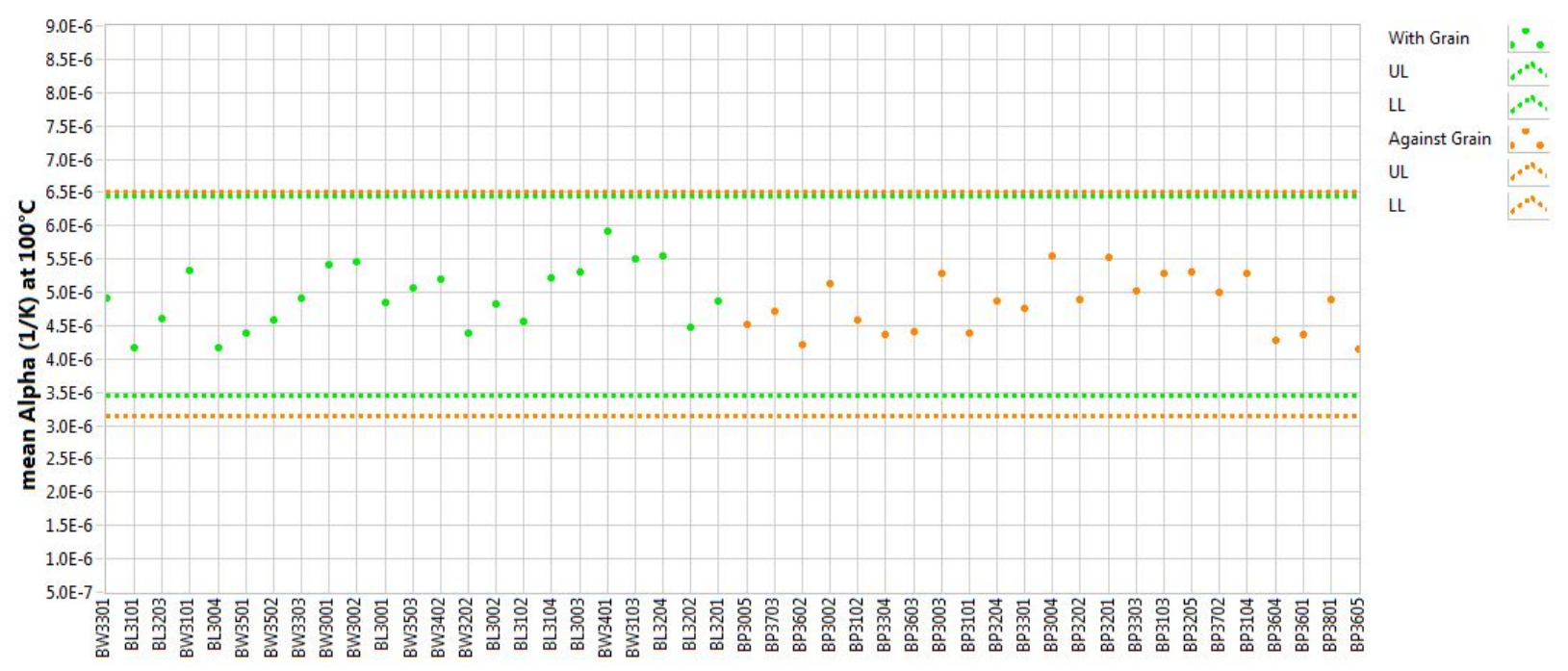

Figure A-77. NBG-18 creep coefficient of thermal expansion at $100^{\circ} \mathrm{C}$.

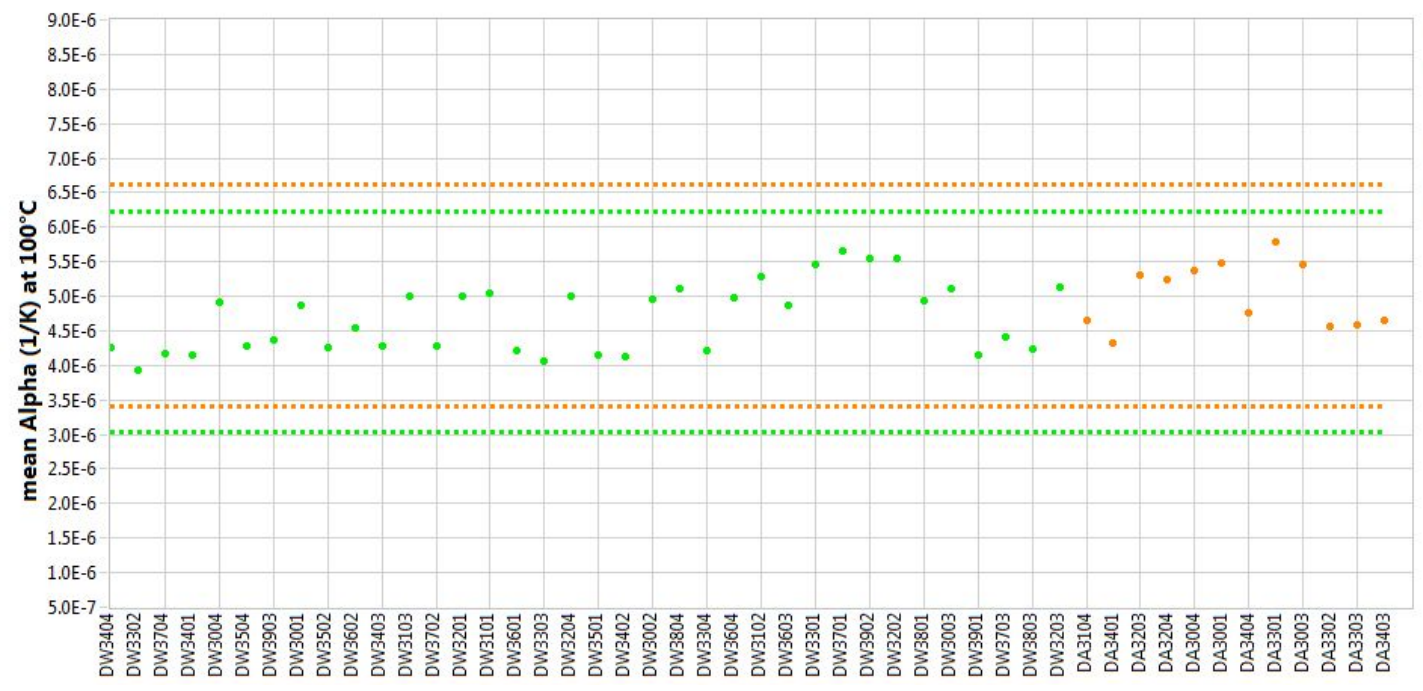

$\begin{array}{lll}\text { With Grain } & \therefore \\ \text { UL } & & \\ \text { LL } & & \\ \text { Against Grain } & \ddots \\ \text { UL } & \end{array}$

Figure A-78. PCEA creep coefficient of thermal expansion at $100^{\circ} \mathrm{C}$. 


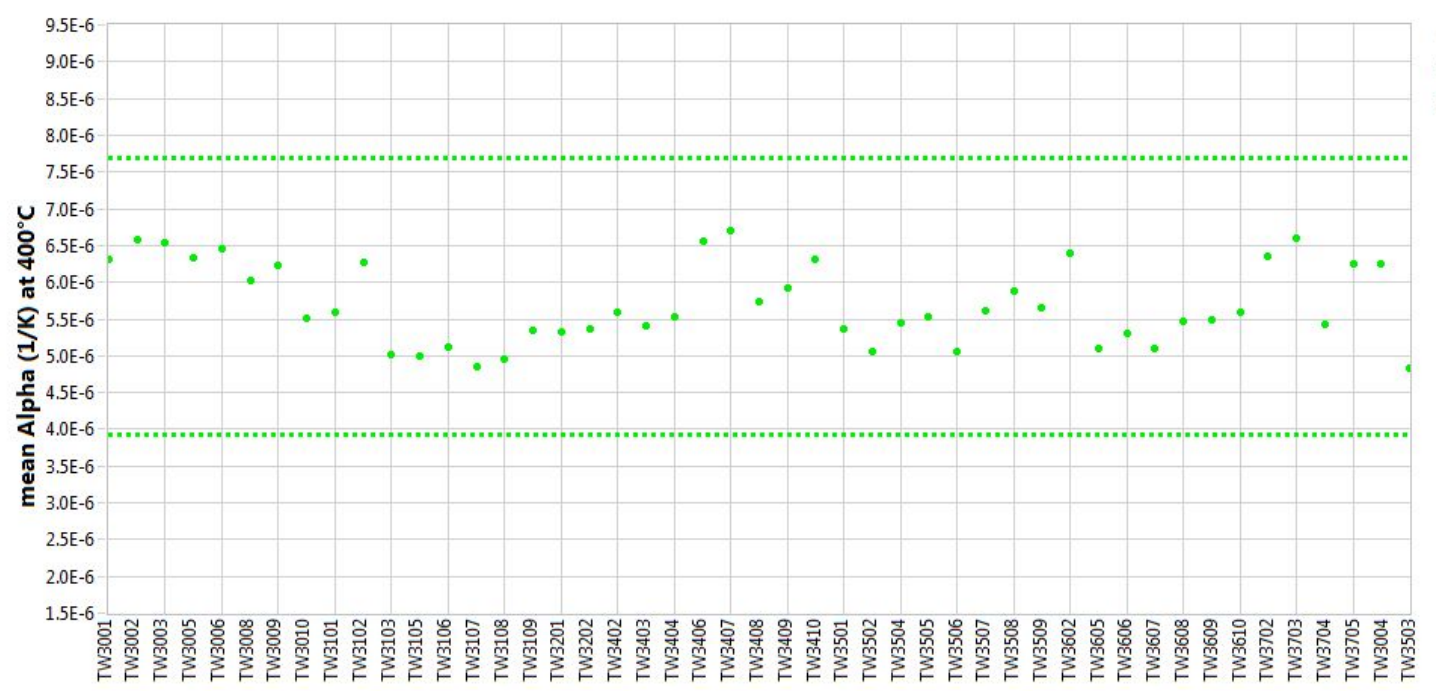

Figure A-79. 2114 creep coefficient of thermal expansion at $400^{\circ} \mathrm{C}$.

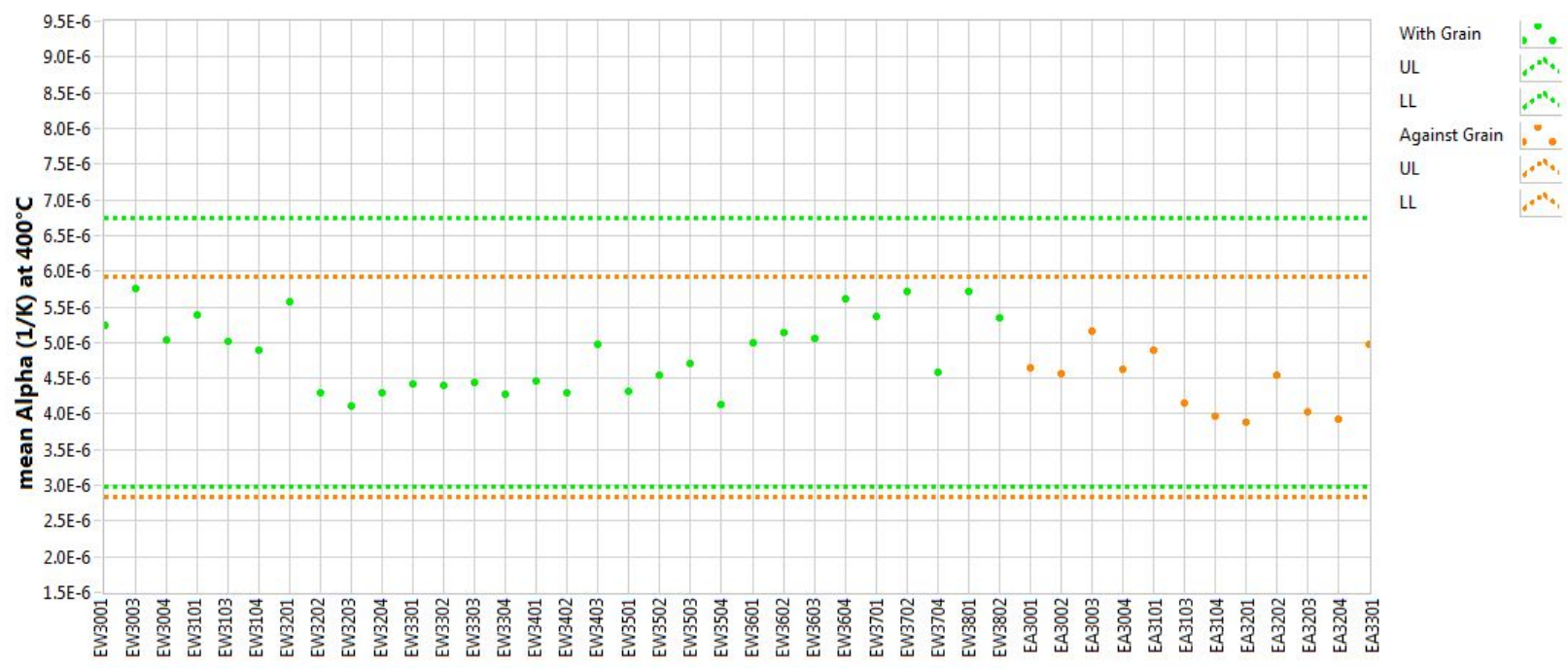

Figure A-80. IG-110 creep coefficient of thermal expansion at $400^{\circ} \mathrm{C}$. 


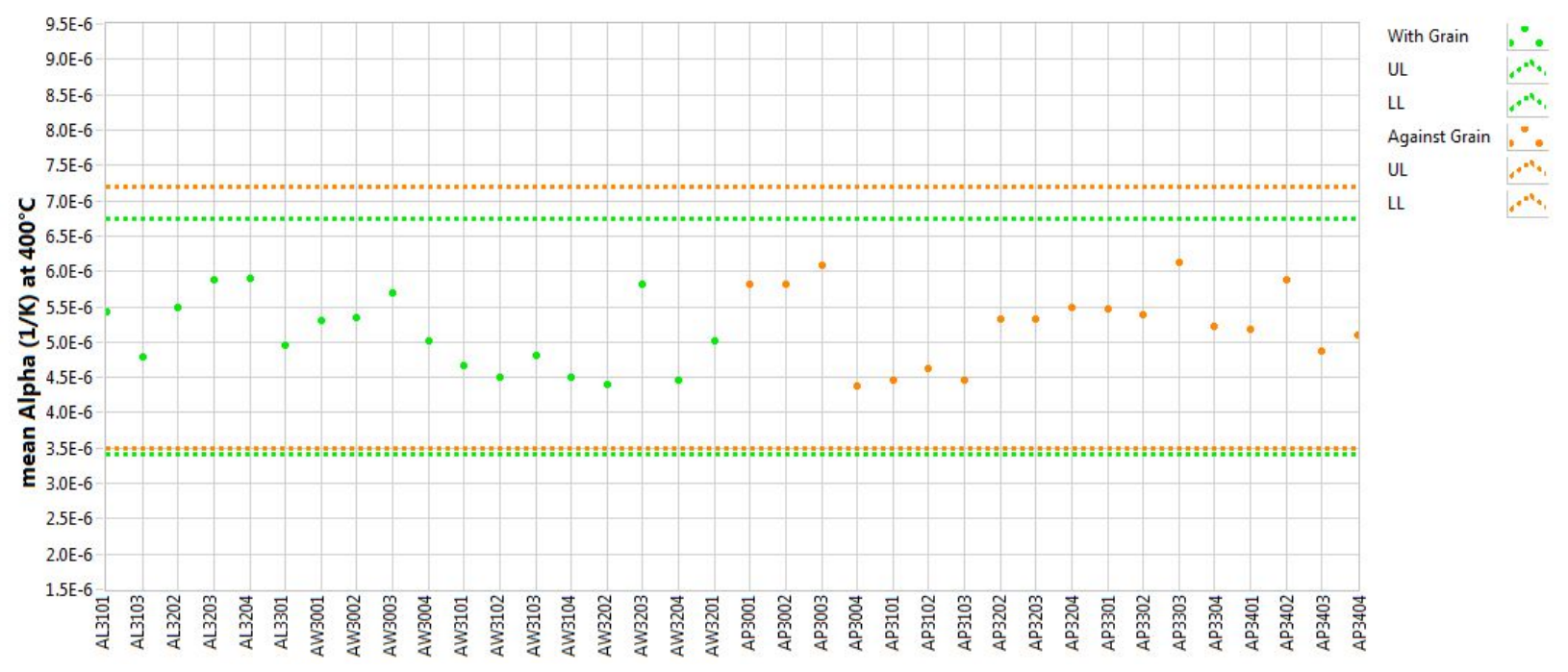

Figure A-81. NBG-17 creep coefficient of thermal expansion at $400^{\circ} \mathrm{C}$.

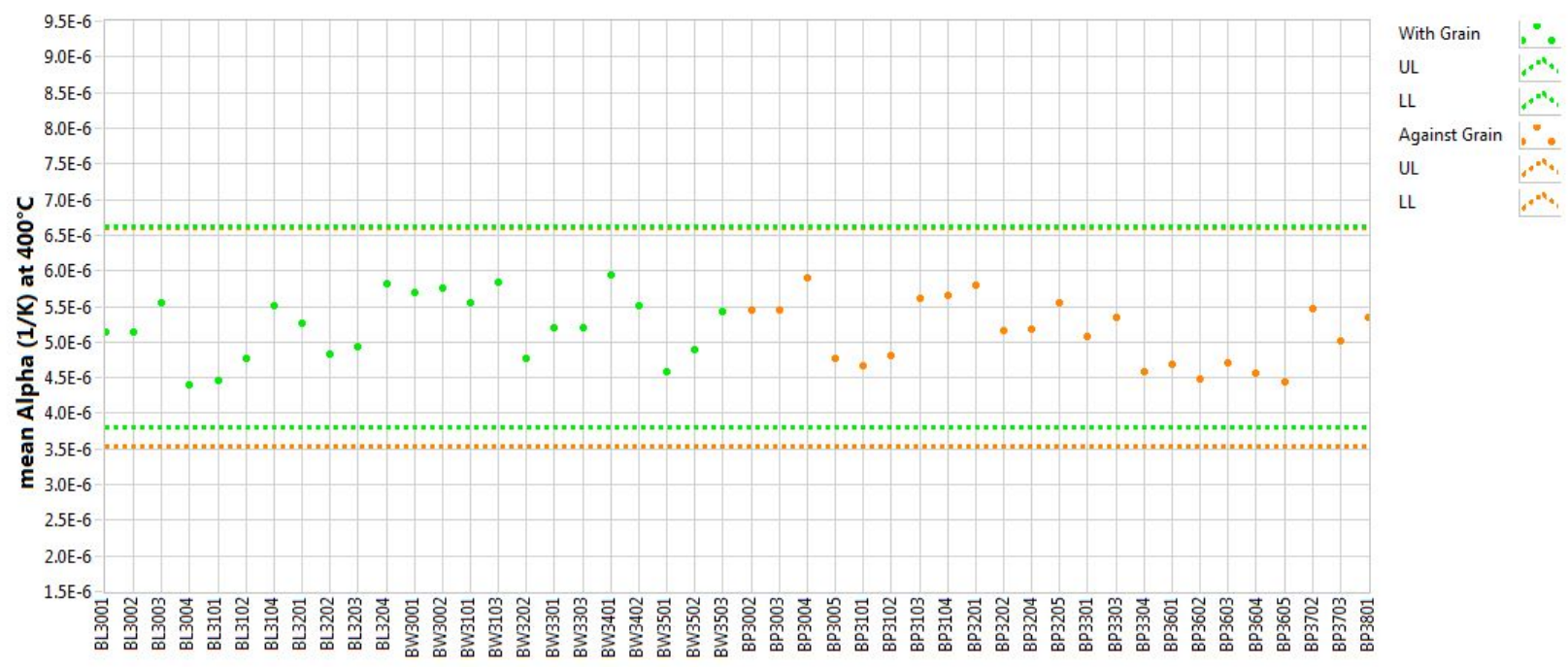

Figure A-82. NBG-18 creep coefficient of thermal expansion at $400^{\circ} \mathrm{C}$. 


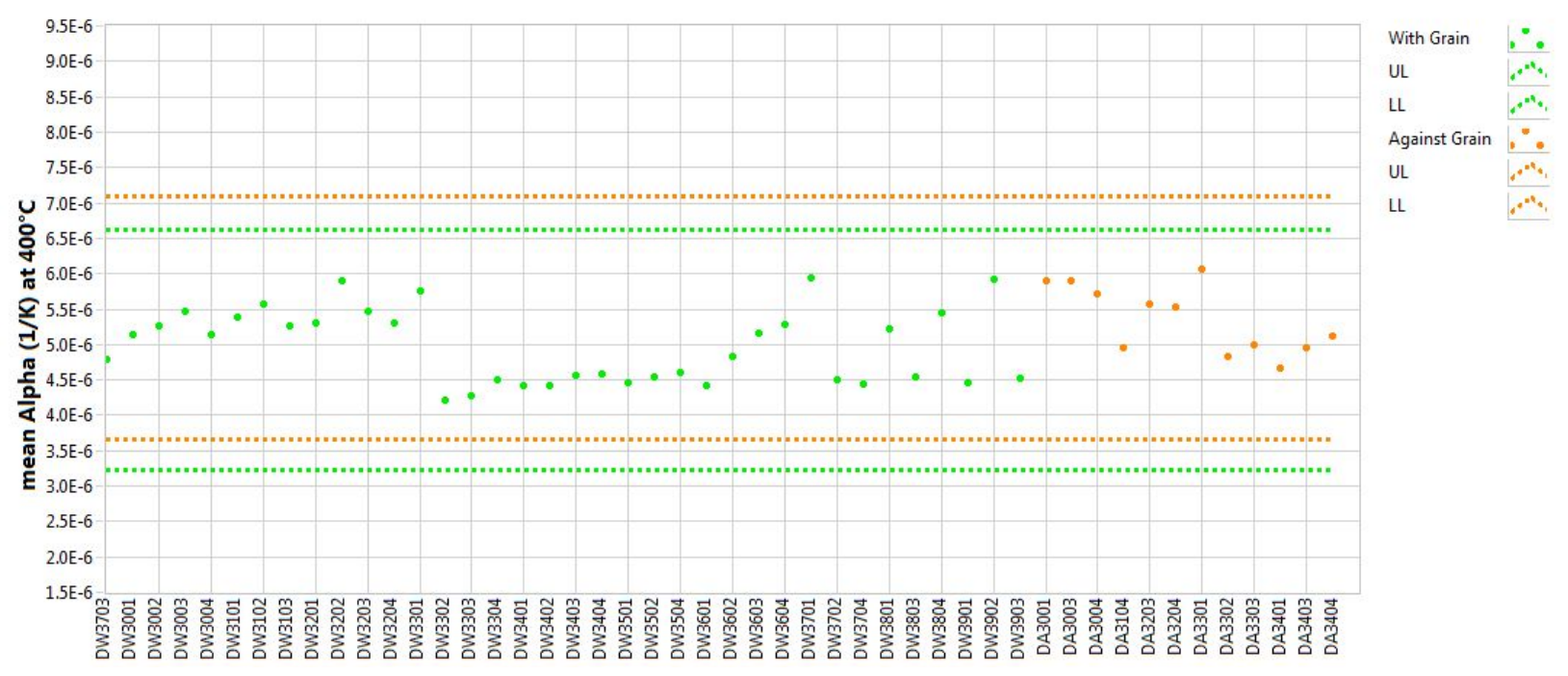

Figure A-83. PCEA creep coefficient of thermal expansion at $400^{\circ} \mathrm{C}$.

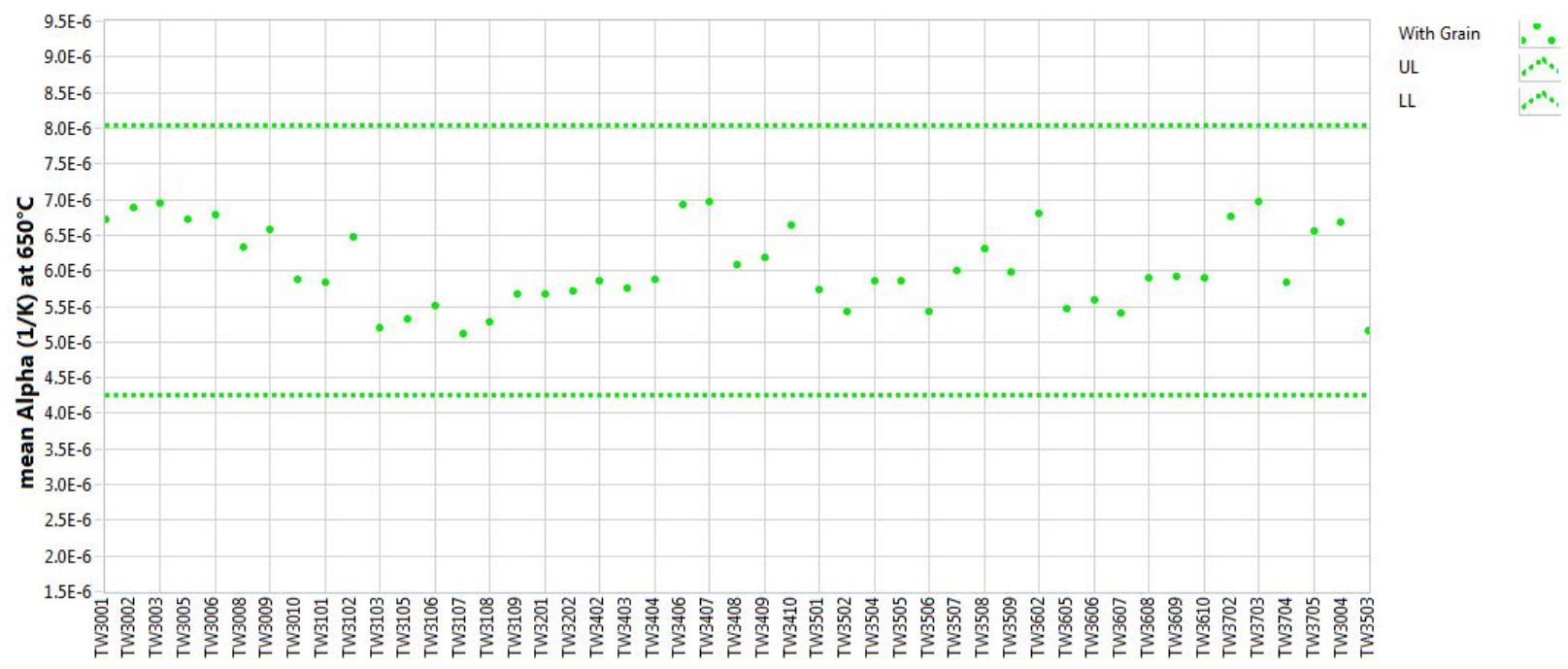

Figure A-84. 2114 creep coefficient of thermal expansion at $650^{\circ} \mathrm{C}$. 


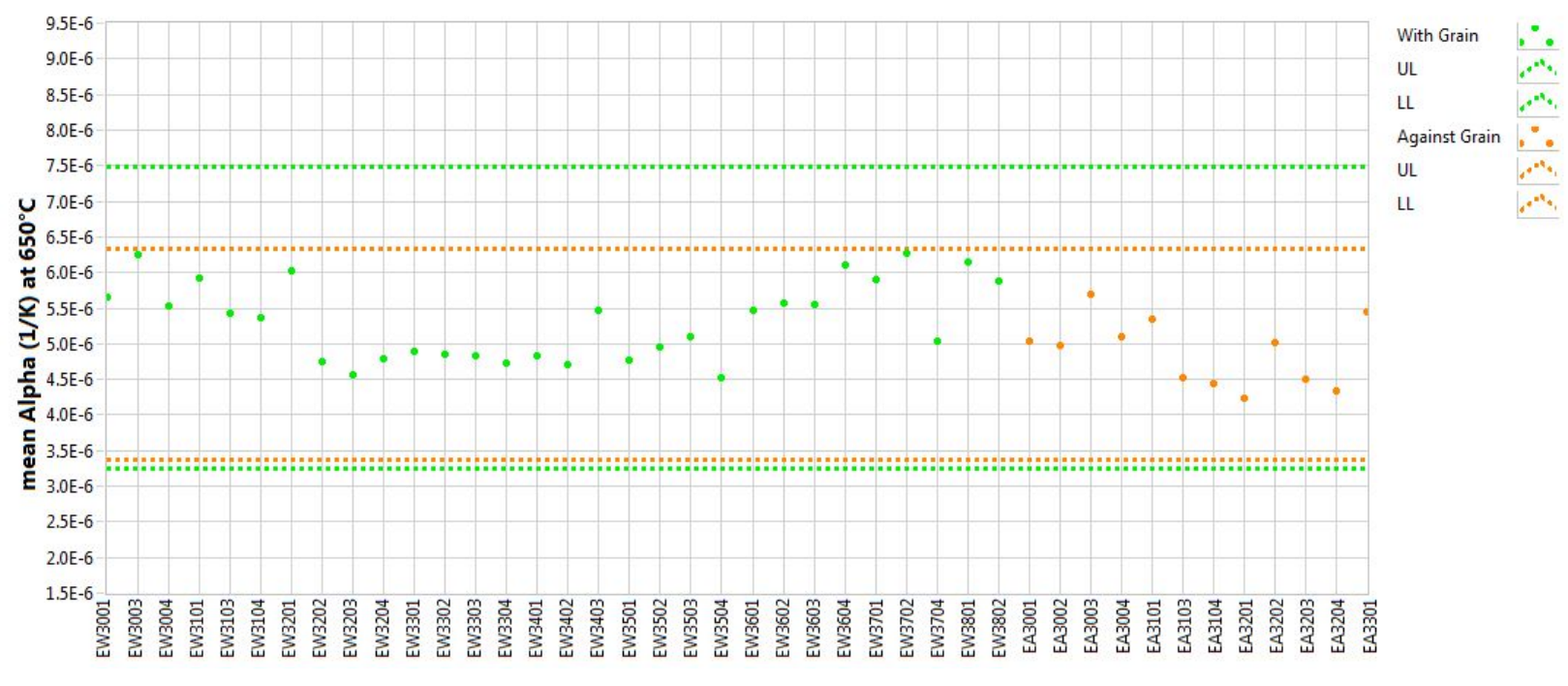

Figure A-85. IG-110 creep coefficient of thermal expansion at $650^{\circ} \mathrm{C}$.

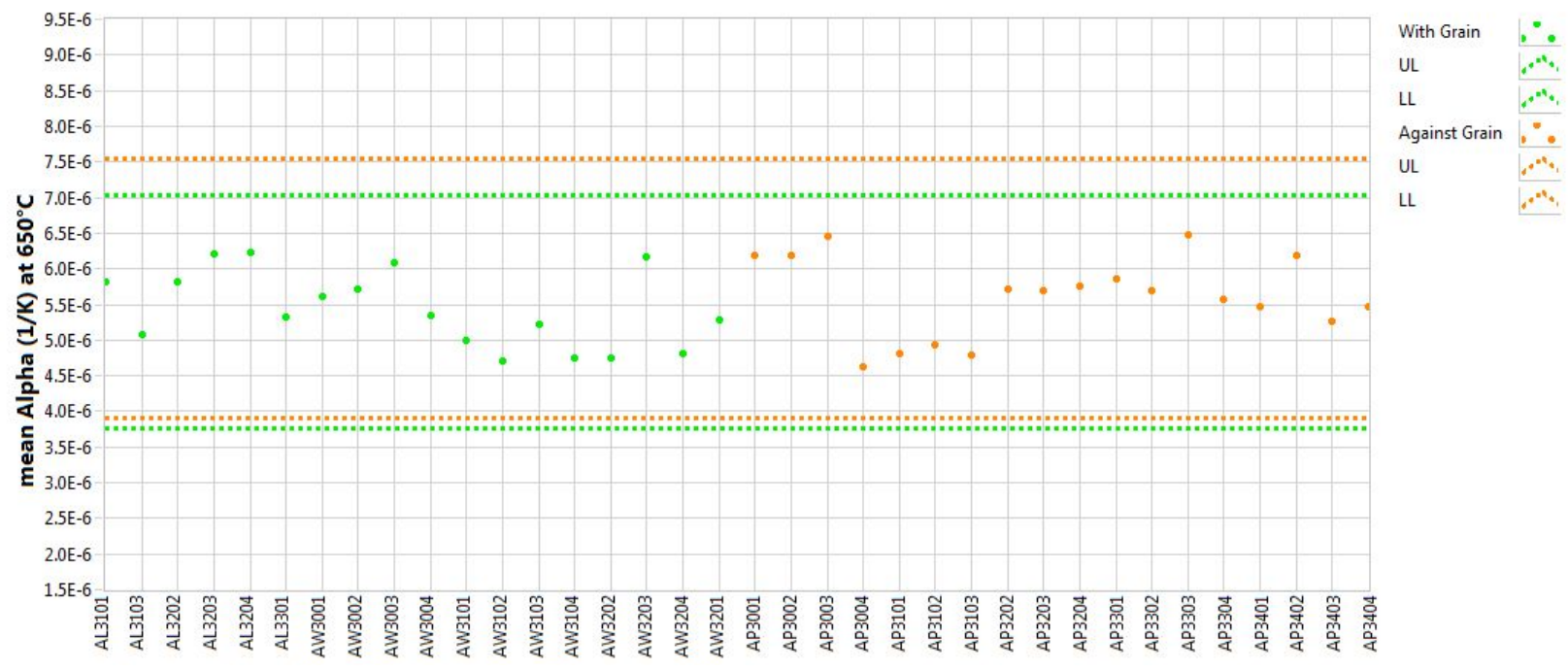

Figure A-86. NBG-17 creep coefficient of thermal expansion at $650^{\circ} \mathrm{C}$. 


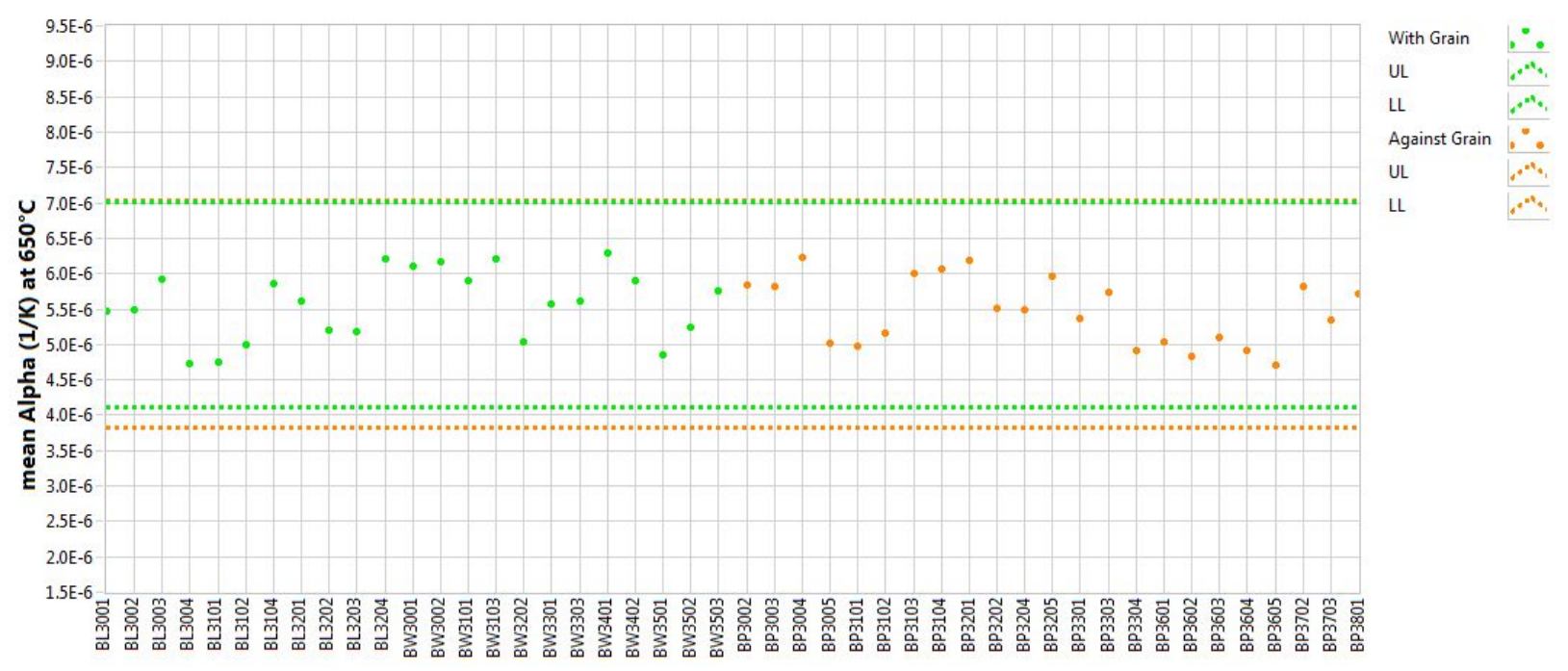

Figure A-87. NBG-18 creep coefficient of thermal expansion at $650^{\circ} \mathrm{C}$.

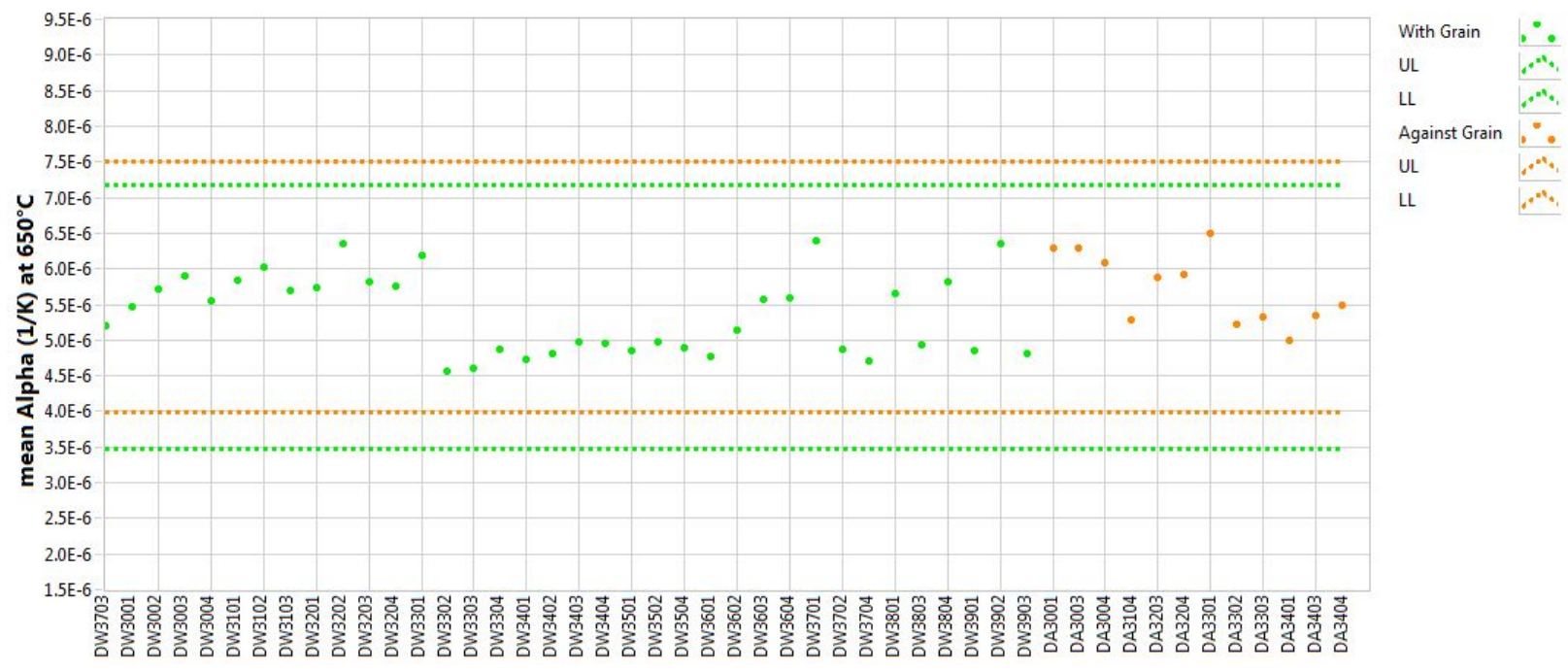

Figure A-88. PCEA creep coefficient of thermal expansion at $650^{\circ} \mathrm{C}$. 


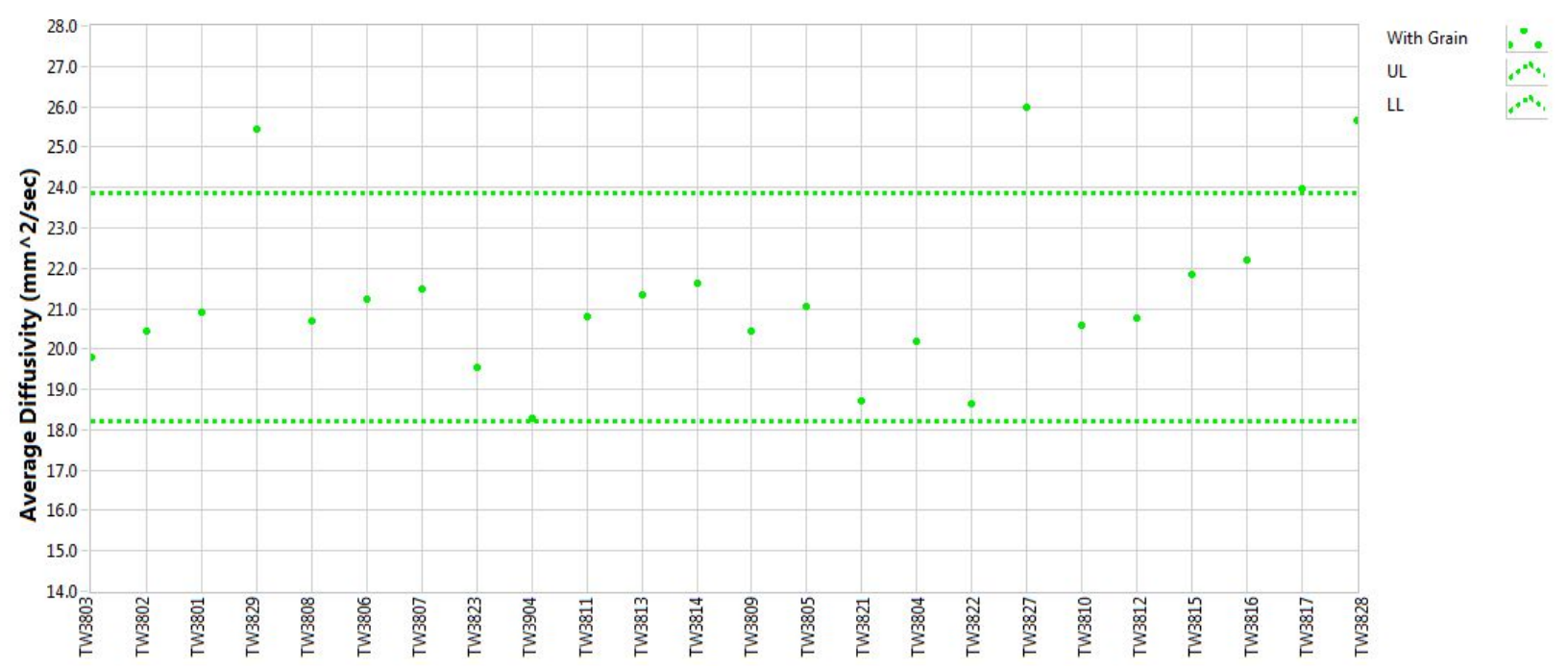

Figure A-89. 2114 piggyback diffusivity at $100^{\circ} \mathrm{C}$.

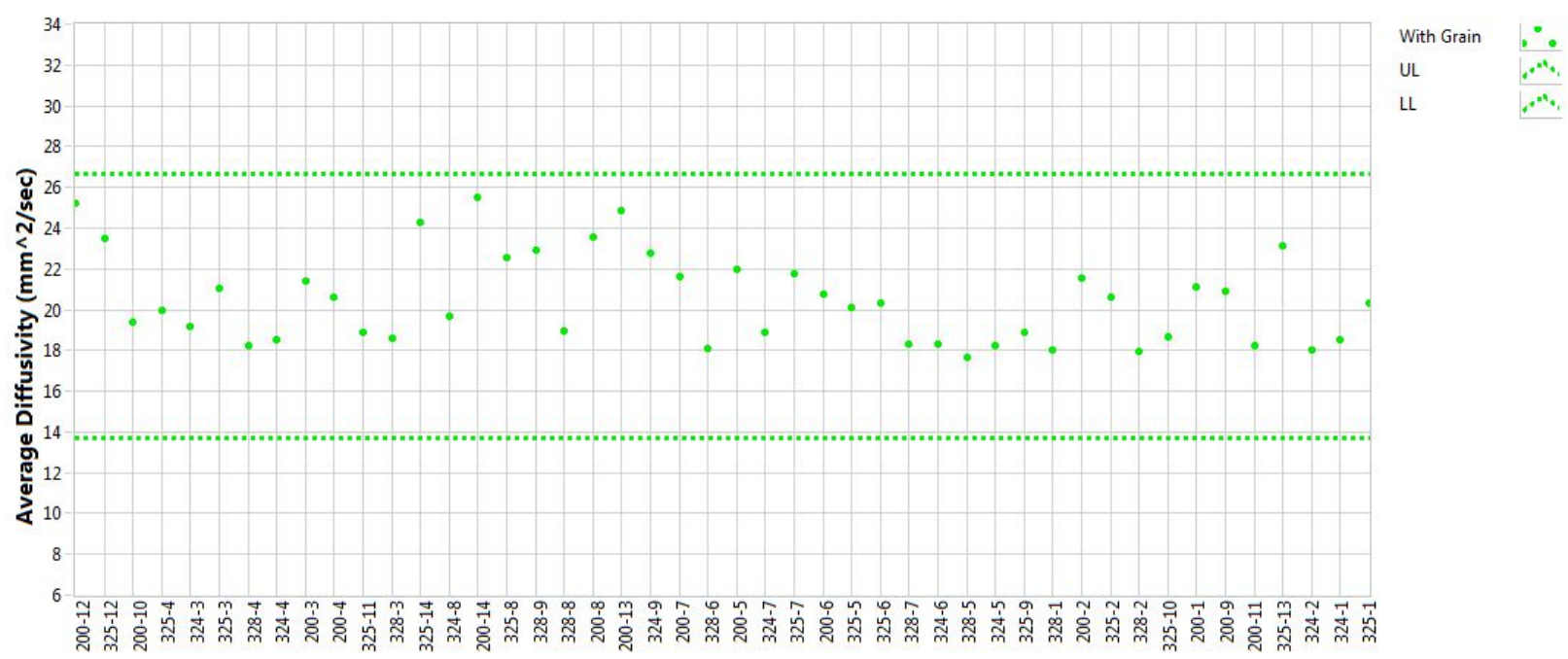

Figure A-90. GrafTech piggyback diffusivity at $100^{\circ} \mathrm{C}$. 


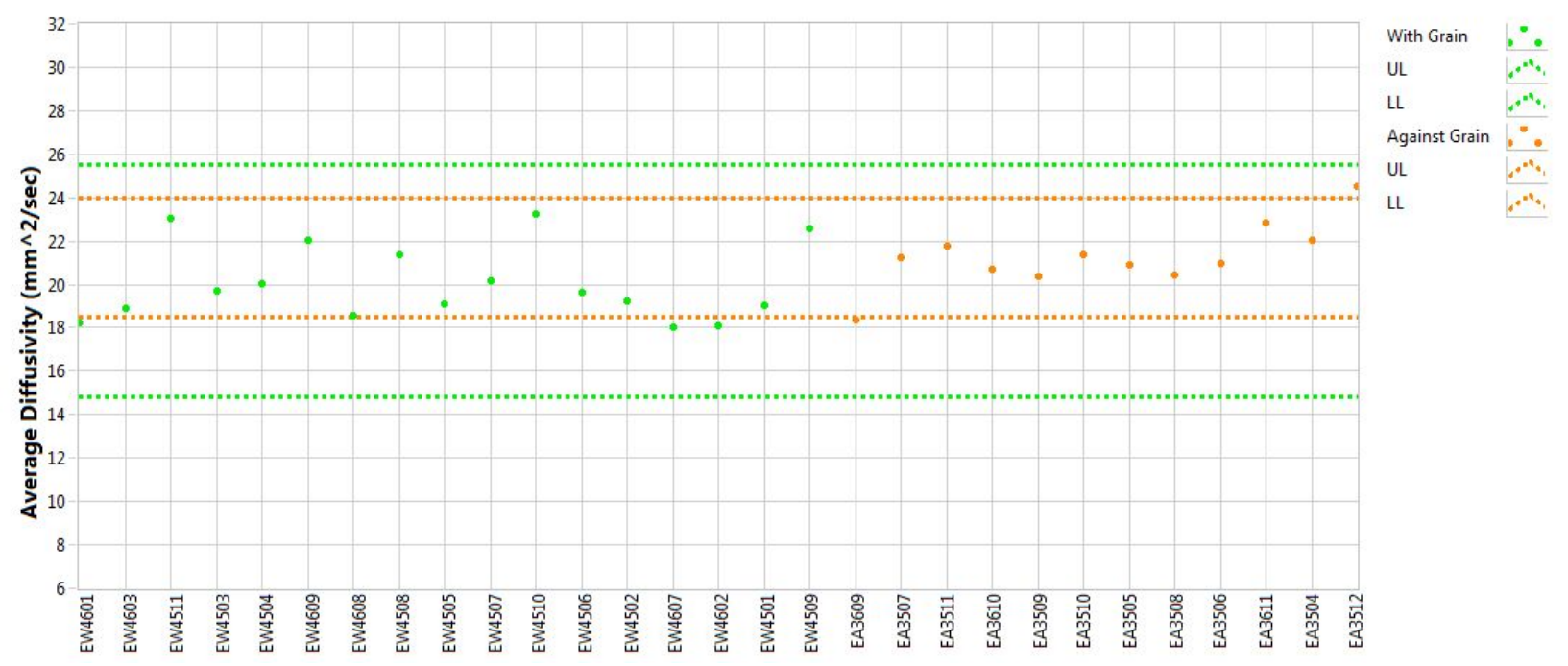

Figure A-91. IG-110 piggyback diffusivity at $100^{\circ} \mathrm{C}$.

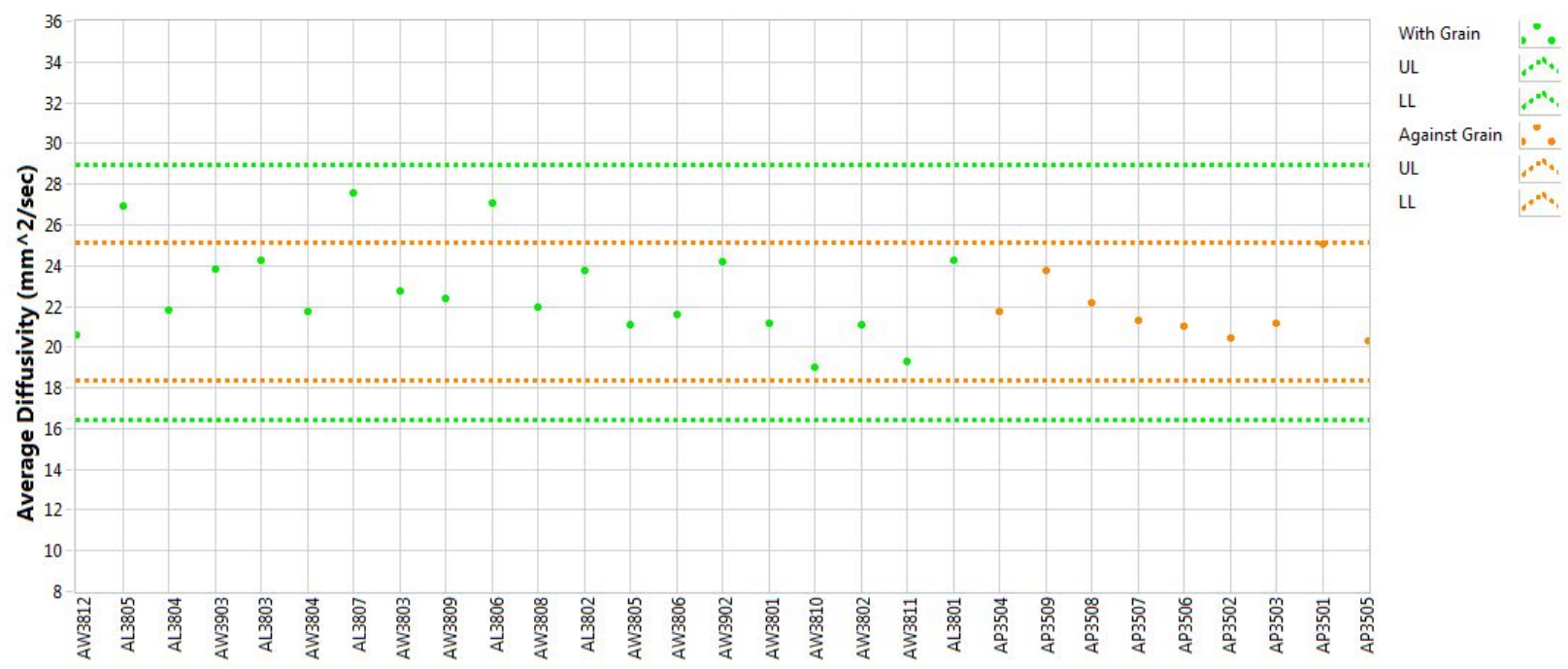

Figure A-92. NBG-17 piggyback diffusivity at $100^{\circ} \mathrm{C}$. 


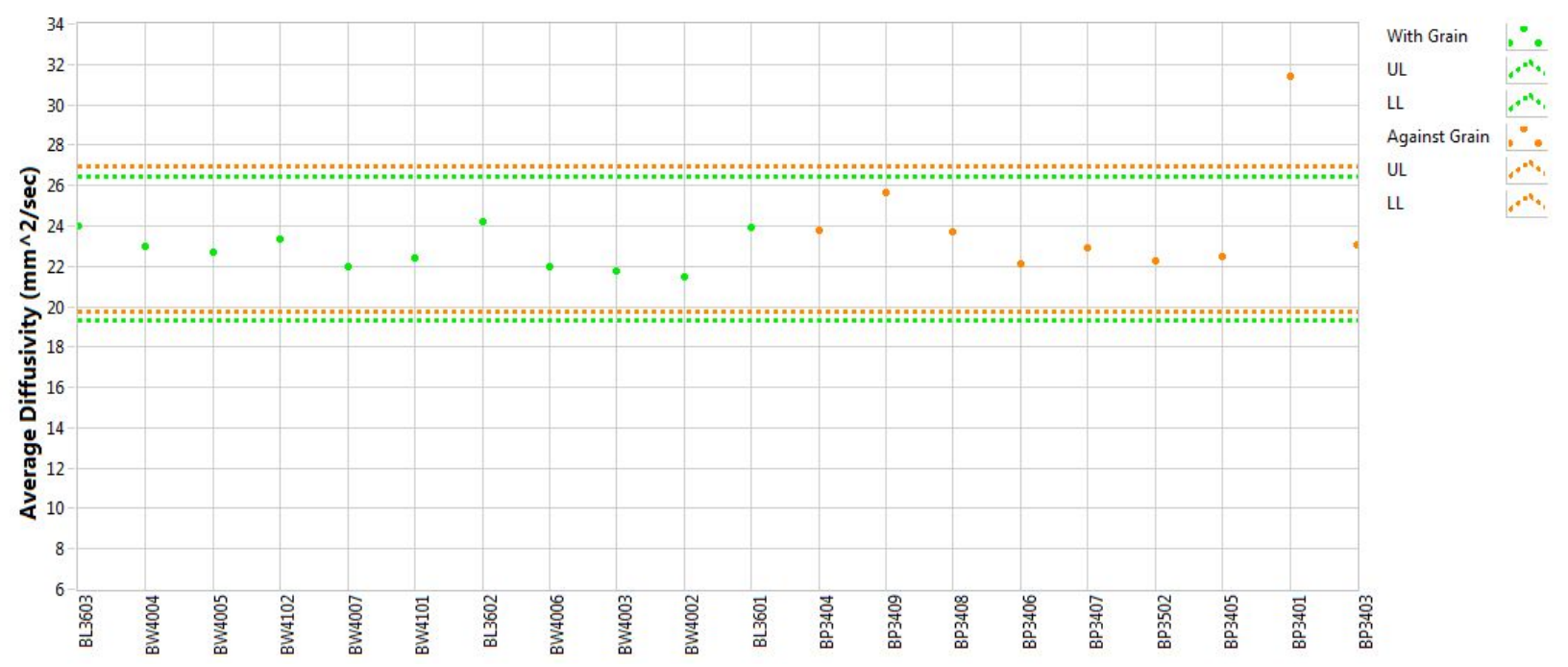

Figure A-93. NBG-18 piggyback diffusivity at $100^{\circ} \mathrm{C}$.

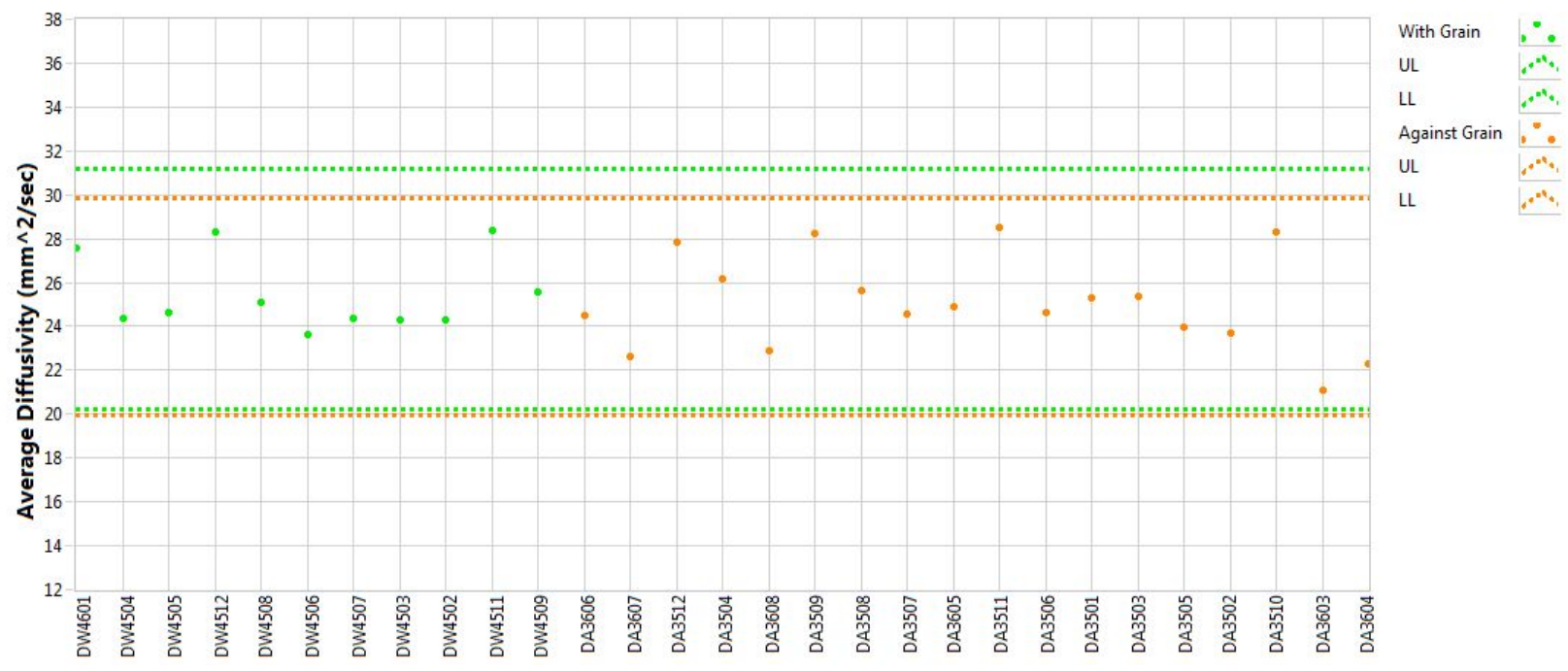

Figure A-94. PCEA piggyback diffusivity at $100^{\circ} \mathrm{C}$. 


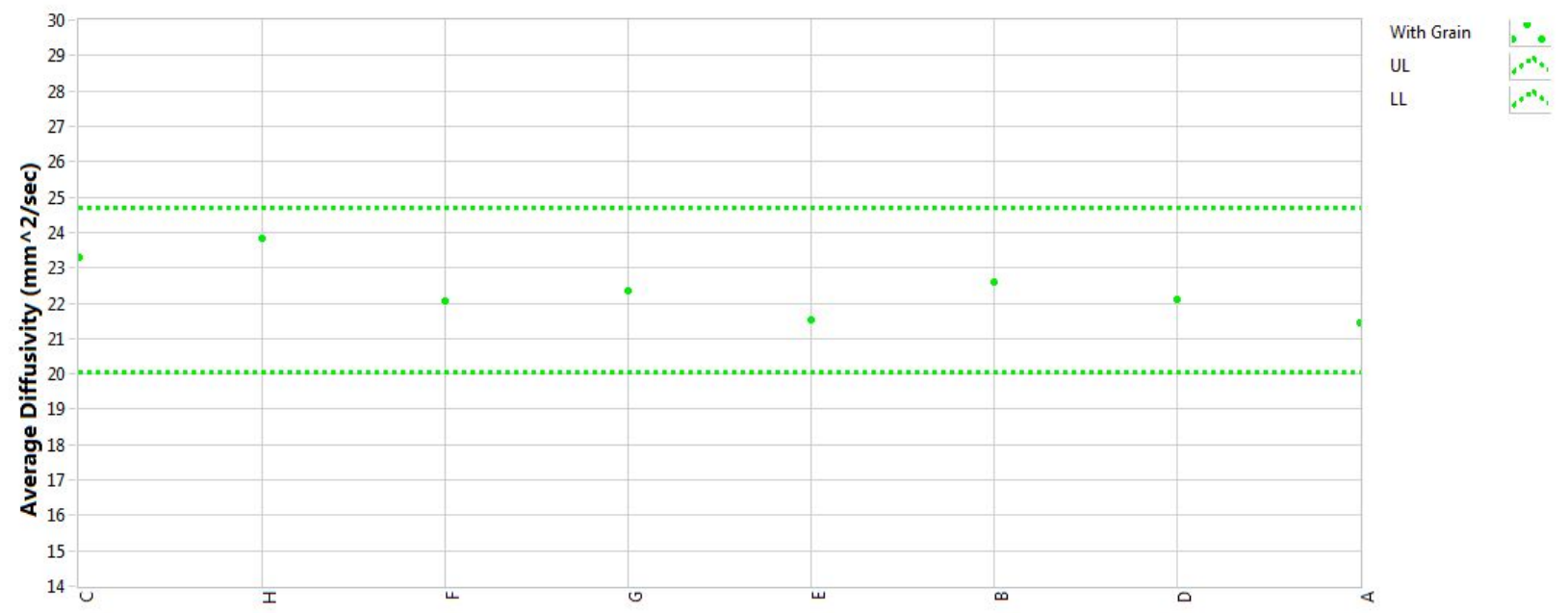

Figure A-95. SGL-SiC piggyback diffusivity at $100^{\circ} \mathrm{C}$.

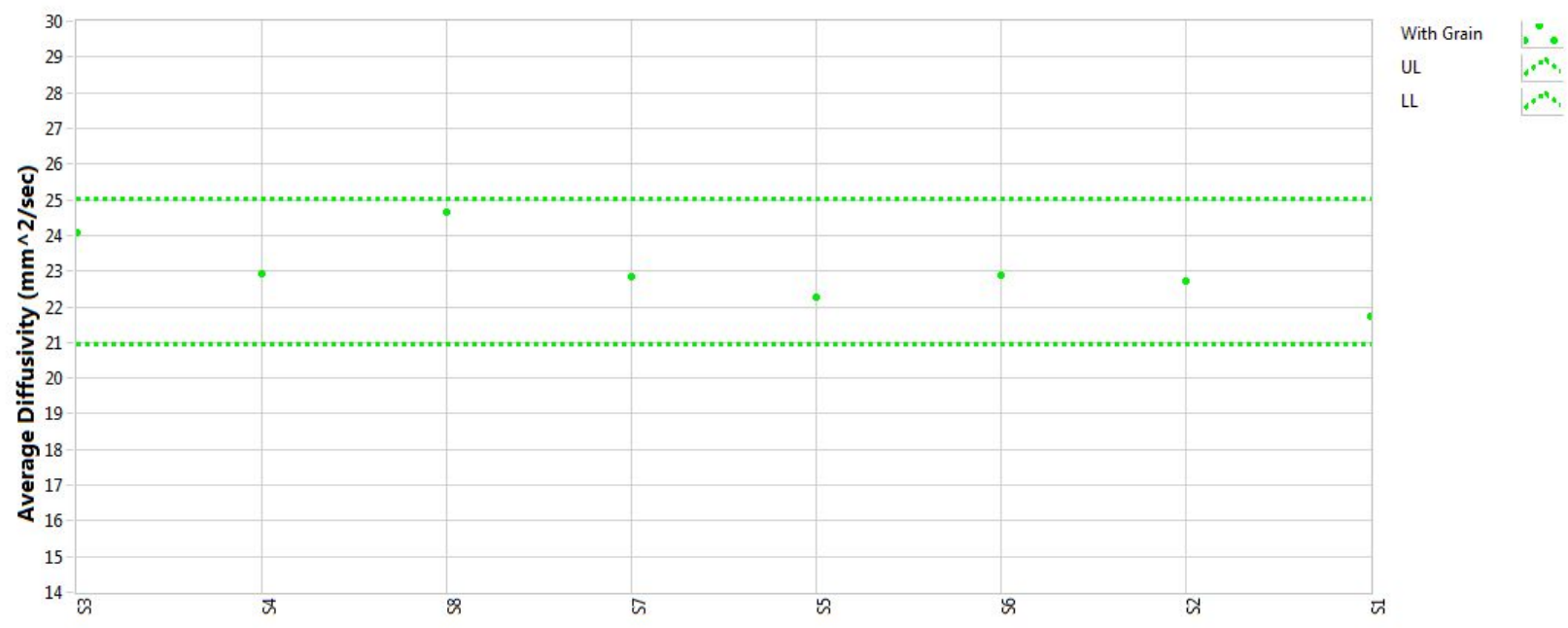

Figure A-96. SGL piggyback diffusivity at $100^{\circ} \mathrm{C}$. 


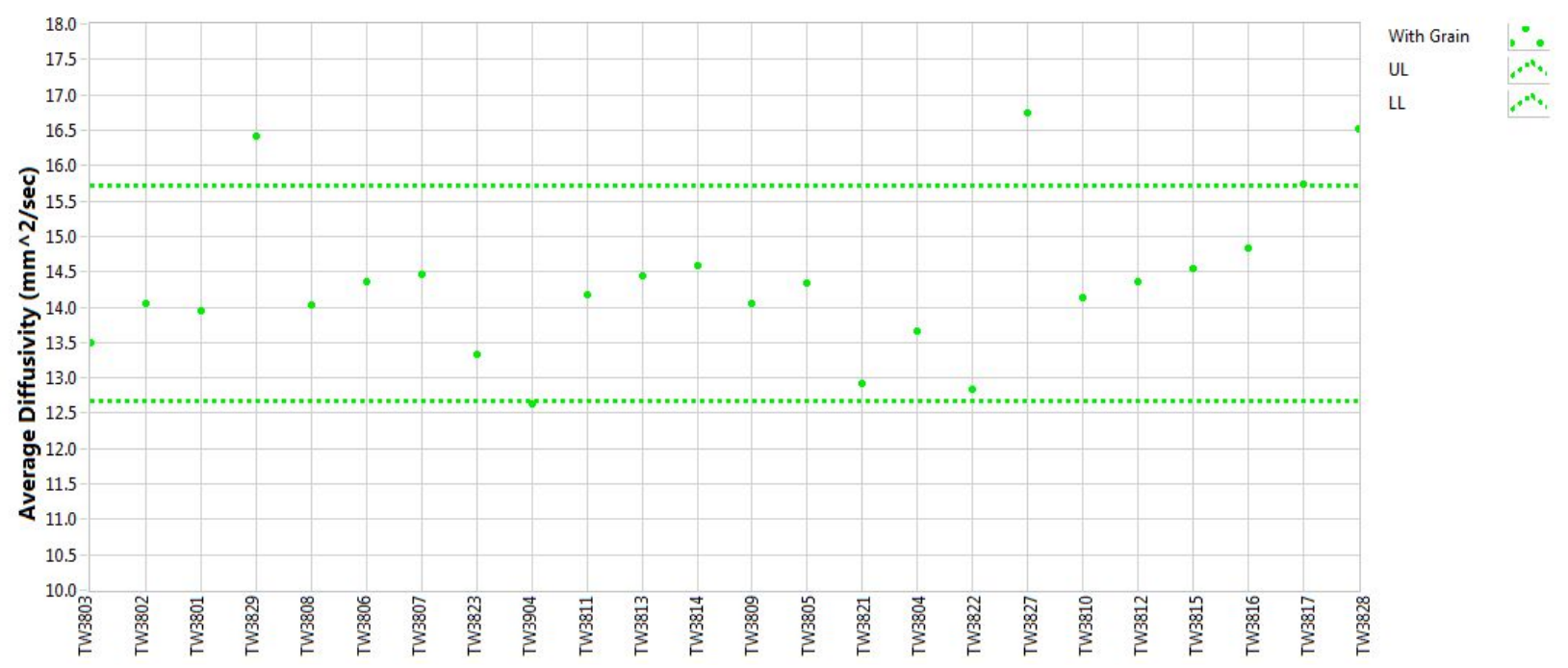

Figure A-97. 2114 piggyback diffusivity at $400^{\circ} \mathrm{C}$.

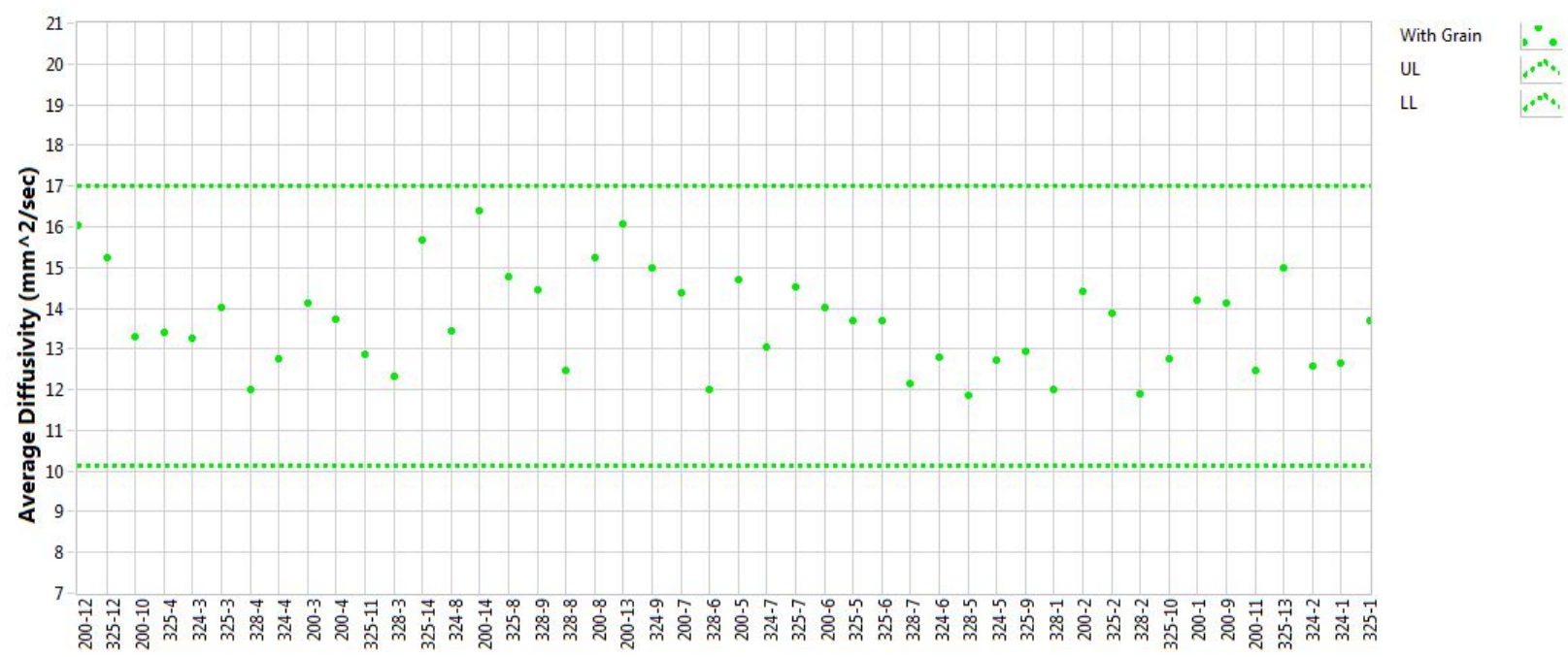

Figure A-98. GrafTech piggyback diffusivity at $400^{\circ} \mathrm{C}$. 


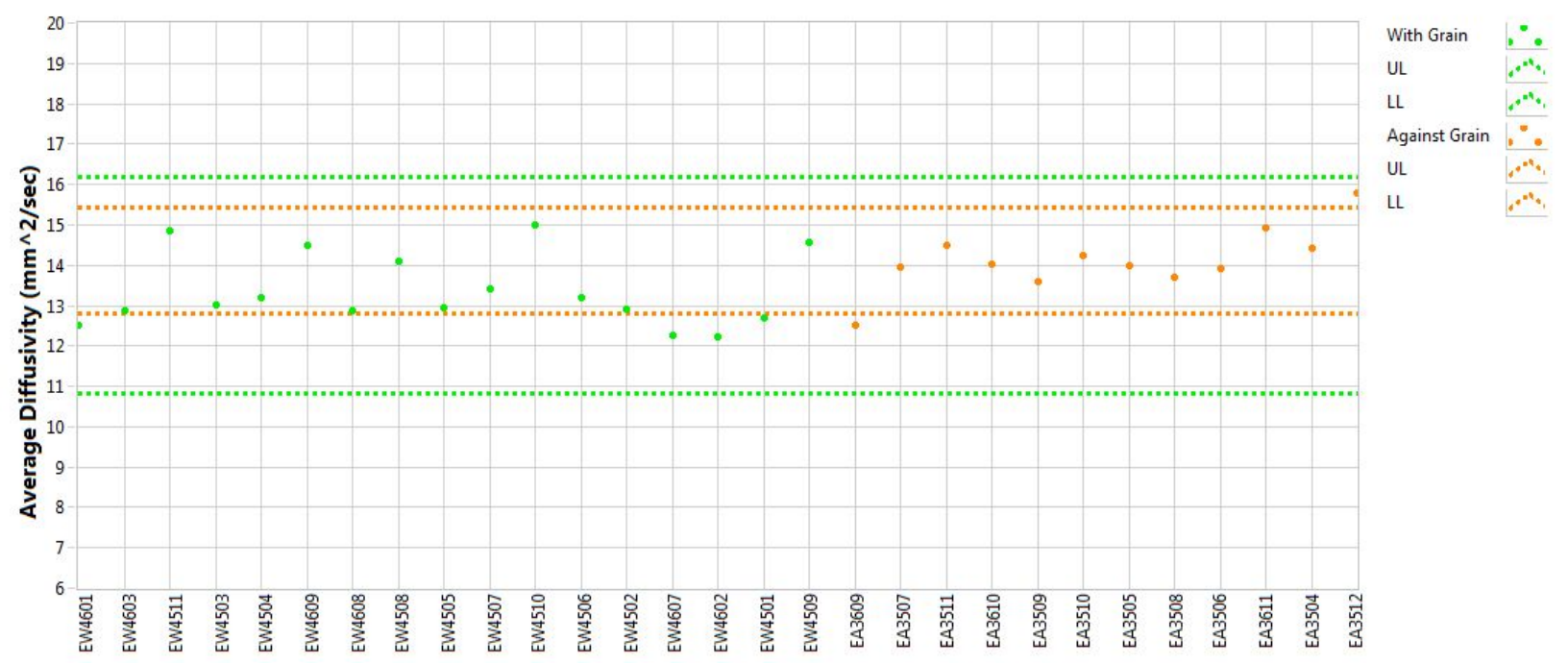

Figure A-99. IG-110 piggyback diffusivity at $400^{\circ} \mathrm{C}$.

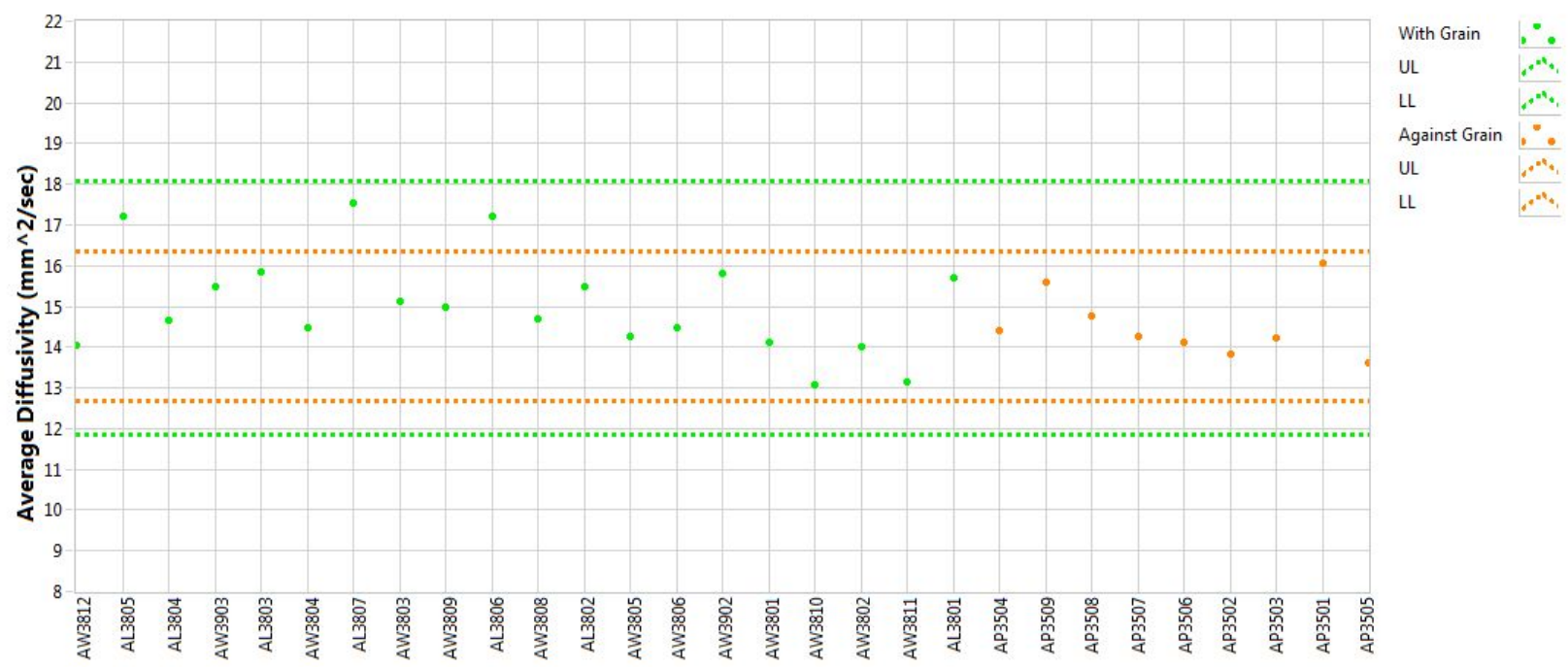

Figure A-100. NBG-17 piggyback diffusivity at $400^{\circ} \mathrm{C}$. 


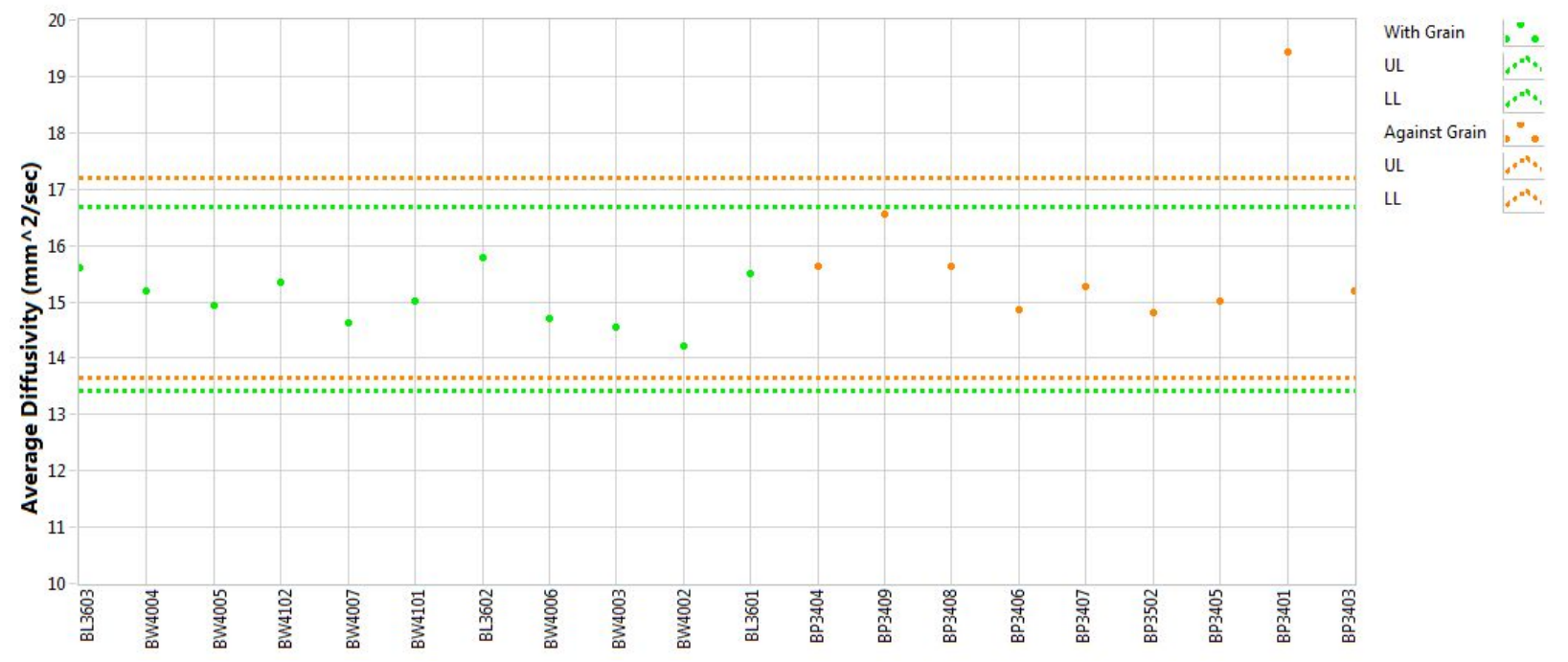

Figure A-101. NBG-18 piggyback diffusivity at $400^{\circ} \mathrm{C}$.

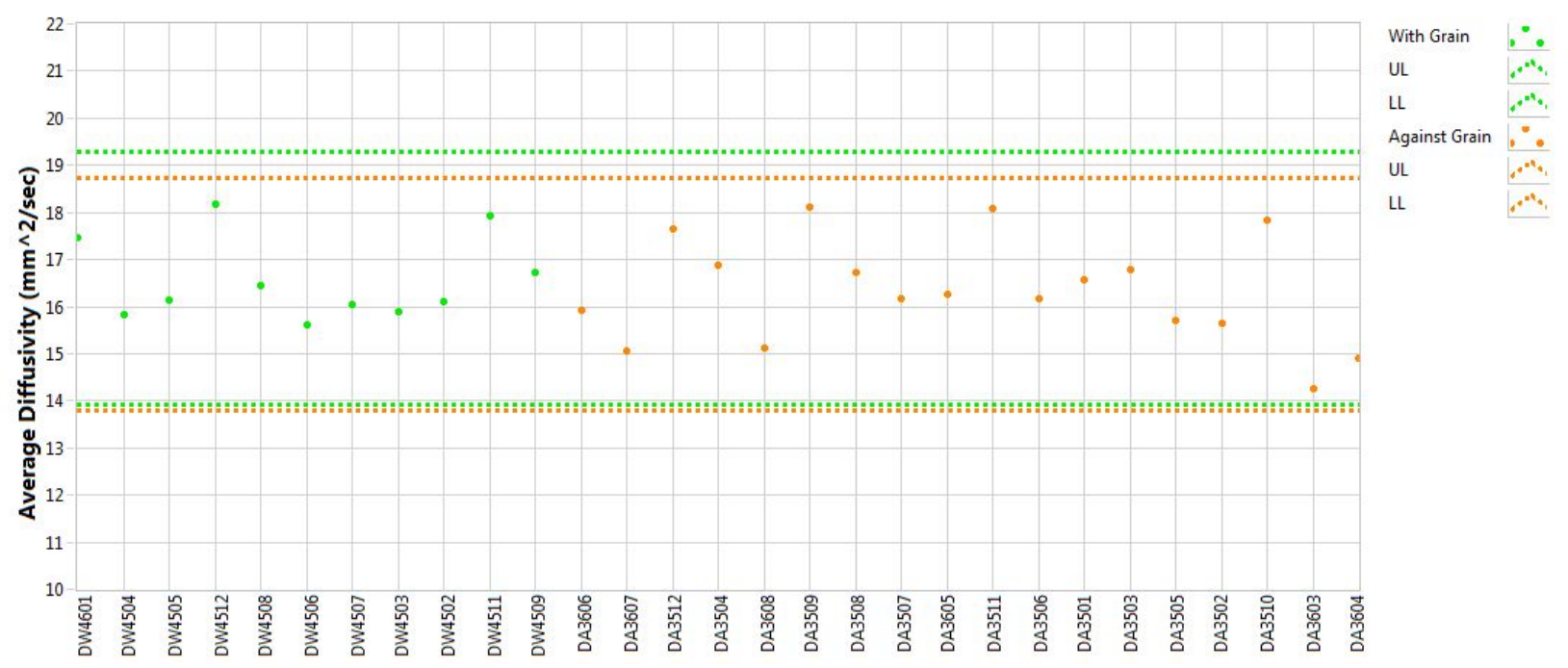

Figure A-102. PCEA piggyback diffusivity at $400^{\circ} \mathrm{C}$. 


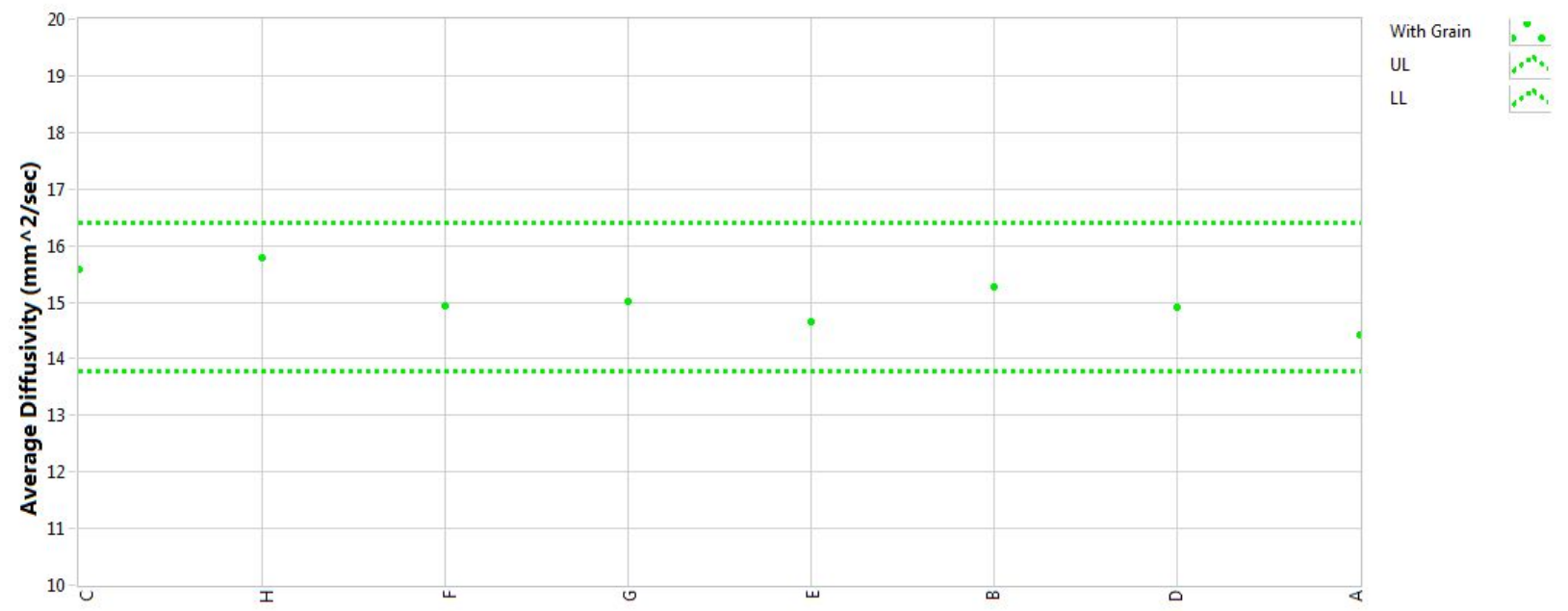

Figure A-103. SGL-SiC piggyback diffusivity at $400^{\circ} \mathrm{C}$.

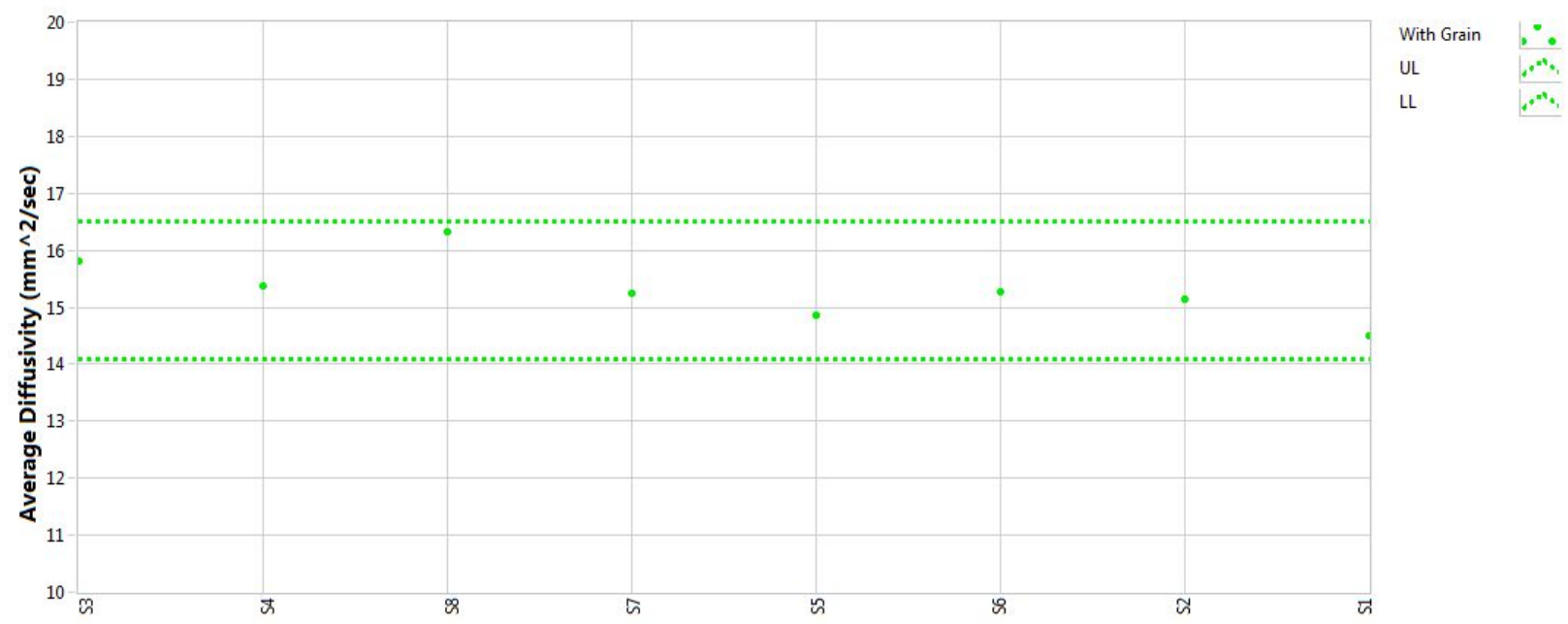

Figure A-104. SGL piggyback diffusivity at $400^{\circ} \mathrm{C}$. 


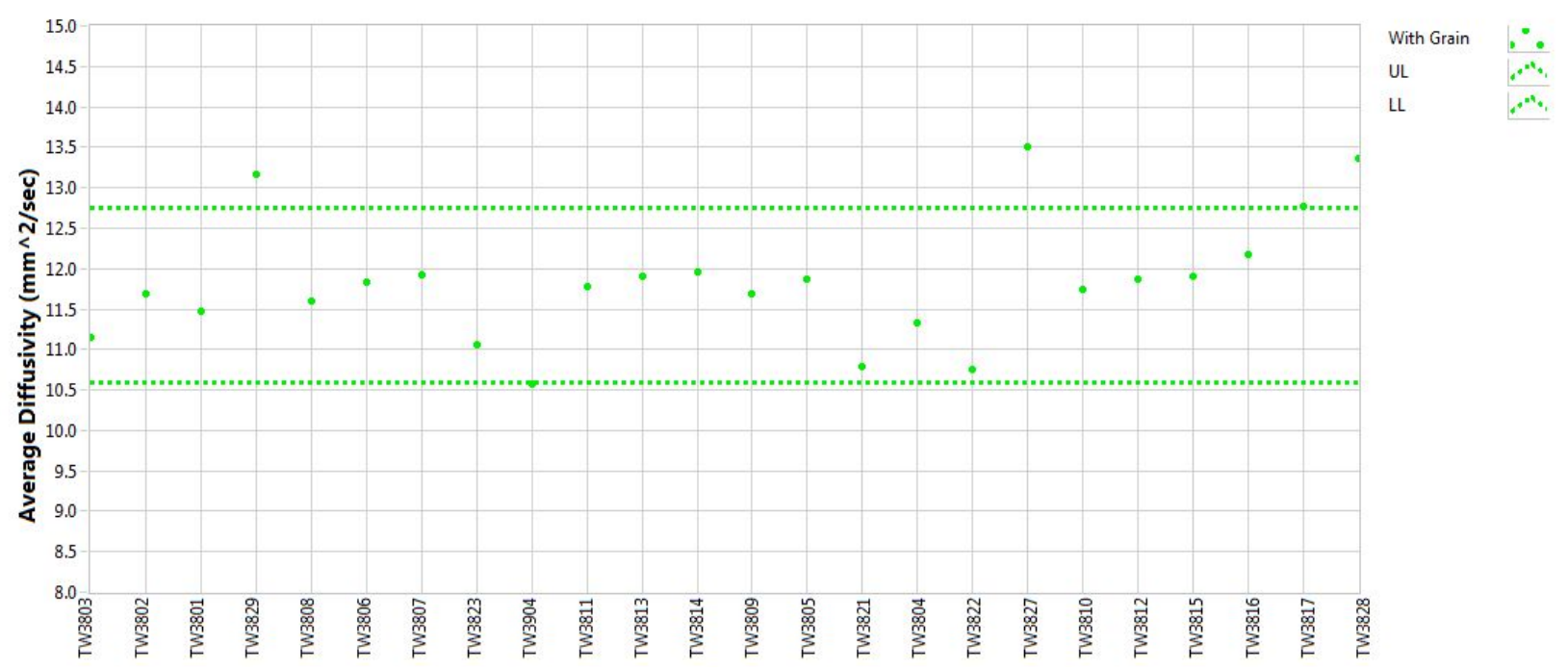

Figure A-105. 2114 piggyback diffusivity at $650^{\circ} \mathrm{C}$.

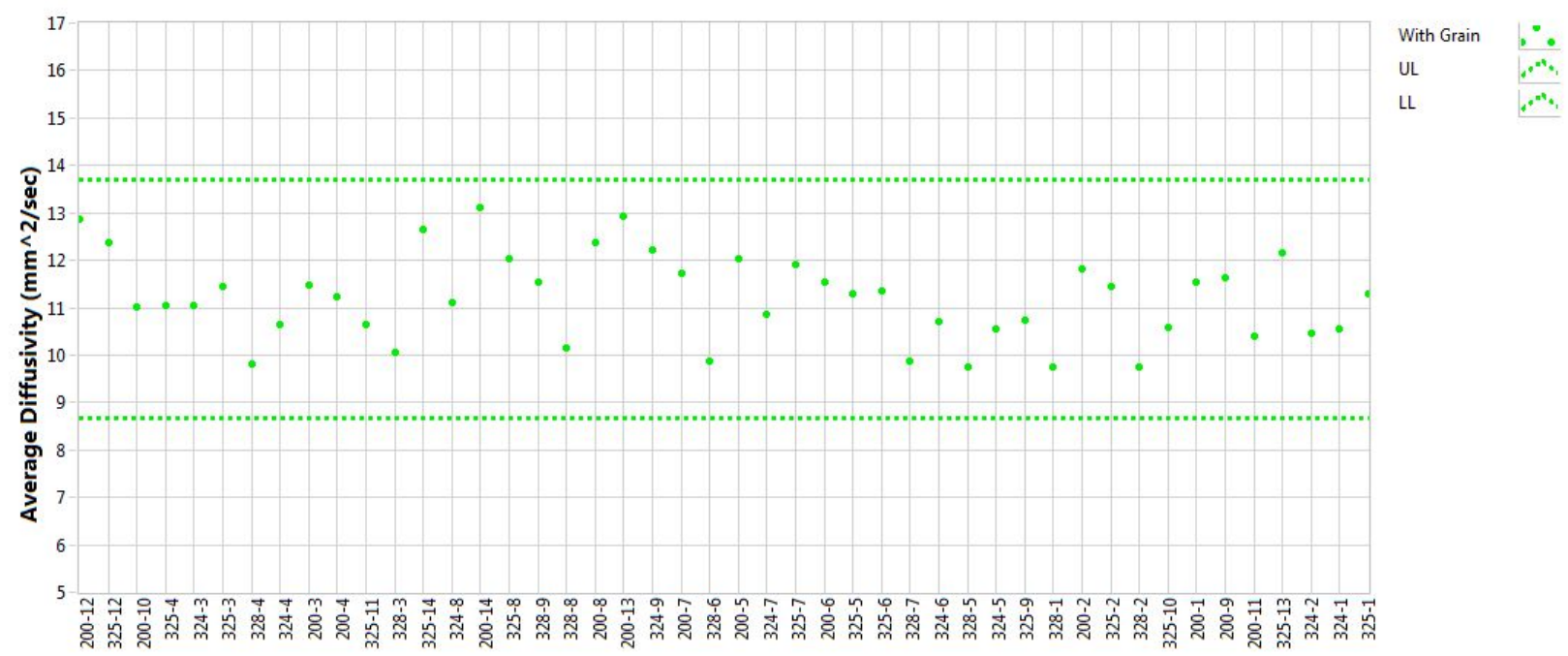

Figure A-106. GrafTech piggyback diffusivity at $650^{\circ} \mathrm{C}$. 


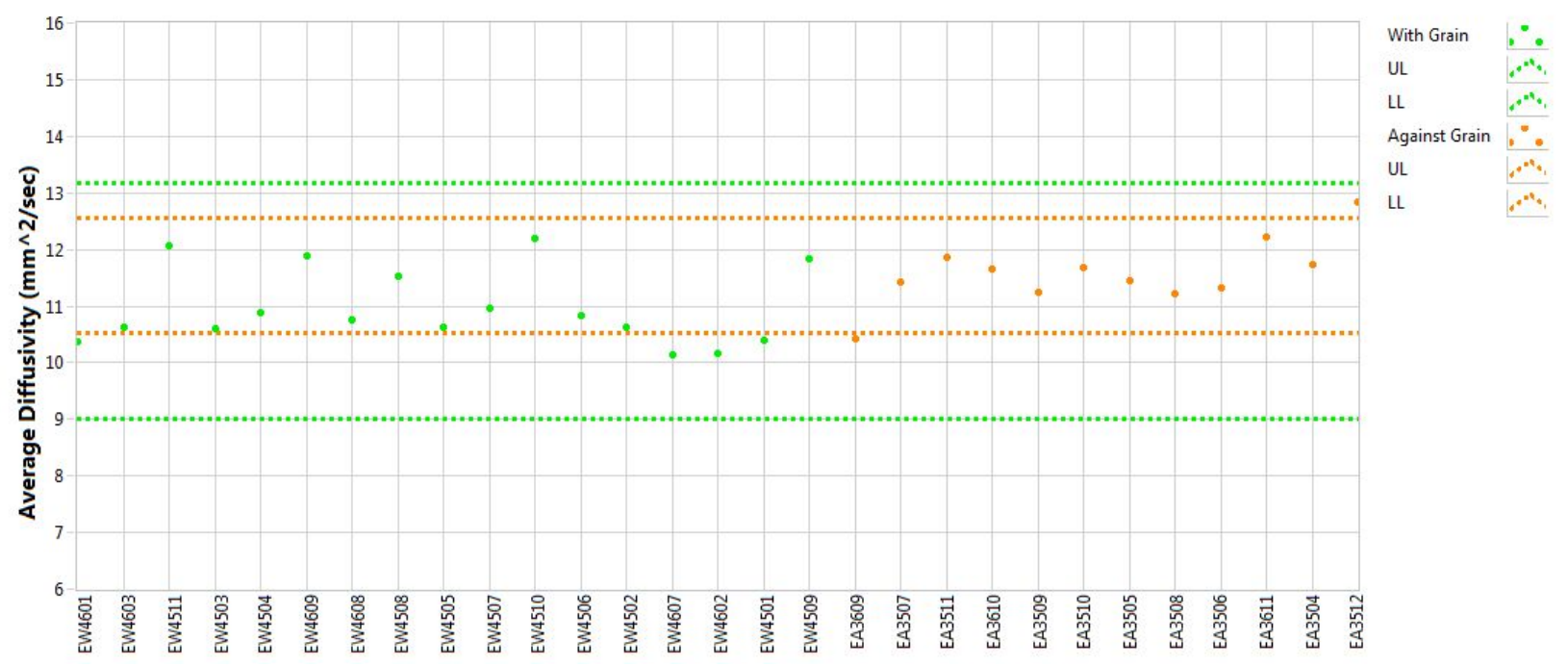

Figure A-107. IG-110 piggyback diffusivity at $650^{\circ} \mathrm{C}$.

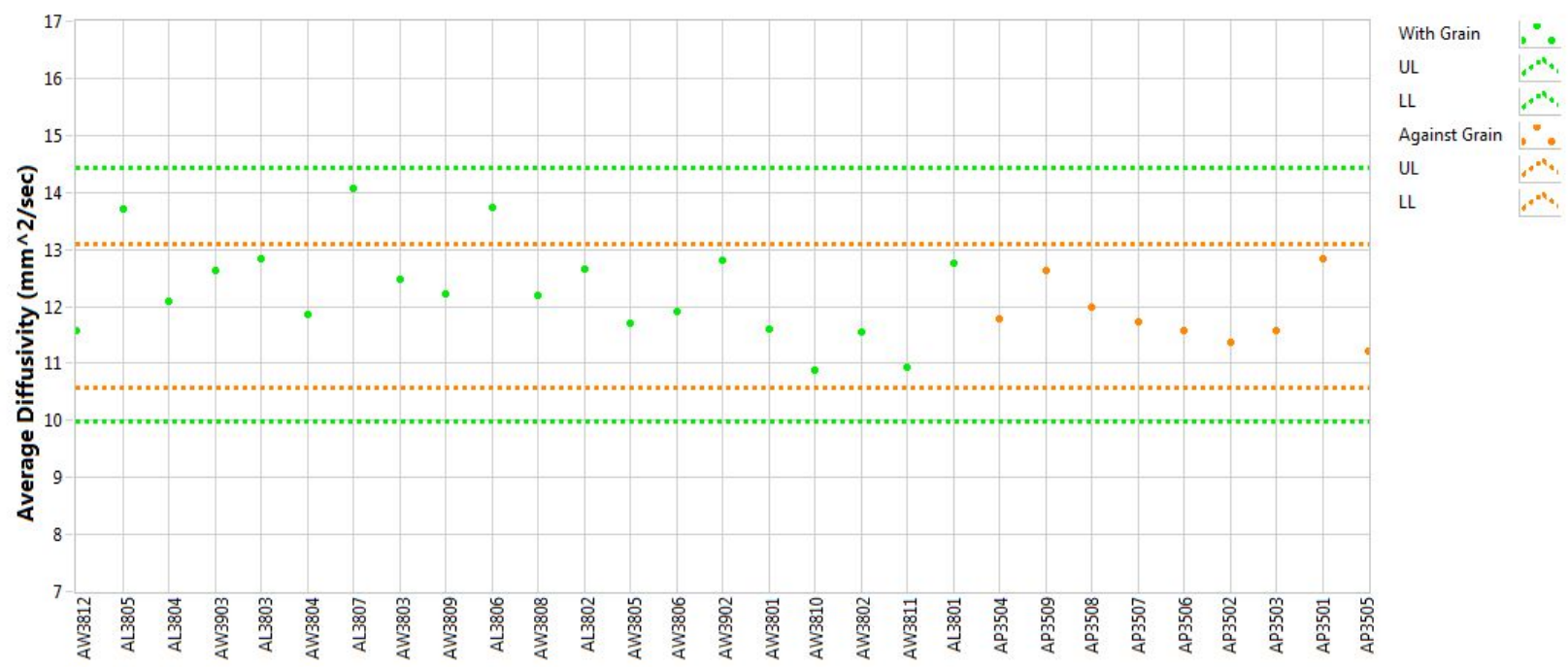

Figure A-108. NBG-17 piggyback diffusivity at $650^{\circ} \mathrm{C}$. 


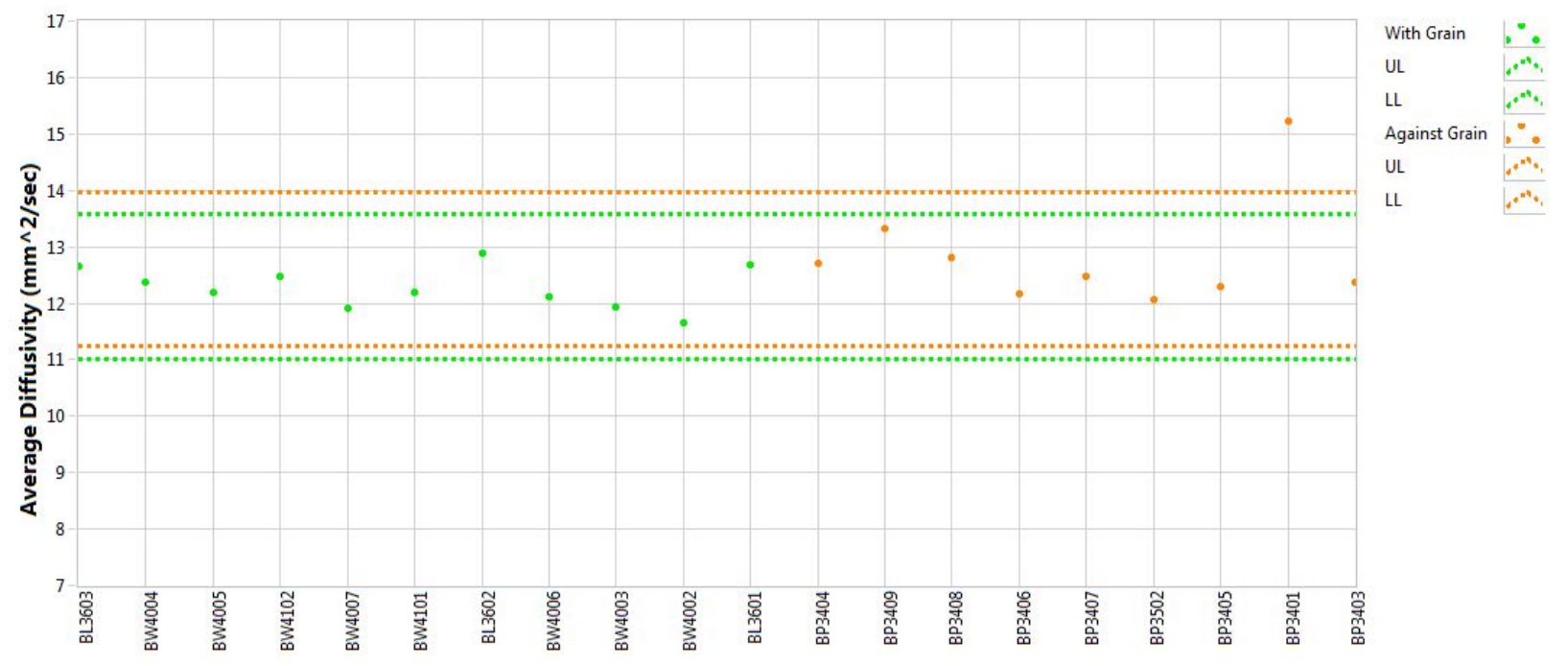

Figure A-109. NBG-18 piggyback diffusivity at $650^{\circ} \mathrm{C}$.

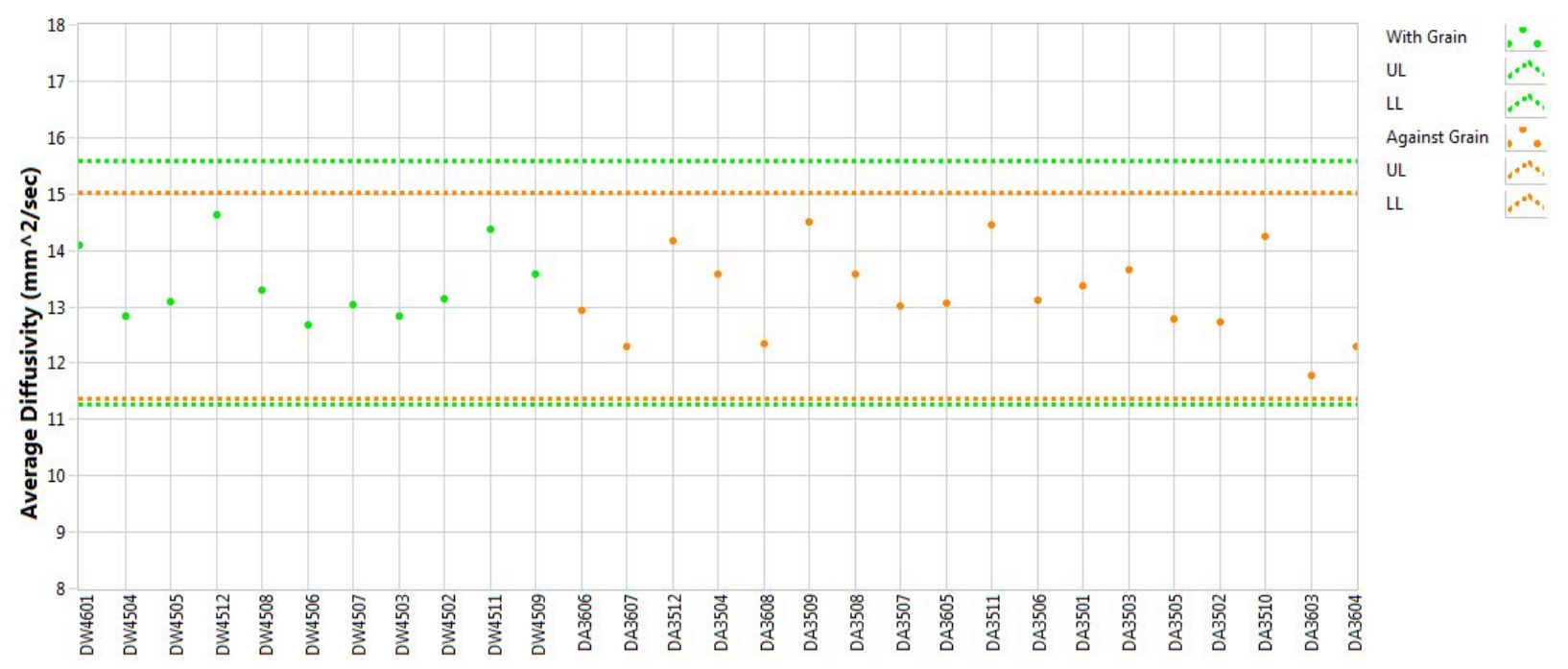

Figure A-110. PCEA piggyback diffusivity at $650^{\circ} \mathrm{C}$. 


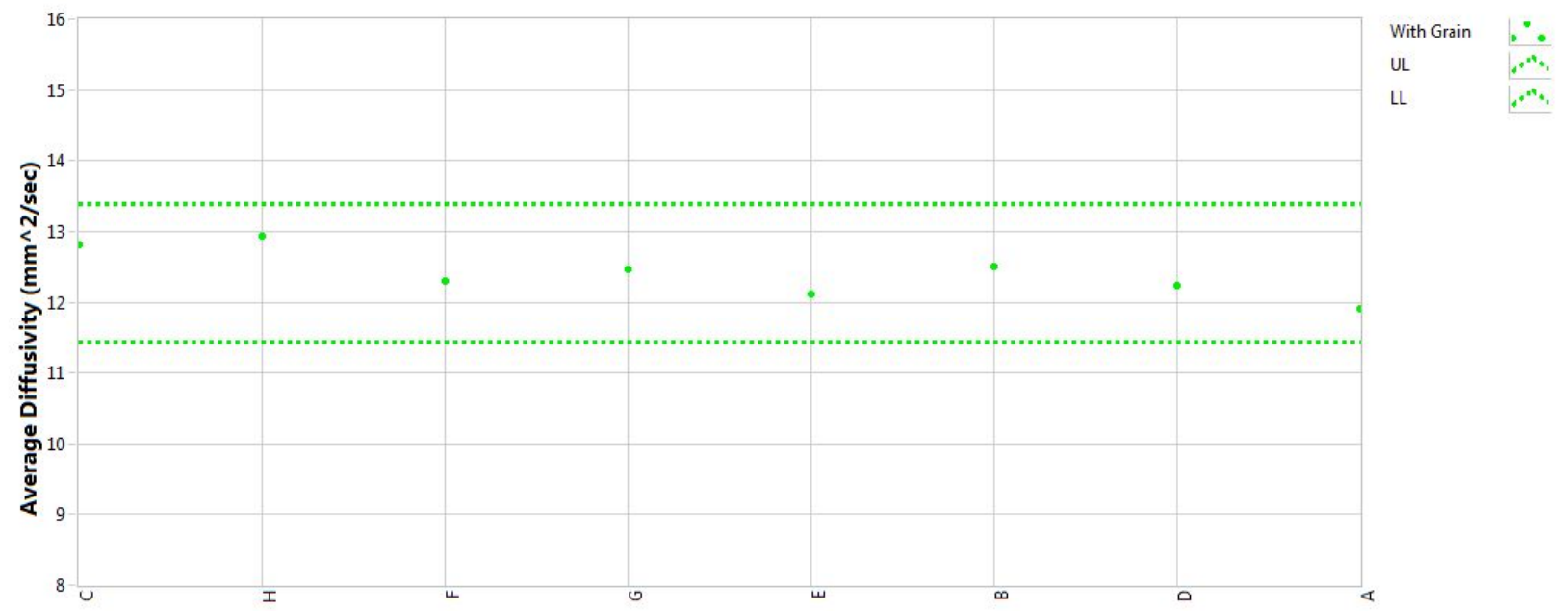

Figure A-111. SGL-SiC piggyback diffusivity at $650^{\circ} \mathrm{C}$.

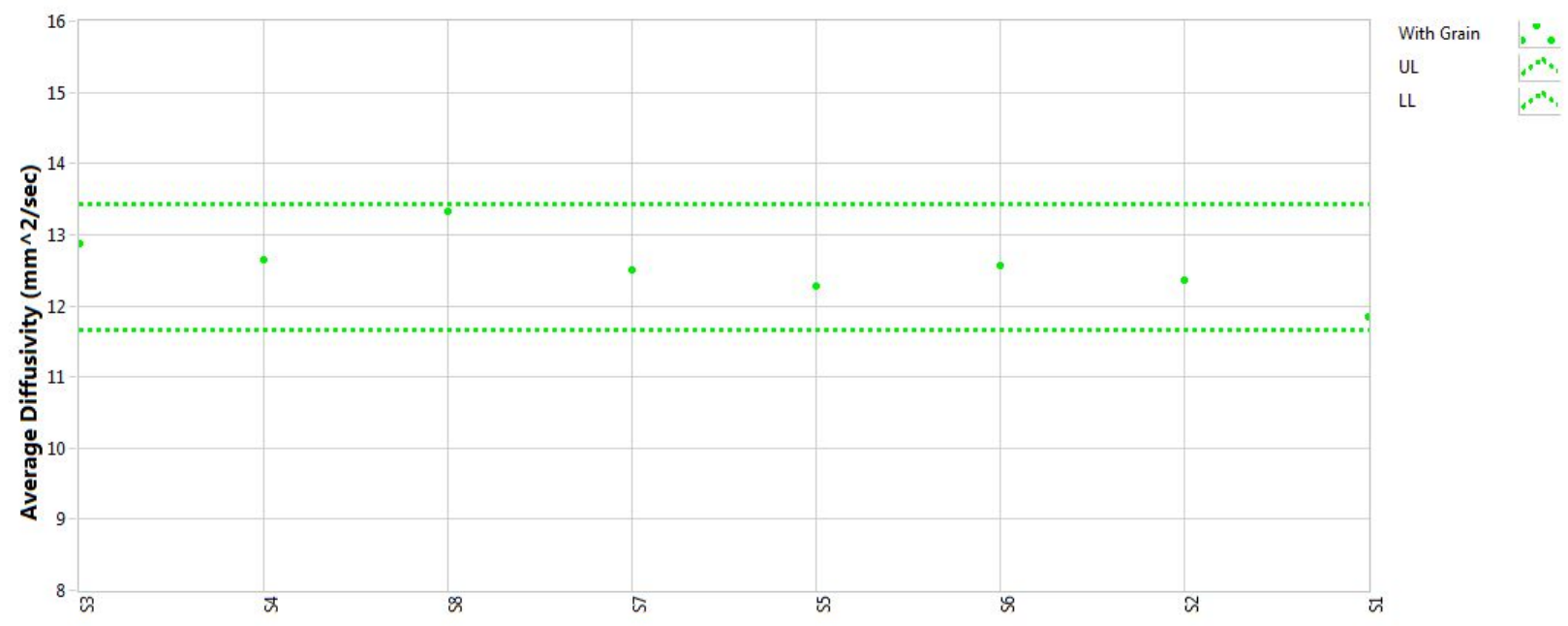

Figure A-112 SGL piggyback diffusivity at $650^{\circ} \mathrm{C}$. 
Appendix B

\section{Statistical Tables}




\section{Appendix B}

\section{Statistical Tables}

Table B-1. Creep specimen length (mm) summary statistics.

\begin{tabular}{|l|c|c|c|c|c|c|}
\hline $\begin{array}{l}\text { Combined } \\
\text { Specimens }\end{array}$ & Mean & Std Dev & CoV (\%) & Median & $\begin{array}{l}\text { Upper } \\
\text { Limit }\end{array}$ & $\begin{array}{c}\text { Lower } \\
\text { Limit }\end{array}$ \\
\hline $\mathbf{2 1 1 4}$ & 25.172 & 0.176 & 0.70 & 25.272 & 25.742 & 24.585 \\
\hline IG-110 & 25.069 & 0.201 & 0.80 & 25.160 & 25.757 & 24.349 \\
\hline NBG-17 & 25.034 & 0.216 & 0.86 & 25.135 & 25.718 & 24.302 \\
\hline NBG-18 & 25.140 & 0.177 & 0.70 & 25.207 & 25.761 & 24.484 \\
\hline PCEA & 25.020 & 0.234 & 0.94 & 25.109 & 25.743 & 24.280 \\
\hline
\end{tabular}

\begin{tabular}{|l|c|c|c|c|c|c|}
\hline $\begin{array}{l}\text { Against } \\
\text { Grain } \\
\text { Specimens }\end{array}$ & Mean & Std Dev & CoV (\%) & Median & $\begin{array}{c}\text { Upper } \\
\text { Limit }\end{array}$ & $\begin{array}{c}\text { Lower } \\
\text { Limit }\end{array}$ \\
\hline $\mathbf{2 1 1 4}$ & & & & & & \\
\hline IG-110 & 24.967 & 0.224 & 0.90 & 25.003 & 25.759 & 24.193 \\
\hline NBG-17 & 25.056 & 0.229 & 0.92 & 25.163 & 25.728 & 24.282 \\
\hline NBG-18 & 25.139 & 0.180 & 0.71 & 25.201 & 25.691 & 24.587 \\
\hline PCEA & 25.070 & 0.219 & 0.87 & 25.136 & 25.722 & 24.407 \\
\hline
\end{tabular}

\begin{tabular}{|l|c|c|c|c|c|c|}
\hline $\begin{array}{l}\text { With Grain } \\
\text { Specimens }\end{array}$ & Mean & Std Dev & CoV (\%) & Median & $\begin{array}{c}\text { Upper } \\
\text { Limit }\end{array}$ & $\begin{array}{c}\text { Lower } \\
\text { Limit }\end{array}$ \\
\hline $\mathbf{2 1 1 4}$ & 25.172 & 0.176 & 0.70 & 25.272 & 25.742 & 24.585 \\
\hline IG-110 & 25.110 & 0.178 & 0.71 & 25.174 & 25.684 & 24.544 \\
\hline NBG-17 & 25.011 & 0.206 & 0.83 & 25.076 & 25.664 & 24.395 \\
\hline NBG-18 & 25.141 & 0.179 & 0.71 & 25.223 & 25.763 & 24.484 \\
\hline PCEA & 25.003 & 0.240 & 0.96 & 25.104 & 25.743 & 24.280 \\
\hline
\end{tabular}


Table B-2. Creep specimen diameter (mm) summary statistics.

\begin{tabular}{|l|c|c|c|c|c|c|}
\hline $\begin{array}{l}\text { Combined } \\
\text { Specimens }\end{array}$ & Mean & Std Dev & CoV (\%) & Median & $\begin{array}{c}\text { Upper } \\
\text { Limit }\end{array}$ & $\begin{array}{c}\text { Lower } \\
\text { Limit }\end{array}$ \\
\hline $\mathbf{2 1 1 4}$ & 12.475 & 0.031 & 0.25 & 12.463 & 12.579 & 12.372 \\
\hline IG-110 & 12.460 & 0.035 & 0.28 & 12.462 & 12.579 & 12.337 \\
\hline NBG-17 & 12.414 & 0.036 & 0.29 & 12.421 & 12.537 & 12.280 \\
\hline NBG-18 & 12.456 & 0.034 & 0.27 & 12.455 & 12.572 & 12.347 \\
\hline PCEA & 12.423 & 0.037 & 0.30 & 12.425 & 12.532 & 12.320 \\
\hline
\end{tabular}

\begin{tabular}{|l|c|c|c|c|c|c|}
\hline $\begin{array}{l}\text { Against } \\
\text { Grain } \\
\text { Specimens }\end{array}$ & Mean & Std Dev & CoV (\%) & Median & $\begin{array}{c}\text { Upper } \\
\text { Limit }\end{array}$ & $\begin{array}{c}\text { Lower } \\
\text { Limit }\end{array}$ \\
\hline $\mathbf{2 1 1 4}$ & & & & & & \\
\hline IG-110 & 12.439 & 0.029 & 0.23 & 12.439 & 12.529 & 12.352 \\
\hline NBG-17 & 12.411 & 0.041 & 0.33 & 12.423 & 12.550 & 12.258 \\
\hline NBG-18 & 12.455 & 0.038 & 0.31 & 12.451 & 12.590 & 12.326 \\
\hline PCEA & 12.421 & 0.037 & 0.30 & 12.426 & 12.508 & 12.344 \\
\hline
\end{tabular}

\begin{tabular}{|l|c|c|c|c|c|c|}
\hline $\begin{array}{l}\text { With Grain } \\
\text { Specimens }\end{array}$ & Mean & Std Dev & CoV (\%) & Median & $\begin{array}{c}\text { Upper } \\
\text { Limit }\end{array}$ & $\begin{array}{c}\text { Lower } \\
\text { Limit }\end{array}$ \\
\hline $\mathbf{2 1 1 4}$ & 12.475 & 0.031 & 0.25 & 12.463 & 12.579 & 12.372 \\
\hline IG-110 & 12.468 & 0.034 & 0.27 & 12.477 & 12.571 & 12.366 \\
\hline NBG-17 & 12.416 & 0.032 & 0.26 & 12.419 & 12.525 & 12.303 \\
\hline NBG-18 & 12.457 & 0.030 & 0.24 & 12.456 & 12.545 & 12.367 \\
\hline PCEA & 12.424 & 0.037 & 0.30 & 12.424 & 12.534 & 12.318 \\
\hline
\end{tabular}


Table B-3. Creep specimen mass (g) summary statistics.

\begin{tabular}{|l|c|c|c|c|c|c|}
\hline $\begin{array}{l}\text { Combined } \\
\text { Specimens }\end{array}$ & Mean & Std Dev & CoV (\%) & Median & $\begin{array}{c}\text { Upper } \\
\text { Limit }\end{array}$ & $\begin{array}{c}\text { Lower } \\
\text { Limit }\end{array}$ \\
\hline $\mathbf{2 1 1 4}$ & 5.534 & 0.010 & 0.18 & 5.533 & 5.558 & 5.512 \\
\hline IG-110 & 5.391 & 0.032 & 0.60 & 5.399 & 5.462 & 5.327 \\
\hline NBG-17 & 5.549 & 0.018 & 0.33 & 5.543 & 5.603 & 5.497 \\
\hline NBG-18 & 5.665 & 0.020 & 0.36 & 5.665 & 5.726 & 5.602 \\
\hline PCEA & 5.417 & 0.020 & 0.37 & 5.416 & 5.453 & 5.379 \\
\hline
\end{tabular}

\begin{tabular}{|l|c|c|c|c|c|c|}
\hline $\begin{array}{l}\text { Against } \\
\text { Grain } \\
\text { Specimens }\end{array}$ & Mean & Std Dev & CoV (\%) & Median & $\begin{array}{c}\text { Upper } \\
\text { Limit }\end{array}$ & $\begin{array}{c}\text { Lower } \\
\text { Limit }\end{array}$ \\
\hline $\mathbf{2 1 1 4}$ & & & & & & \\
\hline IG-110 & 5.357 & 0.035 & 0.66 & 5.364 & 5.441 & 5.280 \\
\hline NBG-17 & 5.547 & 0.019 & 0.35 & 5.542 & 5.600 & 5.496 \\
\hline NBG-18 & 5.676 & 0.017 & 0.30 & 5.679 & 5.727 & 5.630 \\
\hline PCEA & 5.437 & 0.024 & 0.44 & 5.434 & 5.491 & 5.375 \\
\hline
\end{tabular}

\begin{tabular}{|l|c|c|c|c|c|c|}
\hline $\begin{array}{l}\text { With Grain } \\
\text { Specimens }\end{array}$ & Mean & Std Dev & CoV (\%) & Median & $\begin{array}{c}\text { Upper } \\
\text { Limit }\end{array}$ & $\begin{array}{c}\text { Lower } \\
\text { Limit }\end{array}$ \\
\hline $\mathbf{2 1 1 4}$ & 5.534 & 0.010 & 0.18 & 5.533 & 5.558 & 5.512 \\
\hline IG-110 & 5.404 & 0.018 & 0.34 & 5.403 & 5.462 & 5.348 \\
\hline NBG-17 & 5.552 & 0.018 & 0.32 & 5.543 & 5.609 & 5.496 \\
\hline NBG-18 & 5.653 & 0.015 & 0.27 & 5.651 & 5.697 & 5.606 \\
\hline PCEA & 5.411 & 0.014 & 0.25 & 5.413 & 5.450 & 5.372 \\
\hline
\end{tabular}


Table B-4. Creep specimen density $\left(\mathrm{g} / \mathrm{cm}^{3}\right)$ summary statistics.

\begin{tabular}{|c|c|c|c|c|c|c|}
\hline $\begin{array}{l}\text { Combined } \\
\text { Specimens }\end{array}$ & Mean & Std Dev & CoV (\%) & Median & $\begin{array}{l}\text { Upper } \\
\text { Limit }\end{array}$ & $\begin{array}{c}\text { Lower } \\
\text { Limit }\end{array}$ \\
\hline 2114 & 1.8197 & 0.0082 & 0.45 & 1.8196 & 1.8381 & 1.7990 \\
\hline IG-110 & 1.7976 & 0.0147 & 0.82 & 1.7999 & 1.8368 & 1.7540 \\
\hline NBG-17 & 1.8621 & 0.0193 & 1.04 & 1.8631 & 1.9005 & 1.8227 \\
\hline NBG-18 & 1.8833 & 0.0200 & 1.06 & 1.8853 & 1.9441 & 1.8253 \\
\hline PCEA & 1.8148 & 0.0200 & 1.10 & 1.8118 & 1.8642 & 1.7594 \\
\hline $\begin{array}{l}\text { Against } \\
\text { Grain } \\
\text { Specimens }\end{array}$ & Mean & Std Dev & CoV (\%) & Median & $\begin{array}{l}\text { Upper } \\
\text { Limit }\end{array}$ & $\begin{array}{c}\text { Lower } \\
\text { Limit }\end{array}$ \\
\hline \multicolumn{7}{|l|}{2114} \\
\hline IG-110 & 1.8026 & 0.0176 & 0.98 & 1.8051 & 1.8544 & 1.7532 \\
\hline NBG-17 & 1.8613 & 0.0251 & 1.35 & 1.8597 & 1.9363 & 1.7999 \\
\hline NBG-18 & 1.8891 & 0.0171 & 0.90 & 1.8944 & 1.9333 & 1.8461 \\
\hline PCEA & 1.8164 & 0.0271 & 1.49 & 1.8074 & 1.8794 & 1.7468 \\
\hline
\end{tabular}

\begin{tabular}{|l|c|c|c|c|c|c|}
\hline $\begin{array}{l}\text { With Grain } \\
\text { Specimens }\end{array}$ & Mean & Std Dev & CoV (\%) & Median & $\begin{array}{c}\text { Upper } \\
\text { Limit }\end{array}$ & $\begin{array}{c}\text { Lower } \\
\text { Limit }\end{array}$ \\
\hline $\mathbf{2 1 1 4}$ & 1.8197 & 0.0082 & 0.45 & 1.8196 & 1.8381 & 1.7990 \\
\hline IG-110 & 1.7956 & 0.0132 & 0.74 & 1.7948 & 1.8328 & 1.7564 \\
\hline NBG-17 & 1.8629 & 0.0117 & 0.63 & 1.8655 & 1.8939 & 1.8291 \\
\hline NBG-18 & 1.8774 & 0.0214 & 1.14 & 1.8734 & 1.9572 & 1.7935 \\
\hline PCEA & 1.8142 & 0.0175 & 0.97 & 1.8141 & 1.8567 & 1.7703 \\
\hline
\end{tabular}


Table B-5. Creep specimen coefficient of thermal expansion $(1 / \mathrm{k})$ summary statistics at $100^{\circ} \mathrm{C}$.

\begin{tabular}{|l|c|c|c|c|l|l|}
\hline $\begin{array}{l}\text { Combined } \\
\text { Specimens }\end{array}$ & Mean & Std Dev & CoV (\%) & Median & $\begin{array}{l}\text { Upper } \\
\text { Limit }\end{array}$ & $\begin{array}{l}\text { Lower } \\
\text { Limit }\end{array}$ \\
\hline $\mathbf{2 1 1 4}$ & $5.28 \mathrm{E}-06$ & $5.23 \mathrm{E}-07$ & 9.90 & $5.12 \mathrm{E}-06$ & $7.34 \mathrm{E}-06$ & $3.37 \mathrm{E}-06$ \\
\hline IG-110 & $4.38 \mathrm{E}-06$ & $5.28 \mathrm{E}-07$ & 12.07 & $4.28 \mathrm{E}-06$ & $5.97 \mathrm{E}-06$ & $2.77 \mathrm{E}-06$ \\
\hline NBG-17 & $4.79 \mathrm{E}-06$ & $4.93 \mathrm{E}-07$ & 10.29 & $4.81 \mathrm{E}-06$ & $6.47 \mathrm{E}-06$ & $3.20 \mathrm{E}-06$ \\
\hline NBG-18 & $4.75 \mathrm{E}-06$ & $4.13 \mathrm{E}-07$ & 8.71 & $4.74 \mathrm{E}-06$ & $6.14 \mathrm{E}-06$ & $3.34 \mathrm{E}-06$ \\
\hline PCEA & $4.63 \mathrm{E}-06$ & $5.11 \mathrm{E}-07$ & 11.04 & $4.63 \mathrm{E}-06$ & $6.25 \mathrm{E}-06$ & $2.95 \mathrm{E}-06$ \\
\hline
\end{tabular}

\begin{tabular}{|l|c|c|c|c|l|l|}
\hline $\begin{array}{l}\text { Against } \\
\text { Grain } \\
\text { Specimens }\end{array}$ & Mean & Std Dev & CoV (\%) & Median & $\begin{array}{l}\text { Upper } \\
\text { Limit }\end{array}$ & $\begin{array}{l}\text { Lower } \\
\text { Limit }\end{array}$ \\
\hline $\mathbf{2 1 1 4}$ & & & & & & \\
\hline IG-110 & $4.13 \mathrm{E}-06$ & $4.17 \mathrm{E}-07$ & 10.10 & $4.13 \mathrm{E}-06$ & $5.58 \mathrm{E}-06$ & $2.62 \mathrm{E}-06$ \\
\hline NBG-17 & $4.84 \mathrm{E}-06$ & $5.12 \mathrm{E}-07$ & 10.56 & $4.83 \mathrm{E}-06$ & $6.49 \mathrm{E}-06$ & $3.33 \mathrm{E}-06$ \\
\hline NBG-18 & $4.67 \mathrm{E}-06$ & $4.30 \mathrm{E}-07$ & 9.22 & $4.75 \mathrm{E}-06$ & $6.15 \mathrm{E}-06$ & $3.12 \mathrm{E}-06$ \\
\hline PCEA & $4.88 \mathrm{E}-06$ & $4.80 \mathrm{E}-07$ & 9.85 & $4.86 \mathrm{E}-06$ & $6.60 \mathrm{E}-06$ & $3.18 \mathrm{E}-06$ \\
\hline
\end{tabular}

\begin{tabular}{|l|c|c|c|c|c|c|}
\hline $\begin{array}{l}\text { With Grain } \\
\text { Specimens }\end{array}$ & Mean & Std Dev & CoV (\%) & Median & $\begin{array}{l}\text { Upper } \\
\text { Limit }\end{array}$ & $\begin{array}{l}\text { Lower } \\
\text { Limit }\end{array}$ \\
\hline $\mathbf{2 1 1 4}$ & $5.28 \mathrm{E}-06$ & $5.23 \mathrm{E}-07$ & 9.90 & $5.12 \mathrm{E}-06$ & $7.34 \mathrm{E}-06$ & $3.37 \mathrm{E}-06$ \\
\hline IG-110 & $4.48 \mathrm{E}-06$ & $5.40 \mathrm{E}-07$ & 12.08 & $4.51 \mathrm{E}-06$ & $6.27 \mathrm{E}-06$ & $2.71 \mathrm{E}-06$ \\
\hline NBG-17 & $4.73 \mathrm{E}-06$ & $4.82 \mathrm{E}-07$ & 10.17 & $4.68 \mathrm{E}-06$ & $6.55 \mathrm{E}-06$ & $3.05 \mathrm{E}-06$ \\
\hline NBG-18 & $4.83 \mathrm{E}-06$ & $3.89 \mathrm{E}-07$ & 8.06 & $4.73 \mathrm{E}-06$ & $6.03 \mathrm{E}-06$ & $3.67 \mathrm{E}-06$ \\
\hline PCEA & $4.55 \mathrm{E}-06$ & $5.01 \mathrm{E}-07$ & 11.02 & $4.56 \mathrm{E}-06$ & $6.24 \mathrm{E}-06$ & $2.80 \mathrm{E}-06$ \\
\hline
\end{tabular}


Table B-6. Creep specimen coefficient of thermal expansion $(1 / \mathrm{k})$ summary statistics at $400^{\circ} \mathrm{C}$.

\begin{tabular}{|l|c|c|c|c|l|l|}
\hline $\begin{array}{l}\text { Combined } \\
\text { Specimens }\end{array}$ & Mean & Std Dev & CoV (\%) & Median & $\begin{array}{l}\text { Upper } \\
\text { Limit }\end{array}$ & $\begin{array}{l}\text { Lower } \\
\text { Limit }\end{array}$ \\
\hline $\mathbf{2 1 1 4}$ & $5.71 \mathrm{E}-06$ & $5.52 \mathrm{E}-07$ & 9.67 & $5.59 \mathrm{E}-06$ & $7.69 \mathrm{E}-06$ & $3.92 \mathrm{E}-06$ \\
\hline IG-110 & $4.75 \mathrm{E}-06$ & $5.38 \mathrm{E}-07$ & 11.32 & $4.64 \mathrm{E}-06$ & $6.42 \mathrm{E}-06$ & $3.02 \mathrm{E}-06$ \\
\hline NBG-17 & $5.20 \mathrm{E}-06$ & $5.41 \mathrm{E}-07$ & 10.40 & $5.31 \mathrm{E}-06$ & $7.08 \mathrm{E}-06$ & $3.27 \mathrm{E}-06$ \\
\hline NBG-18 & $5.17 \mathrm{E}-06$ & $4.52 \mathrm{E}-07$ & 8.75 & $5.20 \mathrm{E}-06$ & $6.72 \mathrm{E}-06$ & $3.60 \mathrm{E}-06$ \\
\hline PCEA & $5.07 \mathrm{E}-06$ & $5.33 \mathrm{E}-07$ & 10.52 & $5.13 \mathrm{E}-06$ & $6.83 \mathrm{E}-06$ & $3.17 \mathrm{E}-06$ \\
\hline
\end{tabular}

\begin{tabular}{|l|c|c|c|c|l|l|}
\hline $\begin{array}{l}\text { Against } \\
\text { Grain } \\
\text { Specimens }\end{array}$ & Mean & Std Dev & CoV (\%) & Median & $\begin{array}{l}\text { Upper } \\
\text { Limit }\end{array}$ & $\begin{array}{l}\text { Lower } \\
\text { Limit }\end{array}$ \\
\hline $\mathbf{2 1 1 4}$ & & & & & & \\
\hline IG-110 & $4.45 \mathrm{E}-06$ & $4.43 \mathrm{E}-07$ & 9.96 & $4.55 \mathrm{E}-06$ & $5.93 \mathrm{E}-06$ & $2.85 \mathrm{E}-06$ \\
\hline NBG-17 & $5.28 \mathrm{E}-06$ & $5.53 \mathrm{E}-07$ & 10.48 & $5.33 \mathrm{E}-06$ & $7.21 \mathrm{E}-06$ & $3.49 \mathrm{E}-06$ \\
\hline NBG-18 & $5.12 \mathrm{E}-06$ & $4.51 \mathrm{E}-07$ & 8.81 & $5.17 \mathrm{E}-06$ & $6.61 \mathrm{E}-06$ & $3.55 \mathrm{E}-06$ \\
\hline PCEA & $5.35 \mathrm{E}-06$ & $4.85 \mathrm{E}-07$ & 9.06 & $5.33 \mathrm{E}-06$ & $7.09 \mathrm{E}-06$ & $3.67 \mathrm{E}-06$ \\
\hline
\end{tabular}

\begin{tabular}{|l|c|c|c|c|c|c|}
\hline $\begin{array}{l}\text { With Grain } \\
\text { Specimens }\end{array}$ & Mean & Std Dev & CoV (\%) & Median & $\begin{array}{l}\text { Upper } \\
\text { Limit }\end{array}$ & $\begin{array}{l}\text { Lower } \\
\text { Limit }\end{array}$ \\
\hline $\mathbf{2 1 1 4}$ & $5.71 \mathrm{E}-06$ & $5.52 \mathrm{E}-07$ & 9.67 & $5.59 \mathrm{E}-06$ & $7.69 \mathrm{E}-06$ & $3.92 \mathrm{E}-06$ \\
\hline IG-110 & $4.87 \mathrm{E}-06$ & $5.30 \mathrm{E}-07$ & 10.89 & $4.94 \mathrm{E}-06$ & $6.75 \mathrm{E}-06$ & $2.99 \mathrm{E}-06$ \\
\hline NBG-17 & $5.12 \mathrm{E}-06$ & $5.31 \mathrm{E}-07$ & 10.37 & $5.01 \mathrm{E}-06$ & $6.93 \mathrm{E}-06$ & $3.24 \mathrm{E}-06$ \\
\hline NBG-18 & $5.23 \mathrm{E}-06$ & $4.57 \mathrm{E}-07$ & 8.75 & $5.21 \mathrm{E}-06$ & $6.62 \mathrm{E}-06$ & $3.80 \mathrm{E}-06$ \\
\hline PCEA & $4.98 \mathrm{E}-06$ & $5.21 \mathrm{E}-07$ & 10.48 & $4.99 \mathrm{E}-06$ & $6.62 \mathrm{E}-06$ & $3.24 \mathrm{E}-06$ \\
\hline
\end{tabular}


Table B-7. Creep specimen coefficient of thermal expansion $(1 / \mathrm{k})$ summary statistics at $650^{\circ} \mathrm{C}$.

\begin{tabular}{|l|c|c|c|c|l|l|}
\hline $\begin{array}{l}\text { Combined } \\
\text { Specimens }\end{array}$ & Mean & Std Dev & CoV (\%) & Median & $\begin{array}{l}\text { Upper } \\
\text { Limit }\end{array}$ & $\begin{array}{l}\text { Lower } \\
\text { Limit }\end{array}$ \\
\hline $\mathbf{2 1 1 4}$ & $6.05 \mathrm{E}-06$ & $5.63 \mathrm{E}-07$ & 9.29 & $5.90 \mathrm{E}-06$ & $8.05 \mathrm{E}-06$ & $4.25 \mathrm{E}-06$ \\
\hline IG-110 & $5.20 \mathrm{E}-06$ & $5.64 \mathrm{E}-07$ & 10.84 & $5.07 \mathrm{E}-06$ & $6.79 \mathrm{E}-06$ & $3.55 \mathrm{E}-06$ \\
\hline NBG-17 & $5.54 \mathrm{E}-06$ & $5.57 \mathrm{E}-07$ & 10.06 & $5.61 \mathrm{E}-06$ & $7.56 \mathrm{E}-06$ & $3.48 \mathrm{E}-06$ \\
\hline NBG-18 & $5.52 \mathrm{E}-06$ & $4.81 \mathrm{E}-07$ & 8.73 & $5.54 \mathrm{E}-06$ & $7.22 \mathrm{E}-06$ & $3.74 \mathrm{E}-06$ \\
\hline PCEA & $5.45 \mathrm{E}-06$ & $5.62 \mathrm{E}-07$ & 10.30 & $5.48 \mathrm{E}-06$ & $7.28 \mathrm{E}-06$ & $3.50 \mathrm{E}-06$ \\
\hline
\end{tabular}

\begin{tabular}{|l|c|c|c|c|l|l|}
\hline $\begin{array}{l}\text { Against } \\
\text { Grain } \\
\text { Specimens }\end{array}$ & Mean & Std Dev & CoV (\%) & Median & $\begin{array}{l}\text { Upper } \\
\text { Limit }\end{array}$ & $\begin{array}{l}\text { Lower } \\
\text { Limit }\end{array}$ \\
\hline $\mathbf{2 1 1 4}$ & & & & & & \\
\hline IG-110 & $4.89 \mathrm{E}-06$ & $4.72 \mathrm{E}-07$ & 9.66 & $5.00 \mathrm{E}-06$ & $6.33 \mathrm{E}-06$ & $3.37 \mathrm{E}-06$ \\
\hline NBG-17 & $5.62 \mathrm{E}-06$ & $5.67 \mathrm{E}-07$ & 10.09 & $5.69 \mathrm{E}-06$ & $7.55 \mathrm{E}-06$ & $3.91 \mathrm{E}-06$ \\
\hline NBG-18 & $5.47 \mathrm{E}-06$ & $4.73 \mathrm{E}-07$ & 8.65 & $5.50 \mathrm{E}-06$ & $7.03 \mathrm{E}-06$ & $3.83 \mathrm{E}-06$ \\
\hline PCEA & $5.72 \mathrm{E}-06$ & $5.04 \mathrm{E}-07$ & 8.81 & $5.69 \mathrm{E}-06$ & $7.51 \mathrm{E}-06$ & $3.99 \mathrm{E}-06$ \\
\hline
\end{tabular}

\begin{tabular}{|l|c|c|c|c|c|c|}
\hline $\begin{array}{l}\text { With Grain } \\
\text { Specimens }\end{array}$ & Mean & Std Dev & CoV (\%) & Median & $\begin{array}{l}\text { Upper } \\
\text { Limit }\end{array}$ & $\begin{array}{l}\text { Lower } \\
\text { Limit }\end{array}$ \\
\hline $\mathbf{2 1 1 4}$ & $6.05 \mathrm{E}-06$ & $5.63 \mathrm{E}-07$ & 9.29 & $5.90 \mathrm{E}-06$ & $8.05 \mathrm{E}-06$ & $4.25 \mathrm{E}-06$ \\
\hline IG-110 & $5.33 \mathrm{E}-06$ & $5.55 \mathrm{E}-07$ & 10.41 & $5.40 \mathrm{E}-06$ & $7.48 \mathrm{E}-06$ & $3.24 \mathrm{E}-06$ \\
\hline NBG-17 & $5.45 \mathrm{E}-06$ & $5.50 \mathrm{E}-07$ & 10.09 & $5.34 \mathrm{E}-06$ & $7.28 \mathrm{E}-06$ & $3.55 \mathrm{E}-06$ \\
\hline NBG-18 & $5.57 \mathrm{E}-06$ & $4.95 \mathrm{E}-07$ & 8.89 & $5.61 \mathrm{E}-06$ & $7.01 \mathrm{E}-06$ & $4.11 \mathrm{E}-06$ \\
\hline PCEA & $5.36 \mathrm{E}-06$ & $5.57 \mathrm{E}-07$ & 10.38 & $5.33 \mathrm{E}-06$ & $7.17 \mathrm{E}-06$ & $3.47 \mathrm{E}-06$ \\
\hline
\end{tabular}


Table B-8. Creep specimen Young's modulus (GPa) by sonic resonance summary statistics.

\begin{tabular}{|l|c|c|c|c|c|c|}
\hline $\begin{array}{l}\text { Combined } \\
\text { Specimens }\end{array}$ & Mean & Std Dev & CoV (\%) & Median & $\begin{array}{c}\text { Upper } \\
\text { Limit }\end{array}$ & $\begin{array}{c}\text { Lower } \\
\text { Limit }\end{array}$ \\
\hline $\mathbf{2 1 1 4}$ & 17.11 & 0.50 & 2.94 & 17.07 & 18.47 & 15.72 \\
\hline IG-110 & 16.83 & 0.68 & 4.04 & 16.82 & 18.76 & 14.88 \\
\hline NBG-17 & 16.97 & 0.80 & 4.74 & 16.93 & 19.50 & 14.34 \\
\hline NBG-18 & 17.89 & 0.77 & 4.31 & 17.81 & 19.63 & 16.16 \\
\hline PCEA & 14.58 & 0.86 & 5.90 & 14.89 & 17.30 & 11.66 \\
\hline
\end{tabular}

\begin{tabular}{|l|c|c|c|c|c|c|}
\hline $\begin{array}{l}\text { Against } \\
\text { Grain } \\
\text { Specimens }\end{array}$ & Mean & Std Dev & CoV (\%) & Median & $\begin{array}{c}\text { Upper } \\
\text { Limit }\end{array}$ & $\begin{array}{c}\text { Lower } \\
\text { Limit }\end{array}$ \\
\hline $\mathbf{2 1 1 4}$ & & & & & & \\
\hline IG-110 & 17.40 & 0.71 & 4.09 & 17.44 & 18.97 & 15.47 \\
\hline NBG-17 & 16.84 & 0.95 & 5.66 & 16.53 & 19.71 & 14.13 \\
\hline NBG-18 & 18.16 & 0.65 & 3.58 & 17.89 & 20.06 & 16.28 \\
\hline PCEA & 15.34 & 0.48 & 3.13 & 15.23 & 16.45 & 14.17 \\
\hline
\end{tabular}

\begin{tabular}{|l|c|c|c|c|c|c|}
\hline $\begin{array}{l}\text { With Grain } \\
\text { Specimens }\end{array}$ & Mean & Std Dev & CoV (\%) & Median & $\begin{array}{c}\text { Upper } \\
\text { Limit }\end{array}$ & $\begin{array}{c}\text { Lower } \\
\text { Limit }\end{array}$ \\
\hline $\mathbf{2 1 1 4}$ & 17.11 & 0.50 & 2.94 & 17.07 & 18.47 & 15.72 \\
\hline IG-110 & 16.60 & 0.52 & 3.14 & 16.61 & 18.28 & 14.94 \\
\hline NBG-17 & 17.10 & 0.62 & 3.64 & 17.18 & 19.00 & 15.10 \\
\hline NBG-18 & 17.62 & 0.80 & 4.56 & 17.50 & 19.18 & 15.92 \\
\hline PCEA & 14.33 & 0.81 & 5.65 & 14.45 & 17.12 & 11.38 \\
\hline
\end{tabular}


Table B-9. Creep specimen resistivity $(\mu \Omega-\mathrm{m})$ summary statistics.

\begin{tabular}{|c|c|c|c|c|c|c|}
\hline $\begin{array}{l}\text { Combined } \\
\text { Specimens }\end{array}$ & Mean & Std Dev & CoV (\%) & Median & $\begin{array}{l}\text { Upper } \\
\text { Limit }\end{array}$ & $\begin{array}{c}\text { Lower } \\
\text { Limit }\end{array}$ \\
\hline 2114 & 24.83 & 0.70 & 2.80 & 24.58 & 26.20 & 23.28 \\
\hline IG-110 & 26.04 & 0.93 & 3.57 & 26.12 & 28.86 & 23.29 \\
\hline NBG-17 & 24.92 & 0.67 & 2.70 & 24.84 & 26.80 & 23.13 \\
\hline NBG-18 & 23.82 & 0.62 & 2.59 & 23.73 & 25.66 & 21.93 \\
\hline PCEA & 23.58 & 0.75 & 3.18 & 23.49 & 25.48 & 21.69 \\
\hline $\begin{array}{l}\text { Against } \\
\text { Grain } \\
\text { Specimens }\end{array}$ & Mean & Std Dev & $\operatorname{CoV}(\%)$ & Median & $\begin{array}{l}\text { Upper } \\
\text { Limit }\end{array}$ & $\begin{array}{c}\text { Lower } \\
\text { Limit }\end{array}$ \\
\hline \multicolumn{7}{|l|}{2114} \\
\hline IG-110 & 25.46 & 0.84 & 3.30 & 25.30 & 28.11 & 22.74 \\
\hline NBG-17 & 24.99 & 0.61 & 2.42 & 24.92 & 26.48 & 23.55 \\
\hline NBG-18 & 23.58 & 0.59 & 2.50 & 23.56 & 25.16 & 21.99 \\
\hline PCEA & 23.39 & 0.75 & 3.22 & 23.10 & 24.08 & 22.21 \\
\hline
\end{tabular}

\begin{tabular}{|l|c|c|c|c|c|c|}
\hline $\begin{array}{l}\text { With Grain } \\
\text { Specimens }\end{array}$ & Mean & Std Dev & CoV (\%) & Median & $\begin{array}{c}\text { Upper } \\
\text { Limit }\end{array}$ & $\begin{array}{c}\text { Lower } \\
\text { Limit }\end{array}$ \\
\hline $\mathbf{2 1 1 4}$ & 24.83 & 0.70 & 2.80 & 24.58 & 26.20 & 23.28 \\
\hline IG-110 & 26.29 & 0.86 & 3.29 & 26.47 & 29.08 & 23.52 \\
\hline NBG-17 & 24.85 & 0.74 & 2.98 & 24.64 & 26.83 & 23.09 \\
\hline NBG-18 & 24.07 & 0.55 & 2.30 & 24.06 & 25.72 & 22.45 \\
\hline PCEA & 23.66 & 0.75 & 3.17 & 23.70 & 25.25 & 22.08 \\
\hline
\end{tabular}


Table B-10. Creep specimen Young's modulus (GPa) by sonic velocity summary statistics.

\begin{tabular}{|l|c|c|c|c|c|c|}
\hline $\begin{array}{l}\text { Combined } \\
\text { Specimens }\end{array}$ & Mean & Std Dev & CoV (\%) & Median & $\begin{array}{c}\text { Upper } \\
\text { Limit }\end{array}$ & $\begin{array}{c}\text { Lower } \\
\text { Limit }\end{array}$ \\
\hline $\mathbf{2 1 1 4}$ & 19.72 & 0.53 & 2.71 & 19.69 & 20.99 & 18.32 \\
\hline IG-110 & 18.63 & 0.95 & 5.08 & 18.52 & 21.38 & 15.83 \\
\hline NBG-17 & 20.22 & 0.96 & 4.73 & 20.13 & 23.23 & 17.12 \\
\hline NBG-18 & 21.60 & 1.06 & 4.92 & 21.63 & 24.29 & 18.86 \\
\hline PCEA & 18.27 & 0.77 & 4.21 & 18.20 & 20.94 & 15.65 \\
\hline
\end{tabular}

\begin{tabular}{|l|c|c|c|c|c|c|}
\hline $\begin{array}{l}\text { Against } \\
\text { Grain } \\
\text { Specimens }\end{array}$ & Mean & Std Dev & CoV (\%) & Median & $\begin{array}{c}\text { Upper } \\
\text { Limit }\end{array}$ & $\begin{array}{c}\text { Lower } \\
\text { Limit }\end{array}$ \\
\hline $\mathbf{2 1 1 4}$ & & & & & & \\
\hline IG-110 & 19.50 & 0.75 & 3.85 & 19.60 & 21.66 & 17.17 \\
\hline NBG-17 & 19.98 & 1.05 & 5.27 & 19.62 & 21.74 & 17.75 \\
\hline NBG-18 & 21.94 & 0.88 & 4.03 & 21.87 & 25.05 & 18.69 \\
\hline PCEA & 18.11 & 0.69 & 3.83 & 18.11 & 20.61 & 15.60 \\
\hline
\end{tabular}

\begin{tabular}{|l|c|c|c|c|c|c|}
\hline $\begin{array}{l}\text { With Grain } \\
\text { Specimens }\end{array}$ & Mean & Std Dev & CoV (\%) & Median & $\begin{array}{c}\text { Upper } \\
\text { Limit }\end{array}$ & $\begin{array}{c}\text { Lower } \\
\text { Limit }\end{array}$ \\
\hline $\mathbf{2 1 1 4}$ & 19.72 & 0.53 & 2.71 & 19.69 & 20.99 & 18.32 \\
\hline IG-110 & 18.23 & 0.74 & 4.06 & 18.08 & 20.53 & 15.84 \\
\hline NBG-17 & 20.47 & 0.81 & 3.96 & 20.72 & 23.04 & 17.60 \\
\hline NBG-18 & 21.27 & 1.14 & 5.36 & 20.98 & 24.21 & 18.09 \\
\hline PCEA & 18.34 & 0.80 & 4.34 & 18.20 & 20.94 & 15.88 \\
\hline
\end{tabular}


Table B-11. Creep specimen shear modulus (GPa) by sonic velocity summary statistics.

\begin{tabular}{|c|c|c|c|c|c|c|}
\hline $\begin{array}{l}\text { Combined } \\
\text { Specimens }\end{array}$ & Mean & Std Dev & CoV (\%) & Median & $\begin{array}{l}\text { Upper } \\
\text { Limit }\end{array}$ & $\begin{array}{c}\text { Lower } \\
\text { Limit }\end{array}$ \\
\hline 2114 & 7.12 & 0.22 & 3.10 & 7.14 & 7.77 & 6.46 \\
\hline IG-110 & 7.42 & 0.31 & 4.23 & 7.39 & 8.44 & 6.48 \\
\hline NBG-17 & 7.35 & 0.24 & 3.29 & 7.31 & 7.89 & 6.77 \\
\hline NBG-18 & 7.67 & 0.31 & 4.10 & 7.70 & 8.42 & 6.86 \\
\hline PCEA & 6.93 & 0.17 & 2.47 & 6.92 & 7.33 & 6.49 \\
\hline $\begin{array}{l}\text { Against } \\
\text { Grain } \\
\text { Specimens }\end{array}$ & Mean & Std Dev & $\operatorname{CoV}(\%)$ & Median & $\begin{array}{l}\text { Upper } \\
\text { Limit }\end{array}$ & $\begin{array}{c}\text { Lower } \\
\text { Limit }\end{array}$ \\
\hline \multicolumn{7}{|l|}{2114} \\
\hline IG-110 & 7.58 & 0.30 & 4.00 & 7.49 & 8.78 & 6.44 \\
\hline NBG-17 & 7.33 & 0.30 & 4.12 & 7.26 & 8.19 & 6.39 \\
\hline NBG-18 & 7.75 & 0.32 & 4.10 & 7.71 & 8.44 & 7.17 \\
\hline PCEA & 6.95 & 0.22 & 3.10 & 6.95 & 7.44 & 6.40 \\
\hline
\end{tabular}

\begin{tabular}{|l|c|c|c|c|c|c|}
\hline $\begin{array}{l}\text { With Grain } \\
\text { Specimens }\end{array}$ & Mean & Std Dev & CoV (\%) & Median & $\begin{array}{c}\text { Upper } \\
\text { Limit }\end{array}$ & $\begin{array}{c}\text { Lower } \\
\text { Limit }\end{array}$ \\
\hline $\mathbf{2 1 1 4}$ & 7.12 & 0.22 & 3.10 & 7.14 & 7.77 & 6.46 \\
\hline IG-110 & 7.35 & 0.30 & 4.05 & 7.29 & 8.27 & 6.47 \\
\hline NBG-17 & 7.37 & 0.17 & 2.33 & 7.34 & 7.71 & 7.00 \\
\hline NBG-18 & 7.60 & 0.30 & 3.94 & 7.67 & 8.56 & 6.63 \\
\hline PCEA & 6.92 & 0.15 & 2.23 & 6.90 & 7.31 & 6.51 \\
\hline
\end{tabular}


Table B-12. Piggyback specimen length ( $\mathrm{mm}$ ) summary statistics.

\begin{tabular}{|l|c|c|c|c|c|c|}
\hline $\begin{array}{l}\text { Combined } \\
\text { Specimens }\end{array}$ & Mean & Std Dev & CoV (\%) & Median & $\begin{array}{c}\text { Upper } \\
\text { Limit }\end{array}$ & $\begin{array}{c}\text { Lower } \\
\text { Limit }\end{array}$ \\
\hline $\mathbf{2 1 1 4}$ & 6.306 & 0.012 & 0.18 & 6.304 & 6.336 & 6.271 \\
\hline GrafTech & 6.315 & 0.016 & 0.25 & 6.315 & 6.371 & 6.259 \\
\hline IG-110 & 6.242 & 0.017 & 0.27 & 6.241 & 6.290 & 6.189 \\
\hline NBG-17 & 6.284 & 0.021 & 0.34 & 6.277 & 6.355 & 6.212 \\
\hline NBG-18 & 6.295 & 0.023 & 0.36 & 6.296 & 6.359 & 6.227 \\
\hline PCEA & 6.132 & 0.862 & 14.05 & 6.282 & 6.391 & 6.196 \\
\hline PCIB & 6.303 & 0.003 & 0.05 & 6.301 & 6.311 & 6.295 \\
\hline SGL-SiC & 6.375 & 0.015 & 0.24 & 6.375 & 6.403 & 6.341 \\
\hline SGL & 6.295 & 0.017 & 0.28 & 6.290 & 6.329 & 6.256 \\
\hline
\end{tabular}

\begin{tabular}{|l|l|l|l|l|l|l|}
\hline $\begin{array}{l}\text { Against } \\
\text { Grain } \\
\text { Specimens }\end{array}$ & Mean & Std Dev & CoV (\%) & Median & $\begin{array}{c}\text { Upper } \\
\text { Limit }\end{array}$ & $\begin{array}{c}\text { Lower } \\
\text { Limit }\end{array}$ \\
\hline $\mathbf{2 1 1 4}$ & & & & & & \\
\hline GrafTech & & & & & & \\
\hline IG-110 & 6.247 & 0.019 & 0.30 & 6.247 & 6.287 & 6.197 \\
\hline NBG-17 & 6.284 & 0.023 & 0.37 & 6.272 & 6.361 & 6.209 \\
\hline NBG-18 & 6.285 & 0.022 & 0.34 & 6.280 & 6.329 & 6.239 \\
\hline PCEA & 6.046 & 1.084 & 17.92 & 6.284 & 6.400 & 6.193 \\
\hline PCIB & & & & & & \\
\hline SGL-SiC & & & & & & \\
\hline SGL & & & & & & \\
\hline
\end{tabular}

\begin{tabular}{|l|c|c|c|c|c|c|}
\hline $\begin{array}{l}\text { With Grain } \\
\text { Specimens }\end{array}$ & Mean & Std Dev & CoV (\%) & Median & $\begin{array}{c}\text { Upper } \\
\text { Limit }\end{array}$ & $\begin{array}{c}\text { Lower } \\
\text { Limit }\end{array}$ \\
\hline $\mathbf{2 1 1 4}$ & 6.306 & 0.012 & 0.18 & 6.304 & 6.336 & 6.271 \\
\hline GrafTech & 6.315 & 0.016 & 0.25 & 6.315 & 6.371 & 6.259 \\
\hline IG-110 & 6.239 & 0.015 & 0.24 & 6.241 & 6.291 & 6.187 \\
\hline NBG-17 & 6.283 & 0.021 & 0.33 & 6.282 & 6.356 & 6.211 \\
\hline NBG-18 & 6.304 & 0.020 & 0.32 & 6.305 & 6.340 & 6.268 \\
\hline PCEA & 6.279 & 0.031 & 0.49 & 6.280 & 6.383 & 6.168 \\
\hline PCIB & 6.303 & 0.003 & 0.05 & 6.301 & 6.311 & 6.295 \\
\hline SGL-SiC & 6.375 & 0.015 & 0.24 & 6.375 & 6.403 & 6.341 \\
\hline SGL & 6.295 & 0.017 & 0.28 & 6.290 & 6.329 & 6.256 \\
\hline
\end{tabular}


Table B-13. Piggyback specimen diameter ( $\mathrm{mm}$ ) summary statistics.

\begin{tabular}{|l|c|c|c|c|c|c|}
\hline $\begin{array}{l}\text { Combined } \\
\text { Specimens }\end{array}$ & Mean & Std Dev & CoV (\%) & Median & $\begin{array}{c}\text { Upper } \\
\text { Limit }\end{array}$ & $\begin{array}{c}\text { Lower } \\
\text { Limit }\end{array}$ \\
\hline $\mathbf{2 1 1 4}$ & 12.454 & 0.012 & 0.10 & 12.454 & 12.498 & 12.407 \\
\hline GrafTech & 12.425 & 0.054 & 0.44 & 12.416 & 12.604 & 12.242 \\
\hline IG-110 & 12.405 & 0.032 & 0.26 & 12.398 & 12.518 & 12.294 \\
\hline NBG-17 & 12.392 & 0.045 & 0.36 & 12.384 & 12.575 & 12.219 \\
\hline NBG-18 & 12.430 & 0.038 & 0.31 & 12.421 & 12.556 & 12.297 \\
\hline PCEA & 11.988 & 2.265 & 18.89 & 12.389 & 12.606 & 12.200 \\
\hline PCIB & 12.436 & 0.003 & 0.02 & 12.438 & 12.443 & 12.428 \\
\hline SGL-SiC & 12.535 & 0.022 & 0.18 & 12.537 & 12.595 & 12.479 \\
\hline SGL & 12.390 & 0.033 & 0.27 & 12.384 & 12.497 & 12.279 \\
\hline
\end{tabular}

\begin{tabular}{|c|c|c|c|c|c|c|}
\hline $\begin{array}{l}\text { Against } \\
\text { Grain } \\
\text { Specimens }\end{array}$ & Mean & Std Dev & CoV (\%) & Median & $\begin{array}{l}\text { Upper } \\
\text { Limit }\end{array}$ & $\begin{array}{c}\text { Lower } \\
\text { Limit }\end{array}$ \\
\hline \multicolumn{7}{|l|}{2114} \\
\hline \multicolumn{7}{|l|}{ GrafTech } \\
\hline IG-110 & 12.404 & 0.031 & 0.25 & 12.398 & 12.502 & 12.308 \\
\hline NBG-17 & 12.377 & 0.043 & 0.35 & 12.361 & 12.526 & 12.233 \\
\hline NBG-18 & 12.426 & 0.032 & 0.26 & 12.417 & 12.525 & 12.322 \\
\hline PCEA & 11.743 & 2.844 & 24.22 & 12.378 & 12.578 & 12.210 \\
\hline \multicolumn{7}{|l|}{ PCIB } \\
\hline \multicolumn{7}{|l|}{ SGL-SiC } \\
\hline SGL & & & & & & \\
\hline
\end{tabular}

\begin{tabular}{|l|c|c|c|c|c|c|}
\hline $\begin{array}{l}\text { With Grain } \\
\text { Specimens }\end{array}$ & Mean & Std Dev & CoV (\%) & Median & $\begin{array}{c}\text { Upper } \\
\text { Limit }\end{array}$ & $\begin{array}{c}\text { Lower } \\
\text { Limit }\end{array}$ \\
\hline $\mathbf{2 1 1 4}$ & 12.454 & 0.012 & 0.10 & 12.454 & 12.498 & 12.407 \\
\hline GrafTech & 12.425 & 0.054 & 0.44 & 12.416 & 12.604 & 12.242 \\
\hline IG-110 & 12.406 & 0.033 & 0.27 & 12.392 & 12.519 & 12.294 \\
\hline NBG-17 & 12.399 & 0.045 & 0.36 & 12.408 & 12.572 & 12.232 \\
\hline NBG-18 & 12.434 & 0.044 & 0.36 & 12.425 & 12.612 & 12.257 \\
\hline PCEA & 12.411 & 0.055 & 0.44 & 12.404 & 12.635 & 12.188 \\
\hline PCIB & 12.436 & 0.003 & 0.02 & 12.438 & 12.443 & 12.428 \\
\hline SGL-SiC & 12.535 & 0.022 & 0.18 & 12.537 & 12.595 & 12.479 \\
\hline SGL & 12.390 & 0.033 & 0.27 & 12.384 & 12.497 & 12.279 \\
\hline
\end{tabular}


Table B-14. Piggyback specimen mass (g) summary statistics.

\begin{tabular}{|l|c|c|c|c|c|c|}
\hline $\begin{array}{l}\text { Combined } \\
\text { Specimens }\end{array}$ & Mean & Std Dev & CoV (\%) & Median & $\begin{array}{c}\text { Upper } \\
\text { Limit }\end{array}$ & $\begin{array}{c}\text { Lower } \\
\text { Limit }\end{array}$ \\
\hline $\mathbf{2 1 1 4}$ & 1.408 & 0.003 & 0.181 & 1.407 & 1.413 & 1.402 \\
\hline GrafTech & 1.389 & 0.036 & 2.599 & 1.386 & 1.498 & 1.302 \\
\hline IG-110 & 1.352 & 0.007 & 0.497 & 1.354 & 1.363 & 1.344 \\
\hline NBG-17 & 1.407 & 0.005 & 0.325 & 1.408 & 1.422 & 1.392 \\
\hline NBG-18 & 1.430 & 0.006 & 0.445 & 1.431 & 1.444 & 1.417 \\
\hline PCEA & 1.333 & 0.252 & 18.908 & 1.376 & 1.395 & 1.360 \\
\hline PCIB & 1.412 & 0.004 & 0.275 & 1.411 & 1.423 & 1.400 \\
\hline SGL-SiC & 1.462 & 0.010 & 0.679 & 1.461 & 1.485 & 1.440 \\
\hline SGL & 1.407 & 0.005 & 0.324 & 1.408 & 1.418 & 1.395 \\
\hline
\end{tabular}

\begin{tabular}{|c|c|c|c|c|c|c|}
\hline $\begin{array}{l}\text { Against } \\
\text { Grain } \\
\text { Specimens }\end{array}$ & Mean & Std Dev & CoV (\%) & Median & $\begin{array}{l}\text { Upper } \\
\text { Limit }\end{array}$ & $\begin{array}{l}\text { Lower } \\
\text { Limit }\end{array}$ \\
\hline \multicolumn{7}{|l|}{2114} \\
\hline \multicolumn{7}{|l|}{ GrafTech } \\
\hline IG-110 & 1.347 & 0.008 & 0.613 & 1.348 & 1.375 & 1.318 \\
\hline NBG-17 & 1.404 & 0.005 & 0.372 & 1.407 & 1.424 & 1.383 \\
\hline NBG-18 & 1.430 & 0.005 & 0.379 & 1.428 & 1.445 & 1.416 \\
\hline PCEA & 1.310 & 0.318 & 24.237 & 1.377 & 1.404 & 1.355 \\
\hline \multicolumn{7}{|l|}{ PCIB } \\
\hline \multicolumn{7}{|l|}{ SGL-SiC } \\
\hline SGL & & & & & & \\
\hline
\end{tabular}

\begin{tabular}{|l|c|c|c|c|c|c|}
\hline $\begin{array}{l}\text { With Grain } \\
\text { Specimens }\end{array}$ & Mean & Std Dev & CoV (\%) & Median & $\begin{array}{c}\text { Upper } \\
\text { Limit }\end{array}$ & $\begin{array}{c}\text { Lower } \\
\text { Limit }\end{array}$ \\
\hline $\mathbf{2 1 1 4}$ & 1.408 & 0.003 & 0.181 & 1.407 & 1.413 & 1.402 \\
\hline GrafTech & 1.389 & 0.036 & 2.599 & 1.386 & 1.498 & 1.302 \\
\hline IG-110 & 1.355 & 0.002 & 0.160 & 1.355 & 1.359 & 1.350 \\
\hline NBG-17 & 1.408 & 0.004 & 0.278 & 1.410 & 1.422 & 1.392 \\
\hline NBG-18 & 1.430 & 0.007 & 0.511 & 1.432 & 1.439 & 1.425 \\
\hline PCEA & 1.373 & 0.006 & 0.442 & 1.375 & 1.394 & 1.353 \\
\hline PCIB & 1.412 & 0.004 & 0.275 & 1.411 & 1.423 & 1.400 \\
\hline SGL-SiC & 1.462 & 0.010 & 0.679 & 1.461 & 1.485 & 1.440 \\
\hline SGL & 1.407 & 0.005 & 0.324 & 1.408 & 1.418 & 1.395 \\
\hline
\end{tabular}


Table B-15. Piggyback specimen density $\left(\mathrm{g} / \mathrm{cm}^{3}\right)$ summary statistics.

\begin{tabular}{|l|c|c|c|c|c|c|}
\hline $\begin{array}{l}\text { Combined } \\
\text { Specimens }\end{array}$ & Mean & Std Dev & CoV (\%) & Median & $\begin{array}{c}\text { Upper } \\
\text { Limit }\end{array}$ & $\begin{array}{c}\text { Lower } \\
\text { Limit }\end{array}$ \\
\hline $\mathbf{2 1 1 4}$ & 1.8224 & 0.0051 & 0.28 & 1.8232 & 1.8401 & 1.8053 \\
\hline GrafTech & 1.8055 & 0.0580 & 3.21 & 1.8187 & 1.9013 & 1.7401 \\
\hline IG-110 & 1.8281 & 0.0564 & 3.09 & 1.8531 & 1.9096 & 1.7900 \\
\hline NBG-17 & 1.8474 & 0.0195 & 1.05 & 1.8514 & 1.9223 & 1.7707 \\
\hline NBG-18 & 1.8322 & 0.0152 & 0.83 & 1.8322 & 1.8778 & 1.7884 \\
\hline PCEA & 1.7819 & 0.3373 & 18.93 & 1.8460 & 1.9317 & 1.7509 \\
\hline PCIB & 1.8285 & 0.0022 & 0.12 & 1.8280 & 1.8352 & 1.8220 \\
\hline SGL-SiC & 1.8912 & 0.0466 & 2.47 & 1.9092 & 1.9426 & 1.8666 \\
\hline SGL & 1.8443 & 0.0131 & 0.71 & 1.8456 & 1.8768 & 1.8184 \\
\hline
\end{tabular}

\begin{tabular}{|l|l|l|l|l|l|l|}
\hline $\begin{array}{l}\text { Against } \\
\text { Grain } \\
\text { Specimens }\end{array}$ & Mean & Std Dev & CoV (\%) & Median & $\begin{array}{c}\text { Upper } \\
\text { Limit }\end{array}$ & $\begin{array}{c}\text { Lower } \\
\text { Limit }\end{array}$ \\
\hline $\mathbf{2 1 1 4}$ & & & & & & \\
\hline GrafTech & & & & & & \\
\hline IG-110 & 1.7882 & 0.0698 & 3.91 & 1.7867 & 2.0540 & 1.5270 \\
\hline NBG-17 & 1.8515 & 0.0196 & 1.06 & 1.8604 & 1.9246 & 1.7755 \\
\hline NBG-18 & 1.8369 & 0.0149 & 0.81 & 1.8401 & 1.8759 & 1.7987 \\
\hline PCEA & 1.7465 & 0.4235 & 24.25 & 1.8459 & 1.9251 & 1.7554 \\
\hline PCIB & & & & & & \\
\hline SGL-SiC & & & & & & \\
\hline SGL & & & & & & \\
\hline
\end{tabular}

\begin{tabular}{|l|c|c|c|c|c|c|}
\hline $\begin{array}{l}\text { With Grain } \\
\text { Specimens }\end{array}$ & Mean & Std Dev & CoV (\%) & Median & $\begin{array}{c}\text { Upper } \\
\text { Limit }\end{array}$ & $\begin{array}{c}\text { Lower } \\
\text { Limit }\end{array}$ \\
\hline $\mathbf{2 1 1 4}$ & 1.8224 & 0.0051 & 0.28 & 1.8232 & 1.8401 & 1.8053 \\
\hline GrafTech & 1.8055 & 0.0580 & 3.21 & 1.8187 & 1.9013 & 1.7401 \\
\hline IG-110 & 1.8562 & 0.0138 & 0.74 & 1.8602 & 1.9024 & 1.8082 \\
\hline NBG-17 & 1.8456 & 0.0197 & 1.07 & 1.8425 & 1.9181 & 1.7704 \\
\hline NBG-18 & 1.8283 & 0.0149 & 0.82 & 1.8315 & 1.8751 & 1.7854 \\
\hline PCEA & 1.8432 & 0.0255 & 1.38 & 1.8460 & 1.9447 & 1.7454 \\
\hline PCIB & 1.8285 & 0.0022 & 0.12 & 1.8280 & 1.8352 & 1.8220 \\
\hline SGL-SiC & 1.8912 & 0.0466 & 2.47 & 1.9092 & 1.9426 & 1.8666 \\
\hline SGL & 1.8443 & 0.0131 & 0.71 & 1.8456 & 1.8768 & 1.8184 \\
\hline
\end{tabular}


Table B-16. Piggyback specimen diffusivity $\left(\mathrm{mm}^{2} / \mathrm{sec}\right)$ at $100^{\circ} \mathrm{C}$ summary statistics.

\begin{tabular}{|l|c|c|c|c|c|c|}
\hline $\begin{array}{l}\text { Combined } \\
\text { Specimens }\end{array}$ & Mean & Std Dev & CoV (\%) & Median & $\begin{array}{c}\text { Upper } \\
\text { Limit }\end{array}$ & $\begin{array}{c}\text { Lower } \\
\text { Limit }\end{array}$ \\
\hline 2114 & 21.3 & 2.1 & 9.73 & 20.8 & 23.8 & 18.2 \\
\hline GrafTech & 20.5 & 2.2 & 10.68 & 20.2 & 26.7 & 13.7 \\
\hline IG-110 & 20.6 & 1.7 & 8.40 & 20.4 & 26.0 & 15.0 \\
\hline NBG-17 & 22.5 & 2.2 & 9.68 & 21.8 & 27.8 & 17.1 \\
\hline NBG-18 & 23.4 & 2.1 & 9.15 & 23.0 & 26.3 & 19.7 \\
\hline PCEA & 25.2 & 2.0 & 7.94 & 24.6 & 29.9 & 20.8 \\
\hline PCIB & 18.4 & 0.3 & 1.56 & 18.5 & 19.3 & 17.6 \\
\hline SGL-SiC & 22.4 & 0.8 & 3.71 & 22.2 & 24.7 & 20.0 \\
\hline SGL & 23.0 & 0.9 & 4.07 & 22.9 & 25.0 & 21.0 \\
\hline
\end{tabular}

\begin{tabular}{|c|c|c|c|c|c|c|}
\hline $\begin{array}{l}\text { Against } \\
\text { Grain } \\
\text { Specimens }\end{array}$ & Mean & Std Dev & CoV (\%) & Median & $\begin{array}{l}\text { Upper } \\
\text { Limit }\end{array}$ & $\begin{array}{c}\text { Lower } \\
\text { Limit }\end{array}$ \\
\hline \multicolumn{7}{|l|}{2114} \\
\hline \multicolumn{7}{|l|}{ GrafTech } \\
\hline IG-110 & 21.3 & 1.5 & 7.00 & 21.1 & 24.0 & 18.5 \\
\hline NBG-17 & 21.9 & 1.6 & 7.15 & 21.3 & 25.1 & 18.4 \\
\hline NBG-18 & 24.2 & 2.9 & 12.12 & 23.1 & 27.0 & 19.8 \\
\hline PCEA & 25.0 & 2.2 & 8.67 & 24.8 & 29.9 & 19.9 \\
\hline \multicolumn{7}{|l|}{ PCIB } \\
\hline \multicolumn{7}{|l|}{ SGL-SiC } \\
\hline SGL & & & & & & \\
\hline
\end{tabular}

\begin{tabular}{|l|c|c|c|c|c|c|}
\hline $\begin{array}{l}\text { With Grain } \\
\text { Specimens }\end{array}$ & Mean & Std Dev & CoV (\%) & Median & $\begin{array}{c}\text { Upper } \\
\text { Limit }\end{array}$ & $\begin{array}{c}\text { Lower } \\
\text { Limit }\end{array}$ \\
\hline $\mathbf{2 1 1 4}$ & 21.3 & 2.1 & 9.73 & 20.8 & 23.8 & 18.2 \\
\hline GrafTech & 20.5 & 2.2 & 10.68 & 20.2 & 26.7 & 13.7 \\
\hline IG-110 & 20.1 & 1.7 & 8.68 & 19.6 & 25.5 & 14.8 \\
\hline NBG-17 & 22.8 & 2.4 & 10.47 & 22.2 & 28.4 & 16.8 \\
\hline NBG-18 & 22.8 & 1.0 & 4.23 & 22.7 & 26.4 & 19.3 \\
\hline PCEA & 25.5 & 1.7 & 6.85 & 24.6 & 31.2 & 20.2 \\
\hline PCIB & 18.4 & 0.3 & 1.56 & 18.5 & 19.3 & 17.6 \\
\hline SGL-SiC & 22.4 & 0.8 & 3.71 & 22.2 & 24.7 & 20.0 \\
\hline SGL & 23.0 & 0.9 & 4.07 & 22.9 & 25.0 & 21.0 \\
\hline
\end{tabular}


Table B-17. Piggyback specimen diffusivity $\left(\mathrm{mm}^{2} / \mathrm{sec}\right)$ at $400^{\circ} \mathrm{C}$ summary statistics.

\begin{tabular}{|l|c|c|c|c|c|c|}
\hline $\begin{array}{l}\text { Combined } \\
\text { Specimens }\end{array}$ & Mean & Std Dev & CoV (\%) & Median & $\begin{array}{c}\text { Upper } \\
\text { Limit }\end{array}$ & $\begin{array}{c}\text { Lower } \\
\text { Limit }\end{array}$ \\
\hline $\mathbf{2 1 1 4}$ & 14.4 & 1.1 & 7.54 & 14.3 & 15.7 & 12.7 \\
\hline GrafTech & 13.7 & 1.2 & 8.86 & 13.7 & 17.0 & 10.1 \\
\hline IG-110 & 13.7 & 0.9 & 6.74 & 13.7 & 16.7 & 10.6 \\
\hline NBG-17 & 14.9 & 1.1 & 7.62 & 14.7 & 17.6 & 12.0 \\
\hline NBG-18 & 15.4 & 1.1 & 7.04 & 15.2 & 16.8 & 13.7 \\
\hline PCEA & 16.4 & 1.0 & 6.27 & 16.2 & 18.9 & 14.0 \\
\hline PCIB & 12.6 & 0.1 & 1.08 & 12.6 & 13.0 & 12.2 \\
\hline SGL-SiC & 15.1 & 0.5 & 3.02 & 15.0 & 16.4 & 13.8 \\
\hline SGL & 15.3 & 0.6 & 3.63 & 15.3 & 16.5 & 14.1 \\
\hline
\end{tabular}

\begin{tabular}{|c|c|c|c|c|c|c|}
\hline $\begin{array}{l}\text { Against } \\
\text { Grain } \\
\text { Specimens }\end{array}$ & Mean & Std Dev & CoV (\%) & Median & $\begin{array}{l}\text { Upper } \\
\text { Limit }\end{array}$ & $\begin{array}{c}\text { Lower } \\
\text { Limit }\end{array}$ \\
\hline \multicolumn{7}{|l|}{2114} \\
\hline \multicolumn{7}{|l|}{ GrafTech } \\
\hline IG-110 & 14.1 & 0.8 & 5.61 & 14.0 & 15.4 & 12.8 \\
\hline NBG-17 & 14.5 & 0.8 & 5.54 & 14.3 & 16.3 & 12.7 \\
\hline NBG-18 & 15.8 & 1.5 & 9.19 & 15.3 & 17.2 & 13.6 \\
\hline PCEA & 16.3 & 1.1 & 6.87 & 16.2 & 18.7 & 13.8 \\
\hline \multicolumn{7}{|l|}{ PCIB } \\
\hline \multicolumn{7}{|l|}{ SGL-SiC } \\
\hline SGL & & & & & & \\
\hline
\end{tabular}

\begin{tabular}{|l|c|c|c|c|c|c|}
\hline $\begin{array}{l}\text { With Grain } \\
\text { Specimens }\end{array}$ & Mean & Std Dev & CoV (\%) & Median & $\begin{array}{c}\text { Upper } \\
\text { Limit }\end{array}$ & $\begin{array}{c}\text { Lower } \\
\text { Limit }\end{array}$ \\
\hline $\mathbf{2 1 1 4}$ & 14.4 & 1.1 & 7.54 & 14.3 & 15.7 & 12.7 \\
\hline GrafTech & 13.7 & 1.2 & 8.86 & 13.7 & 17.0 & 10.1 \\
\hline IG-110 & 13.4 & 0.9 & 6.67 & 13.0 & 16.2 & 10.8 \\
\hline NBG-17 & 15.1 & 1.2 & 8.24 & 14.8 & 17.8 & 12.0 \\
\hline NBG-18 & 15.0 & 0.5 & 3.26 & 15.0 & 16.7 & 13.4 \\
\hline PCEA & 16.6 & 0.9 & 5.33 & 16.1 & 19.3 & 13.9 \\
\hline PCIB & 12.6 & 0.1 & 1.08 & 12.6 & 13.0 & 12.2 \\
\hline SGL-SiC & 15.1 & 0.5 & 3.02 & 15.0 & 16.4 & 13.8 \\
\hline SGL & 15.3 & 0.6 & 3.63 & 15.3 & 16.5 & 14.1 \\
\hline
\end{tabular}


Table B-18. Piggyback specimen diffusivity $\left(\mathrm{mm}^{2} / \mathrm{sec}\right)$ at $650^{\circ} \mathrm{C}$ summary statistics.

\begin{tabular}{|l|c|c|c|c|c|c|}
\hline $\begin{array}{l}\text { Combined } \\
\text { Specimens }\end{array}$ & Mean & Std Dev & CoV (\%) & Median & $\begin{array}{c}\text { Upper } \\
\text { Limit }\end{array}$ & $\begin{array}{c}\text { Lower } \\
\text { Limit }\end{array}$ \\
\hline $\mathbf{2 1 1 4}$ & 11.8 & 0.8 & 6.43 & 11.8 & 12.7 & 10.6 \\
\hline GrafTech & 11.2 & 0.9 & 8.12 & 11.3 & 13.7 & 8.7 \\
\hline IG-110 & 11.2 & 0.7 & 6.20 & 11.2 & 13.4 & 9.0 \\
\hline NBG-17 & 12.2 & 0.8 & 6.58 & 12.0 & 14.2 & 10.0 \\
\hline NBG-18 & 12.5 & 0.7 & 5.96 & 12.4 & 13.5 & 11.3 \\
\hline PCEA & 13.3 & 0.7 & 5.61 & 13.1 & 15.2 & 11.4 \\
\hline PCIB & 10.5 & 0.0 & 0.26 & 10.5 & 10.5 & 10.4 \\
\hline SGL-SiC & 12.4 & 0.3 & 2.77 & 12.4 & 13.4 & 11.4 \\
\hline SGL & 12.6 & 0.4 & 3.47 & 12.5 & 13.4 & 11.7 \\
\hline
\end{tabular}

\begin{tabular}{|c|c|c|c|c|c|c|}
\hline $\begin{array}{l}\text { Against } \\
\text { Grain } \\
\text { Specimens }\end{array}$ & Mean & Std Dev & CoV (\%) & Median & $\begin{array}{l}\text { Upper } \\
\text { Limit }\end{array}$ & $\begin{array}{c}\text { Lower } \\
\text { Limit }\end{array}$ \\
\hline \multicolumn{7}{|l|}{2114} \\
\hline \multicolumn{7}{|l|}{ GrafTech } \\
\hline IG-110 & 11.6 & 0.6 & 5.05 & 11.6 & 12.6 & 10.5 \\
\hline NBG-17 & 11.9 & 0.5 & 4.64 & 11.7 & 13.1 & 10.6 \\
\hline NBG-18 & 12.8 & 1.0 & 7.64 & 12.5 & 14.0 & 11.2 \\
\hline PCEA & 13.2 & 0.8 & 6.02 & 13.1 & 15.0 & 11.4 \\
\hline \multicolumn{7}{|l|}{ PCIB } \\
\hline \multicolumn{7}{|l|}{ SGL-SiC } \\
\hline SGL & & & & & & \\
\hline
\end{tabular}

\begin{tabular}{|l|c|c|c|c|c|c|}
\hline $\begin{array}{l}\text { With Grain } \\
\text { Specimens }\end{array}$ & Mean & Std Dev & CoV (\%) & Median & $\begin{array}{c}\text { Upper } \\
\text { Limit }\end{array}$ & $\begin{array}{c}\text { Lower } \\
\text { Limit }\end{array}$ \\
\hline $\mathbf{2 1 1 4}$ & 11.8 & 0.8 & 6.43 & 11.8 & 12.7 & 10.6 \\
\hline GrafTech & 11.2 & 0.9 & 8.12 & 11.3 & 13.7 & 8.7 \\
\hline IG-110 & 11.0 & 0.7 & 6.08 & 10.7 & 13.2 & 9.0 \\
\hline NBG-17 & 12.3 & 0.9 & 7.05 & 12.2 & 14.3 & 10.1 \\
\hline NBG-18 & 12.3 & 0.4 & 3.06 & 12.2 & 13.6 & 11.0 \\
\hline PCEA & 13.4 & 0.7 & 4.99 & 13.1 & 15.6 & 11.3 \\
\hline PCIB & 10.5 & 0.0 & 0.26 & 10.5 & 10.5 & 10.4 \\
\hline SGL-SiC & 12.4 & 0.3 & 2.77 & 12.4 & 13.4 & 11.4 \\
\hline SGL & 12.6 & 0.4 & 3.47 & 12.5 & 13.4 & 11.7 \\
\hline
\end{tabular}




\section{Appendix C}

\section{Shipping Documentation for Experimental Grades}




\section{Graftech}

International

GrafTech International Holdings Inc.

12900 Snow Road

Telephone 216.676 .2445

Ship ro:

Idaho National Lab

Attn: W. David Swank, NO P.O. or P.C.

$1765 \mathrm{~N}$. Yellowstone Hwy.
Idaho Falls, ID 83415-2211

Phone No: (Requiréd) $208-526-1698$

\begin{tabular}{|l|l|l|}
\hline Account To Be Charged: & Shipper:
\end{tabular}

Date Issued: 310910 - 3

Consignee:

\begin{tabular}{l|l}
\multicolumn{1}{|c|}{$1 / 27 / 12$} & \multirow{2}{*}{ Freight Charges }
\end{tabular}

$\mathbf{3}^{\text {ra }}$ Party:

FEDEX $X$ Way $Z-D A Y$ Freight charges

\begin{tabular}{l|l|l|l} 
Collect: & Prepaid: & Yes & Value for Shipping:
\end{tabular}

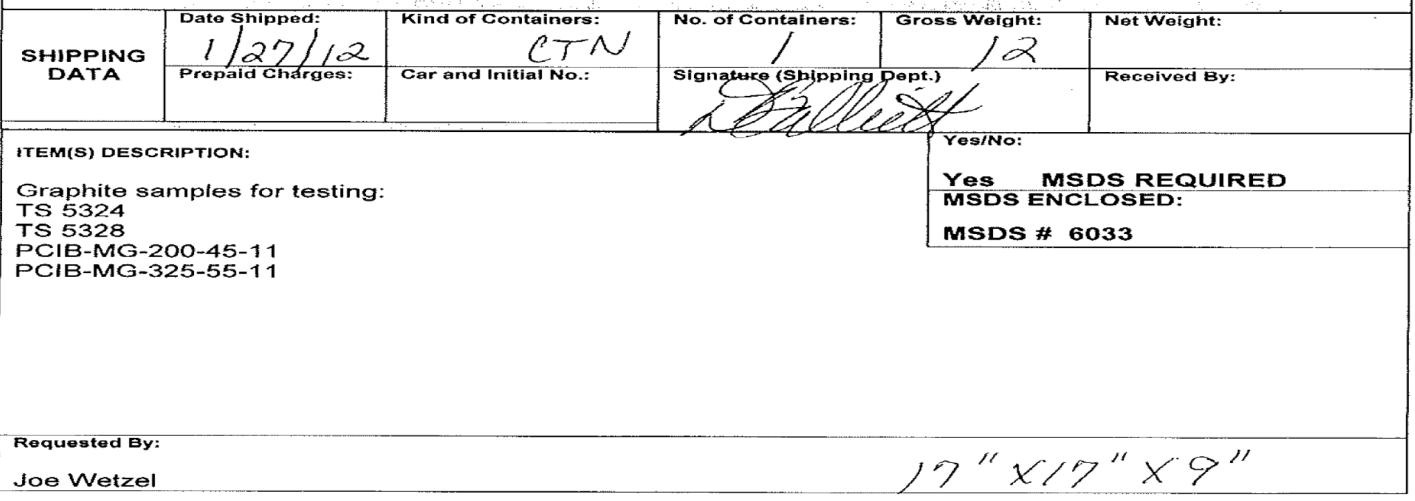




F.O. \# $\quad 102747$
DATE: $\quad 5 / 19 / 2011$

SGL GROUP

FORWARDING ORDER

SHIPPER:

SGL GROUP

THE CARBON COMPANY

900 THERESIA ST.

ST. MARYS, PA 15857

PHONE: 781-2611

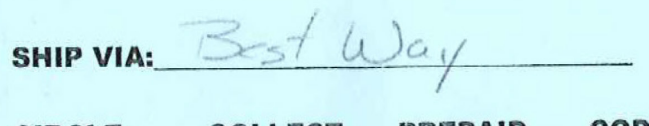

CIRGLE: COLLECT PREPAID COD

THE FOLLOWING GOODS:

\begin{tabular}{l} 
(10) MLBFI Pills \\
$\frac{\text { (18) NBG-17 SiC coated Pills }}{\text { (25) NBG-17 pills }}$ \\
(1) 3 ssiness Cuxd \\
\hline
\end{tabular}

**ECCN\# VALUE

* CUStoms

**(ECCN\# \& CUSTOMS VALUE REQUIRED ON EXPORT SHIPMENTS SHIPMENTS WILL NOT BE MIADE WITHOUT THIS INFORMIAITON)

PERSON(S) REQUESTING SHIPMENT:

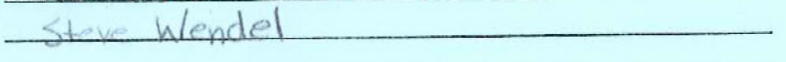

SHIP TO:

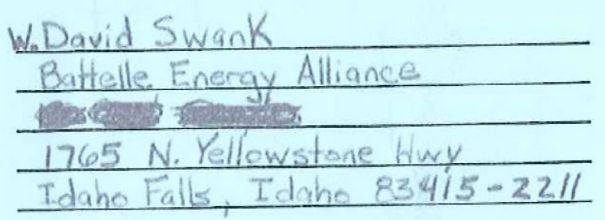

TYPE OF SERVICE:

NEXT DAY 2 DAY 3 DAY GROUND

FORWARDING ORDER MUST BE MADE OUT IN TRIPLICATE (MAKE SURE ALL COPIES ARE LEGIBLE). A COPY WILL BE RETURNED TO ORIGINATOR AS PROOF OF SHIPMENT.

APPROVED BY EXPORT CSR:

(CSR MUST SIGN OFF)

\section{SHIPPING UNITS: NET WEIGHT: GROSS WEIGHT: DIMENSIONS:}

SHIPPING DEPT. USE ONLY:

REV. 09/10/08
WHITE (SHIPPING COPY) YELLOW (ORIGINATOR) BLUE (PACK SLIP) 